DOE/NASA $0198-1$

NASA CR-16i: 21

\title{
Ok.imization and Fabrication of Porous Carbon Electrodes for Fe/Cr Redox Flow Celis
}

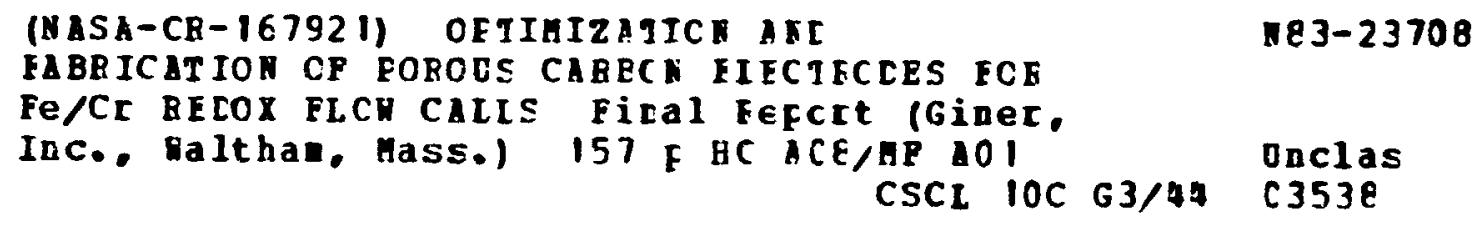

Vinod Jalan, Brian Morriseau, and Larry Swette GINER, INC.

July 1982

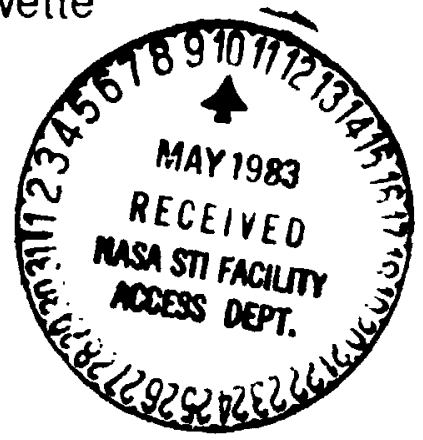

Prepared for

NATIONAL AERONAUTICS AND SPACE ADMINISTRATION Lewis Research Center

Under Contract DEN 3-198

for

U.S. DEPARTMENT OF ENERGY Conservation and Renewable Energy Division of Energy Storage Systems 
DOE/NASA 0198-1

NASA CR-167921

\section{Optimization and Fabricatin of Porous Carbon Electrodes for Fe/Cr Redox Flow Cells}

Vinod Jalan, Brian Morriseau, and Larry Swette GINER, INC.

Waltham, Massachusetts 02154

July 1982

Prepared for

National Aeronautics and Space Administration

Lewis Fesearch Center

Cleveland, Ohio 44135

Under Contract DEN 3-198

for

U.S. DEPARIMENT OF ENERGY

Conservation and Renewable Energy

Division of Energy Storage Systems

Washington, D C. 20545

Under Ir:teragsncy Agreement DE-AI04-80AL12726 



\section{CONTENIS}

I. INTRODUCTION AND SURMARY 1

II. NEGATIVE ELECTRODE SUBSTRATES FOR THE REDOX CELL 6

A. Background 6

E. Types of Substrates Studied 7

C. Physical Characteristics of Substrates 9

D. Pre-Catalyzation Treatment of Substrates 11

III. GOLD ACTIVATION PROCEDURES 20

A. Aqueous/Vacuum Gold Cataiyzation Methoò 21

B. Aqueous/Methanol Gold Catalyzation Processes 24

C. Aqueous/Acetone Gold Catalyzation Process 30

IV. ELECTROCHEMICAL TESTING PROCEDURES 42

A. Electrode Mounting Proceaures 42

B. Electrochemical Test Cell 44

C. Correcticns for Resistance 44

D. Electrochemical Testing Procedures 45

E. Data Reduction Methoảs 49

V. EFFECTS CF CATALYST LOADING 60

A. Effects of Gold Loading 60

B. Effects of Lead Loading 69

VI. EFFECTS OF FELT SUBSTRATES 105

VII. EFFECTS OF GOLD CATALYZATION METHOD 111

A. Aqueous/Vacuum Process 111

B. Methanol-Based Processes 112

VIII. RFFECTS OF VARIATIONS IN TEST PROCEDURES 116

IX . ALTERNATIVE CATALYST SYSTEMS 122

A. Procedures 122

B. Results 123

$\begin{array}{ll}\text { REFERENCES } & 140\end{array}$

APPENDIX - Electrochemical Performance Data Sunmary Tables 143 


\section{INTRODUCTION AND SUMARY}

The NASA-Redox energy storage system has the capability of providing inexpensive, reliable bulk energy storage suitable for the efficient capture of energy from intermittent sources such as solar or wind energy, and it has the potential for meeting the requirements of electric utility applications such as load leveling and peak shaving. All of the reactant species in the system are soluble in hydrochloric acid at practical concentrations, a feature which permits scaling of the energy section of the system independently of the power section. The negative electrode couple is $\mathrm{Cr}^{3+} / \mathrm{Cr}^{2+}$ and the positive electrode couple is $\mathrm{Fe}^{3+} / \mathrm{Fe}^{2+}$; both couples are in the form of chlorides dissolved in hydrochloric acid. The electrochemical conversion reactions take place on inert carbon felt substrates. The solutions are separateỏ by a chloride-ion-permeable membrane which permits chorge transfer while blocking cross-mixing of the reactive species. During discharge of this system, $\mathrm{Cr}^{2+}$ is oxidized to $\mathrm{Cr}^{3+}$ at the negative electrode, and $\mathrm{Fe}^{3+}$ is reduced to $\mathrm{Fe}^{2+}$ at the positive electrode. In a two-tank system the solutions are pumped continuously through the reactor generating energy and gradually reducing the state-of-charge of the bulk solutions. During charging of the system, energy is delivered from an external source and stored by reversing the electrode reactions and gradually raising the state-of-charge of the bulk solutions.

This system has been under development since 1974 with the direction and active participation of the Lewis Research Center of the National Aeronautics and Space Administration (NASA-LeRC) with funding from both NASA and the Department of Energy $(1,2)$. Semi-permeable 
membranes have been developed by Ionics, Inc. that are sufficiently conductive and selective to meet thi requirements for solar and wind energy applications. The system has been scaled up to a $1 \mathrm{~kW}, 11 \mathrm{kWh}$ size without difficulty and many system features such as flow, shunt currents, and electrochemical balance have been studied.

Giner, Inc. has been involved in the development of the redox battery regularly since $1975(3-5)$. After the initial redox couples screenir" program and selection of the iron/chromium combination, the emphasis has been on electrode development, particularly the negative electrode. The $\mathrm{Cr}^{3+} / \mathrm{Cr}^{2+}$ redox reaction occurs at a potential that is $\sim 400 \mathrm{mV}$ more negative than the $\mathrm{H}^{+} / \mathrm{H}_{2}$ reaction. The effect of this positional relationship is that hydrogen evolution is thermodynamically favored over chromic ion reduction on charge. This potential impediment to the development of an efficient redox battery was overcome by the discovery of the gold/lead catalyst system by Giner, Inc. (4-8). In the rapid development following the implementation of this catalyst system, secondary problems related to control and reproducibility of electrodes surfaced. These problems were explored in the previous program (DEN3-97) (5) during which it was discovered that variations in the carbon felt substrate were contributing to variations in electrochemical performance. Significant progress was made in addressing this problem by the introduction of felt pretreatment procedures and the discovery of the alcohol-assisted gold deposition process (9).

The objectives of the present program were:

1) to investigate the negative electrode performance effects of several varieties of commercially available carbon felts, 
2) to investigate the effects of variations in the composition and loading of the gold/lead catalyst system,

3) to investigate catalyzation procedures with emphasis on scale-up feasibility,

4) to fabricate and deliver $1 / 3$ square foot size electrodes, and

5) to investigate potential alternative catalyst systens explored in previous materials' screening studies.

The significant findings were as follows:

1) The felt substrate appears to have considerable influence on the performance of the negative electrode. This is discussed in Section vr. The reaction level, both for hydrogen evolution and the $\mathrm{Cr}^{3+} / \mathrm{ir}^{2+}$ redox reaction, declined with increasing felt processing temperature over the range of $1250^{\circ} \mathrm{C}$ to $2300^{\circ} \mathrm{C}$. In terms of charging efficiency, a felt processed at $1630^{\circ} \mathrm{C}$ gave the highest $\mathrm{Cr}^{2+}: \mathrm{H}_{2}$ ratio, in half cell cyclic voltarmetry testing. These reshats represent preliminary findings and a more comprehensive and systematic study is recommended.

2) The reaction levels, both for hydrogen evolution and the $\mathrm{Cr}^{3+} / \mathrm{Cr}^{2+}$ redox reaction, were found to increase with increasing gold loading over the range of 3 to $50 \mu \mathrm{g} / \mathrm{cm}^{2}$. There were many large deviations from the relationship between the $\mathrm{Cr}^{3+} / \mathrm{Cr}^{2+}$ redox reaction level and simple gold loading, however. It was found that many of the deviations could be accounted for by variations in the particle size (and surface area) of the gold deposits, as determined by transmission electron microscopy. This is discussed in section $v$.

It was also discovered that the $\mathrm{Cr}^{3+} / \mathrm{Cr}^{2+}$ redox reaction level was directly proportional to the quantity of lead deposited, 
independently of gold loading and felt type, and the quantities of lead depositeo were directly proportional to the estimated gold surface areas. This suggests that the quantity of lead deposited is indicative of the underlying gold surface area. The reasons for variations in gold particle size were not determined; further investigation in this area is recommended.

3) In the study of catalyzation procedures (Sections III \& VII) it was found that the felt pretreatment process in hot potassium hydroxide could be carried out more effectively by vacuum back-filling with solution, and that an aqueous gold deposition method was unsuitable in that it resulted in non-uniform distribution and large particles. The alcohol-assisted gold deposition process was scaled-up, using two variations of a simple felt immersion process, without substantial change in performance. These results, although consistent, appeared to be different from results obtained with electrodes prepared by NASA-LeRC. It is recommended that these differences be investigated. 4) Three alternative catalyst systems were examined briefly: gold/bismuth, silver/bismuth and silver/lead (Section IX). The silver systems are very similar to gold, with the silver showing perhaps slightly better hydrogen overvoltage than gold. Because of the low dissolution potential for silver, however, it probably cannot be consicered practical for a muiticell system in which cell reversal might occur. The gold/bismuth system, in comparison to gold/lead, could be slightly more stable in that the dissolution potential for bismuth is about $400 \mathrm{mV}$ less negative than lead; the charging efficiency $\left(\mathrm{C}_{\mathrm{i}}{ }^{2+}: \mathrm{H}_{2}\right.$ ratio), however, may be lower than for gold/lead. In spite of this, the gold/bismuth system may merit further investigation, 
perhaps as an alternative surface for investigation of $\mathrm{Cr}^{3+}$ complex species that have been observed in conjunction with the open-circuit voltage hysteresis phenomenon (10-12).

$-5-$ 
II. NEGATIVE ELECTRODE SUBSTRATES FOR THE REDOX CELL

\section{A. Background.}

Carbonized and graphitized rayon felts have been investigated as substrates for redox cell electrodes at NASA-LeRC $(1,2)$ and at Giner, Inc. (3-5) for the past several years. In the case of the positive electrode it has been found that the ferrous/ferric redox reaction proceeds at an acceptable rate on a carbon substrate without added catalysts. In the case of the negative electrode, however, it was found that, on untreated carbon felt, the chromous/chromic redox reaction proceeded at a low rate and with high polarization, and was accompanied by considerable hydrogen evolution on charge (chromic-ion reduction). In 1978, a lead/gold ( $\mathrm{Pb} / \mathrm{Au})$ catalyst system was developed by Giner, Inc. (4-8) that simultaneously addressed both problems; i.e., gold deposited on the carbon felt appeared to enhance the negative electrode discharge reaction (chromous-ion oxidation) and to provide a good substrate for lead deposition, and the lead simultaneously suppressed hydrogen evolution and catalyzed the charge reaction. Soon after this initial success, however, it was found that the same degree of performance, particularly suppression of hydrogen evolution, could not be reproduced using the identical catalyzing procedures on a new lot of carbon felt. This anomaly initiated an accelerated search for some resolution to the problem and ied to the development of the modified gold deposition procedure presently used $(9-12)$.

During the course of the latter investigation it became apparent that "carbon felt" might not be a very well-defined material for this particular electrochemical system. It is important to note that the carbon and graphite felts under investigation are fabricated in quite 
large quantities primarily for thermal insulation applications, the process controls for such materials, consequently, are not necessar1ly optimal for an electrochemical application. With this information in mind, one of the major objectives of the present program was to examine a broad range of standard felt substrate types commercially available in order to explore the relationship between negative electrode performance and felt type.

\section{B. Types of Substrates Studied.}

The felt thickness of most interest and for which most previous test results have been obtained is nominally $1 / 8 \mathrm{inch}$. The more common thickness available commercially, however, is $1 / 4$ inch; consequentl, both thicknesses were tested. The felts are designated by manufacturers as "carbon" or "graphite" according to percent carbon, degree of graphitization and processing temperature. The processing temperature for felts designated "graphite" is probably above $2100^{\circ} \mathrm{C}$; Fiber Matetials, Inc. (FMI) specifies $2300^{\circ} \mathrm{C}$ and 99.98 carbon, Union Carbide does not ind.cate a processing temperature $د$ specifies 99.68 carbon for felt designated graphite (WDF grade). For "carbon" felts FMI presently has two designations: " $\mathrm{CH}$ " for telts processed to $1250 \mathrm{C}$, and "MH" for felts processed to $1400^{\circ} \mathrm{C}$. For the carbon felt lots studied early in the program, however, the " $\mathrm{CH}$ " designation denoted a processing temperature of about $1500^{\circ} \mathrm{C}$. The assumed processing temperatures are indicated below: 
TABLE I. Eelt Substrates Investigated.

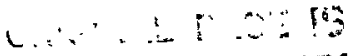

OF POLi Gum

\begin{tabular}{|c|c|c|c|c|c|}
\hline ndor & $\begin{array}{c}\text { Nom. } \\
\text { Thkness. }\end{array}$ & Designation & $\begin{array}{l}\text { Proc. } \\
\text { Temp. }\end{array}$ & I.D. Code & Lot Nn. \\
\hline Fiber Mat. Inc. & $1 / 8 \mathrm{in.}$ & Carbon & $\sim 1500^{\circ} \mathrm{C}$ & FMI $-C-1 / 8$ & G-071:15 \\
\hline iber Mat. Inc. & $1 / 8 \mathrm{in}$. & Graphite & $2300^{\circ} \mathrm{C}$ & FMI -G-1/8 & G-122779 \\
\hline er Mat. Inc. & $1 / 4 \mathrm{in.}$ & Carbon & $\sim 1500^{\circ} \mathrm{C}$ & FMI $-C-1 / 4$ & G-071180 \\
\hline ber Mat. Inc. & $1 / 4$ in. & Graphite & $2300^{\circ} \mathrm{C}$ & FMI-G-1/4 & G-071180 \\
\hline ion Carbide & $1 / 4 \mathrm{in}$. & Graphite & $(99.6 \% \mathrm{C})$ & * UC-G-1/4 & G-051580 \\
\hline
\end{tabular}

Processing temperature not available.

At a later point in the program, three other felts, obtained through NASA-LeRC, were also tested. One of these was an FMI $\mathrm{CH}$-grade known to have been processed to $1250^{\circ} \mathrm{C}$. Another type was a special lot obtained from FMI known to have been processed at $1630^{\circ} \mathrm{C}$. The third type was an FMI graphite felt subjected to a "halogen purification" process by UltraCarbon Corporation. Full descriptions are given below:

TABLE II. Additional Felt Substrates Obtained from NaSA.

\begin{tabular}{llllll} 
Vendor & $\begin{array}{c}\text { Nom. } \\
\text { Thkness. }\end{array}$ & Designation & $\begin{array}{l}\text { Proc. } \\
\text { Temp. }\end{array}$ & I.D. Code & Lot No. \\
\hline Fiber Mat. Inc. & $1 / 8 \mathrm{in}$. & Carbon & $1250^{\circ} \mathrm{C}$ & FMI-C-1/8 & N-091880 \\
Fiber Mat. Inc. & $1 / 8 \mathrm{in}$. & Carbon & $1630^{\circ} \mathrm{C}$ & FMI-C-1/8 & N-122380 \\
$\begin{array}{l}\text { Fiber Mat. Inc. } \\
\text { (UItra Carbon) }\end{array}$ & $1 / 8 \mathrm{in.}$ & Graphite & $\begin{array}{l}2300{ }^{\circ} \mathrm{C} \\
\text { +Ha1.Pur. }\end{array}$ & $\begin{array}{l}\text { ULC/FMI-G- } \\
\text { 1/8 }\end{array}$ & N-0280
\end{tabular}




\section{Physical Characteristics of subatrater.}

An initial examination of the felts as-received revealed

considerable physical differences. The actual thicknesses vary around the nominal valuess a sample of apparent densities is shown below:

TABLE III. Physical Vartations of Pelt samolen.

\begin{tabular}{lccc} 
1.D. Code & Lot No. & $\begin{array}{c}\text { Thickness } \\
(\mathrm{mi} / \mathrm{s} / \mathrm{mm})\end{array}$ & $\begin{array}{c}\text { Apparent Densities } \\
(\mathrm{g} / \mathrm{cm})\end{array}$ \\
\hline FMI-C-1/8 & G-071379 & $95 / 2.4$ & 0.10 \\
FMI-G-1/8 & G-122779 & $85 / 2.2$ & 0.09 \\
FMI-C-1/4 & $G-071180$ & $260 / 6.6$ & 0.11 \\
FMI-G-1/4 & $G-071180$ & $190 / 4.8$ & 0.13 \\
UC-G-1/4 & $G-051580$ & $255 / 6.5$ & 0.08
\end{tabular}

The felts were also found to vary considerably in their wettability and liguid absorption capacity. A $14.5 \mathrm{~cm}^{2}$ sample of each felt was submerged in water and then weighed to measure water absorption. A second sample of each felt was saturated with a $25 / 75$ vol. water/methanol mixture, which wats the felts quite readily, and then weighed to measure liquid absorption.

The results are shown below:

TABLE IV. Liquid Absorption Values for As-Received Felt substrates. I.D. Code Liquid Absorption (mg liquid/ $\mathrm{cm}^{2}$ of felt) $\mathrm{H}_{2} \mathrm{O} \quad \mathrm{H}_{2} \mathrm{O} / \mathrm{CH}_{3} \mathrm{OH}(1: 3)$

FMI $-C-1 / 8$ 31 154

FMI - G-1/8 25 152

FMI $-\mathrm{C}-1 / 4$ 573 472

FMI-G-1/4 50 420

UC-G-1/4 55 438 
All of the felts were hydrophobic to some degree with the graphite felts being generally more hydrophobic than the carbon felts. The 1/4 inch thick FMI carbon felt was the most wettable and the Unior. Carbide graphite felt was the least wettable. This general hydrophobicity presented an obstacle to the process of pretreating the felts with potassium hydroxide. The felts tended to float on the surface of the solution and did not wet even when forcibly submerged in hot solution. This led to an investigation of the physical aspects of the pretreatment frocess, discussed in Section $D$ below; statistical data on the water absorption characteristics of the felts are presented there in detail.

A sample of carbon felt (FMI-C-1/8, Lot 071379) was examined by transmission electron microscopy (TEM) to ascertain the appearance of the fiber surfaces before catalyzation. A photomicrograph of the fibers is shown at low magnification in Figure 1. The fibers are the opaque " $X$ " shape $:$ ithin the white rectangle, (the rough-edged rectangle is part of the gold mounting grid supporting the fibers). The fibers can be seen to be about 10 to $15 \mathrm{microns}$ in diameter with quite smooth surfaces. The small projection on the upper left surface of the horizontal fiber in Figure 1 is shown at higher magnification in Figure 2. The fiber is opaque because of its thickness but the surface particle, which is about $90 \times 400 \mathrm{~nm}$, is partially transparent suggesting that it is carbonaceous (low density) rather than metallic (high density). A smooth surface profile typical for the bare fibers is shown at high magnification in Figure 3. The longituainal contours of the fiber are shown in the photomicrograph in Figure 4, which was obtained by scanning transmission electron microscopy (STEM); it can be seen that the surfaces of the fibers are fluteo giving the appearance of a bundle of about 10 strands. 


\section{Pre-catalyzation Troatment of Substrates.}

OHE: ........

OF FULi, QUALITY

An investigation of substrate pretreatment procedures was initiated

by NASA-LeRC when it was found that the same degree of electrochenical performance could not be reproduced using identical catalyzing procedures on a new lot of felt. Figure 5 illustrates some of the improvements obtained by NASA-LeRC with a low performance felt using a nitric acid pretreatment (11). At the point that the currently used alcohol-assisted gold activation process was initiated, pretreatment in hot IN potassium hydroxide was also introduced as the pretrea'ment of choice (curve $d$ in Figure 5).

As discussed in Section $C$ above, implementation of this pretreatment in potassium hydroxide was impeded by the extreme hydrophobicity of most of the felt types. In an initiall set of experiments (set $A$ ), seven samples were cut from each of the five types of felt. In all cases, a 1.5 in. $\times 1.5$ in. knife edge die was used to produce a standard size of $14.5 \mathrm{~cm}^{2}$. The seven sample groups of each felt type were subjected to the hot $\mathrm{KOH}$ pretreatment according to the following procedure: the samples were submerged in $1 \mathrm{~N} \mathrm{KOH}$ and held below the surface by the weight of a small beaker; the temperature was raised to $75-85^{\circ} \mathrm{C}$ and held for about 30 minutes; the ROH was then drained off and the felts were rinsed and compressed between paper towels repeatedly until the rinse water was neutzal (pH 6-7).

The samples pretreated in this manner were then dried in glass trays at $100-110^{\circ} \mathrm{C}$ overnight and individually weighed. To determine water retention values, each carbon felt was submerged in water and mechanically compressed to expel air; each water saturated felt was then weighed again. 
During the above procedure it was observed that most of the felt types were still fairly hydrophobic after treatment. Additionally, the use of mechanical compression of the felts to expel air was not very effective and somewhat detrimental to the felt structure. For these reasons, it seemed advibable to try a vacuum impregnation technique instead. A second set of samples (10 of each felt type - Set B) were cut for this experiment. The felts were submerged in a beaker of roh and held under solution with a smaller beaker, as done previously. This beaker with the submerged felts was then placed in a vacuum desiccator, evacuated to 100-200 Torr for about one minute and then returned to atmospheric pressure. This procedure was repeated twice at which time typically no more air was released. The felts were then heated to $75-85^{\circ} \mathrm{C}$ for 30 minutes as before, and rinsed to neutral $\mathrm{pH}$. Vacuum impregnation was also used to assist the rinsing process, and as a final step before weighing to determine water retention. In all cases for this procedure, the felts were uniformly more wettable than before treatment, and more wettable than Set A abuve.

The dry weights recorded for the two samplings of the felts show density variations within each set and also, on a broader basis, between the two sets. The dry sample weights (after the hot kOH pretreatment) are shown bejow: 
OF

TABLE V. Dry Weights of substrates $114.6 \mathrm{~cm}^{2}$ mmoleal.

Felt Type Set Qty. Ave $\bar{x}$ (g) Min. (g) Max. (g) std. dev. s (g)

$\begin{array}{lrrrrrr}\text { FMI-C-1/8 } & \text { A } & 7 & 0.327 & 0.309 & 0.355 & 0.016 \\ & B & 10 & 0.324 & 0.307 & 0.342 & 0.012\end{array}$

$\begin{array}{lrrrrrr}\text { FMI-G-1/8 } & \text { A } & 7 & 0.361 & 0.348 & 0.377 & 0.011 \\ & \text { B } & 10 & 0.383 & 0.350 & 0.400 & 0.014\end{array}$

$\begin{array}{rrrrrrr}\text { FMI-C-1/4 } & \text { A } & 7 & 1.007 & 0.982 & 1.055 & 0.025 \\ & \text { B } & 10 & 1.022 & 0.978 & 1.094 & 0.036\end{array}$

$\begin{array}{rrrrrrr}\text { FMI-G-1/4 } & \text { A } & 7 & 1.018 & 0.990 & 1.056 & 0.023 \\ & B & 10 & 0.969 & 0.935 & 0.997 & 0.018\end{array}$

$\begin{array}{rrrrrrr}U C-G-1 / 4 & \text { A } & 7 & 0.662 & 0.648 & 0.677 & 0.012 \\ & \text { B } & 10 & 0.710 & 0.662 & 0.742 & 0.022\end{array}$

As described above, the two sets of felt samples were cleaned in $\mathrm{XOH}$ by two different methods, simple submersion (Set $A$ ) and vacuum impregnation (Set B), and saturated with water by two different methods, nechanical compression (Set A) and vacuum impregnation (Set B). The sets of felt samples vacuum impregnated with water (Set B), were more hydrophilic in general and absorbed more water on average. These results are summarized in Table vI below.

TABLE VI. Weights of Water absorbed by Substrates $\left(14.5 \mathrm{~cm}^{2}\right.$ samples).

\begin{tabular}{|c|c|c|c|c|c|c|}
\hline Felt Type & Set & Qty & $e_{2} \bar{x}_{-i s}$ & Min. (2) & $\operatorname{Max} .(9)$ & std. dev, s (g) \\
\hline FMI $-C-1 / 8$ & $\begin{array}{l}A \\
B\end{array}$ & $\begin{array}{r}7 \\
10\end{array}$ & $\begin{array}{l}1.650 \\
2.438\end{array}$ & $\begin{array}{l}1.188 \\
2.219\end{array}$ & $\begin{array}{l}1.987 \\
2.694\end{array}$ & $\begin{array}{l}0.302 \\
0.173\end{array}$ \\
\hline FMI -G. $1 / 8$ & $\begin{array}{l}A \\
B\end{array}$ & $\begin{array}{r}7 \\
10\end{array}$ & $\begin{array}{l}2.413 \\
3.212\end{array}$ & $\begin{array}{l}2.240 \\
2.982\end{array}$ & $\begin{array}{l}2.743 \\
3.348\end{array}$ & $\begin{array}{l}0.174 \\
0.112\end{array}$ \\
\hline FMI $-C-1 / 4$ & $\begin{array}{l}A \\
B\end{array}$ & $\begin{array}{r}7 \\
10\end{array}$ & $\begin{array}{l}8.634 \\
9.392\end{array}$ & $\begin{array}{l}8.085 \\
9.071\end{array}$ & $\begin{array}{l}9.053 \\
9.720\end{array}$ & $\begin{array}{l}0.368 \\
0.159\end{array}$ \\
\hline FMI -G- $1 / 4$ & $\begin{array}{l}A \\
B\end{array}$ & $\begin{array}{r}7 \\
10\end{array}$ & $\begin{array}{l}5.740 \\
6.189\end{array}$ & $\begin{array}{l}4.702 \\
5.779\end{array}$ & $\begin{array}{l}7.112 \\
7.030\end{array}$ & $\begin{array}{l}0.817 \\
0.443\end{array}$ \\
\hline$U C-G-1 / 4$ & $\begin{array}{l}A \\
B\end{array}$ & $\begin{array}{r}7 \\
10\end{array}$ & $\begin{array}{l}6.165 \\
8.263\end{array}$ & $\begin{array}{l}5.820 \\
7.991\end{array}$ & $\begin{array}{l}6 \quad 512 \\
8.504\end{array}$ & $\begin{array}{l}0.205 \\
0.133\end{array}$ \\
\hline
\end{tabular}


It can be seen that the vacuum impregnated samples (Set B) retained 1 to 2 grams/sample more water and showed less deviation (compare standard deviations) than the mechaniraliy filled felts (Set A) indicating that the vacuum filling method of pretreatment produced more wettable felts resulting in more uniform water absorption. On this basis, this substrate pretreatment $m$ hod (vacuum filling with $1 \mathrm{~N}$ KOH and heating at $80^{\circ} \mathrm{C}$ for 30 minutes) was adopted for all test electrodes prepared in this program.

For the $1 / 3$ square foot electrodes delivered to NASA-LeRC at the end of the program, some of the samples were pretreated in 458 potassium hydroxide instead of the $1 \mathrm{~N}$ solution typically used lequivalent to $\sim 68$ $\mathrm{KOH}$ by weight). 


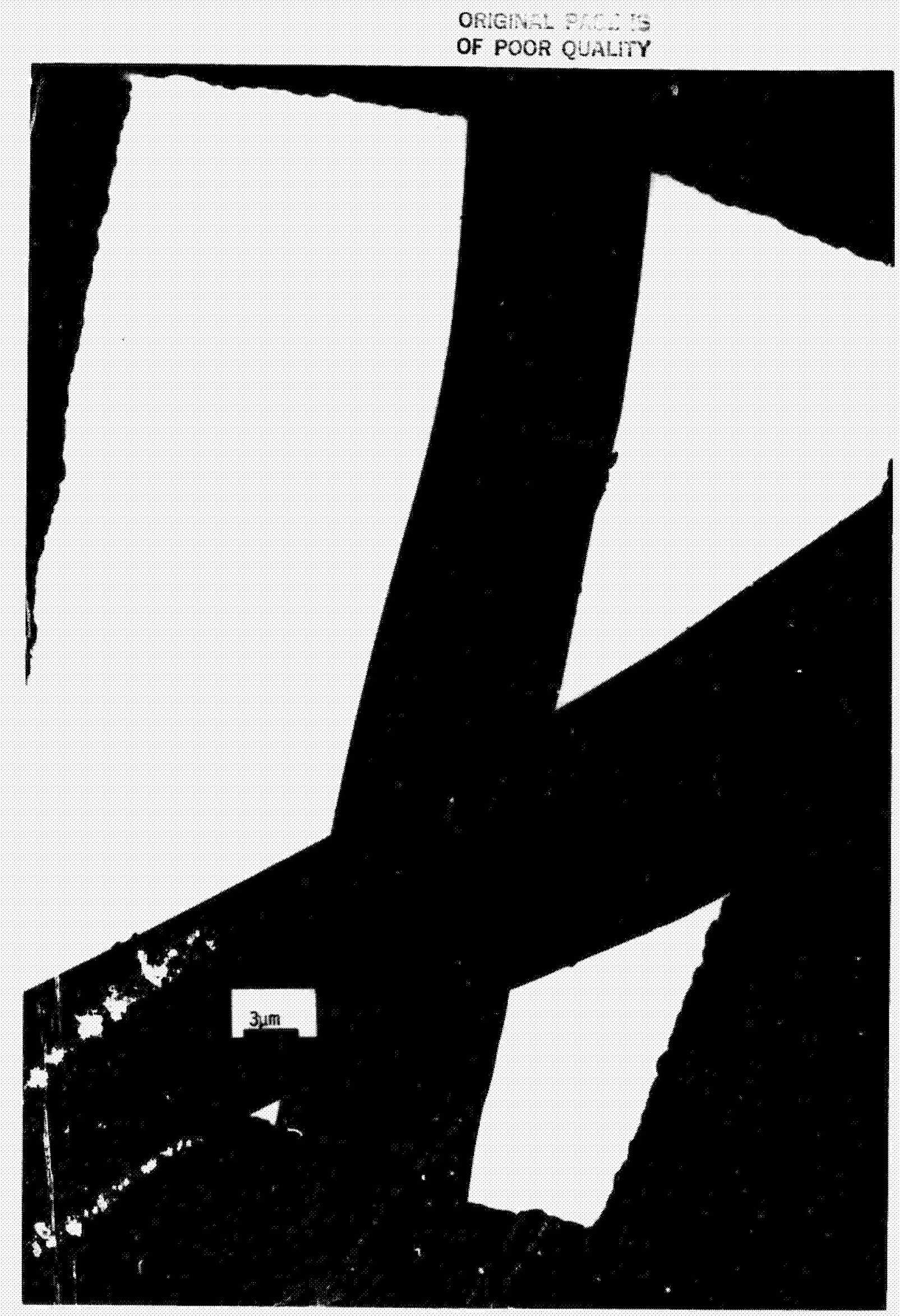

Figure 1. Carbon Felt fibers before Catalyzation (FMI-C-1/8). 


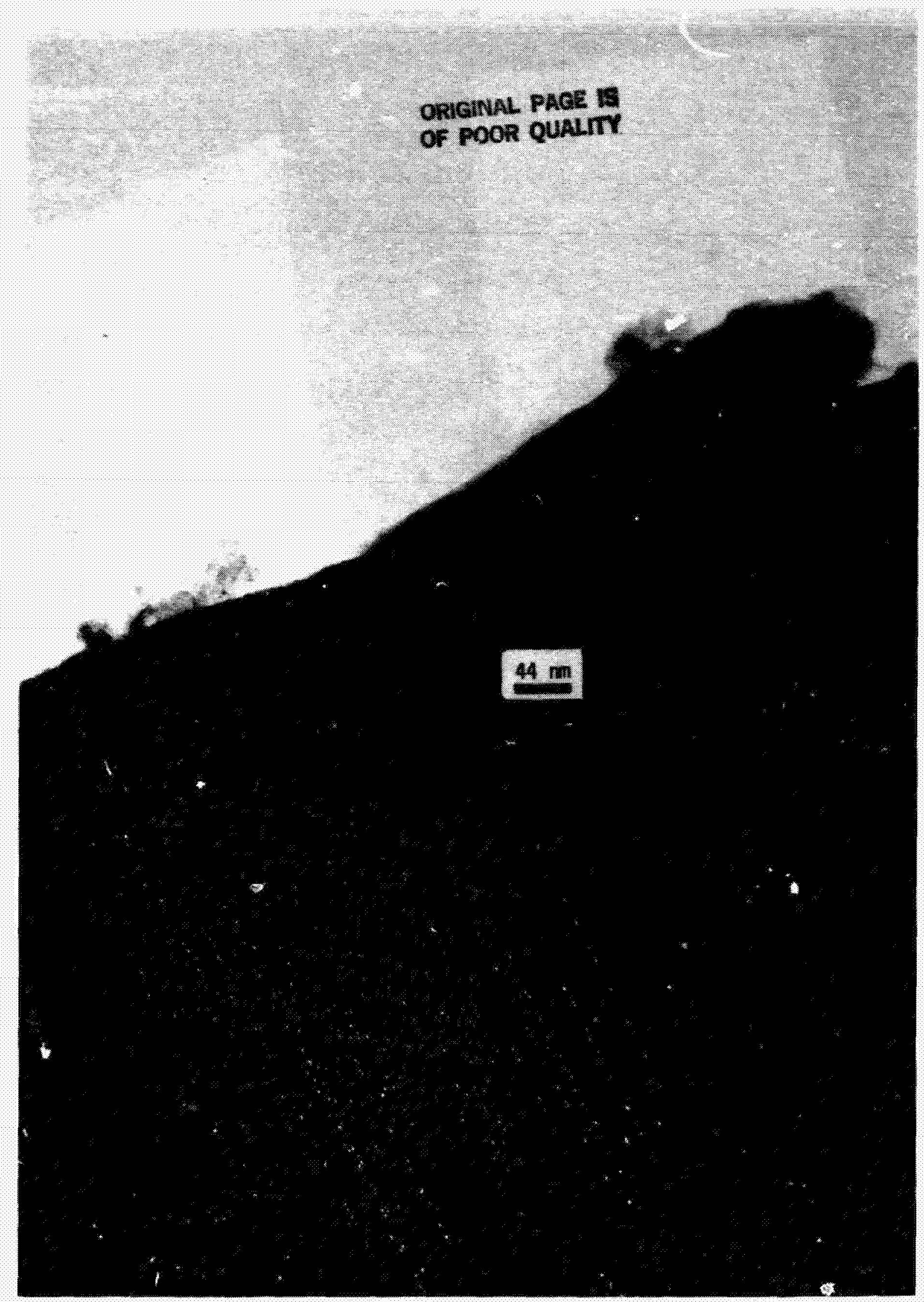

Figure 2. Carbonaceous Particle on Carbon Fiber Before Catalyzation (see Figure 1). 


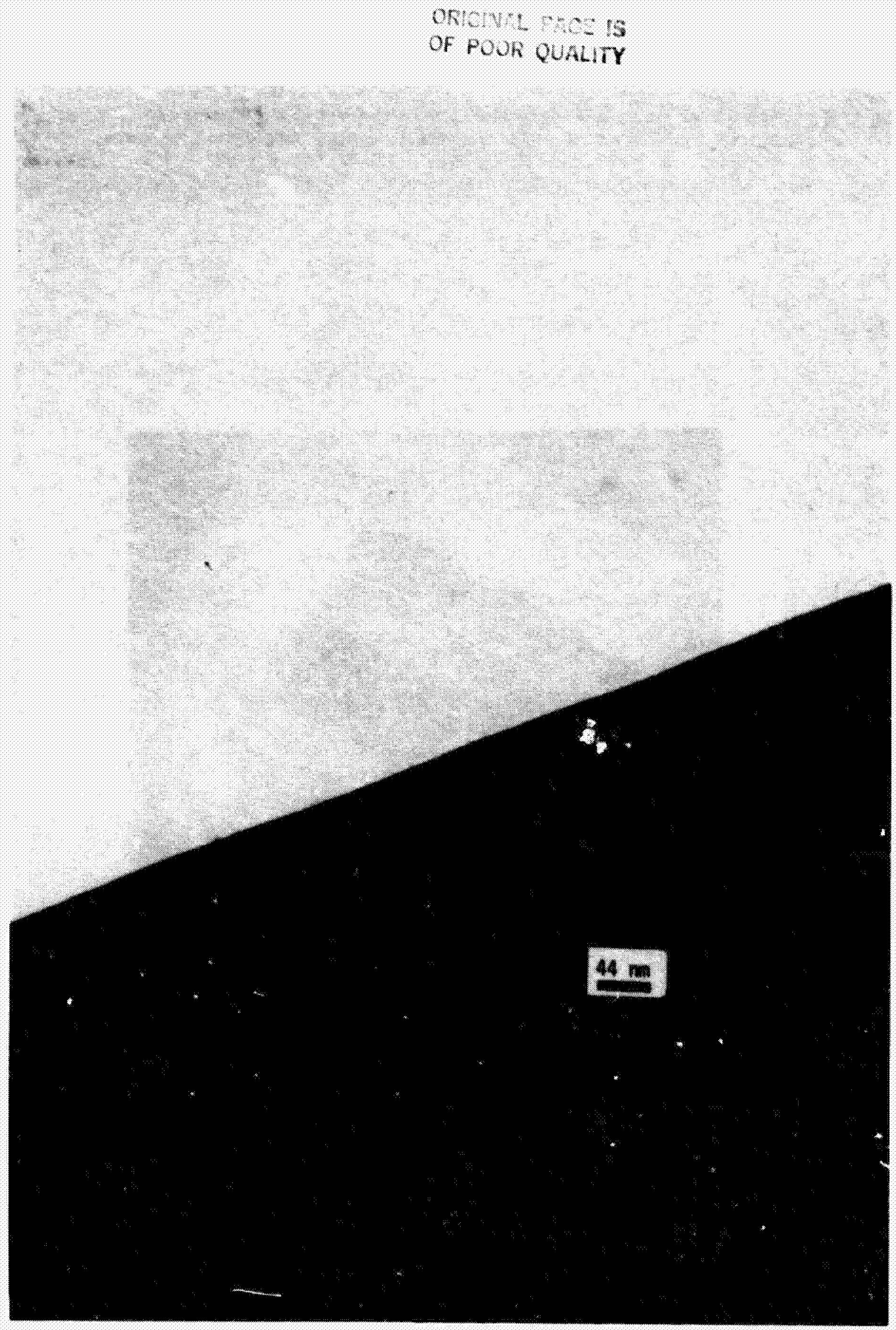

Figure 3. Typical surface of Carbon $f$ iber at lligh

Magnification betore latalyzation (IM $-(-1 / 8)$.

$-17 \cdot$ 
ORICINAL PACE IS
OF POOR QUALITY

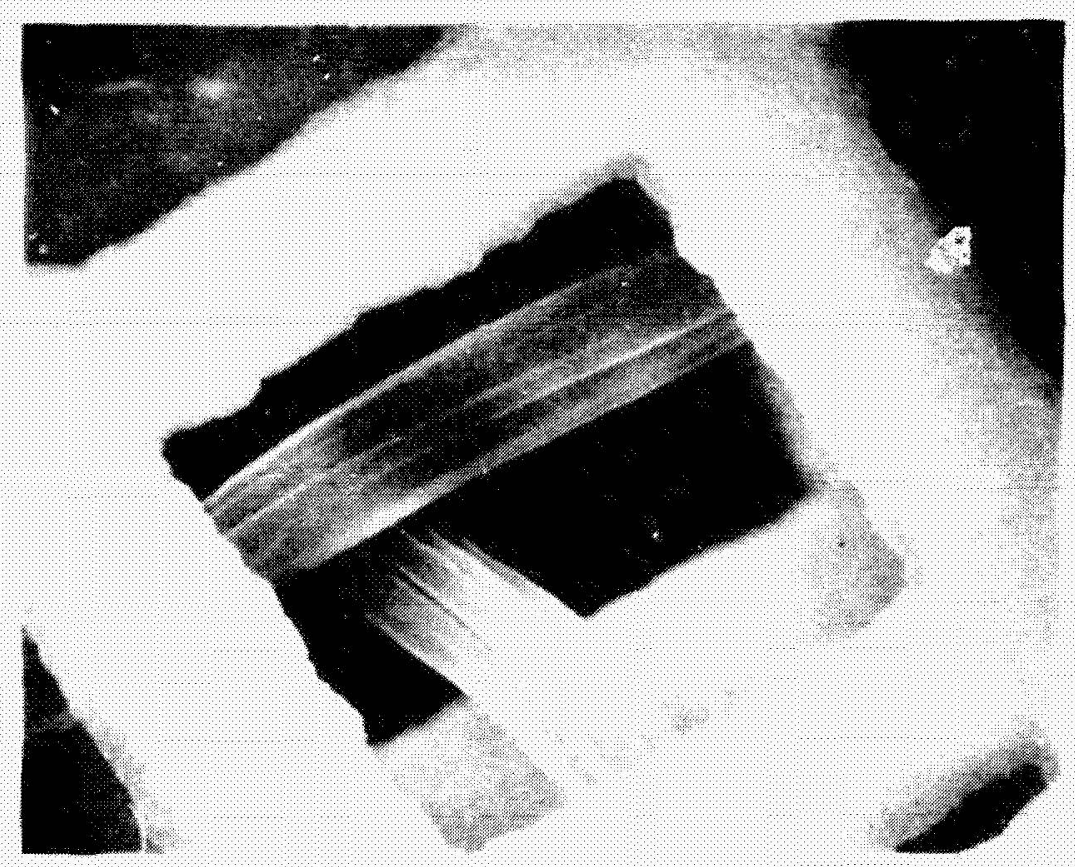

Ficure 4. Surface Appearance of Carbon Felt Fiber by STEM at Low Magnification $(X 800)$. 
ORIGINAL PAGE IS

OF POOR QUALITY

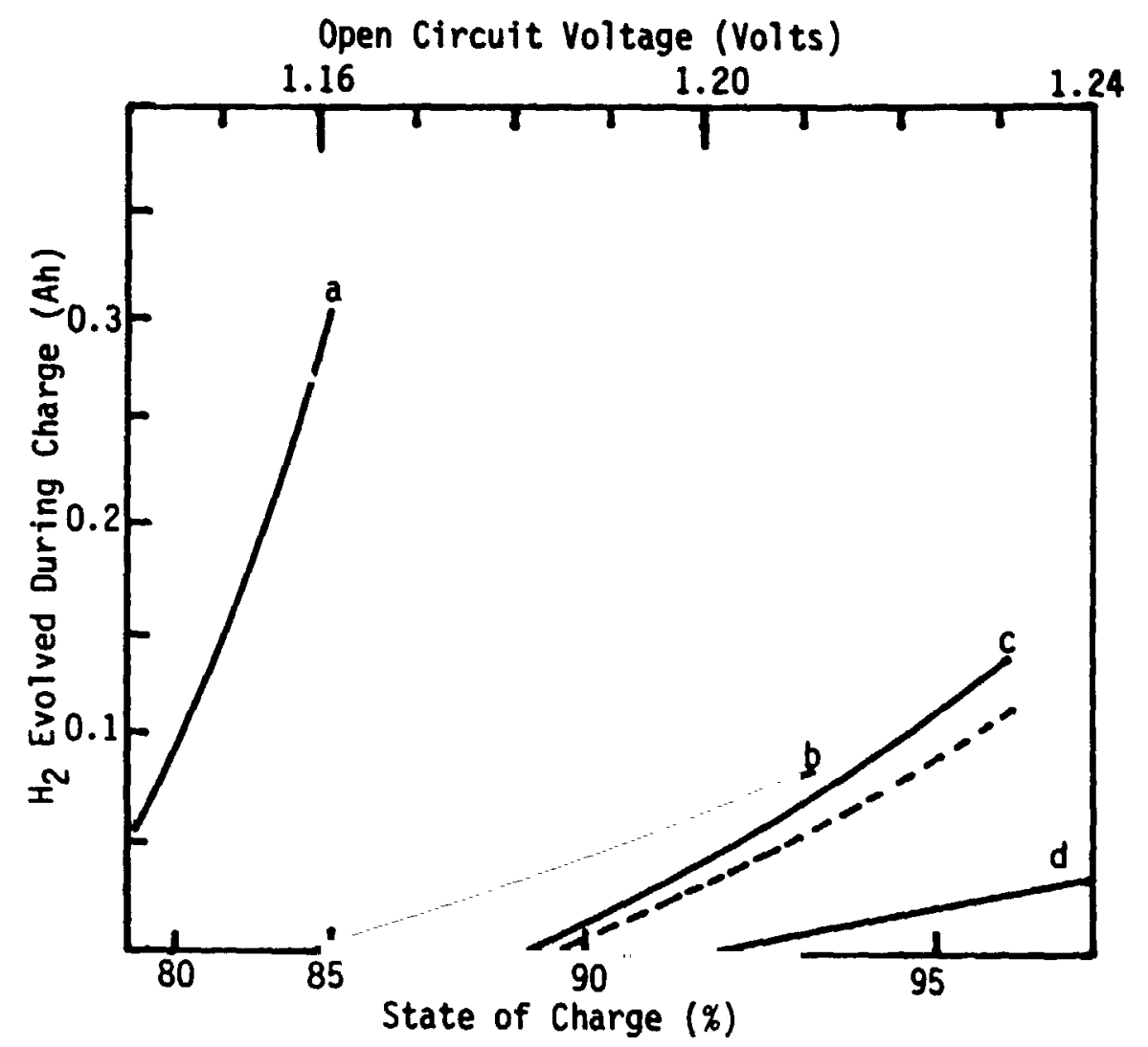

Figure 5. Hydrogen Evolution Characteristics of "Low Performance" Felt Electrodes Showing the Effects of Progressive Improvements in the Catalyzation Techniques; Dashed Line Represents "01d" Felt, Standard Process.

(a) Standard Au Process; (b) $\mathrm{HNO}_{3}$ Treated, Standard Au Process; (c) $\mathrm{HNO}_{3}$ Treated, Improved Au Process;

(d) Alcohol-Assisted Au Process. 


\section{COLD ACTIVATION PROCEDURES}

C. . of the earlier procedures used for depositing gold on the felt substrate consisted of soaking the felt in a dilute aqueous gold chloride solution $\left(1.25 \times 10^{-3} M_{1}\right)$ for 16 hours, draining on a paper towel, drying and baking at $260^{\circ} \mathrm{C}(5)$. When a new lot of carbon felt was activated by this method, it was observed that the gold chloride solution changed from the normal pale yellow color to clear during the soaking steps, suggesting depletion of the gold solution and perhaps an unusual absorption process and/or in situ reduction to gold metal. As noted in Section II-A above, the resulting electrodes gave low performance, i.e., high hyorogen evolution, on an absolute scale as well as relative to $\mathrm{Cr}^{3+}$ reduction, on charge. It was postulated that the "excessive" gold loading of this felt (estimated to be $60 \mu \mathrm{g} / \mathrm{cm}^{2}$ ), implied by the solution color change discussed, might have been a critical factor. This experience contributed to the perception of a neea for a catalyst optimization study in terms of gold loading.

The alcohol-assisted gold activation process was developed in response to the above mentioned problem $(5,9)$. A controlled amount of solution was added to a felt sample in tris process, which permitted predetermined gold loadings. The most commonly used gold loading has been 12 to $13 \mu \mathrm{Au} / \mathrm{cm}^{2}$ of felt. With this as a basis, gold loadings of $3,6,12.5$ and $25 \mu \mathrm{g} / \mathrm{cm}^{2}$ were examined initially; at a later point $50 \mathrm{\mu g} / \mathrm{cm}^{2}$ loadings were also examined. Methods of gold catalyzation are describer below. 
ORIGINAL PAGE IS

OF POOR QUALITY

\section{A. Aqueous/Yacuum Gold Catalyent ion Method.}

In an early atteupt, on this program, to prepare a relatively large selection of electrodes by the alcohol-assisted gold proces, a large volume of appropriate solution was pre-nixed. Because of the processing time involved, a portion of the solution experienced several houre of standing in the container. Over this period of time ( $<8$ hours), the initial yellow color of the gold chloride solution was abserved to fade significantly and small black fibrous strands and needles vere observed throughout the solution, suggesting precipitation of metallic gold. since premixed solution had not previously been stored for any length of time, the short-term instability of cold chloride in alcohol solution had not been sbserved. Because of this potential problem and a contract reguirement to examine scale-up procedures for larger electrodes sizes and quantities, another approach to catalyzation was explored briefly. This method was based on the elimination of alcohol as a co-sclvent/wetting agent. It appeared feasible to saturate the felt substrates with an aqueous solution of gold chloride, since the properly pretreated felts were more wettable and the entrapped air could be readily removed by evacuation of a substrate submerged in gold solution. The average water absorption values for all the felt types had been determined in the pretreatment study, as described in section II $D$, providing a basis for calculating solution concentrations to achieve varlous gold loadings. The procedure and results are deecribed below.

1. Rrocedure. The solution concentrations required to give the four desired gold loadings $\left(3,6,12.5\right.$ and $\left.25 \mu \mathrm{Aw} / \mathrm{cm}^{2}\right)$ were calculated on the basis of the mean value for water absorption measured for the 10 sample sets ("B"-sets) described in section II $D$, Table VI. 
The appropriate solution concentrations are listed below (Table VI): TABLE VII. Gold Deposition Solutions.

\begin{tabular}{|c|c|c|c|c|}
\hline $\begin{array}{l}\text { Gold Loading } \\
\text { Solution Conc. } \\
\text { Felt Type + }\end{array}$ & $\begin{array}{l}25 \mu g / c^{2} \\
(j \mathrm{Au} / \mathrm{ml})\end{array}$ & $\begin{array}{l}12.5 \mu \mathrm{g} / \mathrm{cm}^{2} \\
(\mu \mathrm{g} \mathrm{Au} / \mathrm{ml})\end{array}$ & $\begin{array}{c}6 \mathrm{ug} / \mathrm{cm}^{2} \\
(\mu \mathrm{g} \text { Au/ml) }\end{array}$ & $\begin{array}{c}3 \mu g / \mathrm{cm}^{2} \\
(\mu g \text { Au/mI) }\end{array}$ \\
\hline FMI-C-1/8 & 148.7 & 74.3 & 37.2 & 18.6 \\
\hline FMI-G-1/8 & 112.9 & 56.4 & 28.2 & 14.1 \\
\hline FMI $-C-1 / 4$ & 38.6 & 19.3 & 9.6 & 4.8 \\
\hline$F M I-G-1 / 4$ & 58.6 & 29.3 & 14.6 & 7.3 \\
\hline$U C-G-1 / 4$ & 43.9 & 21.9 & 11.0 & 5.5 \\
\hline
\end{tabular}

The most concentrated solutions were made first from a stock solution of $4750 \mathrm{\mu g} \mathrm{Au} / \mathrm{ml}$; the other solutions were made as successive 2:1 dilutions. Each carbon felt was submerged in the appropriate solution, held below the surface by the weight of a beaker, and evacuated to 100-200 Torr three times in succession. The saturated felt was then lifted out of solution and laid on a preweighed Teflon film in a shallow glass dish to determine the absorbed solution weight. The Teflon film was used as a barrier to desorption of the liquid from the felt in direct contact with glass. The felts were then dxied at $100^{\circ} \mathrm{C}$ for 2 hours and baked at $260^{\circ} \mathrm{C}$ for 2 hours for thermal reduction of the gold salt to gold.

2. Results. The quantities of gold solution absorbed by each type of felt and the equivalent gold loadings are summarized in Table VIII. Comparing the actual to target gold loadings it can be seen that the vacuum filling method is somewhat less suitable for exact control of the gold quantity deposited because of the variations in felt porosity. This was a fairly small effect, however, (5-108 devistion). 
TABLE VIII. SUMMARY OF GOLD DEPOSITION ON CARBON FELTS Aqueous/Vacuum Impregnation Process

\begin{tabular}{|c|c|c|c|c|}
\hline $\begin{array}{l}\text { Target Gold loadings } \rightarrow \\
\quad\left(\mu \mathrm{g} \mathrm{Au} / \mathrm{cm}^{2}\right)\end{array}$ & 25 & 12.5 & 6 & 3 \\
\hline FMI-C-1/8, Dry wt. (g) & 0.342 & 0.335 & 0.331 & 0.325 \\
\hline $\mathrm{H}_{2} \mathrm{O}$ absorbed $(\mathrm{g})$ & 2.271 & 2.223 & 2.537 & 2.310 \\
\hline Soln. abs. (g) & 2.234 & 2.479 & 2.767 & 2.585 \\
\hline Gold loading $\left(\mathrm{\mu g} / \mathrm{cm}^{2}\right)$ & 22.9 & 12.6 & 7 & 3.3 \\
\hline FMI-G-1/8, Dry wt. (g) & 0.383 & 0.383 & 0.391 & 0.350 \\
\hline $\mathrm{H}_{2} \mathrm{O}$ abs. (g) & 3.270 & 3.145 & 3.304 & 2.982 \\
\hline Soln. abs. (g) & 3.182 & 3.480 & 3.670 & 3.309 \\
\hline Gold loading $\left(\mu \mathrm{g} / \mathrm{cm}^{2}\right)$ & 24.3 & 13.4 & 7.1 & 3.2 \\
\hline FMI-C-1/4, Dry wt. (g) & 1.000 & 1.094 & 1.000 & 1.035 \\
\hline $\mathrm{H}_{2} \mathrm{O}$ abs. $(\mathrm{g})$ & 9.337 & 9.467 & 9.411 & 9.335 \\
\hline Soln. abs. (g) & 9.200 & 10.608 & 10.353 & 10.173 \\
\hline Gold loading $\left(\mathrm{\mu g} / \mathrm{cm}^{2}\right)$ & 24.6 & 14 & 6.9 & 3.4 \\
\hline FMI-G-1/4, Dry wt. (g) & 0.971 & 0.943 & 0.971 & 0.982 \\
\hline $\mathrm{H}_{2} \mathrm{O}$ abs. $\quad(\mathrm{g})$ & 6.908 & 6.217 & 6.042 & 5.823 \\
\hline Soln. abs. (g) & 6.855 & 7.221 & 6.969 & 6.866 \\
\hline Gold loading $\left(\mathrm{l}: \mathrm{g} / \mathrm{cm}^{2}\right)$ & 27.6 & 14.5 & 7.0 & 3.5 \\
\hline UC-C-1/4, Dry wt. (g) & 0.692 & 0.707 & 0.742 & 0.713 \\
\hline $\mathrm{H}_{2} \mathrm{O}$ abs. $(\mathrm{g})$ & 8.293 & 8.213 & 8.218 & 8.290 \\
\hline Soln. abs. (g) & 8.103 & 8.677 & 8.903 & 8.894 \\
\hline Gold loading $\left(\mathrm{\mu g} / \mathrm{cm}^{2}\right)$ & 24.6 & 13.0 & 6.8 & 3.4 \\
\hline $\begin{array}{l}\text { Sample number for each felt type: } \\
\text { (See Table VI) }\end{array}$ & 2 & 1 & 3 & 4 \\
\hline
\end{tabular}


The electrochemical performance of electrodes prepared in this manner, discussed later in Section VII, suggested a low gold surface area. It was postulated that, unlike an alcoholic-based gold solution, the açueous golc solution is comparatively stable; thus during drying of the feits, the gold chloride crystals instead of depositing within the felt may have been selectively deposited near the top surface by continuous capillary migration of the solution to the surface. Continuous ovaporation from the surface, then, would concentrate the solut : on which would not only result in a surface gold deposit but would also promote larger crystal growth. Examination of the elecurodes by transmission electron microscopy confirmed this hypothesis. One side of the felt showed almost no evidence of gold and the other side exhibited not only evidence of gold but very large crystallites. Typical surfaces are shown in Figure 6 (low gold side) and Figure 7 (high gold side). The transparent projections in Figure 6 are probably graphite particles. The gola particles in Figure 7 are $350-400 \mathrm{~nm}$, about 5-10 times normal. Rased on these results, the aqueous/vacuum gold catalyzation process was rejected.

\section{B. Aqueous/Methanel Gold Catalyzation Processes.}

The use of alcohol as a co-solvent/wetting agent was first investigated on the previous program (DEN3-97) (5). Initially, 50/50 isopropanol/water solutions were used. The presently used process, based on methanol, was developed in further experiments at NASA-LeRC $(9,12)$, and has yielded excellent results in $1 \mathrm{~kW}, 11 \mathrm{kWh}$ prototype system tests $(10,11)$.

The gold loading was established by adding a predetermined volume of gold chloride solution of appropriate concentration to the felt 
substrate. The potential problem of gold precipitation in the presence of alcohol, mentioned in Section $A$ above, was obviated by preparing and storing only the aqueous portion of the solution; the required quantity of methanol was then added to the exact volume of aqueous solution required immediately prior to use. The total volume of solution required for each type of felt was selected on the basis of the mean water absorption values measured as described in Secticn II $-D$ !Table VI); the goli concentration was adjusted in each case to give the desired gold loading. Tailuing of the solution volume $z$ nd concentration in this way permitted complete wetting without excess solution for each felt type in spitc of large variations in thickness, apparent donsity and liguid absorption capacity over the range of samples.

Two different physical approaches to introduction of the gold solution to the felts were used. For the majority of electrodes prepared and tested on this program the solution was added dropwise over the surface of the felt (usually a $14.5 \mathrm{~cm}^{2}$ sample). For the $1 / 4$ inch thick felts an immersion process was used. Immersion processes patterned on the method used at NASA-LeRC, were also investigated for scale-up of catalyzation methods. These are discussed below.

\section{Rrocedures.}

\section{a. Gold Catalyzation: Dropwise Solution Addition.} The first step was to prepare a gold solution to match the felt type being catalyzed (all samples were pretreated in potassium hydroxide as described in Section II-D). A $\cdots+a l$ volume of solution was selected according to the mean water absorption vajue $\mathrm{j}$ i...h in Table vi. The appropriate quantity of golu chlori. . (f. - $A u / \mathrm{cm}^{2}$ times 14.5 
$\mathrm{cm}^{2}$ ) was obtained by selecting an aqueous gold chloride solution of four times the desired concentration and one fourth the desired volume. Immediately before use, this solution was diluted to the desired volume (e.g. $2.44 \mathrm{ml}$ for FMI $-c-1 / 8$ felt) by adding methanol.

The indivioually compounded solutions prepared in this manner were added to the felt samples in a dropwise fashion over the entire surface. Half of the solution volume was applied to each face of the sample. This method was typical for $1 / 8$ inch thick felts.

To complete the catalyzation process, the saturated felts were placed in Teflon coated pans, dried in air at ambient temperature for 2 to 3 hours ano then oven dried at $100-110^{\circ} \mathrm{C}$ for 16 hours; for the final thermal decomposition of gold chloride to gold, the samples were transferred to a Pyrex tray and baked at $260^{\circ} \mathrm{C}$ for 2 hours.

\section{b. Gold Catalyzation: Single Immersion Method (1/4 in. Felts).}

A tray of the same dimensions as the felt samples $\left(1.5\right.$ in $\left.\times 1.5 \mathrm{in}, 14.5 \mathrm{~cm}^{2}\right)$ was fabricated from polyethylene sheet for the immersion catalyzation method. The method consisted of adding half the required volume of gold chloride solution to the tray, immersing the felt to absorb the solution, adding the remainder of the solution to the tray and then re-immersing the felt from the opposite face.

In the case of the $1 / 8$ inch thick felts it was found that half the required solution volume ( 1 to $1.5 \mathrm{ml}$ ) was insufficient to completely cover the bottom surface of the polyethylene immersion tray. For this reason, most of the $1 / 8$ inch thick test electrodes prepared were catalyzed by the dropwise method described in subsection (a) above. In the case of the $1 / 4$ inch thick felts, however, half the required solution volume ( 3 to $4.5 \mathrm{ml}$ ) was sufficient to cover the bottom of the 
tray, and the immersion method worked well. The drying and thermal conversion processes used to complete the catalyration by this method were the same as described in subsection (a) above.

\section{c. Gold Catalyratione Double Immersion Method.}

A variation of the immersion method described above was investigated as a possible approach for scale up of the catalyration process. The problem of insufficient solution volume in the case of $1 / 8$ inch thick felts, discussed in subsection (b) above, was resolved by utilizing the entire volume of solution reguired at half the desired concentration, but in two steps. Specifically, a felt was immersed in a volume of solution, derived from the mean water absorption value ir. Table VI, containing half the gold chloride required for a particular gold loading. The sample was then air dried for 2 to 3 hours, oven dried at $100-110^{\circ} \mathrm{C}$ for 16 hours, and then inmersed from the opposite face in a second aliquot of solution of exactly the same volume and concentration. Following the second irmersion step the sample was again dried in air and at $100-110^{\circ} \mathrm{C}$, and then baked at $260^{\circ} \mathrm{C}$ for 2 hours, as described in subsection (a) $z^{\prime}$ 'ove.

\section{d. Gold Catalyzation: Double Immersion Method II.}

In this method, the same procedures as described for the Double Immersion Method I were followed except that between immersion steps the samples were also baked at $260^{\circ} \mathrm{C}$ for 2 hours; thus the electrodes prepared by this process were exposed to two thermal decomposition steps. 


\section{Results.}

The electrochenical performance data measured for each felt type using the methanol-based catalyzation methods are discussed in section v. The physical features related to the gold catalyzation method are discussed here.

A selection of the catalyzed felts were examined by electron microscopy to try to verify the presence of gold on the substrate fibers, to determine the distribution of the gold and to measure particle sires. In an initial attempt at the NASA-LeRC electron microscopy lab using conventional scanning electron microscopy, no gold particles were found (the electrode had been prepared by the aqueous/methanol dropwise method, $13 \mathrm{ug} \mathrm{Au} / \mathrm{cm}^{2}$ ). A second at tempt with the same electrode, using Robinson Back-scattered Eltitron Imaging (REEI), was more sucessful. Tbrough enhanced contrast by atomic number discrimination, the RBEI technique revealed the presence of particles of 50 to $150 \mathrm{~nm}$ diameter on the catalyzed felt but not on a bare felt. It was inferred that the particles were gold but analytical verification was not within the capability of the instrument.

In the last quarter of the program, electron microscopy service was obtained by Giner, Inc. Ahrough another gnurce, and broad cross-section of electrodes were examined. The technique rsed, almost exclusively, was transmission electron microscopy (TEy). Using this method, low density particles like carbon and graphite appear transparent and high density materials like gold appeor opaquei the carbon fiber also appears opaque becsuse it is 10 to 15 micrans thick. Thus the photographs obtained by TEM show a profile or silhouette of the edge of the fiber. 
As was discussed in Section II $-C$ and illustrated in Figures 1 and 2, before catalyzation the fibers are generally quite smooth and $f$ ree $f$ dence particles, although occasional carbon or graphite particles are observed. After catalyzation, dense particles, frequently showing crystalline geometries, are observed. Such particles were positively identified as joid by energy dispersive analysis by $x$-ray (EDAX) during scanning transmission electron microscopy (STEM). A surface yian of a fjber obtained by STEM, showing particles identsi. cu as gold, is presented in Figure 8 at a magnification of $12.500 \mathrm{times,}$ and in Figure 9 at a magnification of 50,000 times. The lower rectangular particle in Figure 9 has dimensions of $120 \times 180 \mathrm{~mm}$. The electrode had a gold lcoring of $12.5 . . \mathrm{g} / \mathrm{cm}^{2}$ and was prepared by the dropwise aqueous/methanol procedure. A TEM photograph of the same electrode is shown in Figure 10. It can be seen that two particle sizes are present; a few large geometric shapes with dimensions of 50 to $100 \mathrm{~nm}$, and a multitude of small farticles with dimensions of 10 to $20 \mathrm{~nm}$. The smaller size particles were more typical for this electrode, as shown in another view in Section $v$. The dual particle size distribution was observed for other electrodes prepared by the same dropwise aqueous/methanol catalyzation process at different gold loadings e.g. 25 and $50{ }_{\mu} \mathrm{g} / \mathrm{cm}^{2}$ (see Section V! .

No $1 / 4$ inch thick felts were examined by electron microscopy; consequently, the physical configuration of the gold obtained by the Single Immersion Methed of Catalyzation was not defined. Samples of electrodes made by both Double Immersion methods were examined by transmission electron microscopy, however. A TEM photograph of a typical surface exhibited by an electrode piepared by the Double 
Imersion I methcd of catalyzation $\left(12.5 \mu \mathrm{g} \mathrm{Au} / \mathrm{cm}^{2}\right)$ is shown in Figure 11. Only one range of particle sizes was observed. The particles are relatively widely spaced and in the range 35 to $50 \mathrm{~nm}$ in size.

Typical surfaces obtained by the Double Immersion II method of aqueous/methanol gold catalyzation (thermal conversion at $260^{\circ} \mathrm{C}$ between immersion steps) are shown in Figures 12 and 13 for an electrode with a gold loading of $12.5 \mu \mathrm{g} / \mathrm{cm}^{2}$. Compared to the particles obtained by the Double Immersion I process, the particles in this case are much larger, 100 to $130 \mathrm{~nm}$, and generally more widely spaced.

\section{Aqueous/Acetone Gold Catalyzat un Process.}

The substitution of acetone for methanol as the co-solvent/wetting agent for gold catalyzation was tried at NASA-LeRC and repurted to give results equivalent to the methanol-based process. This alternative was examined briefly on this program. Two electrodes were prepared, one at a gold loading of $12.5 \mu \mathrm{g} / \mathrm{cm}^{2}$ ano another at $50 \mu \mathrm{g} / \mathrm{cm}^{2}$. Tre dropwise method of dispersing the gold solution on the felt sample was used, as described previously in Section III-B. The electrodes were similarly dried in air for $2-3$ hours, oven dried at $100-110^{\circ} \mathrm{C}$ for $\sim 16$ hours, and then baked at $260^{\circ} \mathrm{C}$ for 2 hours. The electrochemical performance of the electrodes is discussed in Section VII.

The electrode with a $12.5 \mu \mathrm{g} / \mathrm{cm}^{2}$ gold loading was examined by transmission electron microscopy, as described in section II-B-2, for comparison to the electrodes prepared by the aqueous/methanol processes. Typical surfaces are illustrated in the TEM photographs shown in Figures 14 and 15. The gold particles were found to be widely spaced and cuite large in size, 100 to $150 \mathrm{~nm}$. Triangular shapes of similar dimensions to 
that shown in Figure 14 were observed previously for the aqueous/methanol dropwise method (Figure 10) and for the Double Imersion-II method (Figure 12). The two particles shown in Figure 15 are widely divergent in size; the small particle is about $40 \mathrm{~nm}$ long, the large particle is about $130 \times 150 \mathrm{~nm}$. 
ORIGINAL PACE IS

OF POCR QUALITY

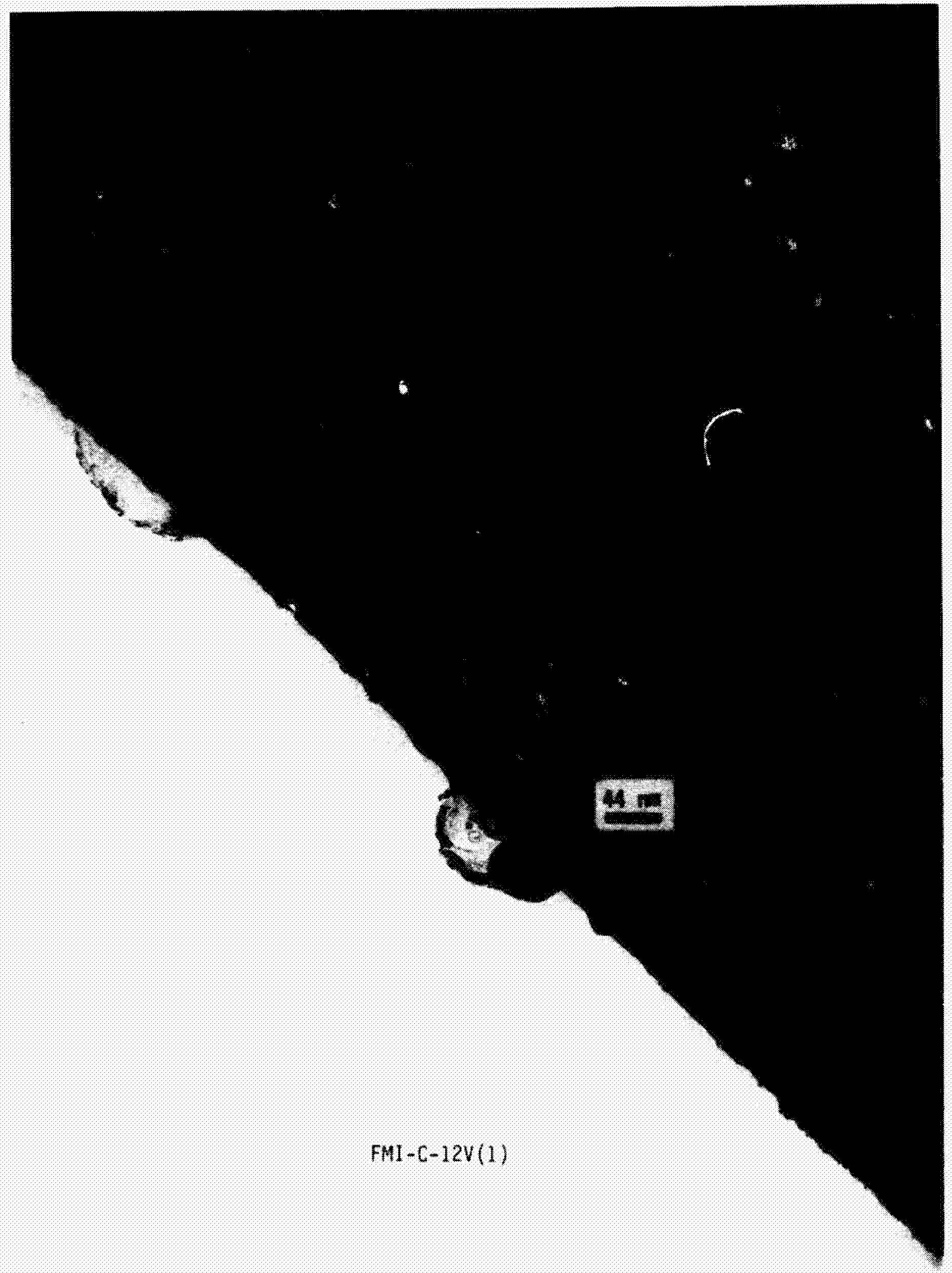

Figure 6. Surface Obtained by Aqueous/Vacuum Gold Catalyzation Method (Low Gold Side). 


\section{ORICINAL PACE N OF POOR QUALTY}

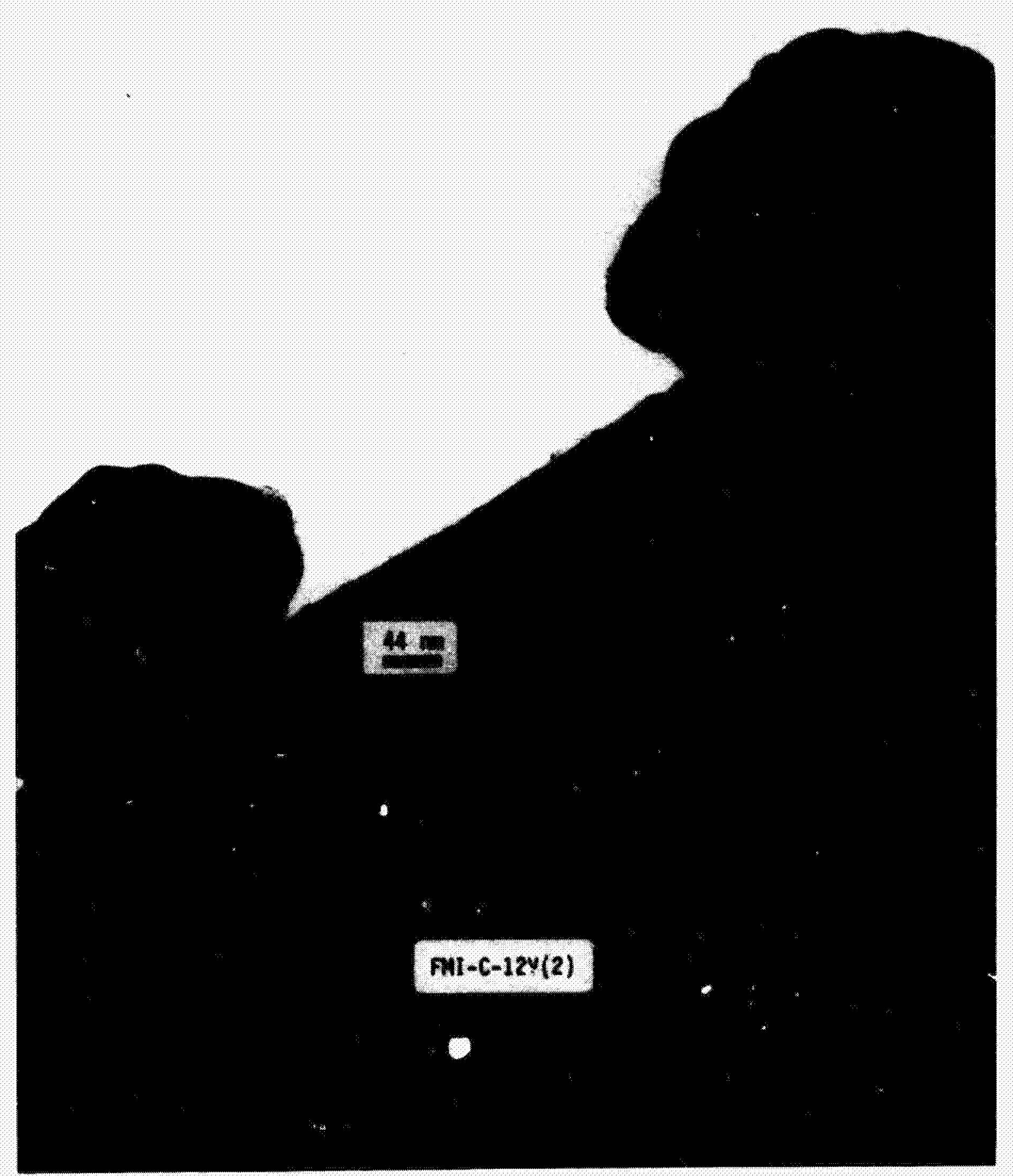

Figure 7. Particles Obtained by Aqueous/Vacuum Gold Catalyzation Method (High Gold Side).

$-33-$ 
ORIGHRL PATE IS

OF POOR QUALTY

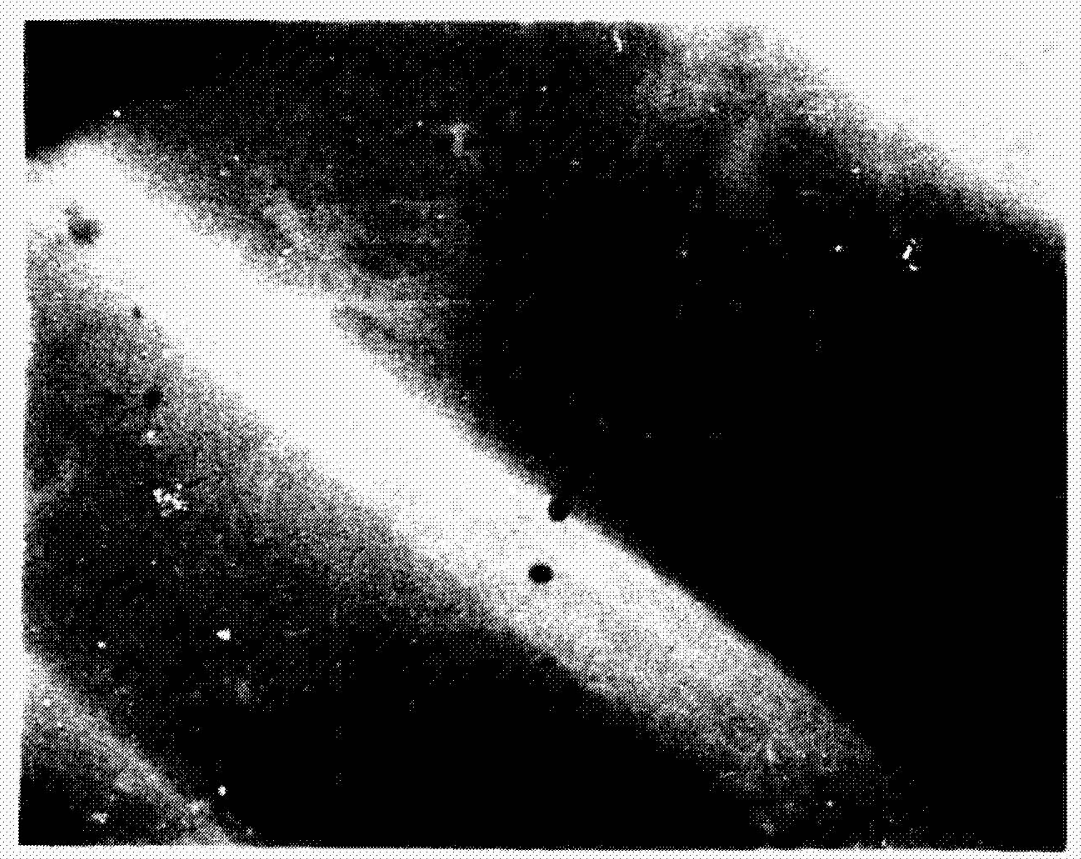

Figure 8. Surface View of Fiber (STEM; $X 12,500$ )

with Particles Identified as Gold by EDAX

Analysis. Electrode Prepared by Aqueous/

Methanol Gold Process (Dropwise, $12.5 \mu \mathrm{g} / \mathrm{cm}^{2}$ ). 


\section{ORIGINAL PACE IS \\ OF POOR QUALITY}

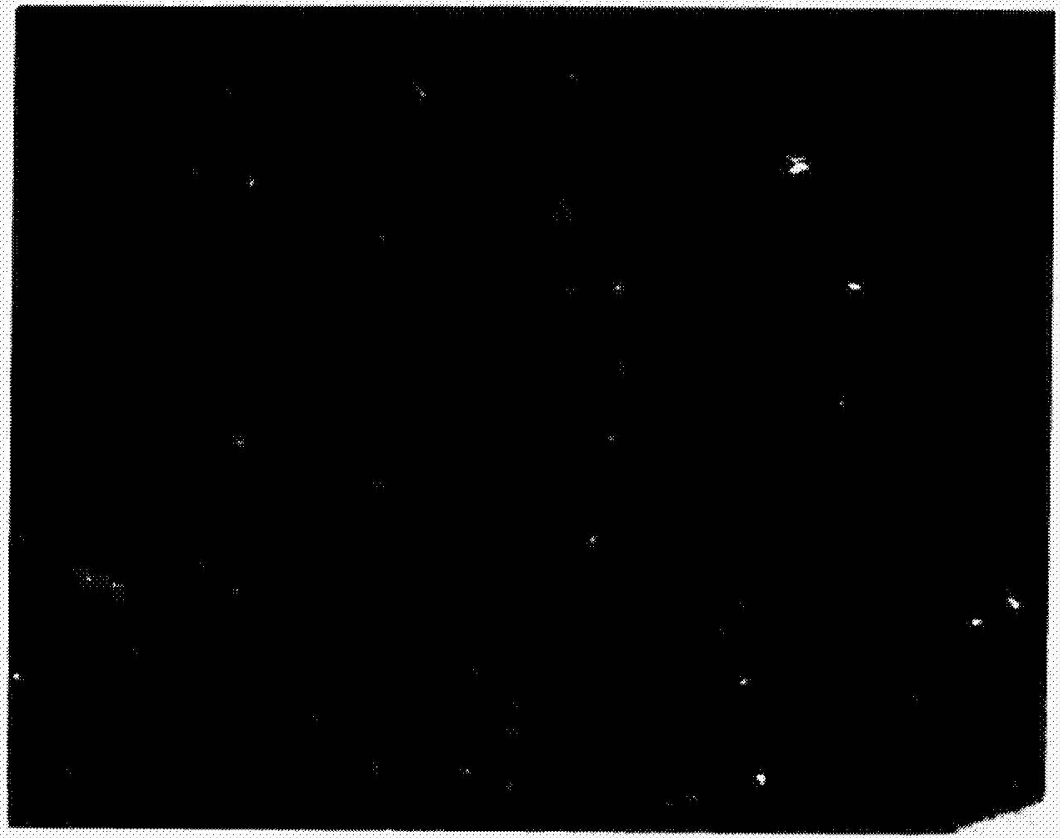

Figure 9. Surface View of Fiber with Gold Particles at Higher Magnification $(X 50,000)$. Lower Particle $=120 \times 180 \mathrm{~nm}$. 


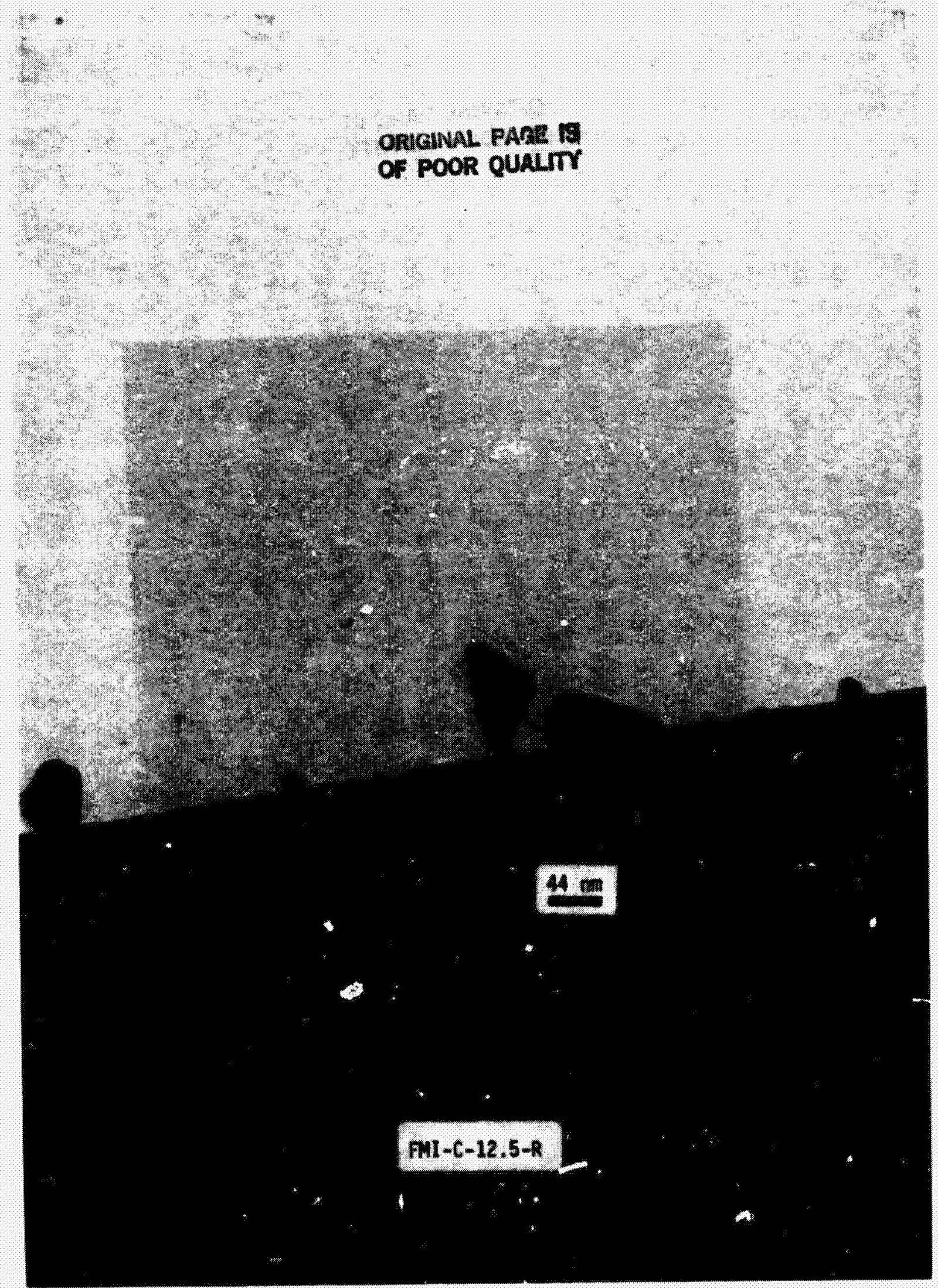

Figure 10. Gold Particles Obtained by Aqueous/Methanol

Process - Dropwise (12,5 ug Au/ $\mathrm{cm}^{2}$; See Fig. 34 also). 


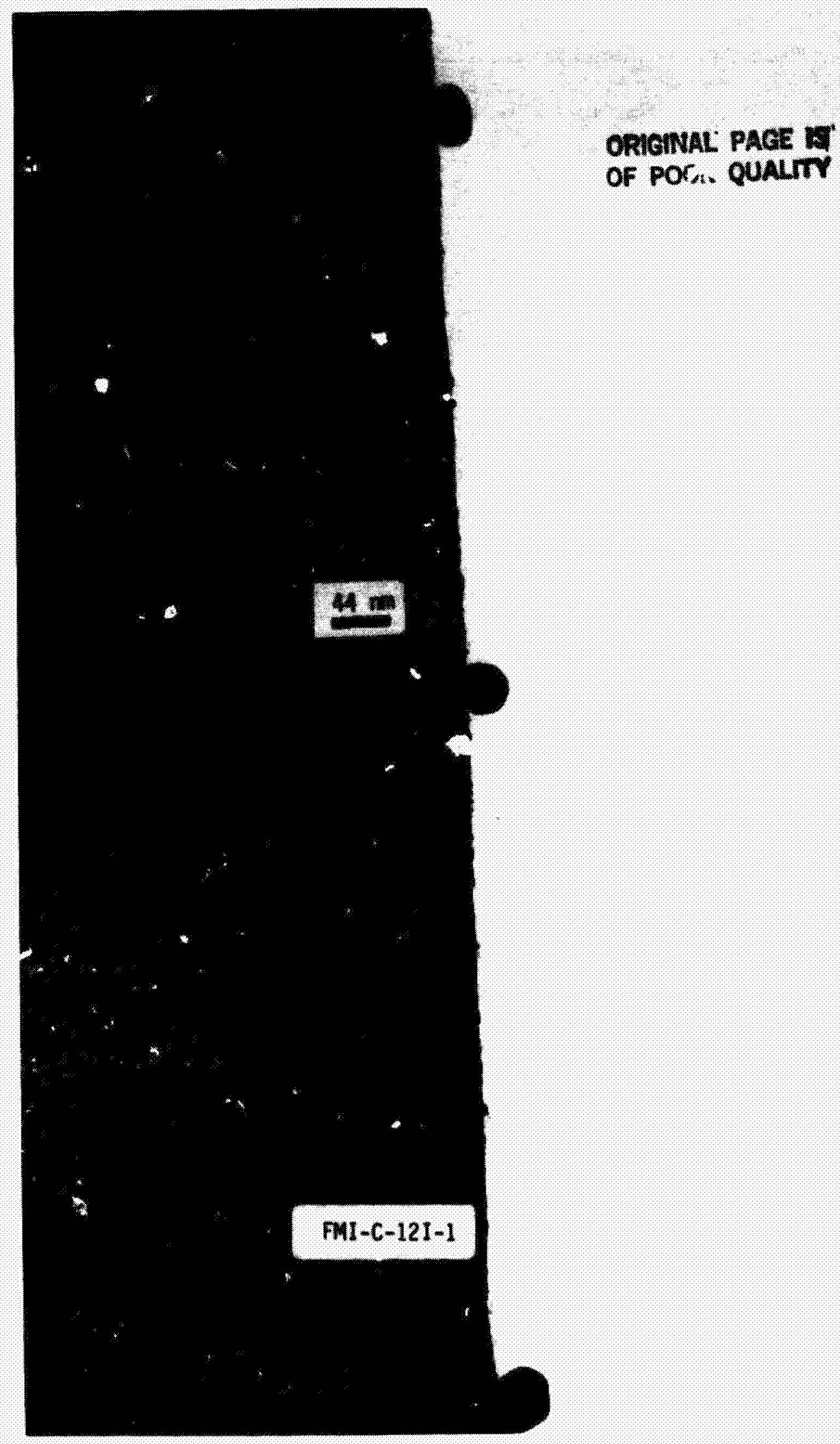

Figure 11. Typical Surface Obtained by Aqueous/Methanol Double Immersion-1 Process for Gold Catalyzation $\left(12.5 \mathrm{\mu g} \mathrm{Au} / \mathrm{cm}^{2}\right)$. 


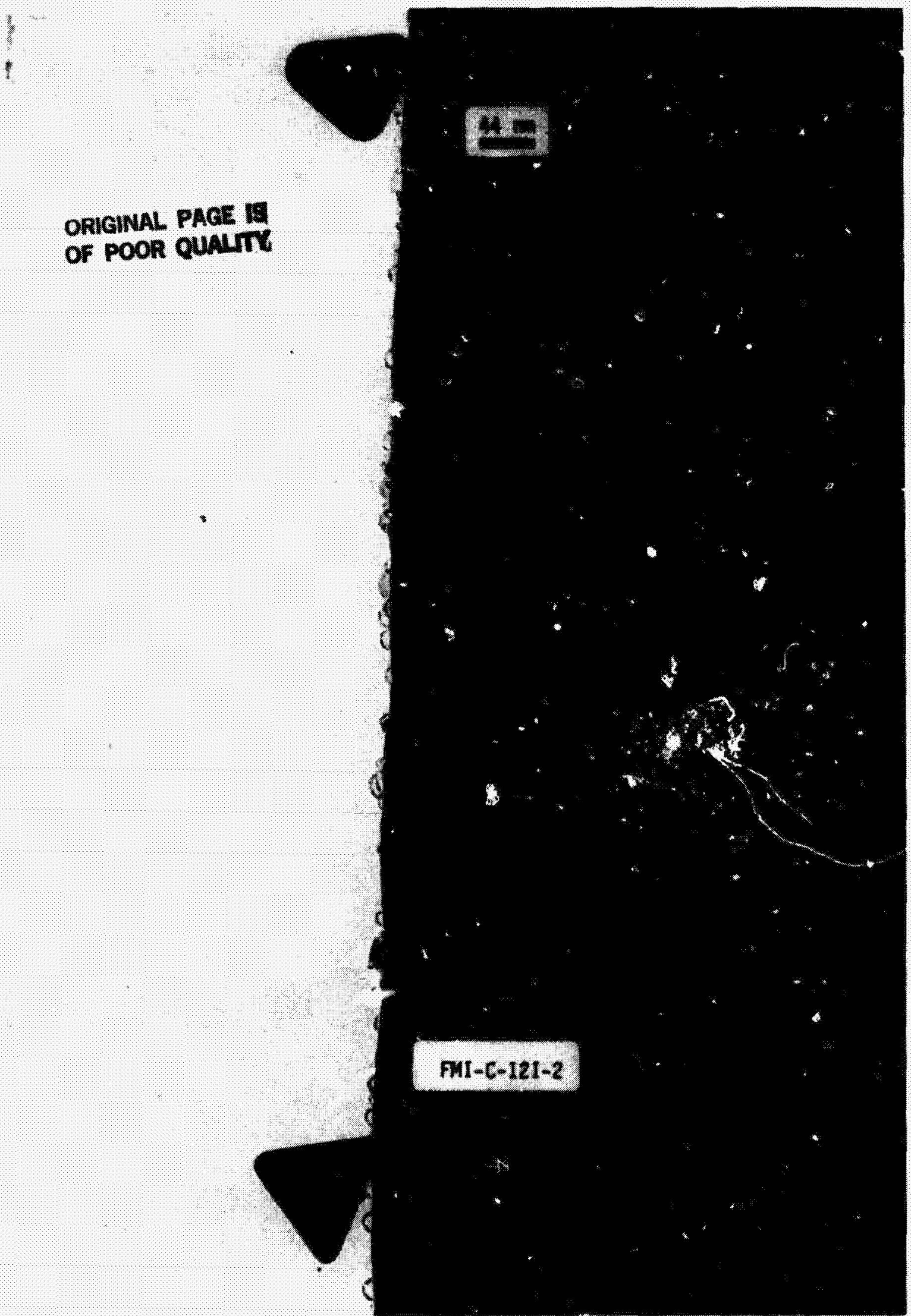

Figure 12. Gold Particles Obtained by Aqueous/Methanol Double Immersion-II Process for Gold Catalyzation; View 1 ( $\left.1 . .5 \mu \mathrm{g} \mathrm{Au} / \mathrm{cm}^{2}\right)$. 


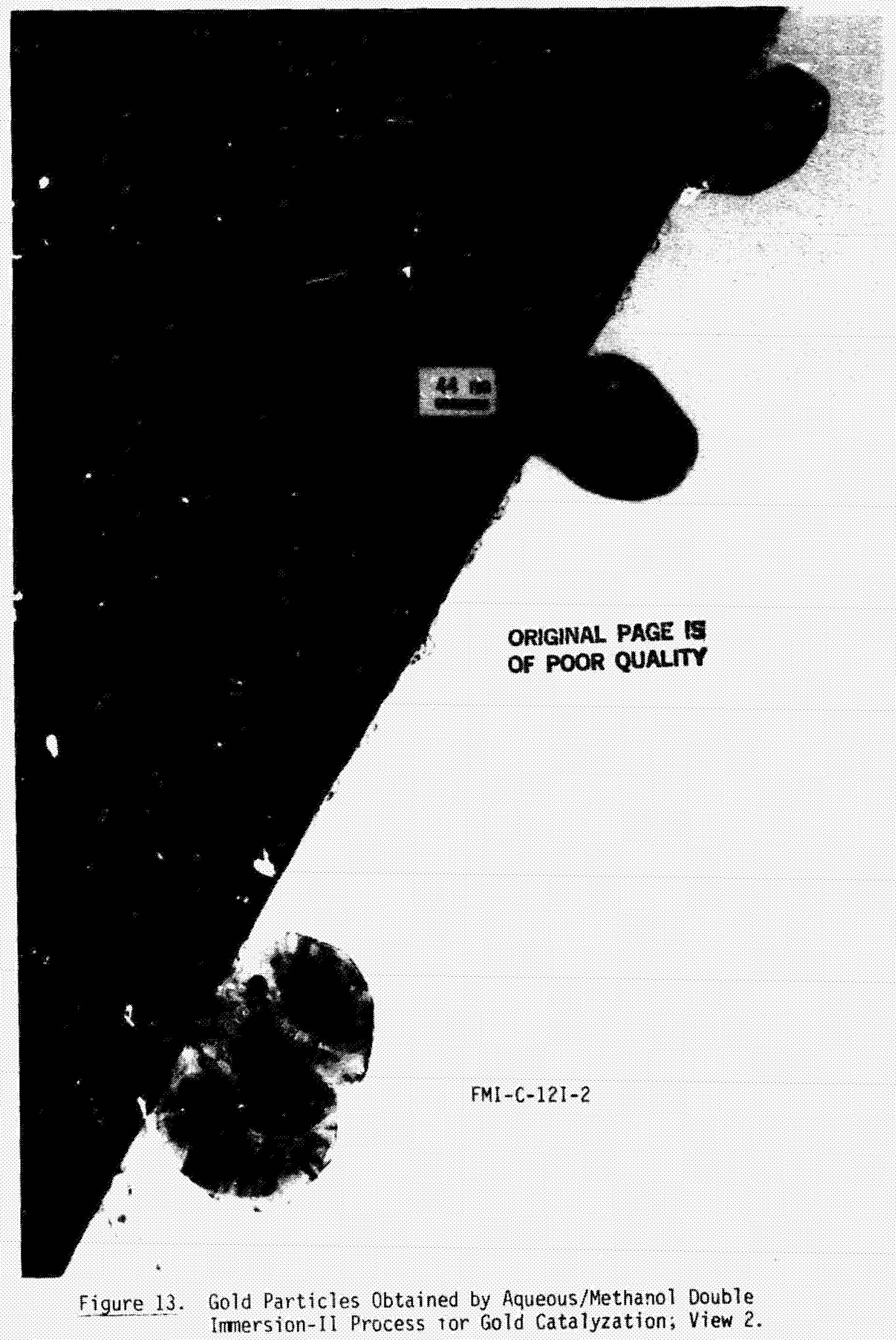

$-39$. 


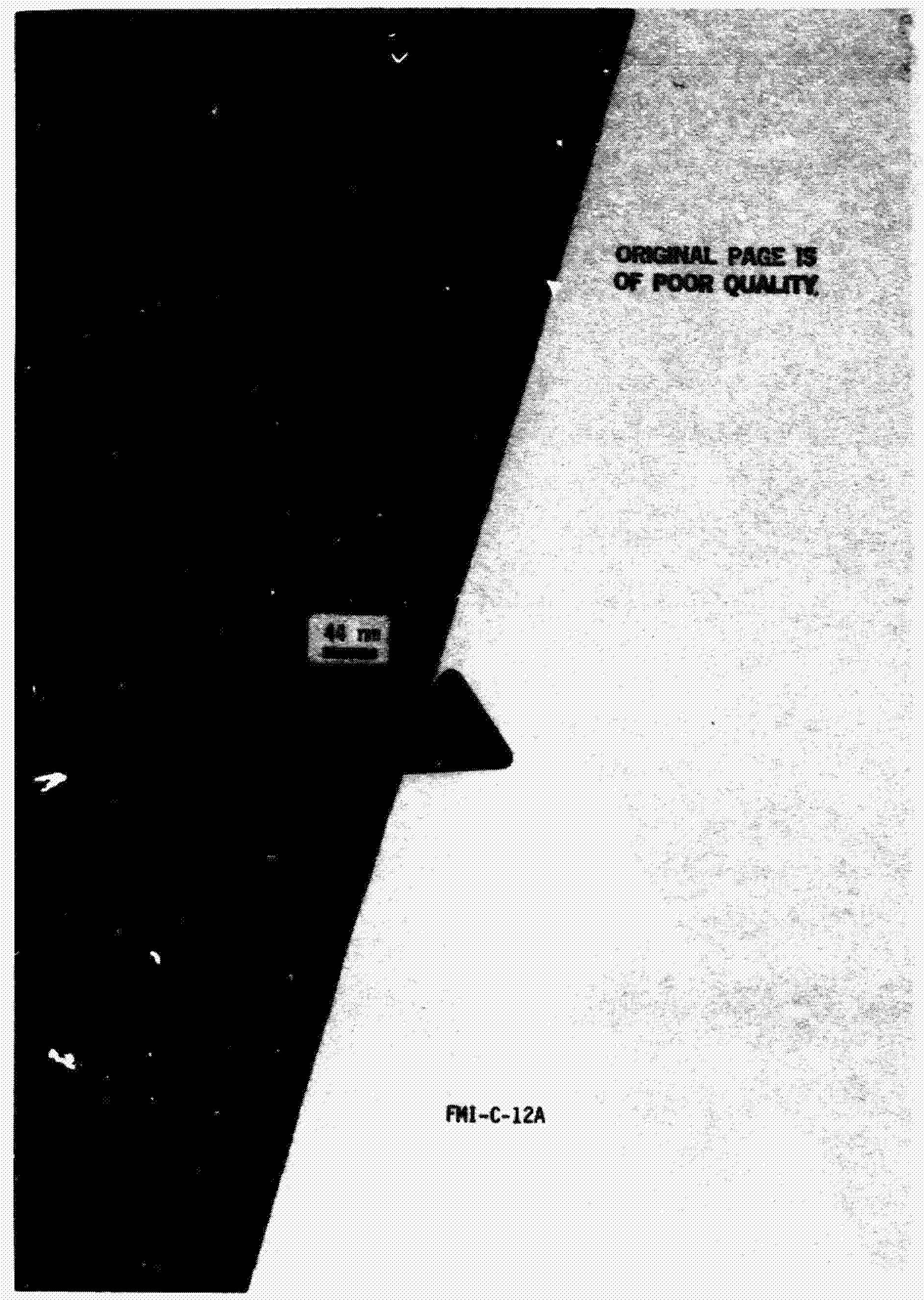

Figure 14. Gold Particles Obtained by Substitution of Acetone

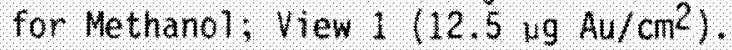




\section{ORTCNAL PAEE IS of Poor cuniry}

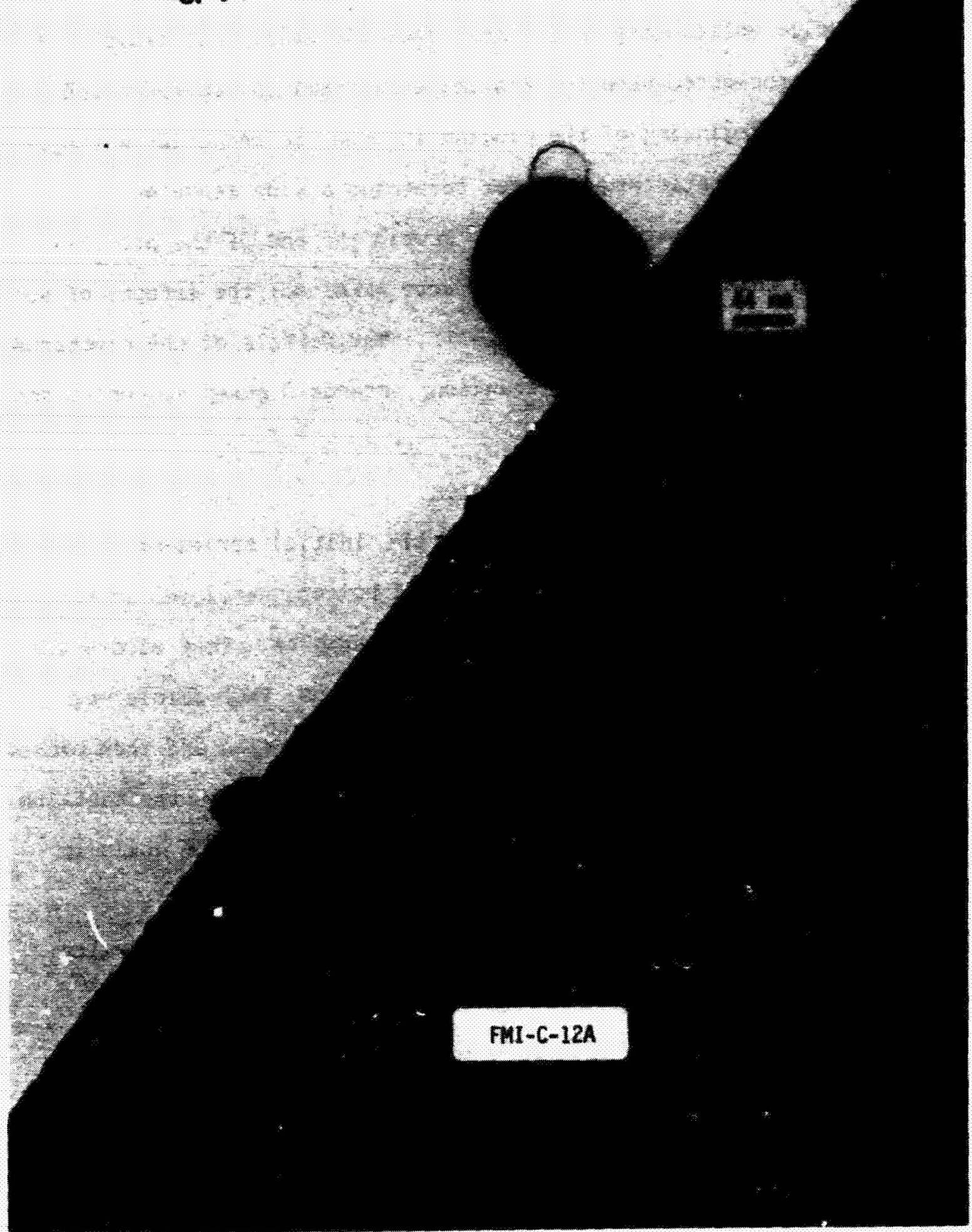

Figure 15. Gold Particles Obtained by Aqueous/Acetone Process Dropwise; View $2\left(12.5 \mu \mathrm{gu} / \mathrm{cm}^{2}\right)$. 


\section{ELECTROCGEMICAL TESTING PROCEDURES}

All of the electrochemical testing performed on this program was done by cyclic voltametry in a three electrode cell. All aspects of the initial procedures used for testing were examined, upgraded and refined at the beginning of the program in order to establish a single well-defined diagnostic sequence for screening a wide range of substrates and catalyzation methods. Toward the end of the program, variations in this standard procedure were examined; the effects of such variations are discussed in Section VIII. The details of the electrode mounting, cell configurations, solutions, standard sweep sequences and so forth, are described below.

\section{A. Electrode Mounting Proceduces.}

1. Tantalum coil Holder. In the initial series of electrochemical tests, a tantalum wire coil holder, developed in the previous program, was used to mount the felt samples. Test electrodes were cut from the felts as $0.8 \mathrm{~cm}$ diameter circles. Each circle was first saturated under vacuum with the test cell solution and then picked up with Teflon-coated tweezars and carefully place between the tantalum wire coils. Tweezers were also used to gently compress the coils in order to promote better electrical contact.

The tantalum felt contact was a continuing source of difficulty with this type of holder. Resistance w:s always high, sometimes exceeding the capacity of the iR compensator, and nonreproducible. Efforts to reduce contact resistance often resulted in excessive compression of the felt. In addition, the tantalum holder contributed to the observed reactions, e.g., plating and deplating lead. 


\section{ORIGINAL PAGE IS \\ OF POOR QUALITY}

\section{2. "unred-alip" Electrode Bolder. This type of electrode}

holder was developed by Dr. Margaret Reid and Dr. Robert Post at MSA-LeRC to reduce contact resistance problems and the undesirable compression of the carbon felt associated with the tantalum wire electrode holder (11). The holder, shown in Figure 16, consists of a binder clip with added copper contact surfaces and a heavy threaded brass connector rod. A 1.5 $\mathrm{cm}$ wide strip of felt was clamped between the copper contacts and $1.3 \mathrm{~cm}$ of its length isolated by means of pressure from the stop-off clamp. The entire binder clip assembly was then submerged momentarily in hot $\left(130^{\circ} \mathrm{C}\right)$ Ceresin wax, allowing the melted wax to wick up the felt as far as the end of the stop-off clamp, as depicted in Figure 16. To provide an external electrical contact, a length of the connector rod was masked $w i^{+h}$ Teflon tape prior to dipping. The stop-off clamp and masking were removed once the wax had hardened. Thus, only the unwaxed $1.5 \times 1.3 \mathrm{~cm}\left(2 \mathrm{~cm}^{2} / \mathrm{side}\right)$ felt section was exposed to the solution for testing.

The waxed-clip holder was generally superior to the tantalum wire holder, and was used for most of the testing in the balance of the program. It worked particularly well for the $1 / 8$ inch thick carbon felts. Much greater care was reguired to mount $1 / 8$ inch thick graphite felts because of their greater fragility, however. In the case of $1 / 4$ inch thick carbon felt, the wax demarcation was much more difficult to control; some of the mounted electrodes seemed to have some wax within the felt above the stop-off clamp. The $1 / 4$ inch thick graphite felts (FMI G-1/4 and UC-G-1/4) could not be mounted successfully because of the combination of thickness and fragility, and could only be tested in the tantalum holder. 


\section{B. Eleatrochenical Test cell.}

The test cell, illustrated in Figure 17 consisted of a $75 \mathrm{ml}$ glass vessel threaded to accept a plastic screw cap provided with five standard taper ports (ECO Model 494). The center port contained a specially designed Teflon plug with threaded contacts to which the waxed-clip electrode was attached. Counter electrodes, consisting of graphite rods (Ultra-Carbon "F") cuntained in fritted glass tubes, were placed on either side of the working electrode. saturated calomel reference electrode (SCE) and nitrogen gas bubbler occupied the remaining ports. The gas bubbler was equipped with a two-way stopcock so that nitrogen could be bubbled through the solution or over the surface. A small Teflon-covered magnetic stirring bar was generally provided for in situ mixing of reactants. During testing, the stirring was stopped and nitrogen bubbling was switched to a surface flow.

\section{Corrections for Resistance.}

Some of the very first test results, using the tantalum wire electrode holder, were obtained without correction for resistance. The current-potential peaks recorded on cyclic voltametry under these conditions were rounded off and skewed away from the reversible potential. This was particularly a problem with the tantalum wire holder, as mentioned above, because the electrical contact to the felt was not reproducible. Electrical contact problems were reduced substantially through the use of the waxed-clip holder, particularly with regard to variability. However, the actual potentials, especially at the switching points, remained somewhat undefined. Consequently, electronic compensation for iR loss was implemented at about the same time as the introduction of the waxed-clip holder. 
The device used measures the current flowing to or from the working electrode and feeds back a proportional voltage in series with the input signal to the potentiostat. The triangular linear potential sweep signal, rather than the working-to-reference voltage, is used as the input for the potential axis of the voltamogran. The iR compensation point is determined by monitoring the working-to-reference potential on an oscilloscope while increasing the level of compensation; the onset of oscillation represents the beginning of over-capensation. It appeared that being within $1 / 4$ to $1 / 2$ of a turn (on a ten turn potentioneter) of the oscillation point was adequate compensation in most cases, i.e., the effect of closer correction was negligibly small.

Two devices of different capacity were built; a $50 \mathrm{~mA}$ unit and a $1000 \mathrm{~mA}$ unit. The $50 \mathrm{~mA}$ unit was used for all measurements with the tantalum wire holder. The $1000 \mathrm{~m}$ unit was necessary when using the larger electrodes in the waxed-clip holder. The $1000 \mathrm{~ms}$ unit was difficult to use initially because it sometines induced irreversible oscillation requiring interruption of the controlled potential. This problem was alleviated by introducing a current limiting resistor in the counter electrode line. An example of the correction obtained with electronic iR compensation is illus'srated in Figure 18.

D. Electrochemical Testing Procedures.

All measurements were made versus a saturated calomel electrode (SCE) at room temperature. The felt test electrode was always saturated with solution by evacuating the cell after immersion of the electrode, and the solution was deaerated with nitrogen before each run. Pairs of counter electrodes in fritted glass tubes were designated for each solution composition to reduce cross-mixing between tests; the three 
compositions were 1) $\mathrm{HCl}$, 2) $\mathrm{BCl}, \mathrm{PbCl}_{2}$, and 3) $\mathrm{BCl}, \mathrm{PbCl}_{2}, \mathrm{CrCl}_{3}$.

A Wenking potentiostat was used to control the electrode potential in response to a cyclic linear potential sweep signal provided by a Hewlett-Packard function generator (Model 3310B). The cell working-to-reference potential was used to drive the $\mathrm{Y}$-axis and the resulting current (as voltage drop across a 1.0 ohm precision resistor) was recorded on the $X$-axis of a Linseis $X-Y$ recorder (Model 1700). When electronic iR compensation was used, the triangular sweep signal rather than cell working-to-reference potential was used to drive the potential axis, as discussed in Section $C$ above.

At the beginning of the program, the negative potential region was explored using a gold-activated carbon felt in $1.0 \mathrm{~N}$ hydrochloric acid. Various ranges were examined, as shown in Figure 19. Sweeps that extended to the more positive potentials showed more variability in the hydrogen evolution current observed at $-1000 \mathrm{mV}$ versus SCE; with repeated cycling this current tended to reduce to the level observed for sweeps held below $0.0 \mathrm{~V}$ vs. SCE. On this basis, the negative electrode test region was initially set at 0.0 to $-1.0 \mathrm{~V}$ vs. SCE. It is also apparent from these curves that no reactions other than $\mathrm{B}^{+}$reduction (hydrogen evolution) were observed over a wide potential region in hydrochloric acid.

The sweep rate used in Curves 1 through 5 in Figure 19 was 10 $\mathrm{mV} / \mathrm{s}$. In Curve 6 the sweep rate was changed to $100 \mathrm{mV} / \mathrm{s}$ without effect on the observed current. Since this was the case, a sweep rate of 100 $\mathrm{mV} / \mathrm{sec}$ was selected for this particular test, $\mathrm{H}^{+}$reduction on gold-activated felt in $\mathrm{HCl}$, to avoid excessive hydrogen evolution. For all other tests the sweep rate was kept at $10 \mathrm{mV} / \mathrm{s}$. 
When iR compensation was introduced, it was found that in many cases the current became almost asymptotic at $-1000 \mathrm{mV}$ which sometimes induced irreversible oscillation in the potentiostat. For this reason, the negative electrode test region was shifted $50 \mathrm{mV}$ more positive, i.e. $+50 \mathrm{mV}$ to $-950 \mathrm{mV}$ v8. SCE. The potential was always applied at approximately $0.0 \mathrm{~V}$.

A routine test procedure then consister of recording cyclic voltammograms in the following sequence (as a composite figure):

1) $\mathrm{B}^{+}$Reduction in $1.0 \mathrm{~N} \mathrm{BCl}$. The hydrogen evolution characteristics of the bare carbon felt or the gold-activated felt were always examined in $1.0 \mathrm{~N} \mathrm{BCl}$ only. The hydrogen evolution rate on gold was generally about two orders of magnitude larger than on the bare felt and five to ten times greater thar. other reastion levels. Consequently, the $\mathrm{B}^{+}$reduction curve on gold/carbon felt (Aw/C) is frequently shown with a current scale multiplier in the composite voltanmograms.

2) $\mathrm{Pb}^{2+} / \mathrm{Pb}$ and $\mathrm{B}^{+} / \mathrm{H}_{2}=\mathrm{On}-\mathrm{Pb}$ Redox Reactions. At the completion of the first test, the counter electrode set was exchanged and lead chloride was introduced to the solution. In initial testing, $0.5 \mathrm{ml}$ of a $10^{-2} \mathrm{M}$ aqueous $\mathrm{PbCl}_{2}$ solution was added to the $50 \mathrm{ml}$ volume of $1.0 \mathrm{~N} \mathrm{HCl}$ test solution to give a solution $10^{-4} \mathrm{M}$ in $\mathrm{Pb}^{2+}$. Later the lead chloride concentration was changed to $10^{-3} \mathrm{M}$ (which is close to the saturation level in hydrochloric acid) in order to more closely simulate the lead levels attained in the flowing solution redox battery. In order to achieve this concentration it was necessary to add lead chloride crystals to the $50 \mathrm{ml}$ cell volume of hydrochloric acid. This procedure proved to be somewhat undesirable both because of the mall quantity of material involved and the difficulty in achieving 
complete dissolution. Consequently, instead of adding lead chloride to the solution, a large volume of $1.0 \mathrm{~N} \mathrm{BCl}$ was premixed with $10^{-3} \mathrm{M}$ $\mathrm{PbCl}_{2}$ and a $50 \mathrm{ml}$ quantity of this solution was substituted for the BCl-only solution used in the previous test. The solution was stirred and deaerated again for 20 minutes.

Cyclic voltamograms were then recorded over the same potential range, at $10 \mathrm{mV} / 8$ starting at $0.0 \mathrm{~V}$, to measure lead plating $\left(\mathrm{Bb}^{2+}\right.$ reduction; $-550 \mathrm{mV}$ v8. SCE), the subsequent hydrogen evolution on the lead plated on gold and/or carbon (-800 to $-950 \mathrm{mV} \mathrm{VB}$. SCE), and lead deplating (Pb oxidation; $-500 \mathrm{mV}$ v8. SCE) on the return sweep. A voltannogran was typically recorded after the third or fourth cycle.

3) $\mathrm{Cr}^{3+} / \mathrm{Cr}^{2+}$ Redox Reaction. After completion of the testing with lead chloride, the counter electrode set was again exchanged and chromic chloride $\left(\mathrm{CrCl}_{3} \cdot 6 \mathrm{H}_{2} \mathrm{O}\right.$; Baker Reagent Gd.) was added to the solution for measurement of the $\mathrm{Cr}^{3+} / \mathrm{Cr}^{2+}$ redox reaction. In most cases two concentrations of chromic chloride were tested, $10 \mathrm{~mm}$ and $50 \mathrm{mr}$. The solution was stirred with the magnetic stirrer and by bubbling nitrogen for 20 to 30 minutes after the salt addition. Dissolution of these quantities of chromic chloride occurred almost immediately; extensive stirring was used to ensure uniform concentration of reactants within the felt electrode structure and equilibrium with the bulk solution.

Cyclic voltammograms were again recorded over the +50 to $-950 \mathrm{mV}$ potential range at $10 \mathrm{mV} / \mathrm{s}$ starting at $0.0 \mathrm{~V}$ ve SCE. The charging reaction $\left(\mathrm{Cr}^{3+}\right.$ reduction) begins coincident with lead plating at about $-525 \mathrm{mV}$ v8 SCE and shows a peak at about $-650 \mathrm{mV}$. Most electrodes showed a minimum in the cathodic current following the $\mathrm{Cr}^{3+}$ reduction 
peak and preceding the onset of hydrogen evolution. On the return sweep, the discharge reaction $\left(\mathrm{Cr}^{2+}\right.$ oxidation) hegine at about $-650 \mathrm{aV}$ v8 SCE and shows a major peak at about $-550 \mathrm{mV}$, the trailing side of this oxidation peak generally exhibited a shoulder and analler peaks trailing off towards $0.0 \mathrm{~V}$. At the $10 \mathrm{m \textrm {Cr } ^ { 3 + }}$ concentration, the $\mathrm{Pb}^{2+} / \mathrm{Pb}$ redox peaks generally projected through the $\mathrm{Cr}^{3+} / \mathrm{Cr}^{2+}$ redox peaks quite noticeably. This was the primary reason for testing at this concentration, 1.e., to see if the $\mathrm{Pb}^{2+} / \mathrm{Pb}$ redox reaction occurred at approximately the same level in the presence of the $\mathrm{Cr}^{3+} / \mathrm{Cr}^{2+}$ couple.

E. Data Reduction Methods.

In order to search for performance effects related to parameters such as gold loading and type of felt substrate, it was necessary to extract and condense the information collected by cyclic voltametry. This was done by tabulating selected anodic and cathodic current features known to be reievant to system performance and replotting these values against the controlled variables like gold loading. In the last quarter of the program, an additional set of data was derived from the voltammograms in the form of curve integrations to yield charge (current $X$ time). These methods of selecting data points are described in detall below.

1. Current Data. The anodic and cathodic current data points that were typically selected from the voltanmograms and tabulated are 1llustrated in the representative voltammograms shown in Figures 20 and 21. The curves shown in Figure 20 are a composite of two separate voltammograms recorded on the same grid. The first curve exhibits the electrochemical features displayed by a gold-activated carbon felt in 
hydrochloric acid before the addition of lead chloride. The only reaction observed is hydrogen evolution. The data point selected to represent the level of this reaction is the current measured at the potential sweep switching point, $-950 \mathrm{mV}$ vs SCE. This is referenced as data point " 1 " in the figure, and has been symbolized as " $\mathrm{I}_{\mathrm{c}} \mathrm{B}^{+}$on $\mathrm{Au} / \mathrm{C}^{\prime \prime}$, the $\mathrm{H}^{+}$reduction current on gold-on-carbon felt at $-950 \mathrm{mV}$. This data point was found to be highly sensitive to the accuracy of iR compensation used and was thus somewhat less reproducible than other data points. The second curve in Figure $2 ;$ exhibits the electrochemical features displayed by a carbon felt electrode (with or without gold) in hydrochloric acid after the addition of lead chloride. The reactions observed then were lead plating followed by hydrogen evolution and, on the return sweep, lead deplating. The data point selected to represent the level of hydrogen evolution after the addition of lead chloride is referenced as point " $2 "$ in the figure, and has been symbolized as ${ }^{\mathrm{I}} \mathrm{I}^{\mathrm{H}^{+}}$on $\mathrm{Pb} / \mathrm{Au}$ lor $\mathrm{Pb} . \cdots$, the $\mathrm{H}^{+}$reduction current at $-950 \mathrm{mV} \mathrm{vs}$. SCF. The level of the lead plating reaction is referenced as data point "5" in the figure, and has been symbolized as "I ${ }_{c} \mathrm{~Pb}^{2+n}$, the $\mathrm{Pb}$ reduction current. The subsequent deplating reaction level is referenced as data point " 6 " and has been symbolized as " $\mathrm{I}_{\mathrm{a}} \mathrm{Pb}$ ", the $\mathrm{Pb}$ oxidation current.

The two curves shown in Figure 21 are also a composite of two separate voltammograms recorded on the same grid. Joth curves exhibit the electrochemical features displayed by a carbon felt electrode (with gold in this illustration) after the addition of both lead chloride and chromic chloride to the hydrochloric acid; the smaller curve was obtained at a chromic chloride concentration of $10 \mathrm{mM}$ and the larger 
ORIGINAL PF.GE IS

OF POOR QUALITY

curve at $50 \mathrm{mM}$. The level of hydrogen evolution $\left(\mathrm{B}^{+}\right.$reduction superimposed on $\mathrm{Cr}^{3+}$ reduction) at $-950 \mathrm{mV}$ is referenced a data point "3" for both concentrations. A data point collected to represent the cathodic minimum between the $\mathrm{Cr}^{3+}$ reduction peak and hydrogen evolution is identified as point " 4 " and has been symbolized as "I $\mathrm{c}^{\mathrm{B}}$ 'min.".

The data point selected to represent the level of the negative electrode charging reaction is referenced as current peak "7" and has been symbolized as " $\mathrm{I}_{c} \mathrm{Cr}^{3+n}$, the $\mathrm{Cr}^{3+}$ reduction current. The data point selected to represent the level of the negative electrode discharge reaction is referenced as point " 8 " in the figure and has been symbolized as " $\mathrm{I}_{\mathrm{a}} \mathrm{Cr}^{2+}$, the $\mathrm{Cr}^{2+}$ oxidation current. In the case of the $10 \mathrm{mM}$ chromic chloride concentration, the current was read at $-550 \mathrm{mV}$ rather than at the peak, since the.peak was representative of the underlying lead oxidation reaction rather than $\mathrm{Cr}^{2+}$ oxidation.

The data point numbers described above have been keyed to the columns of data shown in the Tables in Sections V and VI. The columns of data, :epresenting different felt substrates and gold loadings or procedures, were then examined for trends.

2. Charge Data. The anodic and cathodic current data points described above are subject to some experimental error related to the accuracy of the IR compensation used and the degree to which the resistive elements are reproducible and amenable to compensation, e.g., ohmic potential drops (resistivity of the diffusion layer) versus liguid diffusion potential and surface film resistance. By comparison, the area defined by a curve (current $x$ time) is less ambiguous. In addition, measurement of the charge permitted quantitative separation of various 
features $\omega^{\circ}$ interest. For example, the anount of lead plated on the cathodic side can be determined (before the addition of chromic chloride) by measuring the area under the anodic part of the curve for lead oxidation, designated $\mathrm{Q}_{\mathrm{a}} \mathrm{Pb}$. This value is relatively unambiguous compared to the cathodic charge, which is the sum of the lead flating charge, $Q_{c} \mathrm{~Pb}^{2+}$. (both from within the felt and from bulk diffusion to the surfaces) and the $\mathrm{B}^{+}$reduction charge, $\mathrm{Q}_{\mathrm{c}} \mathrm{B}^{+}$. The lead oxidation charye, $Q_{a} P b$, was assumed to be the same $b$-fore and after the addition of chromic chloride. This assumption was made based on the appearance of the composite reactions for $\mathrm{Pb}^{2+} / \mathrm{Fb}$ and $\mathrm{Cr}^{3+} / \mathrm{Cr}^{2+}$ at

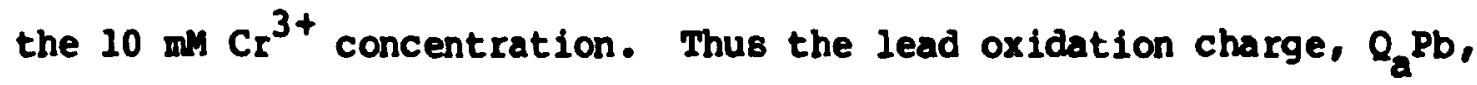
(measured before the addition of chromic chloride) was subtracted from the total anodic charge measured for the combined reactions $\left(Q_{a} P b+\right.$ $\mathrm{Q}_{\mathrm{a}} \mathrm{Cr}^{2+}$ ) after the addition of chromic chloride, to yield the $\mathrm{Cr}^{2+}$ oxidation charge, $\mathrm{O}_{\mathrm{a}} \mathrm{C}^{2+}$. Since the catalytic surface changes through the anodic portion of the curve (1.e. lead deplates), the total chromium charge was separated into two segmente, the major peak region before the end of lead deplating, referred to as " $\mathrm{Q}_{\mathrm{a}} \mathrm{Cr}^{2+}$ irailing". The trailing side of the lead oxidation peak was used as the dividing line. The various charge segments discussed here are ilustrated in Figure 22. Curve segments were integrated by the paper weight-ratio method. 

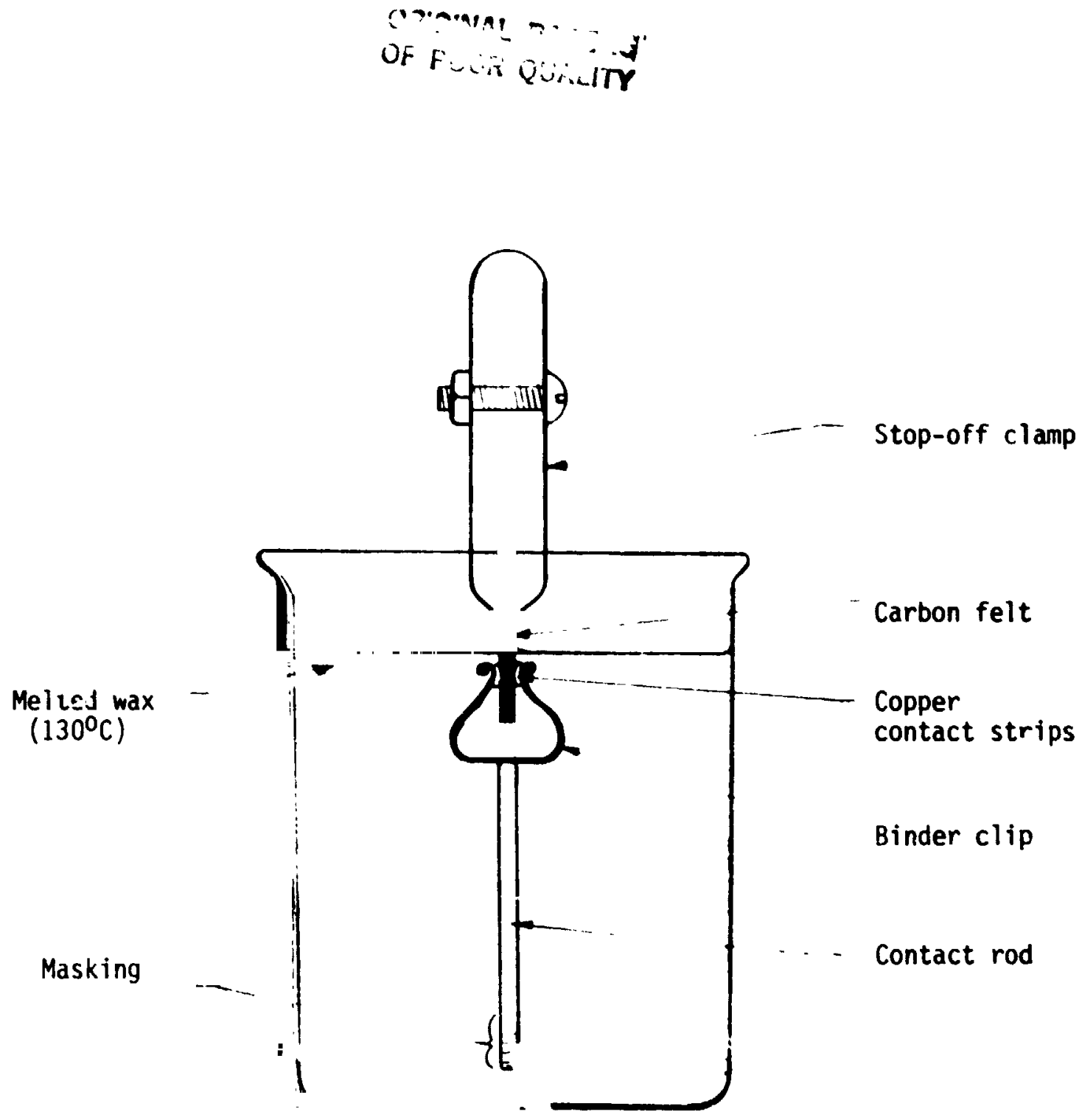

Figure 16. Waxed-clip Electrode Holder; Waxing Procedure 


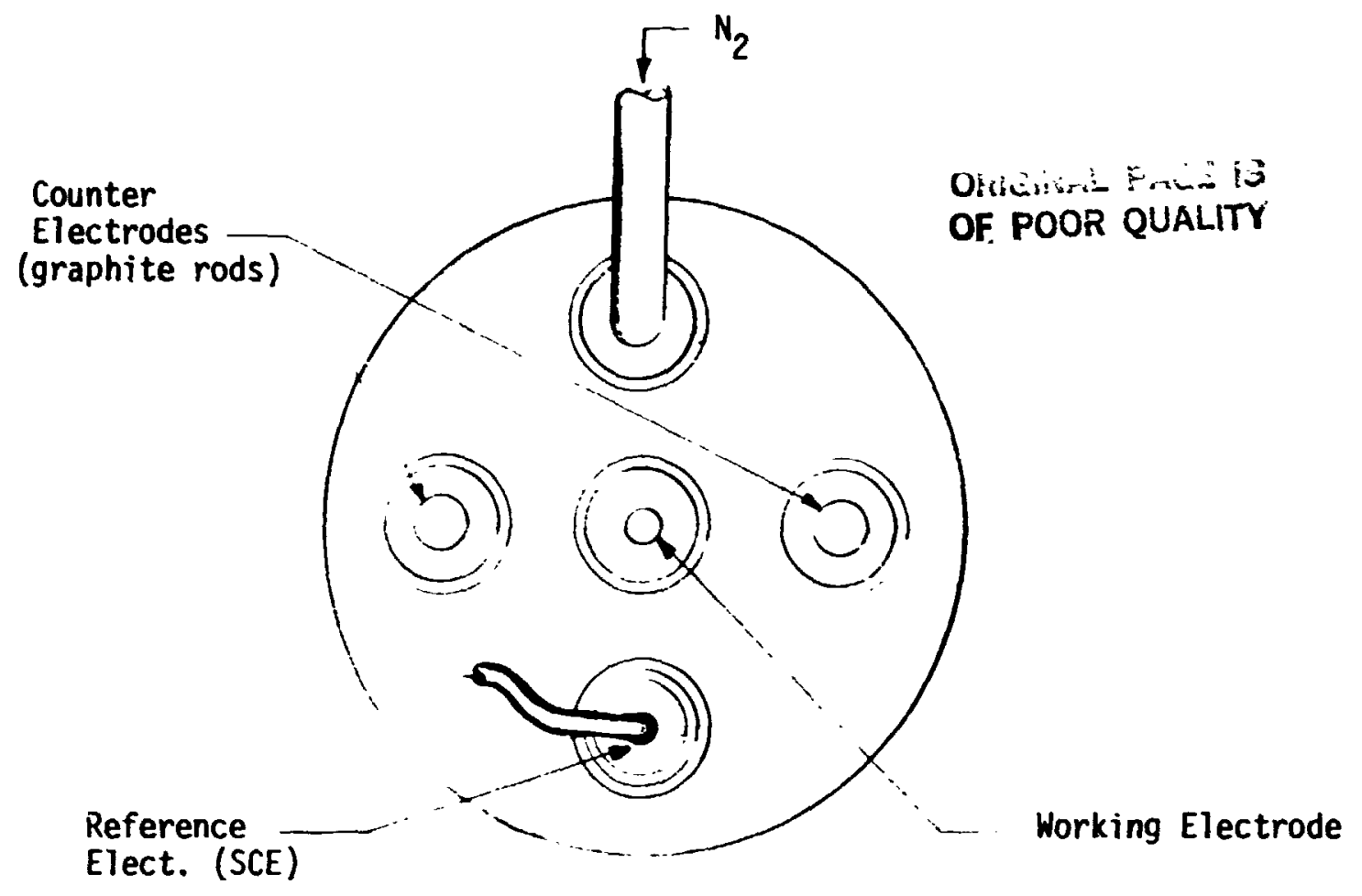

- Wkg. Elect. Contact

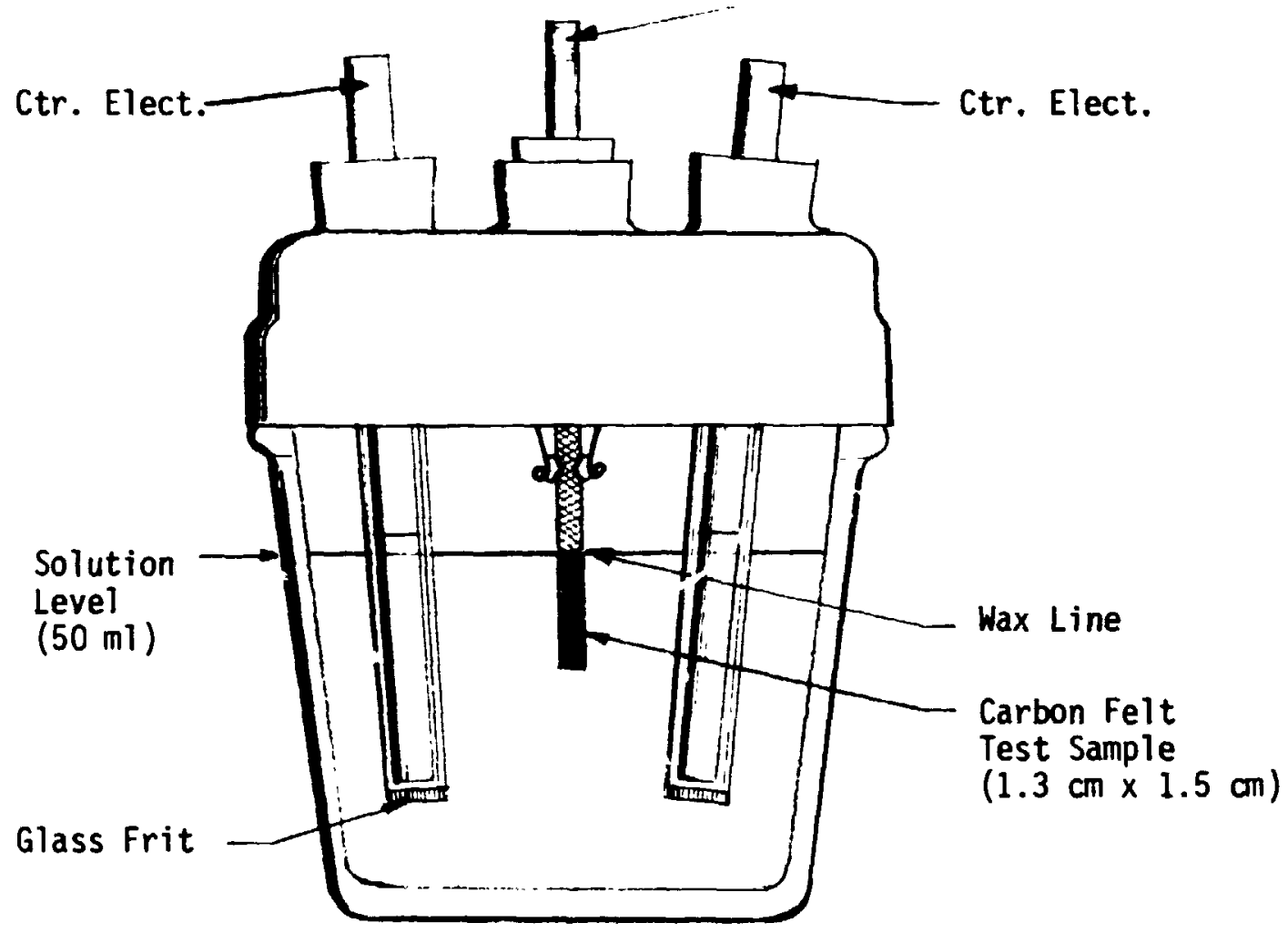

Figure 17. Cell Configuration with Waxed-Clip Holder 


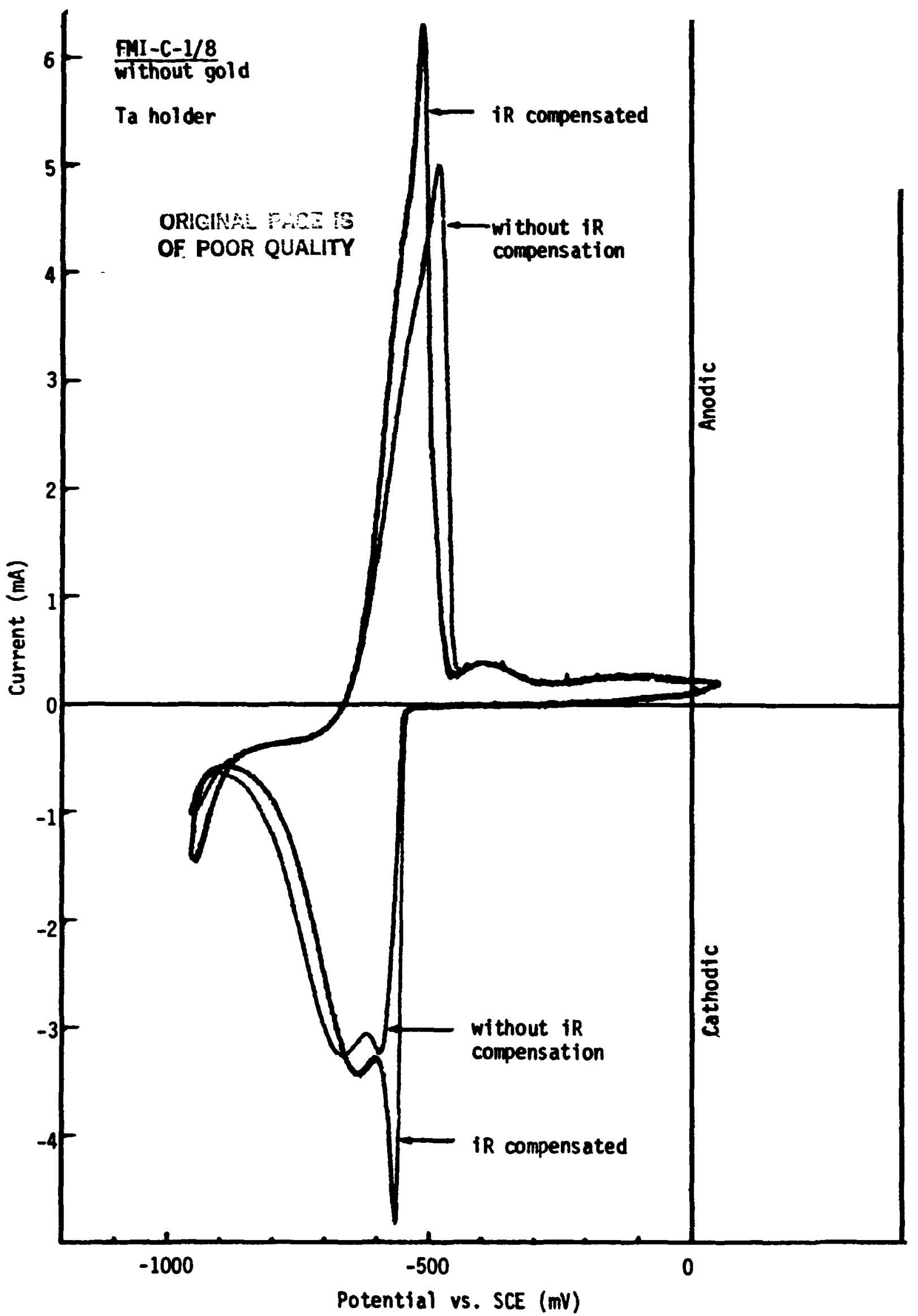

Figure 18. Comparison of voltamograms with and without $1 R$ compensation.

$-55-$ 


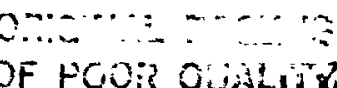

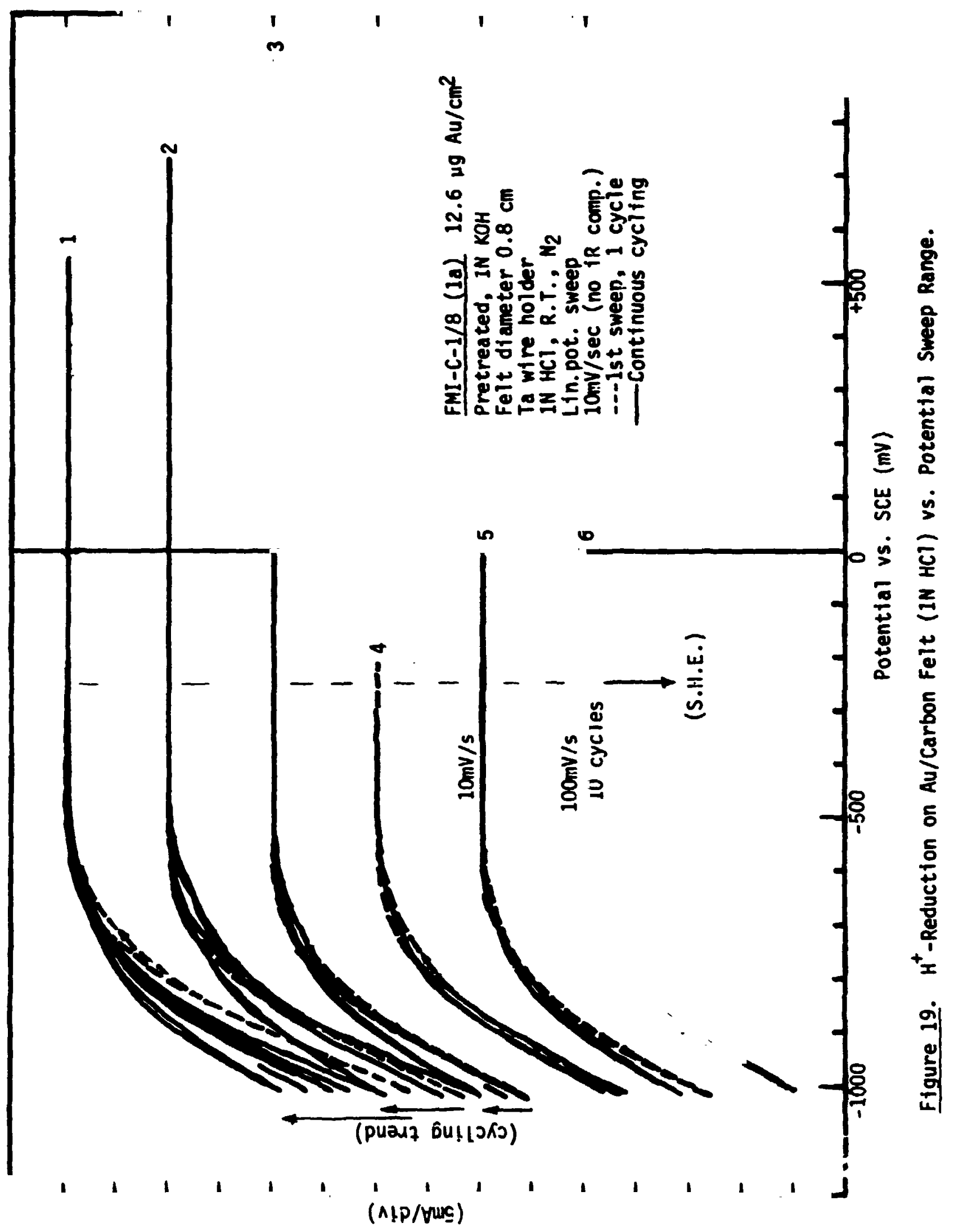

quadung s!poyzes 


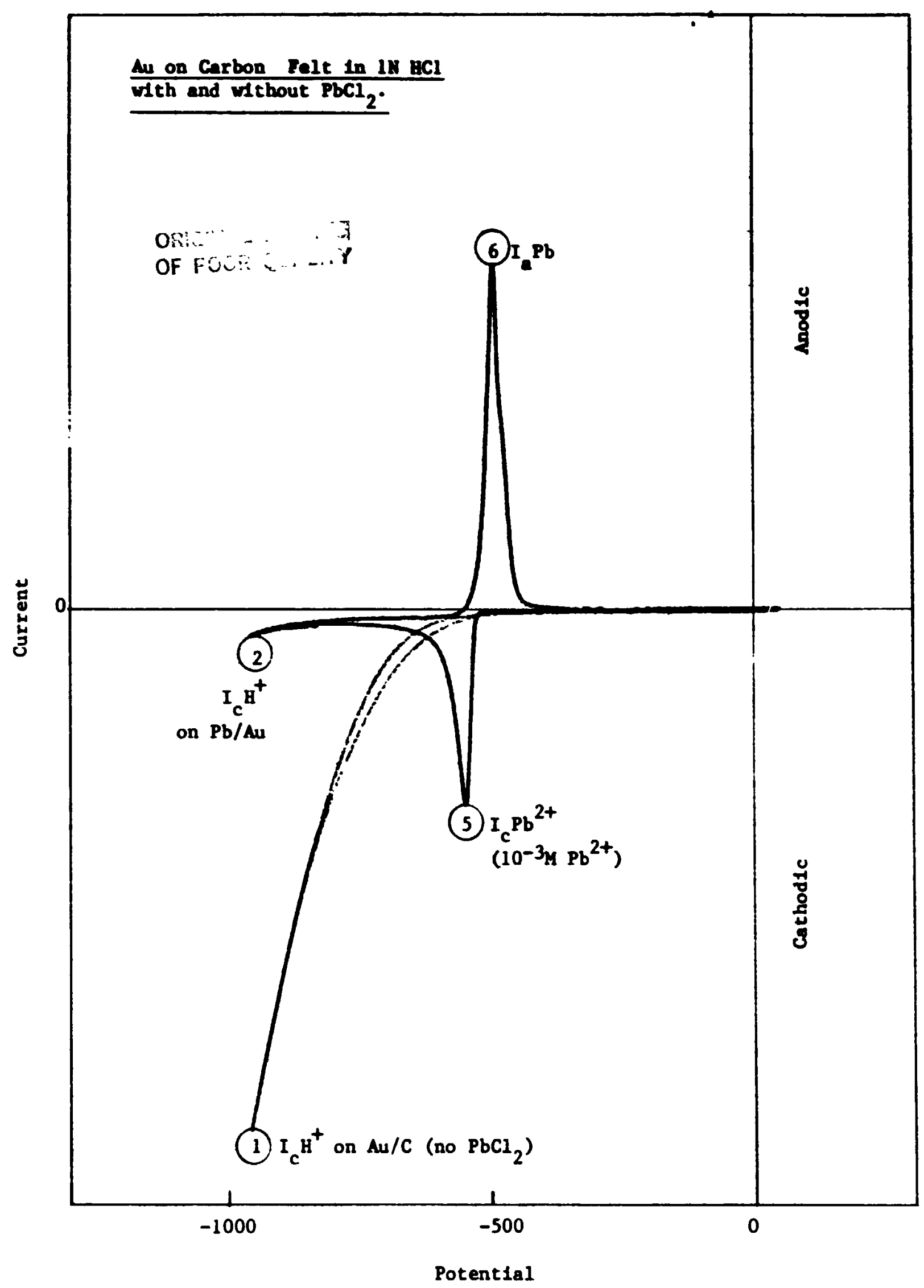

Figure 20. Representative Voltammogran Showing Data Points Sumarized in Tables. 


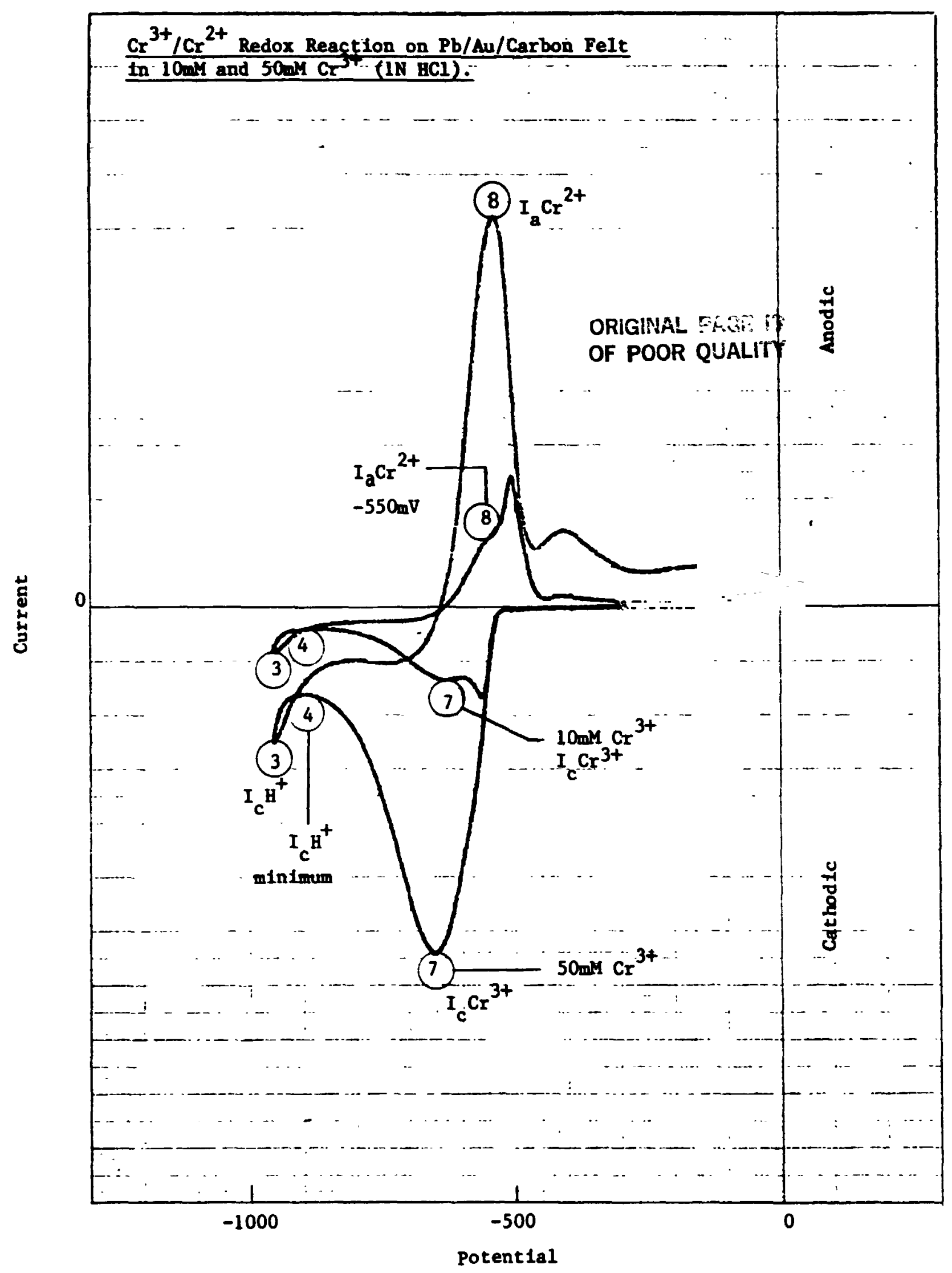

Figure 21. Representative Voltarmogram Showing Data Points Surmarized in Tables. 


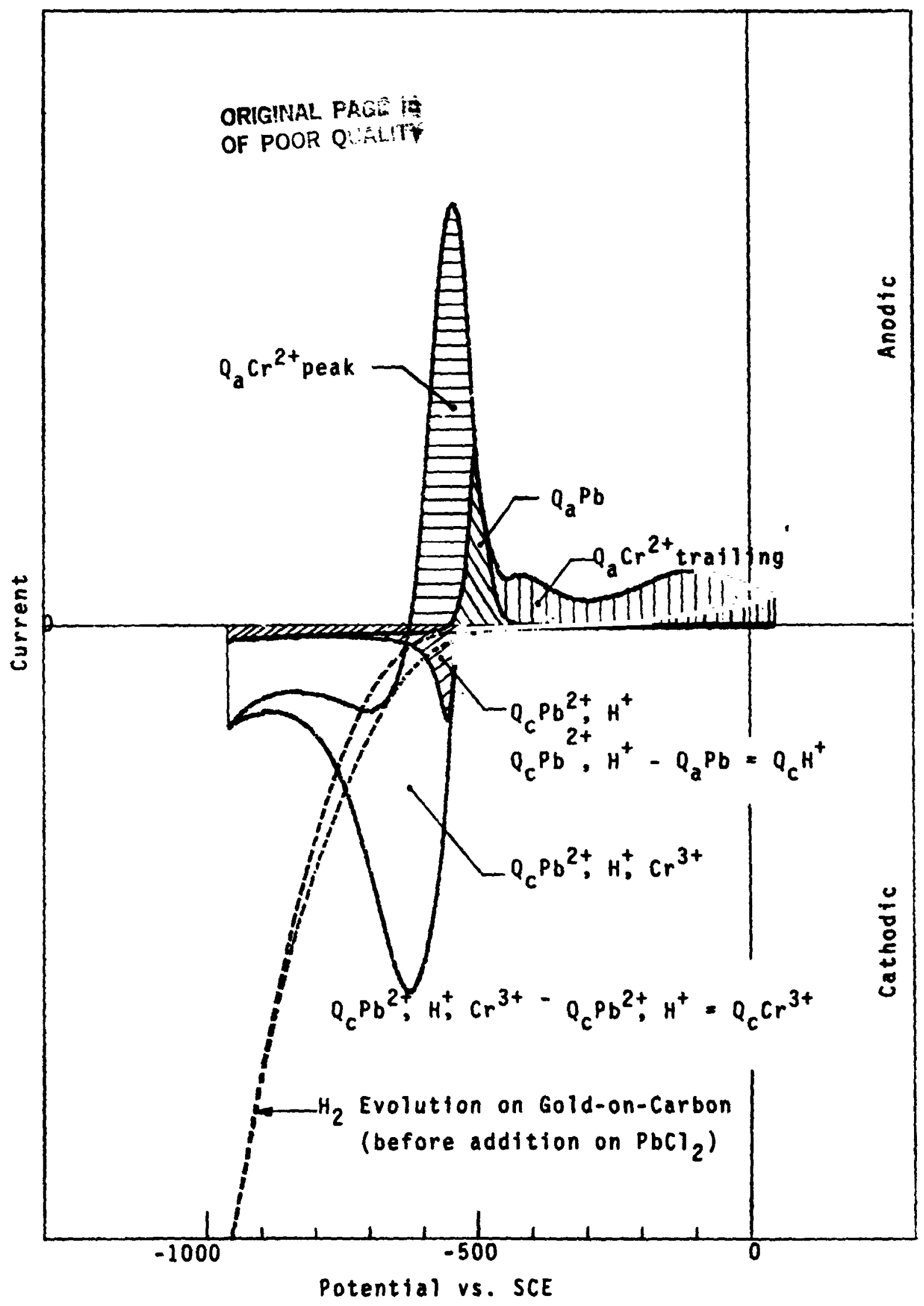

Figure 22. Definition of Anodic and Cathodic Charge Segments 
v. EFFECTS OF CATALYST LOADING

\section{A. Effects of Gold Loading.}

One of the major tasks of this program was to examine the effects of gold catalyst loading on electrochemical performance. In earlier work preceding this program, the gold loading was not precisely defined. As mentioned in Section III, gold deposition was accomplished by prolonged immersion of a felt sample in a dilute aqueous gold solution, followed by drying and baking (5). Customarily this produced a satisfactory electrode. However, when a new lot of carbon felt was processed by this method, it was found to decolorize the solution suggesting extensive or complete absorption of the gold chloride. The total gold loading was estimated to be as high as $60 \mu \mathrm{g} / \mathrm{cm}^{2}$ and the resulting electrode gave poor performance. It was postulated that the gold loading was "excessive" and new procedures, designed to control gold loading, together with felt pretreatment procedures, were introduced with improved results. A typically used gold loading has been $12-13 \mu \mathrm{g} / \mathrm{cm}^{2}$; with this as a base line, the following range of loadings were tes ed: $0,3,6,12.5,25$ and $50 \mu \mathrm{g} / \mathrm{cm}^{2}$.

\section{Rrecedures.}

The initial test matrix planned, to explore both gold loading and type of substrate, extended to all five of the felt types discussed in Section II ( $1 / 8$ and $1 / 4$ inch thick carbon and graphite felts). However, as discussed in Section IV, after adoption of the waxed-clip electrode procedure as the mounting method of choice, in was discovered that it was not applicable to the two $1 / 4$ inch thick graphite felts because of the combination of thickness and fragility. Consequently, only the $1 / 8$ inch thick carbon and graphite felts and the $1 / 4$ inch thick carbon felt 
ORIGINAL PARGE IS

OF POOR QUALITY

were examined over the range of gold laadings. Later in the nrogram, the three additional 1/8 inch thick felt types received from MSA (see section II-B) were also examined versus gold loading but with fewer sample points: $0,12.5$ and $50 \mu \mathrm{g} / \mathrm{cm}^{2}$. To summarize, the actual test matrix then was as follows:

TABLE IX. Gold Loading/Substrate Test Matrix.

\begin{tabular}{|c|c|c|c|c|c|c|c|c|}
\hline $\begin{array}{l}\text { Felt Type } \\
\text { I.D. Code }\end{array}$ & $\begin{array}{l}\text { Lot } \\
\text { Number }\end{array}$ & $\frac{60}{0}$ & & & ngs & & $\frac{\left.m^{2}\right)}{50}$ & $\begin{array}{c}\text { Table } \\
\text { Ref. }\end{array}$ \\
\hline$F M I-C-1 / 8$ & G-071379 & $x$ & $x$ & $x$ & $x$ & $x$ & $x$ & $A-I / I V$ \\
\hline FMI-G-1/8 & G-122779 & $x$ & $x$ & $x$ & $x$ & $x$ & $x$ & $A-I I / I V$ \\
\hline FMI-C-1/4 & G-071180 & $x$ & $x$ & $x$ & $x$ & $x$ & & A-III/IV \\
\hline$F M I-C-1 / 8$ & N091880 & $x$ & & & $x$ & & $x$ & $A-V / V I$ \\
\hline$\frac{U L C}{F M I}-G-1 / 8$ & $\mathrm{~N}-0280$ & $x$ & & & $x$ & & $x$ & $A-V / V I$ \\
\hline$F M I-C-1 / 8$ & $N-122380$ & $x$ & & & $x$ & & & $A-V I I I / V I$ \\
\hline
\end{tabular}

All of the felt samples were pretreated in IN KOH as described in Section II-D, catalyzed with gold by the dropwise aqueous/methanol process dcscribed in Section III-B, mounted by the waxed-clip procedure $\left(2 \mathrm{~cm}^{2}\right.$; and tested as described in Section IV. The test results are discussed below in terms of the effects of gold loading; substrate effects on performance will be discussed in the next section (Section vI).

\section{Results: Electrochemical Performance.}

The cyclic voltammetry data is sumarized as selected data points (described in Section IV-E) which have been collected in Tables A-I to A-VIII in the Appendix. These data tables are cross-referenced to the type of substrate felt in Table IX above. All of the data points have 
been grouped together, irrespective of felt type, and examined here as average values of each performance parameter versus gold loading.

\section{a. Hydrogen Exolution Characteristics.}

The average rate of hydrogen evolution ( ${ }^{+}$reduction) observeo at $-950 \mathrm{mV}$ vs SCE for the gold-on-carbon surfaces in hydrochloric acid before the addition of lead chloride is displayed versus gold loading in Figure 23. It can be seen that without gold ( 0.0 gold loading), the hydrogen evolution rate is at about the 1 to $2 \mathrm{~mA}$ level. All of the bare felt substrates exhibited such high hydrogen overvoltage. With the addition of as little as $3 \mathrm{\mu g}$ of $\mathrm{gold} / \mathrm{cm}^{2}$, the average rate of hydrogen evolution increased by more than two orders of magnitude, and from 12.5 to $50 \mu \mathrm{g} / \mathrm{cm}^{2}$ the rate was nearly constant at $\sim 200 \mathrm{~mA}$. Thus it appears that the hydrogen evolution rate becomes very large in the presence of very small quantities of gold but is fairly insensitive to total gold loading. Such a test does not have a great deal of quantitative analytical value but could serve as a qualitative test for the presence or absence of gold on a felt.

The lead plated surfaces obtained after the addition of lead chloride to the hydrochloric acid solution showed a much higher hydrogen overvoltage resulting in a reduction of the hydrogen evolution rates by about one order of magnitude on average. There also appears to be a direct correlation between the hydrogen evolution rate and the gold loading; these results are shown in Figure 24. This may suggest incomplete coverage of the gold by lead, at least under the static experimental conditions used in these tests. 
ORIGINAL PAGE IS

\section{b. $\mathrm{Pb}^{2+} / \mathrm{Pb}$ Redox Characteristics.}

OF POOR QUALITY

An indication of the level of the lead redox reaction is

given by the cathodic and anodic peak heights, as discussed in section IV-E.

The average anodic peak height is plotted versus gold loading in Figure

25. It can be seen that there is only a low correlation with gold

loading and a large degree of variability around each mean-data point.

Electrodes without gold generally show deviations from the trends

observed even for the lowest gold loadings. This will be discussed

further in Section B below.

$$
\text { c. } \mathrm{Cr}^{3+} / \mathrm{Cr} \mathrm{r}^{2+} \text { Redox Characteristics. }
$$

The chromous ion oxidation current peak was used as an

indication of the level of the $\mathrm{Cr}^{3+} / \mathrm{Cr}^{2+}$ redox reaction. The mean values are shown versus gold loading in Figure 26. Again, there appears to be a weak direct relationship between the level of the $\mathrm{Cr}^{3+} / \mathrm{Cr}^{2+}$ redox reactions and gold loading, and considerable variability around the mean values. Note the similarity to the plot of the lead oxidation current versus gold loading in Figure 25; this relationship will be discussed in Section B below.

As discussed earlier, in order to quantitatively separate various anodic features of the voltammograms, the anodic segments of the curves were integrated. The quantity of lead deposited was measured as the oxidation charge before the addition of chromic chloride (designated $\left.\mathrm{Q}_{a} \mathrm{~Pb}\right)$, and was deducted from the total anodic charge after the addition of chromic chloride, the remaining charge was designated $\mathrm{Q}_{\mathrm{a}} \mathrm{Cr}^{2+}$ Total. The mean values of the measured data points are shown versus gold loading in Figure 27. It can be seen that there is a trend similar to that observed for the analogous plot of current-data points 
in Figure 26, i.e., there is an increasing level of $\mathrm{Cr}^{3+} / \mathrm{Cr}^{2+}$ redox activity with increasing gold loading, and with a stronger correlation to $\mathrm{O}_{\mathrm{a}} \mathrm{Cr}^{2+}$ than $\mathrm{I}_{\mathrm{a}} \mathrm{Cr}^{2+}$. The anodic charge is shown separated into two segments, the chromium oxidation charge before the end of lead deplating (designated $Q_{a} \mathrm{Cr}^{2+}$ Peak) and after lead deplating (designated $\rho_{\mathrm{a}} \mathrm{Cr}^{2+}$ Trailing; see Figure 22), and plotted versus gold loading in Figure 28. It can be seen that there is a stronger correlation with the $\mathrm{Q}_{\mathrm{a}} \mathrm{Cr}^{2+}$ Peak charge and gold loading than with the $\mathrm{O}_{\mathrm{a}} \mathrm{Cr}^{2+}$ Trailing charge and gold loading. Thus, although there is in general some correlation between reactivity and gold loading, the effect of the gold seems to be expressed secondarily through the overdeposit of lead; this is discussed below in Section B.

\section{Results: Gold structure and Performance.}

One group of the electrodes tested was selected for examination of the corresponding physical configuration and distribution of the gold catalyst. Thi; group of electrodes was based on the $1 / 8$ inch thick carbon felt (FMI-C-1/8, lot G-071379) for which the most electrochemical performance data was available. Gold loadings from 0.0 to $50 \mathrm{\mu g} / \mathrm{cm}^{2}$ were available with multiple tests at some of the loadings. The replicate data points were of particular interest because of the scatter in performance. This is illustrated in Figure 29 for the $\mathrm{Cr}^{3+} / \mathrm{Cr}^{2+}$ redox activity, displayed as $\Omega_{a} \mathrm{Cr}^{2+}$ Total, versus gold loading.

High magnification views of the surfaces of the carbon fibers were obtained by transmission electron microscopy (TEM), as described earlier in section III. The TEM photographs are presented in Figures 30-41; the corresponding data points are boxed in Figure 29. The electrode with $3 \mathrm{\mu g}$ $\mathrm{Au} / \mathrm{cm}^{2}$ exhibited very few particles of gold, widely spaced and 
fairly large in size, 75-80 nm. Two views are shown in Figures 30 and 31, each showing a single large crystal of gold.

The surface of the electrode with $12.5 \mathrm{~m} \mathrm{Au} / \mathrm{cm}^{2}$, which showed lower performance (marked FMI-C-12 in Figure 29), showed little evidence of gold on the sample examined. Transparent projections, possibly carbon, appear on the surface in Figure 32. A single crystal of gold about $25 \times 30 \mathrm{~nm}$ can be seen in Figure 33. The low performance may indicate few gold particles of large size not found in these views. A remake at the same gold loading (marked FMI-C-12.5R in Figure 29) showed much better performance. A representative surface of this electrode is shown in Figure 34; it can be seen that there are many 15-20 $\mathrm{nm}$ size particles of gold. Another view was presented earlier in Figure in (Section III); on that surface two particle size ranges were observed, a few large geometric shapes with dimensions of 50-100 nm together with many small particles in the 10-20 nm range.

The surface of the electrode with $25 \mu \mathrm{g} \mathrm{Au} / \mathrm{cm}^{2}$, which showed the lowest performance of the three samples tested (marked FMI-C-25 in Figure 29), is presented in Figures 35 and 36 . Most of the gold particles were fairly large geometric shapes in the range of $60-120 \mathrm{~nm}$; a few areas, as in Figure 36 showed small 10-15 nm particles in addition. A second remake was not examined. A third remake at this same gold loading (marked FMI-C-25R in Figure 29) gave the best performance. Representative s.rfaces are shown in Figures 37 and 38 . Most of the particles are in the 30-50 $\mathrm{nm}$ range. The second view (Figure 38 ) shows one $30 \times 90 \mathrm{~nm}$ crystallite as well as a few particles in the 5-15 $\mathrm{nm}$ range. 
The surface of the electrode with $50 \mathrm{\mu g} \mathrm{Au} / \mathrm{cm}^{2}$ exhibi: ec a very broad range of particle sizes. Some areas showed a uniform collection of closely spaced small particles in the range of $15-35 \mathrm{~nm}$, as seen in Figure 39. Other areas showed a uniform collection of widely spaced large particles as seen in Figure 40. The three particles illustrated have dimensions of $30 \times 160 \mathrm{~nm}, 50 \times 110 \mathrm{~nm}$ and $70 \times 100 \mathrm{~nm}$. Still other areas showed a highly non-uniform distribution of particle sizes and spacing, as il lustrated in Figure 41 (note that this photograph is at lower magnification). The largest gold crystallite, in the center of the field, has dimensions of approximately $150 \times 230 \mathrm{~nm}$; in close proximity, golỏ particles of from 10 to $50 \mathrm{~nm}$ - an be seen deposited on the surface of carbon particles projecting from the fiber, and in other locations on the fiber.

From these results it is. apparent that there is a qualitative correlation between the $\mathrm{Cr}^{3+} / \mathrm{Cr}^{2+}$ redox activity and gold particle size, i.e., low activity coincides with large particle sizes and vice- ersa. An attempt has been made to quantify these results by measuring the gold particle sizes observed in each case. An average particle size wa: calcilated for each TEM view presented in Figures 30-41. The following values were obtained: 
TABLE X. Gold Particle sizes $(5)+C-1 / 8)$.

ORIGINAL PAGE IS: OF POOR QUALITY

\begin{tabular}{lccccc}
$\begin{array}{l}\text { Electrode } \\
\text { I.D. Code }\end{array}$ & $\begin{array}{c}\text { Gold Loading } \\
\left(\mu \mathrm{g} / \mathrm{cm}^{2}\right)\end{array}$ & $\begin{array}{c}\text { Fig. } \\
\text { No. }\end{array}$ & $\begin{array}{c}\text { Particle Sizes } \\
\overline{\mathrm{x}}\end{array}$ & $\mathrm{s}$ & $\begin{array}{c}\text { Count } \\
\mathbf{n}\end{array}$ \\
\hline FMI-C-3 & 3 & 30 & 75 & - & 1 \\
FHI-C-12 & 3 & 31 & 75 & - & 1 \\
FMI-C-12 & 12.5 & 33 & 31 & - & 1 \\
FMI-C-12.5R & 12.5 & 34 & 19.8 & 4.1 & 19 \\
& 12.5 & 10 & 24.3 & 23.2 & 17 \\
FMI -C-25 & 25 & 35 & 64.3 & 21.2 & 10 \\
& 25 & 36 & 37.5 & 24.0 & 24 \\
FMI-C-25R & 25 & 37 & 29.3 & 4.8 & 13 \\
& 25 & 38 & 26.2 & 17.5 & 22 \\
FMI-C-50 & & & & & \\
& 50 & 39 & 24.8 & 5.9 & 21 \\
& 50 & 46 & 86.7 & 7.6 & 3 \\
& 50 & 41 & 45.7 & 43.0 & 25 \\
\hline
\end{tabular}

The mean particle sizes determined for each view were then averaged to give the values shown in Table XI. These values were then used to estimate the gold surface rea (based on spherical shapes) in each case and the corresponding real $\mathrm{gi}$. surface for each $2 \mathrm{~cm}^{2}$ electrode sample. 
TABLE XI. Estimated Gold Surface Area.

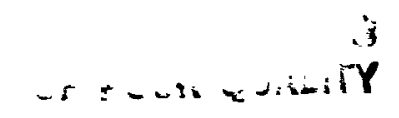

\begin{tabular}{lcccc}
$\begin{array}{c}\text { Electrode } \\
\text { I.D. Code }\end{array}$ & $\begin{array}{c}\text { Gold Loaging } \\
\left(\mu \mathrm{g} / \mathrm{cm}^{2}\right)\end{array}$ & $\begin{array}{c}\text { Ave. Particle Size } \\
(\mathrm{nuj})\end{array}$ & $\begin{array}{c}\mathrm{s}^{(1)} \\
\left(\mathrm{m}^{2} / \mathrm{g}\right)\end{array}$ & $\begin{array}{c}\mathrm{As}^{(2)} \\
\left(\mathrm{cm}^{2} \text { of Au }\right)\end{array}$ \\
\hline FMI-C-3 & 3 & 75 & 4.1 & 0.25 \\
FMI-C-12 & 12.5 & 31 & 10.0 & 2.50 \\
FMI-C-12.5R & 12.5 & 22.1 & 14.1 & 3.51 \\
FMI-C-25 & 25 & 50.9 & 6.1 & 3.05 \\
FMI-C-25R & 25 & 27.5 & 11.3 & 5.65 \\
FMI-C-50 & 50 & 49.9 & 6.2 & 6.22 \\
\hline
\end{tabular}

$$
\begin{aligned}
(1)_{S} & =\text { Surfare Airea }\left(\mathrm{m}^{2} / \mathrm{g}\right)=\pi\left(D \times 10^{-9}\right)^{2} /(0.5236)\left(D \times 10^{-7}\right)^{3}\left(\rho_{A u} ;\right. \\
D & =\text { Ave. Particle Size }(\mathrm{nM}),{ }_{A u}=19.32 \mathrm{~g} / \mathrm{cm}^{3} \\
(2)_{A_{S}} & =\text { Gold Area/Electrode }\left(\mathrm{mm}^{2}\right)=\left(2 \mathrm{~cm}^{2}\right)\left(10^{-6}\right)\left(\text { gold loading, } \mu \mathrm{g} / \mathrm{cm}^{2}\right)\left(10^{4}\right) \mathrm{S}
\end{aligned}
$$

The real gold area ( $A_{S}$-values from Table XI) for each electrore has been substituted for gold loading to replot the values for $\mathrm{Cr}^{3+} / \mathrm{Cr}^{2+}$ redox activity shown in Figure 29; this is shown as $\mathrm{Q}_{\mathrm{a}} \mathrm{Cr}^{2+}$ Total versus gold area in Figure 42. A linear regression analysis of this datá yielōs a correlation coefficient of 0.953 ; this compares to a correlation of 0.688 for the same values of $\mathrm{Q}_{\mathrm{a}} \mathrm{Cr}^{2+}$ Total plotted against simple gold loading points in Figure 29. Thus it appears that, in accordance with the theory of catalysis, the surface area of the gold deposit is a determining factcr in electrode performance; the reasons for variations $i$ the gold particle size have not been determined, however. Many factors such as solution stability, surface active groups on the felts, and various processing parameters (such as time and temperature), could affect particle size. 


\section{B. Effects of head Loading.}

The quantity of lead deposited on a single electrode sample has been found to be a linear function of the concentration of lead chloride in solution. This was determined by recording voltammograms for a single electrode (FMI-C-1/8, Lot G-071379, $12.5 \mu \mathrm{g} \mathrm{Aw} / \mathrm{Cm}^{2}$ ) at increasing increments of lead chloride concentration in $1 \mathrm{~N} \mathrm{BCl}$. The curves obtained are shown as a composite in Figure 43. The quantity of lead deposited, measured as oxidation chazge $\left(G_{a} P b\right)$, is plotted versus lead chloride concentration in Figure 44.

The quantity of lead deposited on an electrode from solutions of constant lead chloride concentration (e.g. I $\mathrm{mM} \mathrm{PbCl}_{2}$ ), however, has been observed to vary with the electrode sample by up to a factor of three or more. For example, two "identical" electrodes (i2.5 $\mathrm{\mu g}$ $\mathrm{Au} / \mathrm{cm}^{2}$ on FMI $-\mathrm{C}-1 / 8$, Table A-IV Appendix) showed lead deposits of 75.7 millicoulombs and 99.7 millicoulombs. There also seemed to be only a weak correlation on average with gold loading, as discussed in Section A (Figure 25). When the lead deposit is considered in terms of the real gold surface area, however, a much stronger relationship is observed. The gold surface area estimates obtained frcm the TEM photographs of $1 / 8$ inch thick carbon felt electrodes ( $A_{S}$ values from Table XI; are plotted in lieu of the gold loading points versus quantity of lead $\left(Q_{a} P b\right)$ in Figure 45. A linear regression analysis of this data yields a correlation coefficient of 0.946 ; this compares to a correlation of 0.699 for the same values of $Q_{a} P b$ plotted against simple gold loading points in Figure 29. 
From this data it can be seen that the quantity of lead deposited appears to be influenced by the surface area of the underlying gold deposit on the felt; in turn, the quantity of lead deposited from solutions of constant lead chloride concentrations is also an approximate measure of the gold surface area of the electrode.

Electrodes without gold generally showed deviations from the trends observed even for the lowest gold loadings. The amount of lead deposited was frequently higher on a bare felt substrate tinan on electrodes with gold, e.g., on $1 / 8$ inch thick graphite felts (Table A-IV, Appendix). Lead deposition was generally shifted 25 to $50 \mathrm{mV}$ more negative than on gold, however, and the quantity was not stable i.e., the peak heights tended to decline with repeated cycling. For these reasons, the 0.0 gold loadings (bare felts) may not be a logical extrapolation of performance data.

1. Hydrogen Eyolution Characteristics. The rate of hydrogen evolution was measured at different lead loadings in the incremental lead concentration experiment displayed in Figure 43. The quantities of lead deposited in $f$ case $\left(Q_{a} P b\right)$, and the equivalent lead loadings in $\mu \mathrm{g} / \mathrm{cm}^{2}$, are shown tugether with the hydrogen evolution rates measured $\left(\mathrm{I}_{c} \mathrm{~B}^{+}\right.$at $-950 \mathrm{mV}$ vs. SCE) in Table XII below: 
TABLE XII. Effect of head Loading on $\mathrm{A}^{+}$Byolution Bate.

FMI-C-1/8 Lot G-071379

(Gold Loading, $\left.12.5 \mu \mathrm{g} / \mathrm{cm}^{2}\right) \quad I_{c} H^{+}$at $-950 \mathrm{mV}$ vs. SCE

$\begin{array}{lccc}\begin{array}{c}\mathrm{Pb}^{2+} \\ (\mathrm{mH})\end{array} & \begin{array}{c}\mathrm{Q}_{\mathrm{a} b} \\ (\mathrm{mCO})\end{array} & \begin{array}{c}\mathrm{Pb} \text { Loadjing } \\ \left(\mu \mathrm{g} / \mathrm{cm}^{2}\right)\end{array} & \begin{array}{c}1 \mathrm{~N} \mathrm{HCl} \\ (\mathrm{mA})\end{array} \\ 0.0 & 0.0 & 0.0 & 208.0 \\ 0.03 & 0.5 & 0.27 & 3.7 \\ 0.1 & 5.0 & 2.7 & 2.2 \\ 0.3 & 18.6 & 10.0 & 1.4 \\ 1.0 & 74.2 & 40.0 & 1.8\end{array}$

From these data it can be seen that the hydrogen evolution rate on a gold activated carbon substrate is reduced by two orders of magnitude at a lead loading of as low as $0.27 \mathrm{\mu g} / \mathrm{cm}^{2}$; further increases in the lead loading produce only slight additional suppression of hydrogen evolution.

It was shown earlier in section $A$ that the hydrogen evolution rate increased with increasing gold loading (Figure 24) at a fixed concentration of lead chloride $(1 \mathrm{mil})$. It was suggested there that this might be due to incomplete coverage of the gold with lead. This would seem to be in conflict with the results presented above, in which hydrogen evolution is almost completely suppressed at a lead chloride concentration of only $0.03 \mathrm{mil}$. However, the trend of increasing hydrogen evolution rates with increasing gold loading may be the result of loral effects, i.e. very small particles of gold uniformly distributed may be easily covered with lead, but very large particles (as have sometimes been observed) may deplete the solution of $\mathrm{Pb}^{2+}$ ions locally before a monolayer of lead is formed or before some gold particles are 


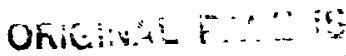

OF POOR Quining

plated; the resulting islands of exposed gold mä account for the slight increase in hydrogen evolution observed. This phenomenon would be expected to be peculiar to the static test conditions used in cyclic voltammetry; localized lead chloride depletion should not occur in a flowing redox battery.

\section{2. $c_{r^{3+}}^{3+} / \mathrm{Cr}^{2+}$ Redox Characteristics.}

The $\mathrm{Cr}^{3+} / \mathrm{Cr}^{2+}$ redox reaction is influenced in the opposite sense from the $\mathrm{B}^{+}$reduction reaction by the quantity of lead deposited, producing the desired separation of these two reactions. with no lead, the $\mathrm{Cr}^{3+}$ reduction reaction on the gold/carbon surface is shifted to much more negative potentials concurrent with $\mathbf{H}_{2}$ evolution, and only a small amount of $\mathrm{Cr}^{2+}$ is formed; oxidation of the $\mathrm{Cr}^{2+}$ is observed as a broad peak on the return sweep (see dashed line in Figure 46). As $\mathrm{Pb}^{2+}$ is added in increments the potential for lead deposition shifts to less negative potentials (see Figure 43) which simultaneously shifts the initiation of $\mathrm{Cr}^{3+}$ reduction to less negative potentials also; the $\mathrm{Cr}^{3+} / \mathrm{Cr}^{2+}$ redox reactions at the four lead chloride concentrations are shown as a composite in Figure 47 . On the return sweep, $\mathrm{Cr}^{2+}$ oxidation in the absence of lead occurs after the $\mathrm{Pb}$-oxidation potential $(-550 \mathrm{mV})$ on the gold surface. In the presence of lead, $\mathrm{Cr}^{2+}$ oxidation begins on the lead surface before the oxidation of lead $(-60$ to $-60 \mathrm{mV})$. When the quantity of lead plated is low, as for $0.03 \mathrm{mM} \mathrm{PbCl}{ }_{2}$, most of the $\mathrm{Cr}^{2+}$ oxidation occurs after lead deplating in what has been referred to previously as the "trailing" region; as the quantity of lead is increased, the total amount of $\mathrm{Cr}^{3+}$ reduced increases and $\mathrm{Cr}^{2+}$ oxidation shifts to more negative potentials to what has been referred to previously as the 
ORIE:

OF PCOR QUALITY

"peak" region. These effects are sumarized in Table XIII below and in

Figure 48. The anocic charge segments were separated as shown in Figure

22 (Section IV).

Table XIII. Effect of Lead Loading on $\mathrm{Cr}^{3+} / \mathrm{Cr}^{2+}$ Redox Rate.

FMI-C-1/8 Lot G-071379

\begin{tabular}{|c|c|c|c|c|}
\hline \multicolumn{3}{|c|}{ Gold Loading, $12.5 \mu \mathrm{g} / \mathrm{cm}^{2}$} & \multicolumn{2}{|c|}{$\mathrm{Q}_{a} \mathrm{Cr}^{2+}$ (in $\left.50 \mathrm{~mm} \mathrm{Cr}^{3+}\right)$} \\
\hline $\begin{array}{l}\mathrm{Pb}^{2+} \\
\text { (mid) } \\
\end{array}$ & $\begin{array}{c}\mathrm{Q}_{\mathrm{a}} \mathrm{Pb} \\
\text { (mCoul) }\end{array}$ & $\begin{array}{l}\text { Pb Loadjing } \\
\left(\mu \mathrm{g} / \mathrm{cm}^{2}\right)\end{array}$ & $\begin{array}{l}\text { Peak } \\
\text { (mCoul) }\end{array}$ & $\begin{array}{l}\text { Trailing } \\
\text { (mCoul) }\end{array}$ \\
\hline 0.0 & 0.0 & 0.0 & 0 & $\sim 160$ \\
\hline 0.03 & 0.5 & 0.27 & 23 & 253 \\
\hline 0.1 & 5.0 & 2.7 & 109 & 307 \\
\hline 0.3 & 18.6 & 10.0 & 228 & 322 \\
\hline 1.0 & 74.2 & 40.0 & 458 & 405 \\
\hline
\end{tabular}

At a constant concentration of lead chloride (l my typically), the guantity of lead deposited $\left(Q_{a} \mathrm{~Pb}\right)$ appeared to be an indication of the underlying gold surface area, as discussed earlier. The charge values for $\mathrm{Cr}^{3+} / \mathrm{Cr}^{2+}$ redox activity for the three types of carbon felt electrodes art shown versus the lead deposited in Figures 49 (FMI-C-1/8), 50 (FMI-G-1/8) and 51 (FMI-C-1/4). It can be seen that there is a good correlation between the lead loading $\left(Q_{a} P b\right)$ and $\mathrm{Cr}^{3+} / \mathrm{Cr}^{2+}$ redox activity irrespective of gold loading. This same corresponciance is shown more broadly in Figure 52 in which all 1/8 inch thick felt test data was plotted (including the $1250^{\circ} \mathrm{C}$ felt and the halogen treated felt).

Based on this data it may be concluded that the quantity of lead deposited, measured as the lead oxidation charge $\left(\mathrm{Q}_{\mathrm{a}} \mathrm{Pb}\right)$ in $1 \mathrm{mM}$ $\mathrm{PbCl}_{2} / 1 \mathrm{~N} \mathrm{HCl}$, is a reflection of the real gold surface area of an 
electrode, and gives a better indication of the relative level of $\mathrm{Cr}^{3+} / \mathrm{Cr}^{2+}$ redox activity that will be exhibited by an electrode than simple gold loading values. 
ORIGINAL PAGE IS

OF POOR QUALITY

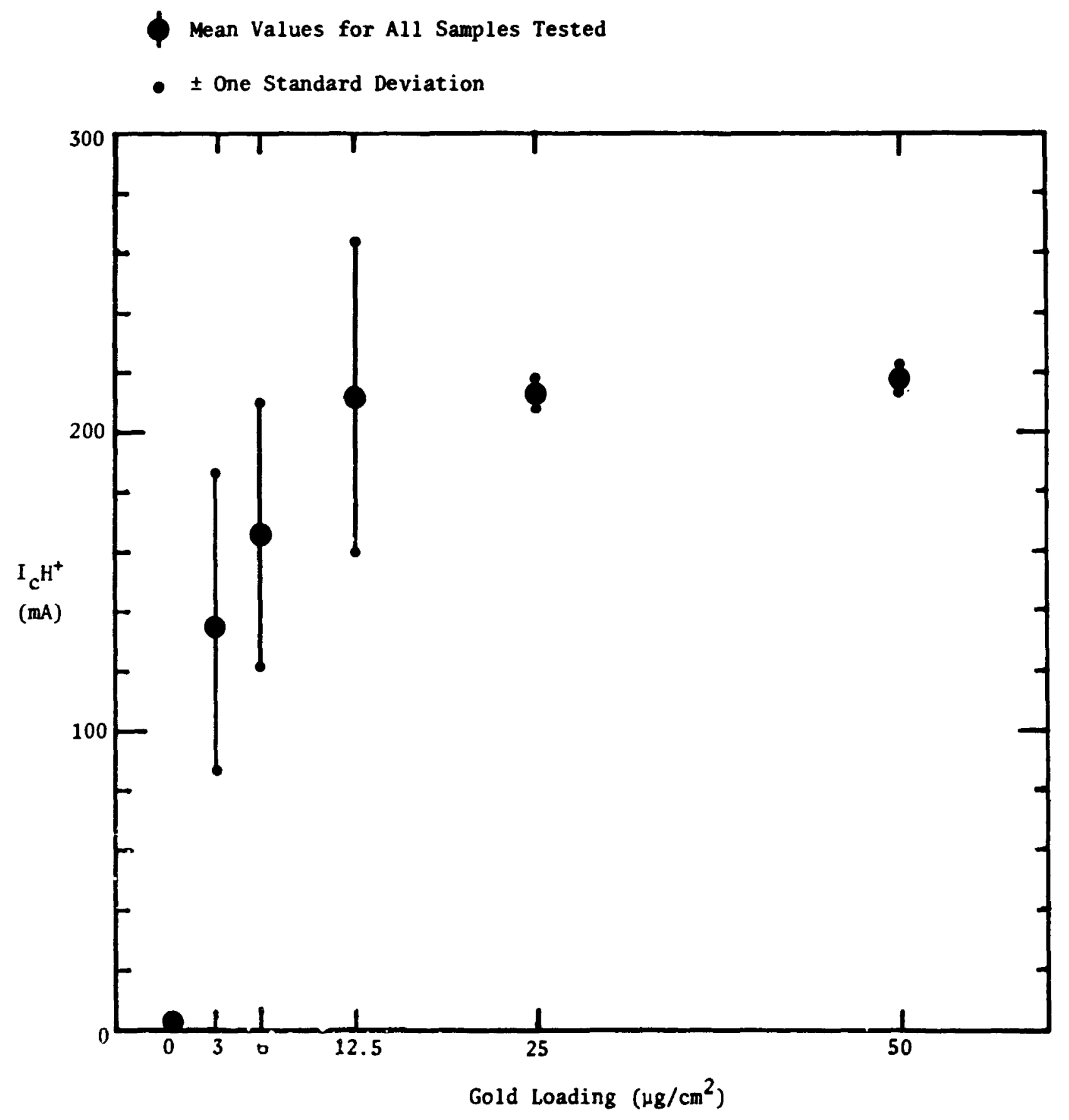

Figure 23. Hydrogen Evolution Current at $-950 \mathrm{mV}$ (SCE) versus Gold Loading, Before Adding Lead Chloride (on Gold). 
- Linear regression analysis on $\bar{x} ;$ corr coeff $=0.990$

Mean values

- $\quad \pm$ One standard dev.

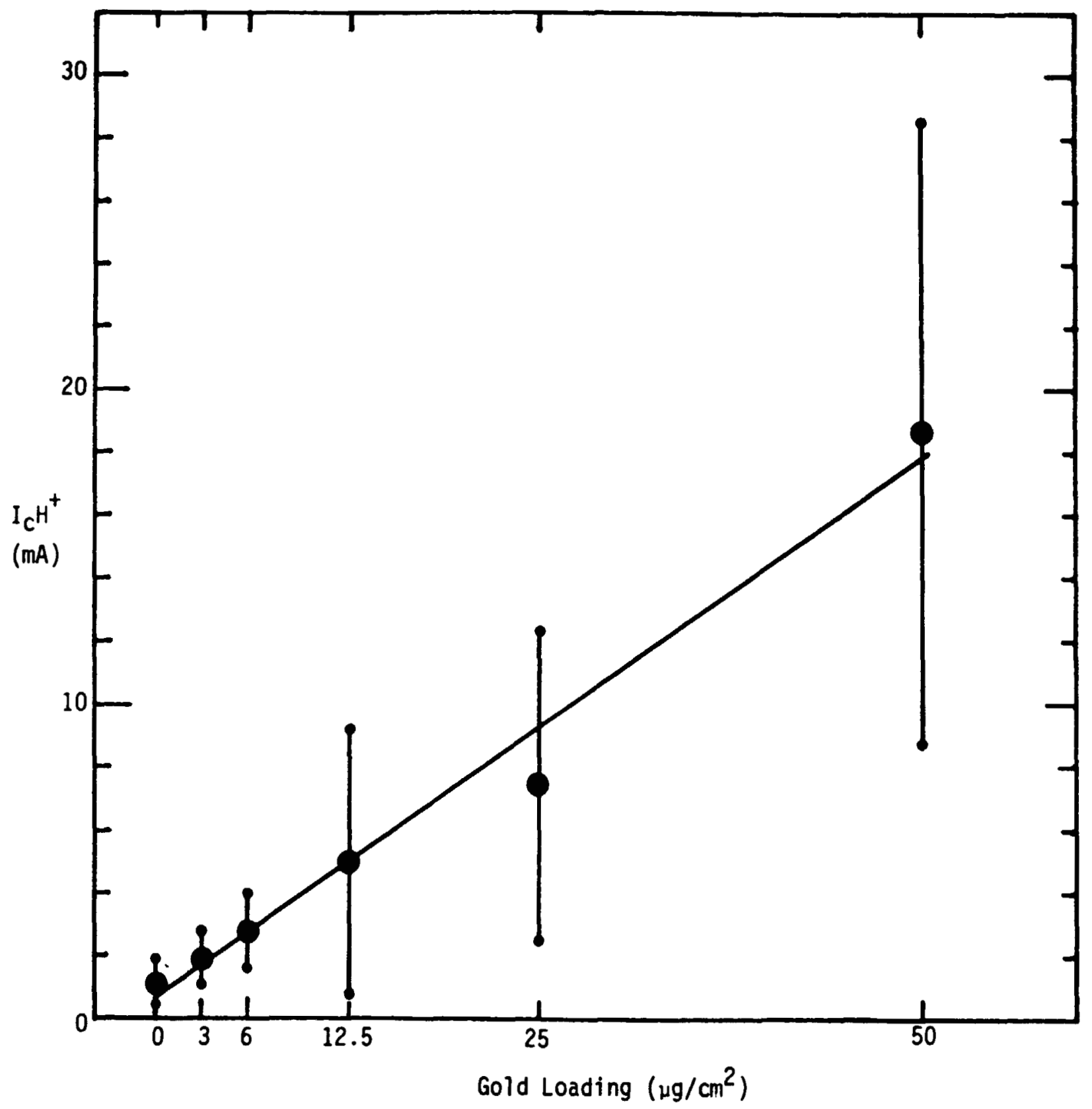

Figure 24. Hydrogen Evolution Current at $-950 \mathrm{mV}$ (SCE) varsus Gold Loading, After Adding Lead Chloride (on Lead/Gold). 


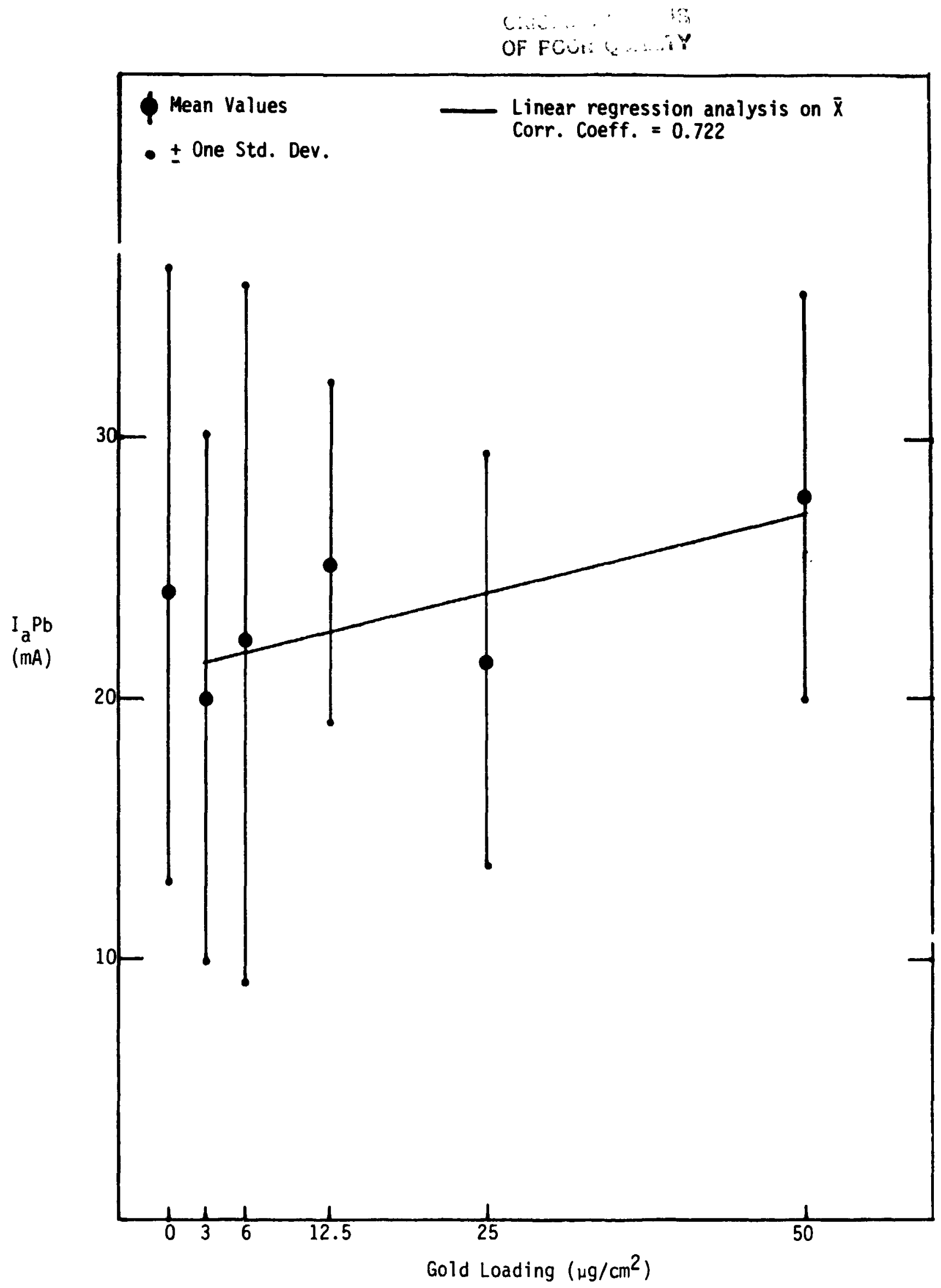

Figure 25. Lead Oxidation Current Peak vs. Gold Loading -77- 


\section{ORIGINAL PRGE IS}

OF POOR QUALITY

$\$$ Mean Values

- $\quad \pm$ One Std. Dev.

Lin. Regres. Anal. on $\bar{X}$

Corr. Coeff. $=0.884$

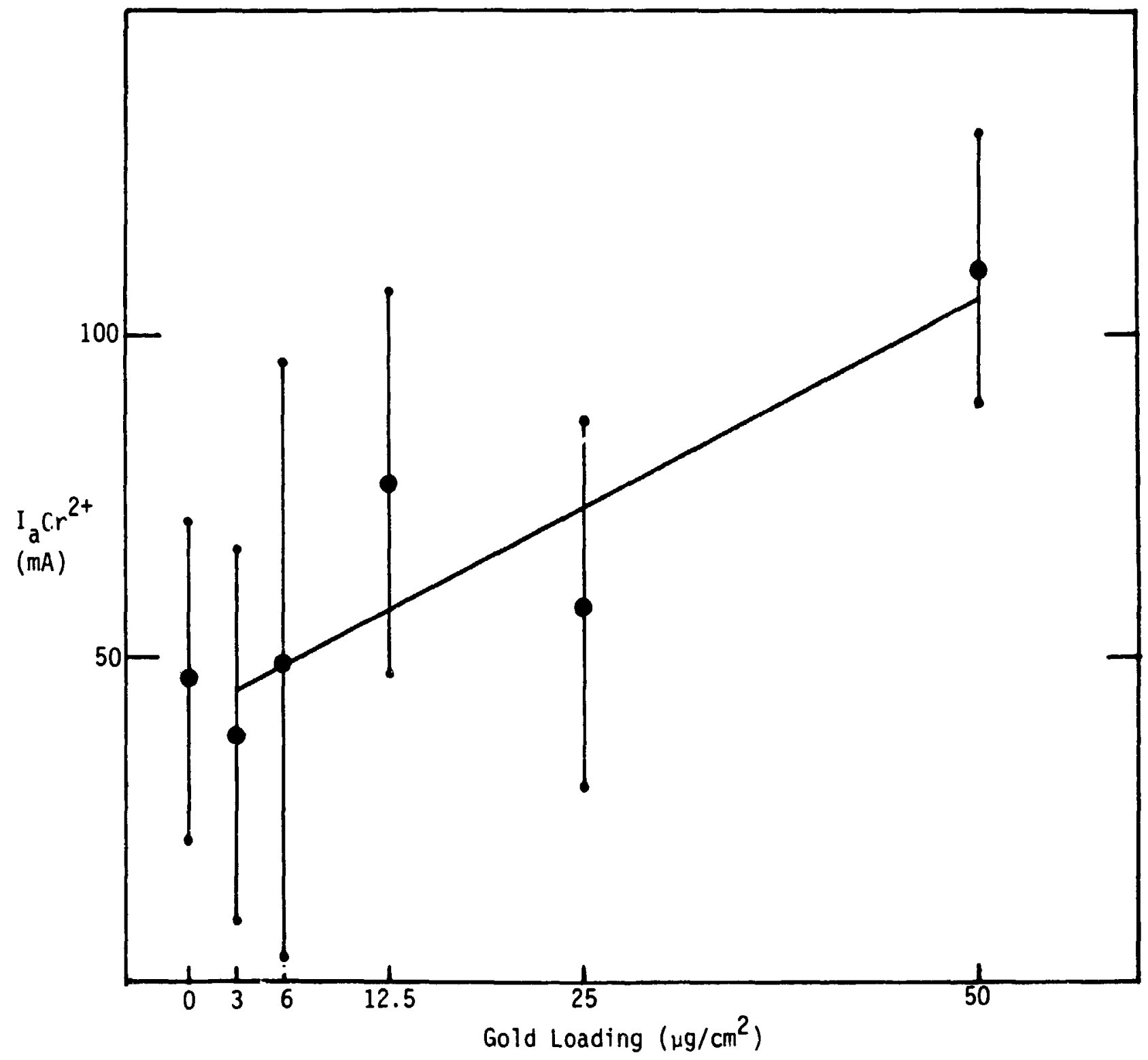

Figure 26. $\mathrm{Cr}^{2+}$ Oxidation Current Peak vs. Gold Loading 
ORIGINRL Fiñ is

OF POOR QUALITY

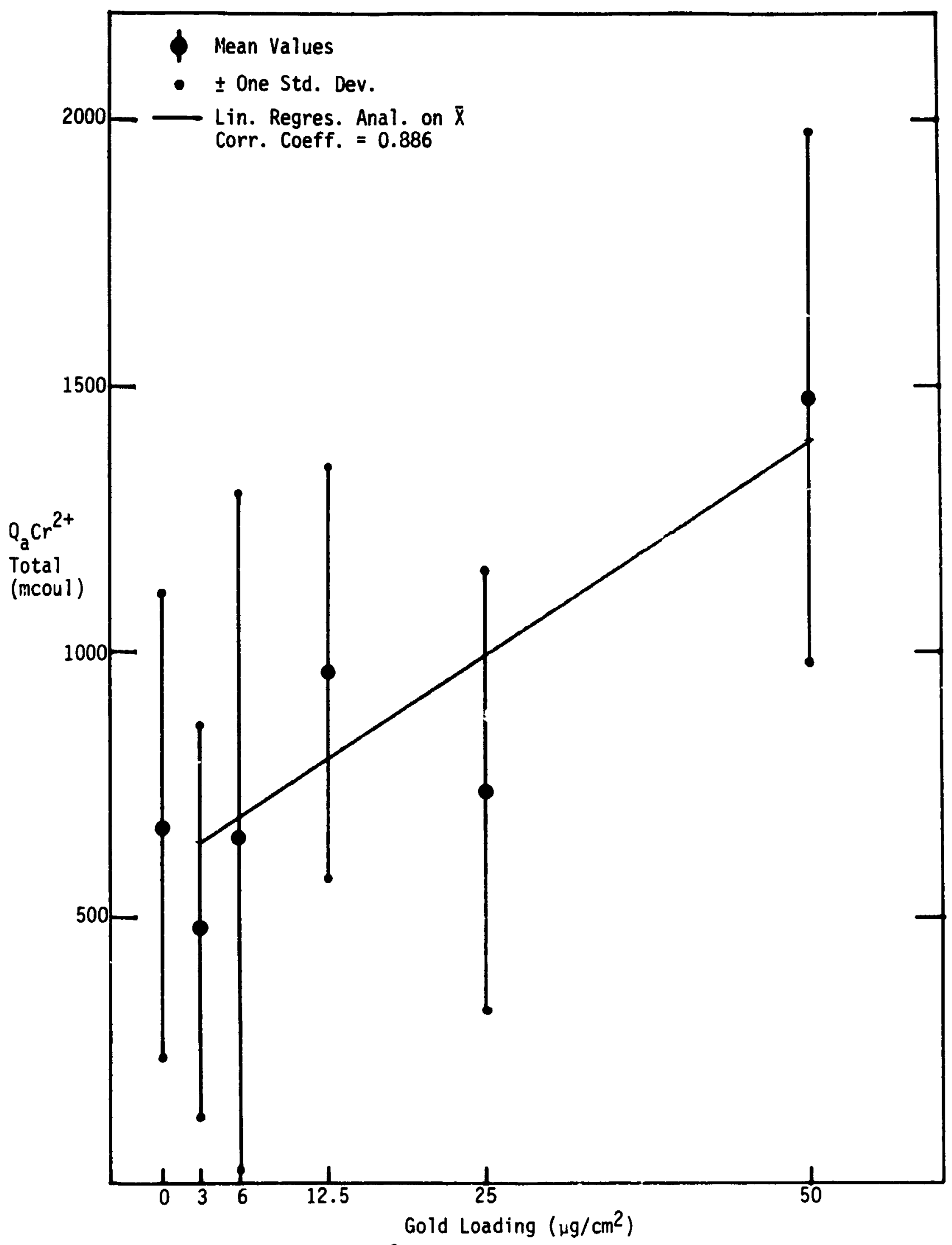

Figure 27. $\mathrm{Cr}^{2+}$ Oxidation Charge vs. Gold Loading 
- Lin. Regres. Anal. (mean values)

Corr. Cueff. $=0.905$

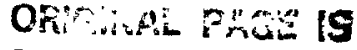

OF POCE QLALITY

-O- Li.. Regres. Anal. (mean values)

Corr. Coeff. $=0.843$

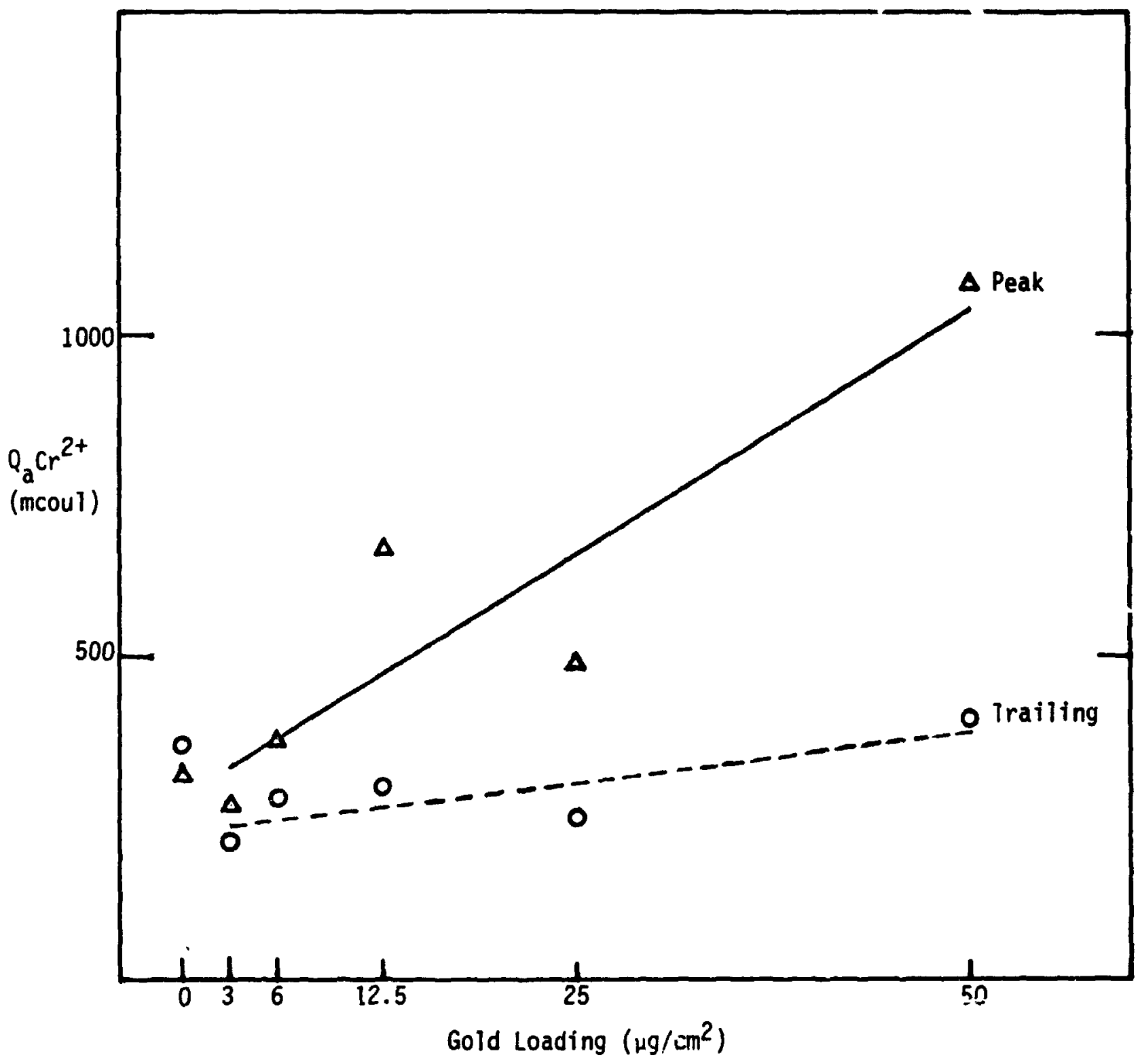

Figure 28. "Peak" and "Trailing" $\mathrm{Cr}^{2+}$ Oxidation Charge Segments versus Gol" " nading. 


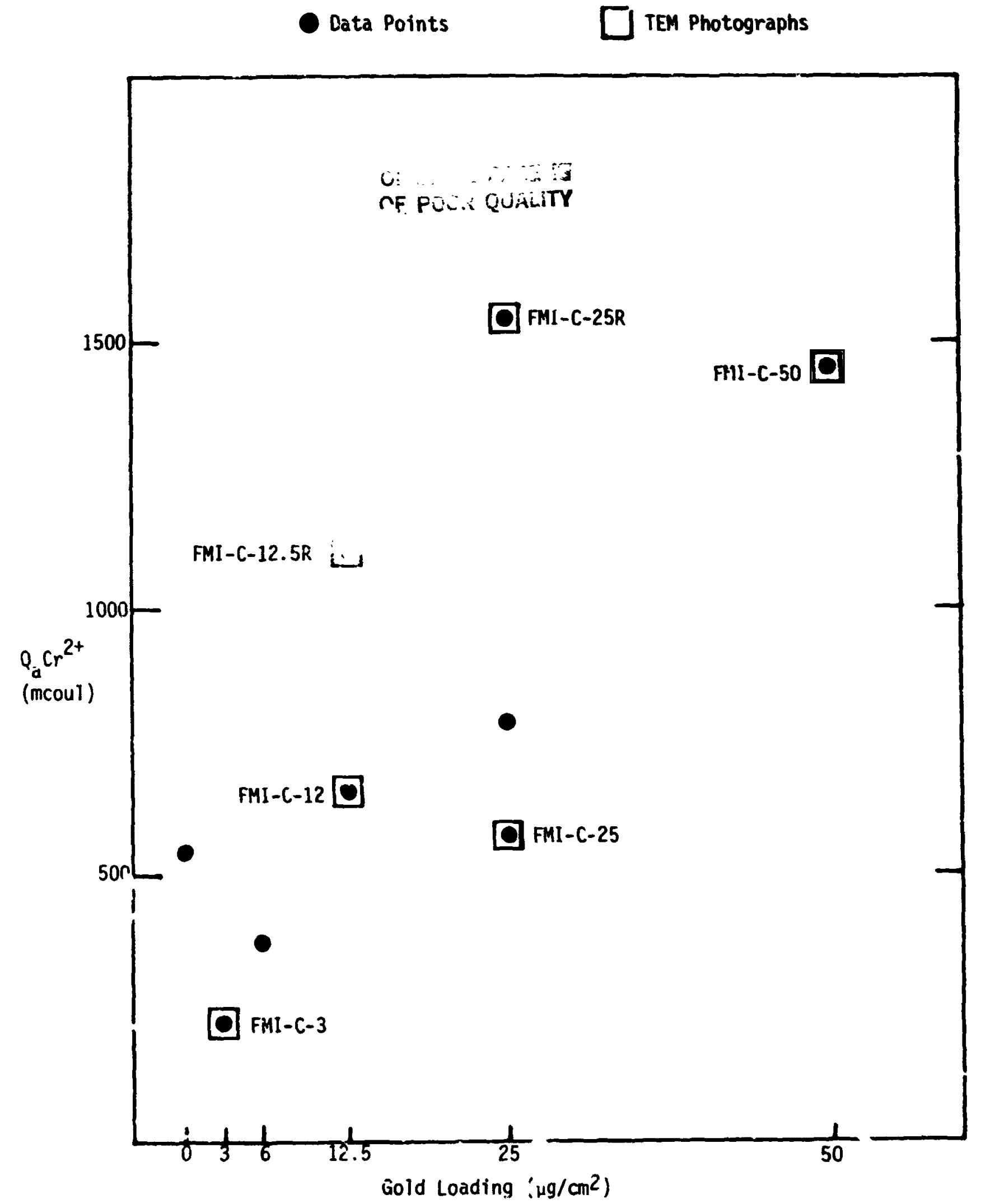

Figure 29. $\mathrm{Cr}^{2+}$ Gria " in Charge versus Gold Loading:

Key to Elertron llicrographs (FHI-C-1/8), 


\section{ORIGINAL PACE IS OF POOR QUALITY}

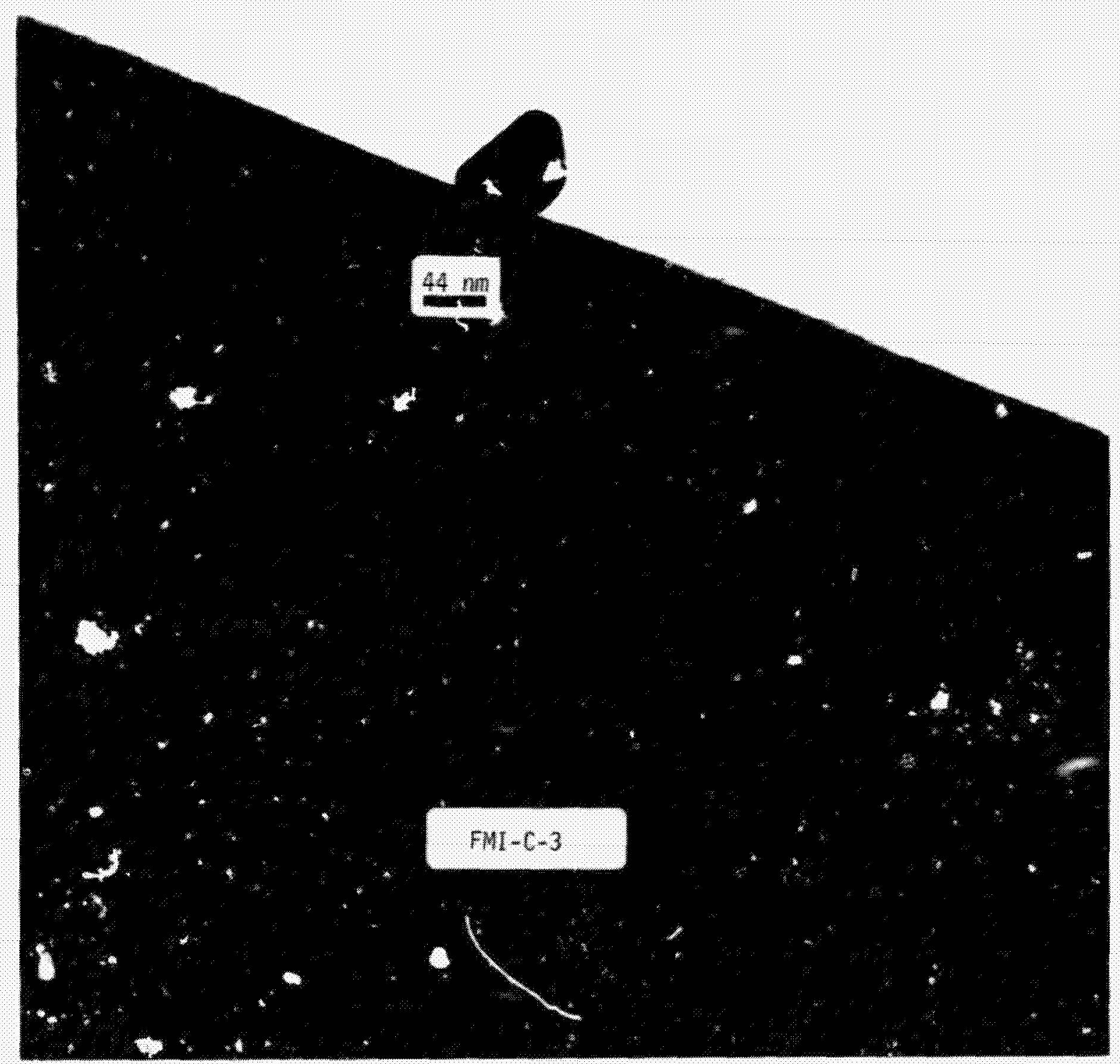

Figure 30. Gold Partic:3 at $3 \mu \mathrm{g} / \mathrm{cm}^{2}$ Loading; View 1. 
ORIGINAL PACE IS

OF POOR QUALITY

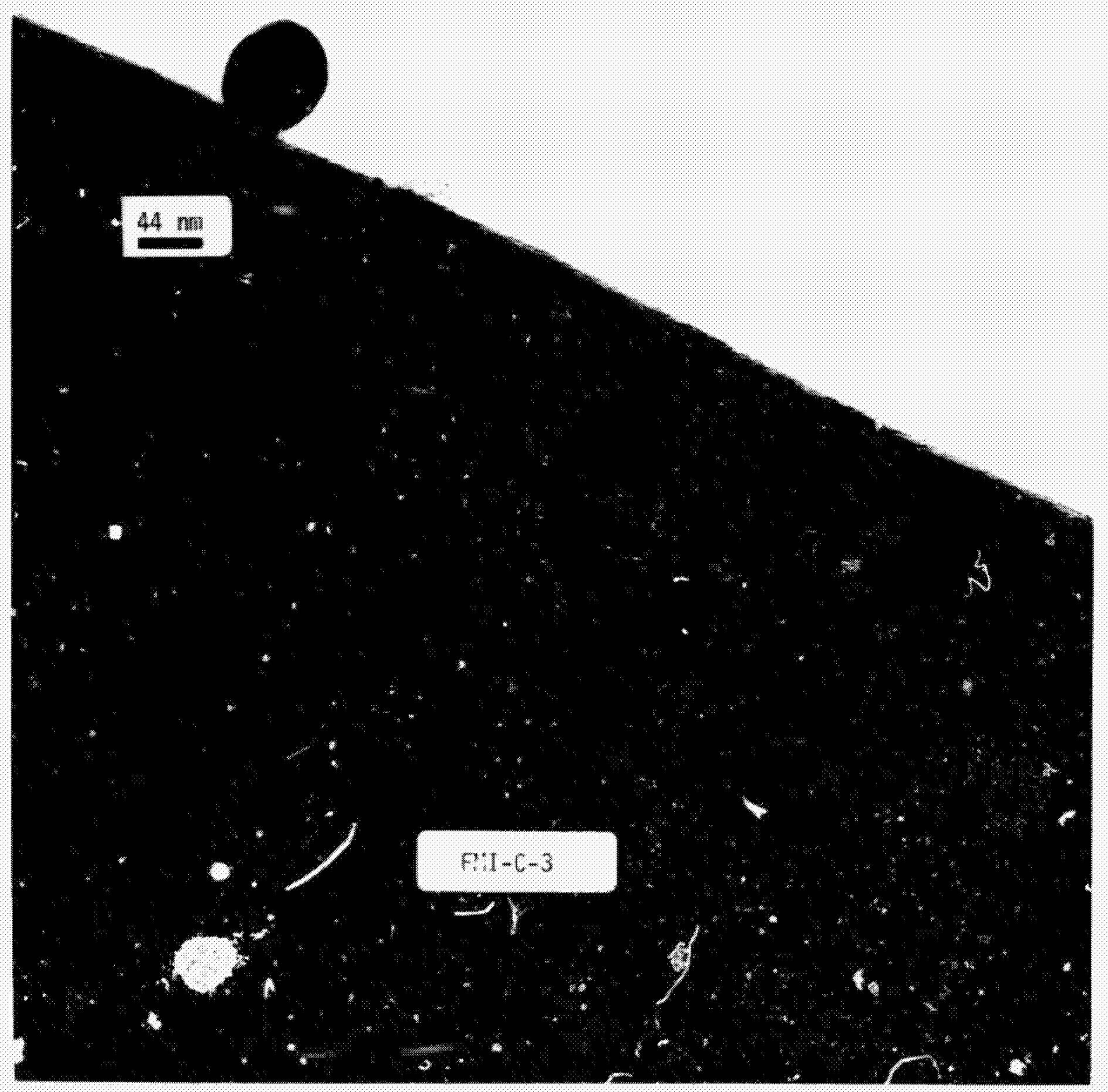

Figure 31. Gold Particle at $3 \mu \mathrm{g} / \mathrm{C}^{2}$ Loading; View ?. 


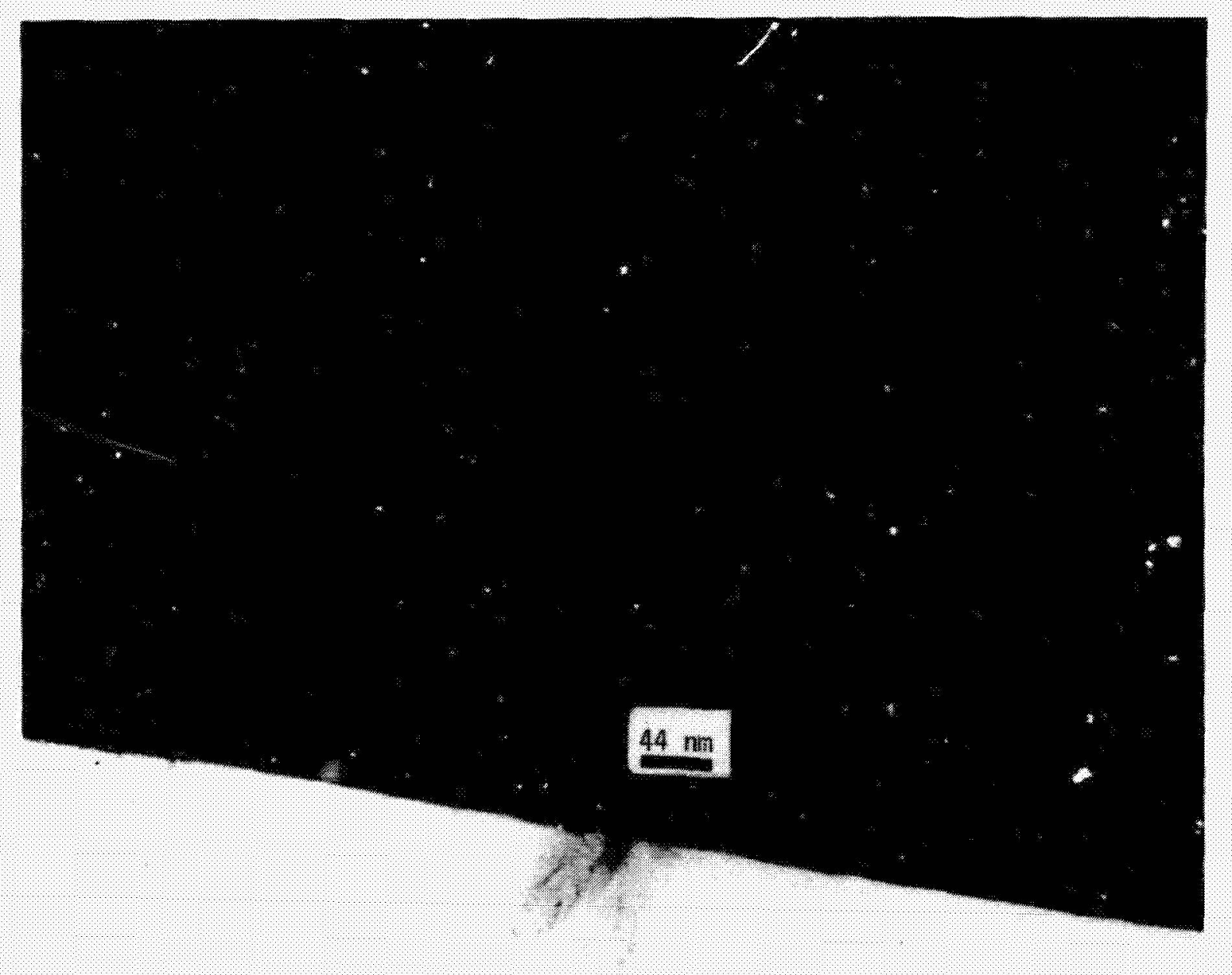

ORICINAL PHCE IS
OF POOR QUALII

FMI $-C-12$

Figure 32. Surface obtained at $12.5 \mathrm{ug}$ Au/ $/ \mathrm{cm}^{2}$ Loading; View 1 Lower Performance Electrode, see figure 29\%. 


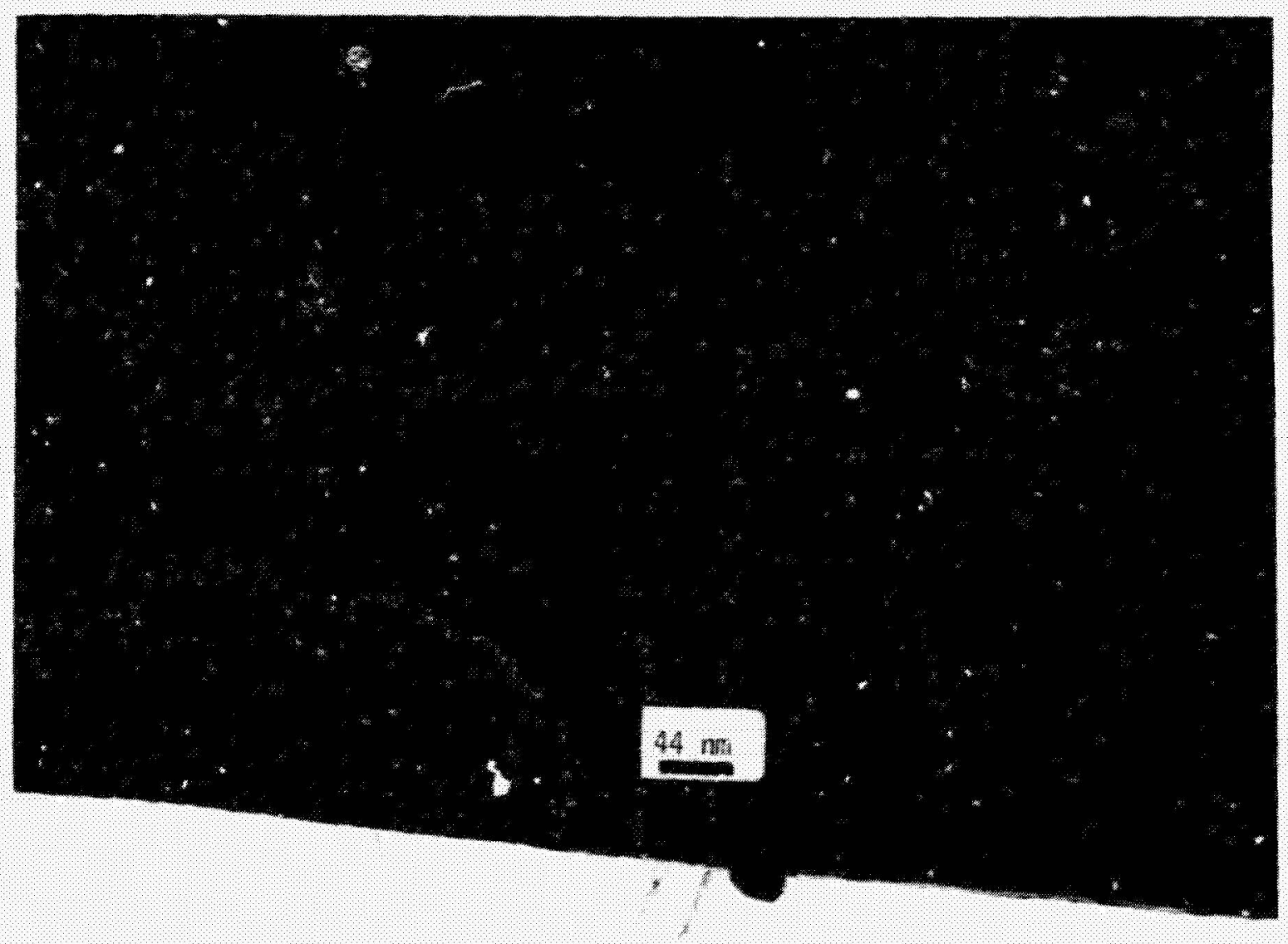

otremat: $=0-$ *s

of POON Q-ALIT,

Mit-6: $: 2$

ligure 33. Surface obtained at 12.5 .9 Au/ $\mathrm{cm}^{2}$ Loading; View 2

(1 ower Performance [lectrode, see Figure 29). 


\section{ORIGINAL PHEE IS OF POOR QUALTY}

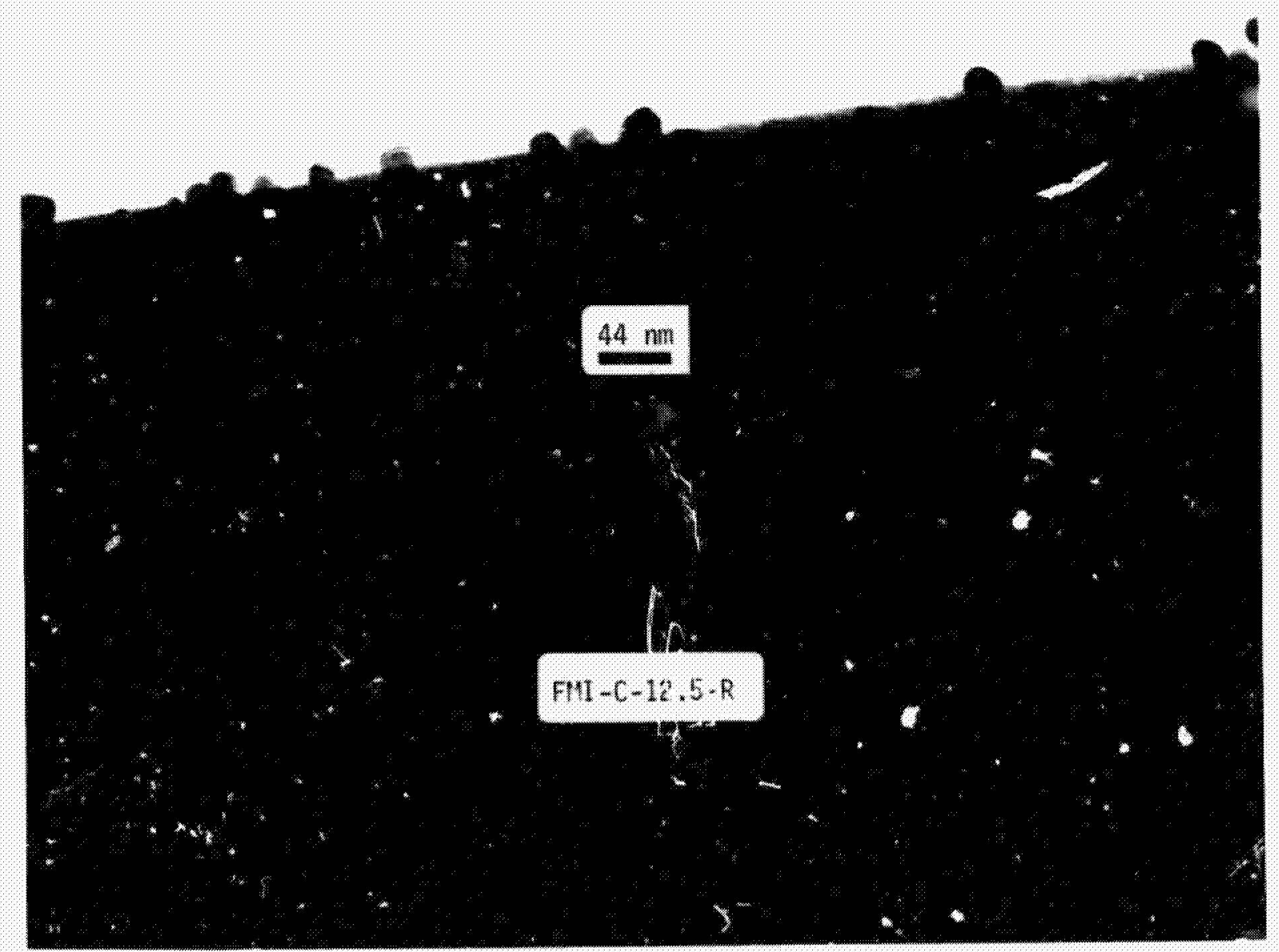

Figure 34. Gold Particles ontained at $12.5 \mu \mathrm{g} / \mathrm{cm}^{2}$ Loading - Remake; View 2 View 1, Fizure 10: Higher Performance Clectrode, see figure 29 ). 


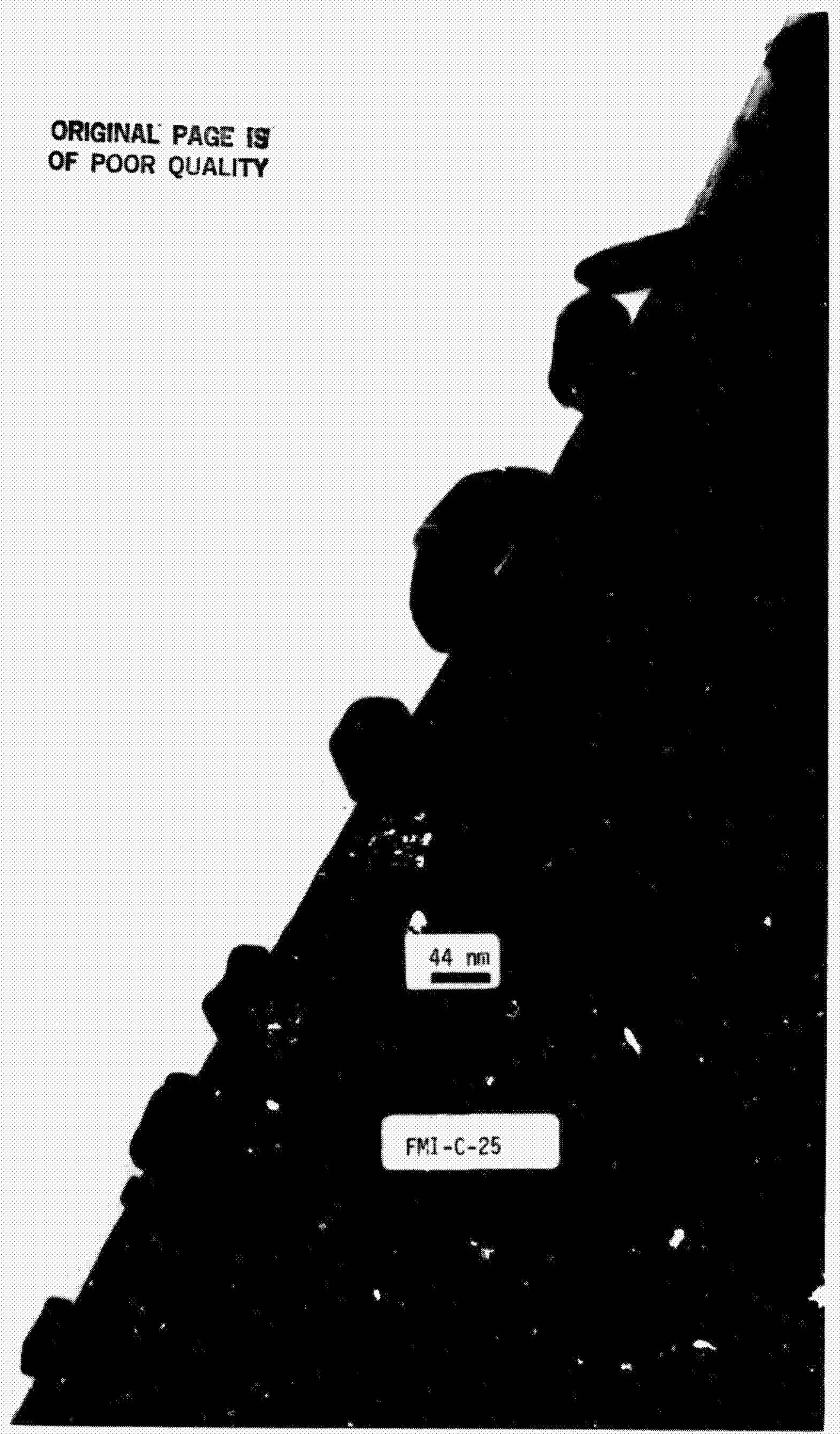

L.e 35. Gold Particles obtained at $25 \mu \mathrm{g} / \mathrm{cm}^{2}$ Loading; View 1 (Lower Perfomance El rtrode, see Figure 29). 


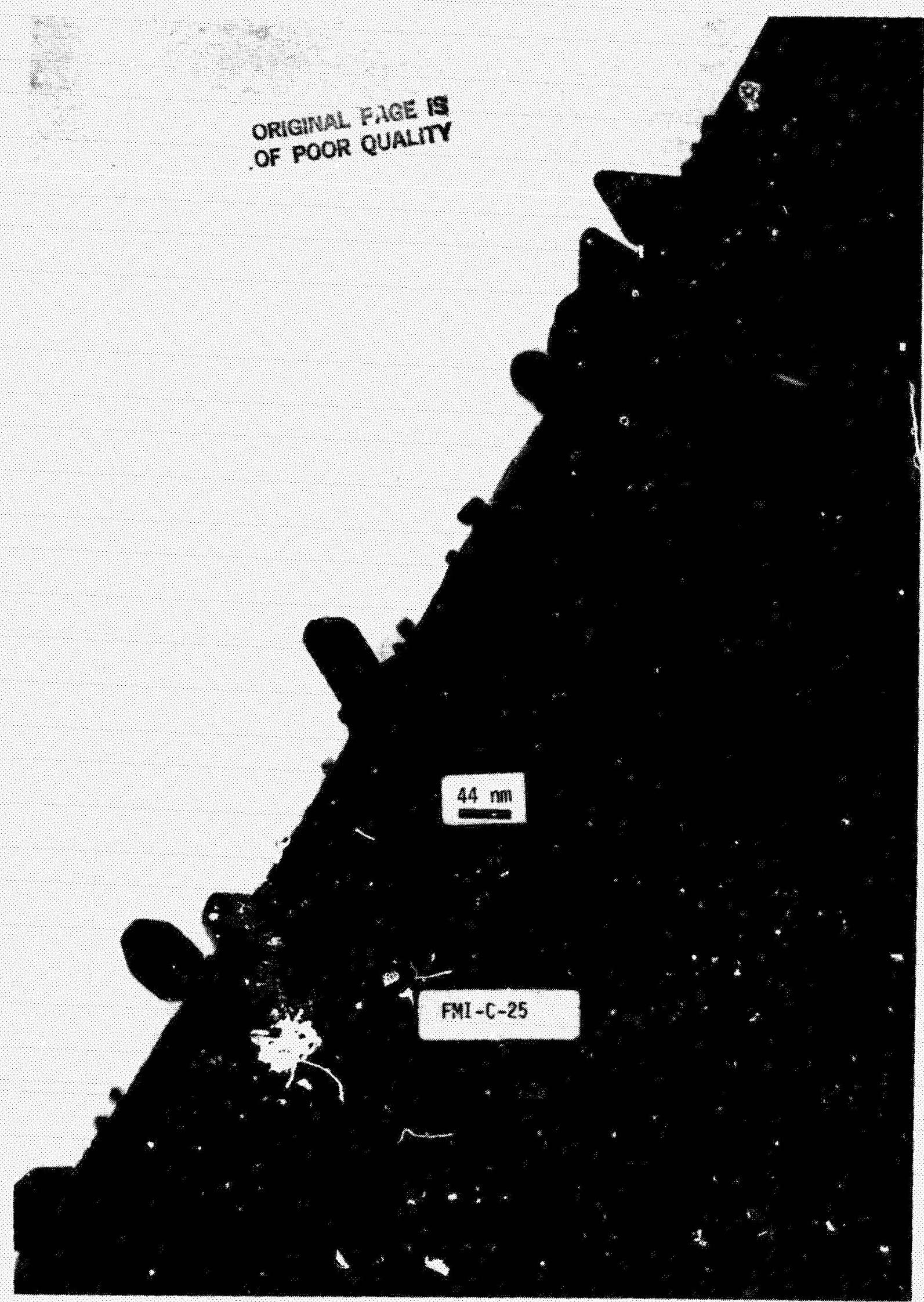

Figure 36. Gold Particles obtained at $25 \mathrm{\mu g} / \mathrm{cm}^{2}$ Loading; View 2 (Lower Performance Electrode, see Figure 29). 


\section{CRICWH: PAGE IS \\ of POOR QUALITY.}

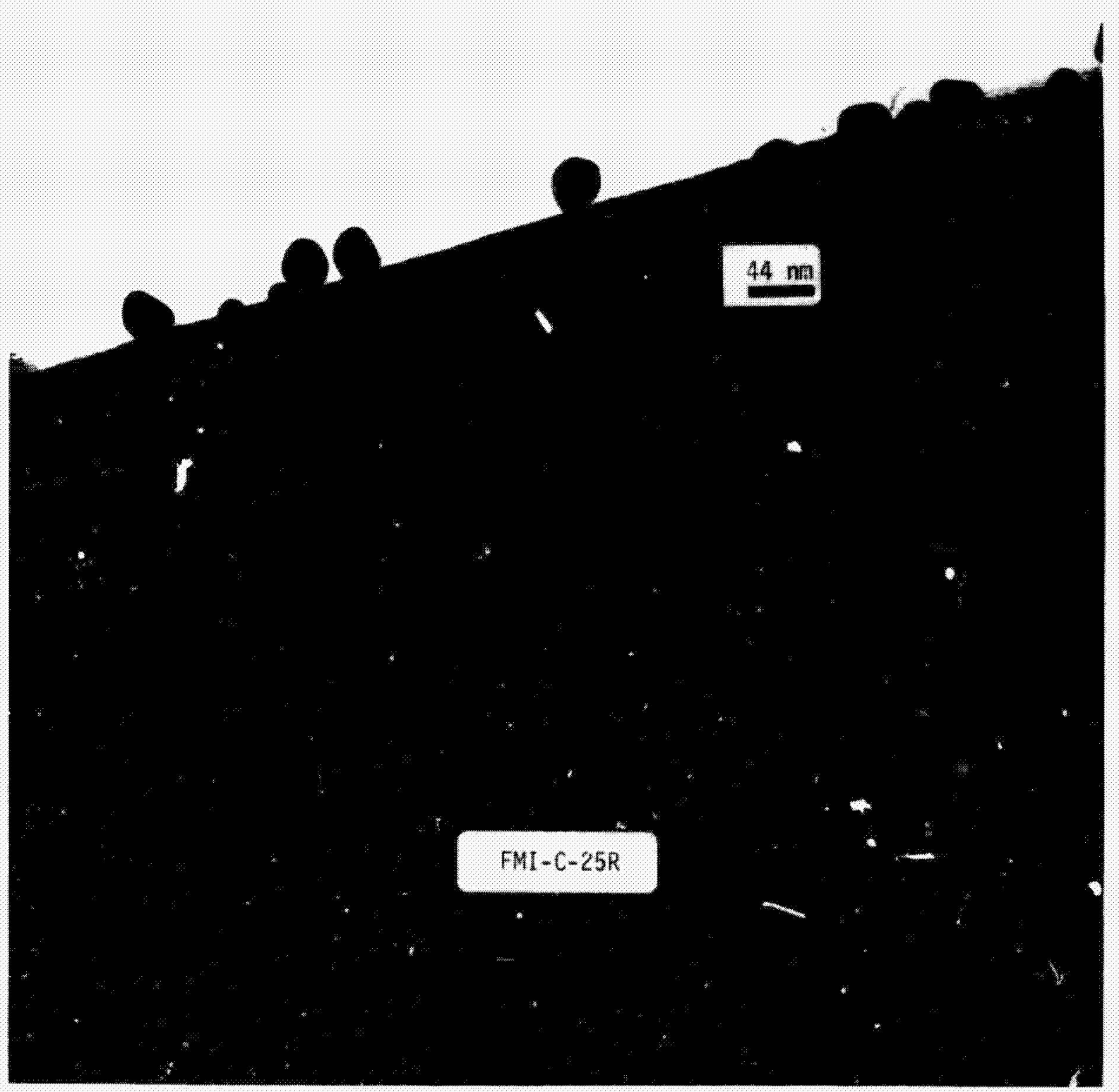

Figure 37. Gold Particles Obtained at $25 \mu \mathrm{g} / \mathrm{cm}^{2}$ Loading - Renake; View 1 (4haher Perfornance Electrode, see Figure 29). 


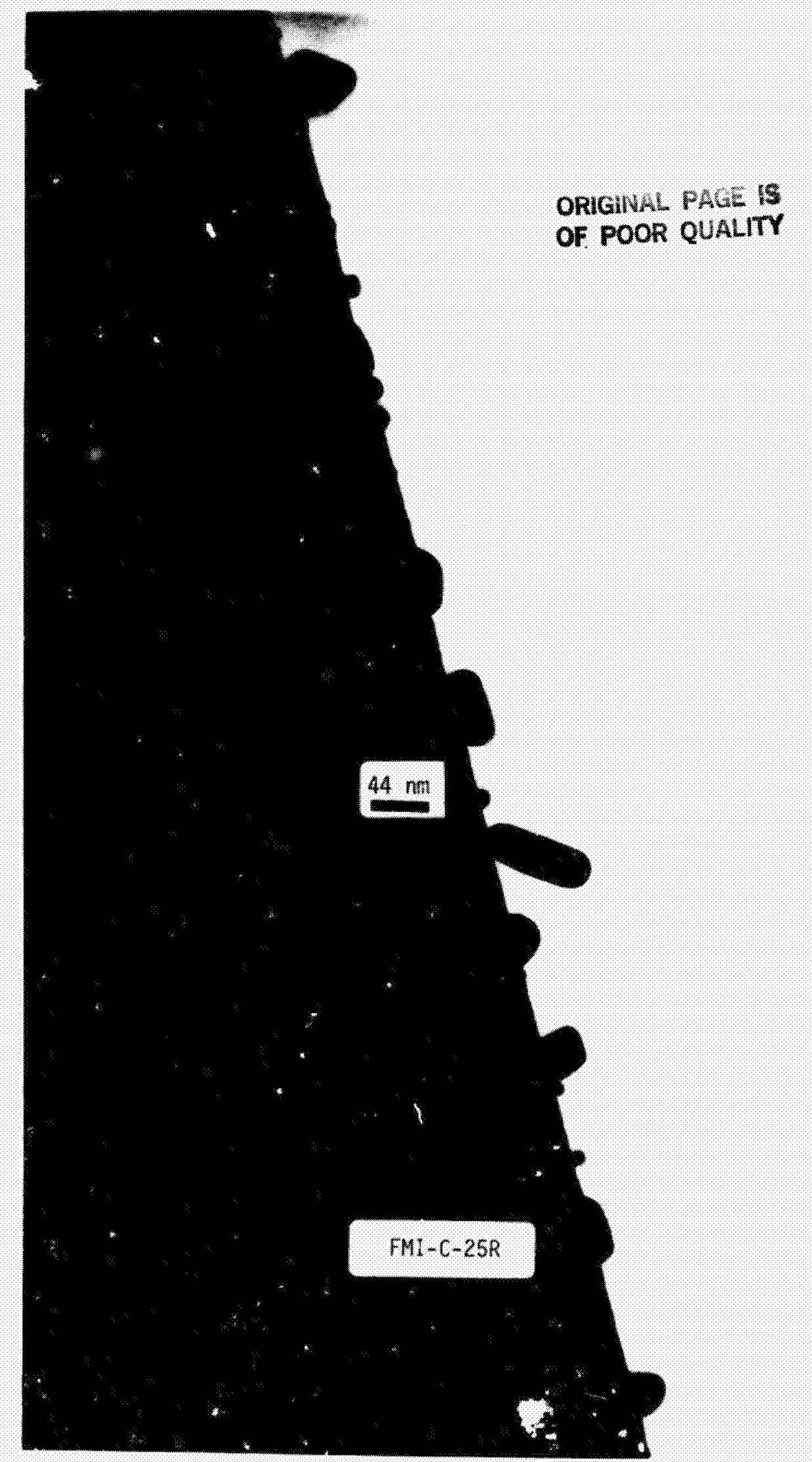

Fyme 36. Gold Particles obtained at $25 \mathrm{ug} / \mathrm{cm}^{2}$ Loading - Rentke: Vhu 2 (Thgher Performance Electrole, see Finure 23) 


\section{ORIGINAL PACE IS}

OF POOR QUALITY

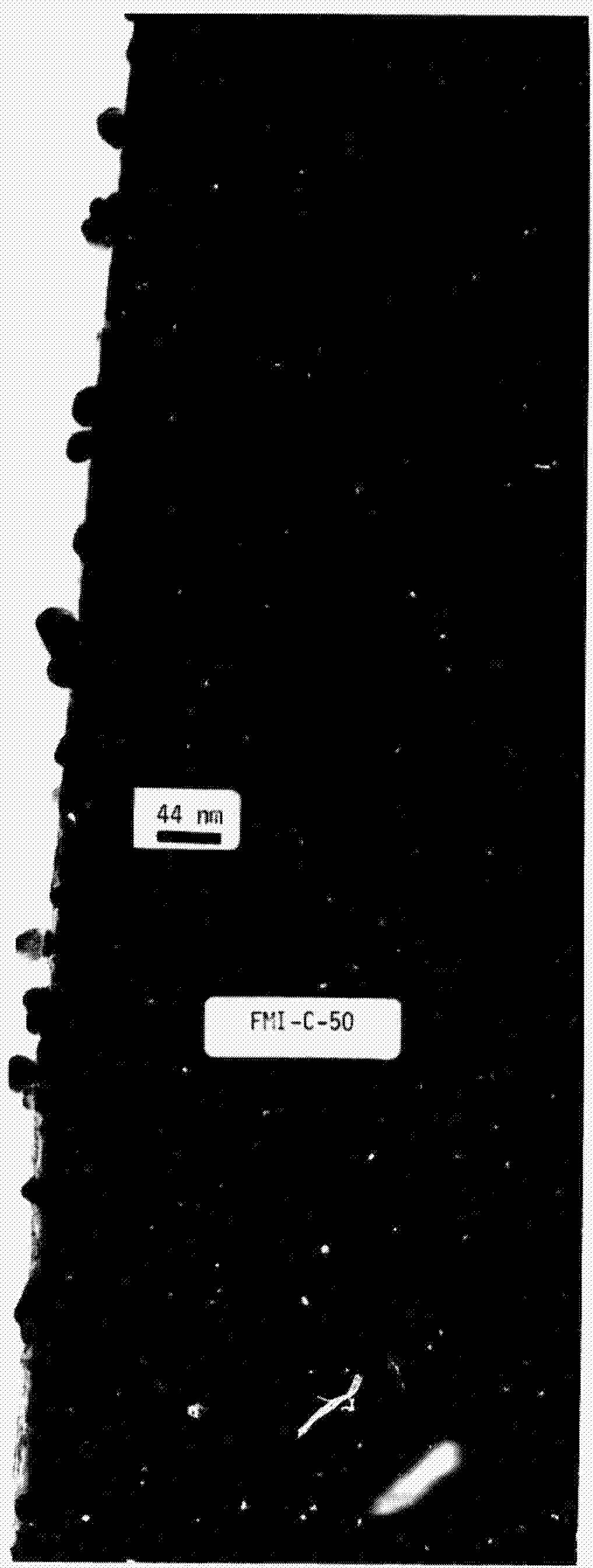

Figure 39. Gold Particles Obtained at $50 \mu \mathrm{g} / \mathrm{cm}^{2}$ Loading; View 1 . 


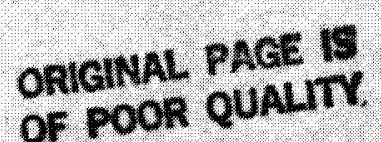

94 rII

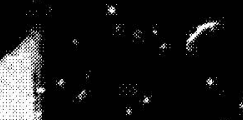

FMI $-C-50$

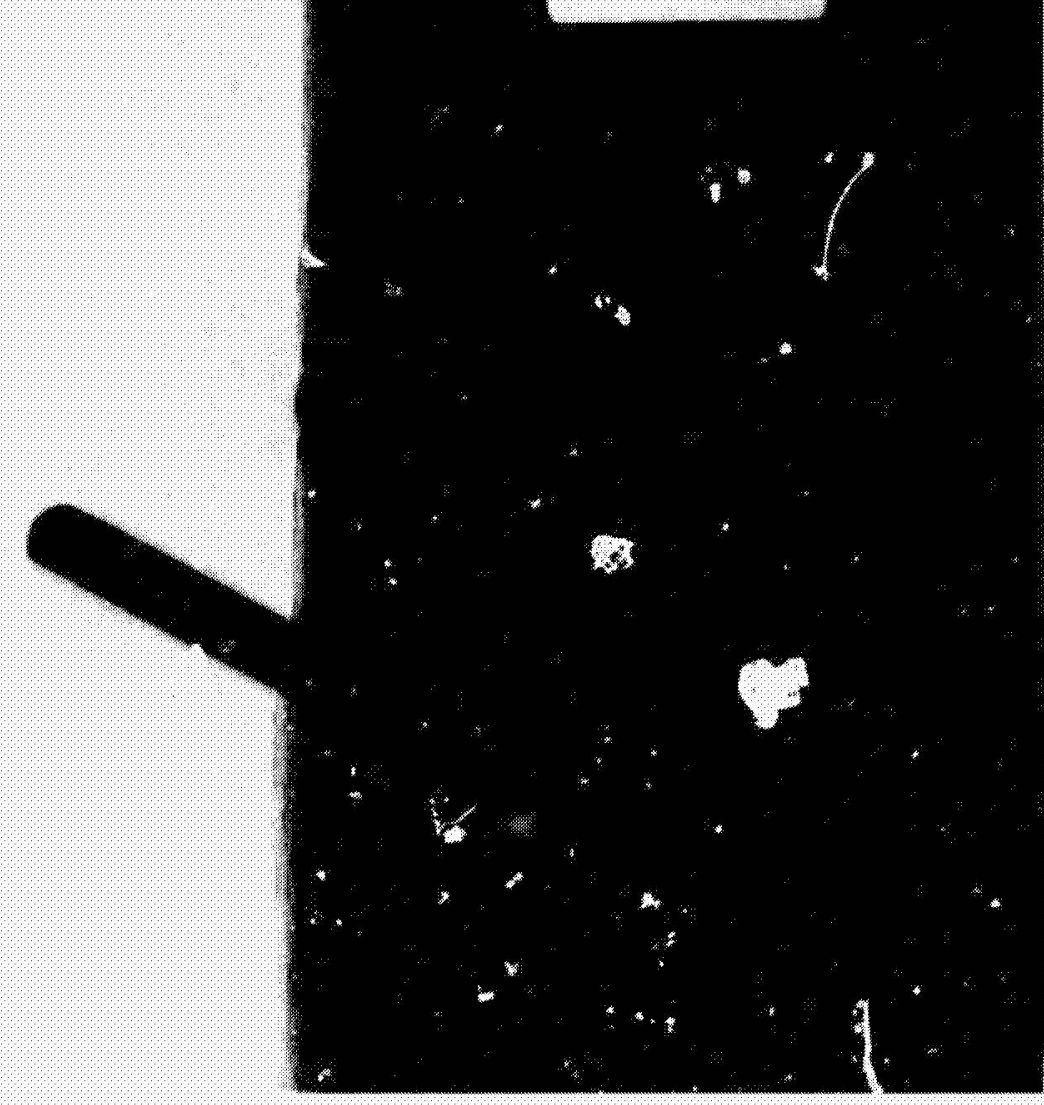

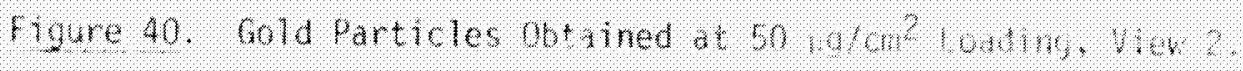




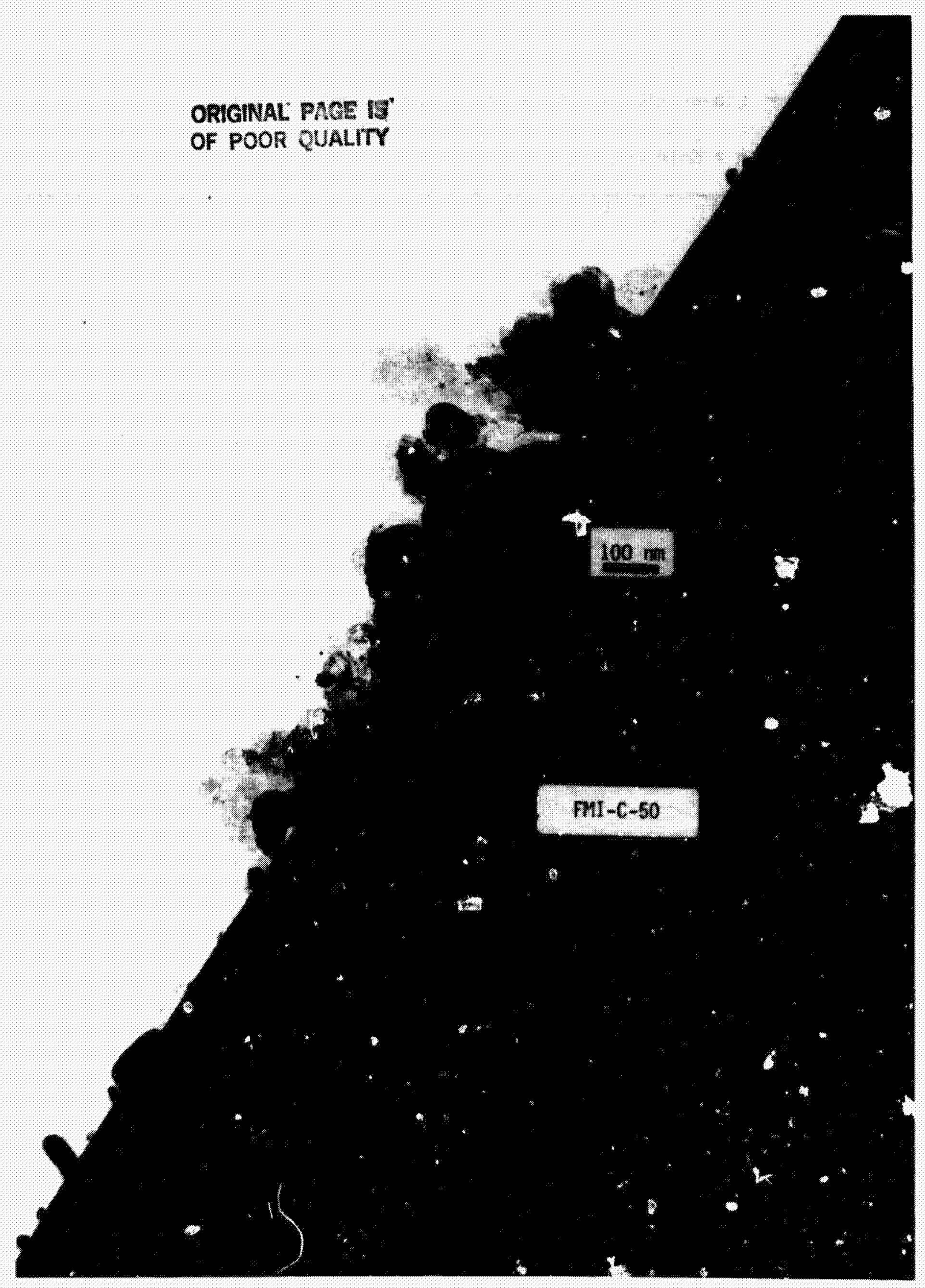

Figurz 41. Gold Particles Obtained at $50 \mu \mathrm{g} / \mathrm{cm}^{2}$ Loading; View 3 (note scale change). 
- Linear Regression Analysis; Corr. Coeff. $=0.953$

(1) $n=$ Gold Loading $\left(\mu \mathrm{g} / \mathrm{cm}^{2}\right)$

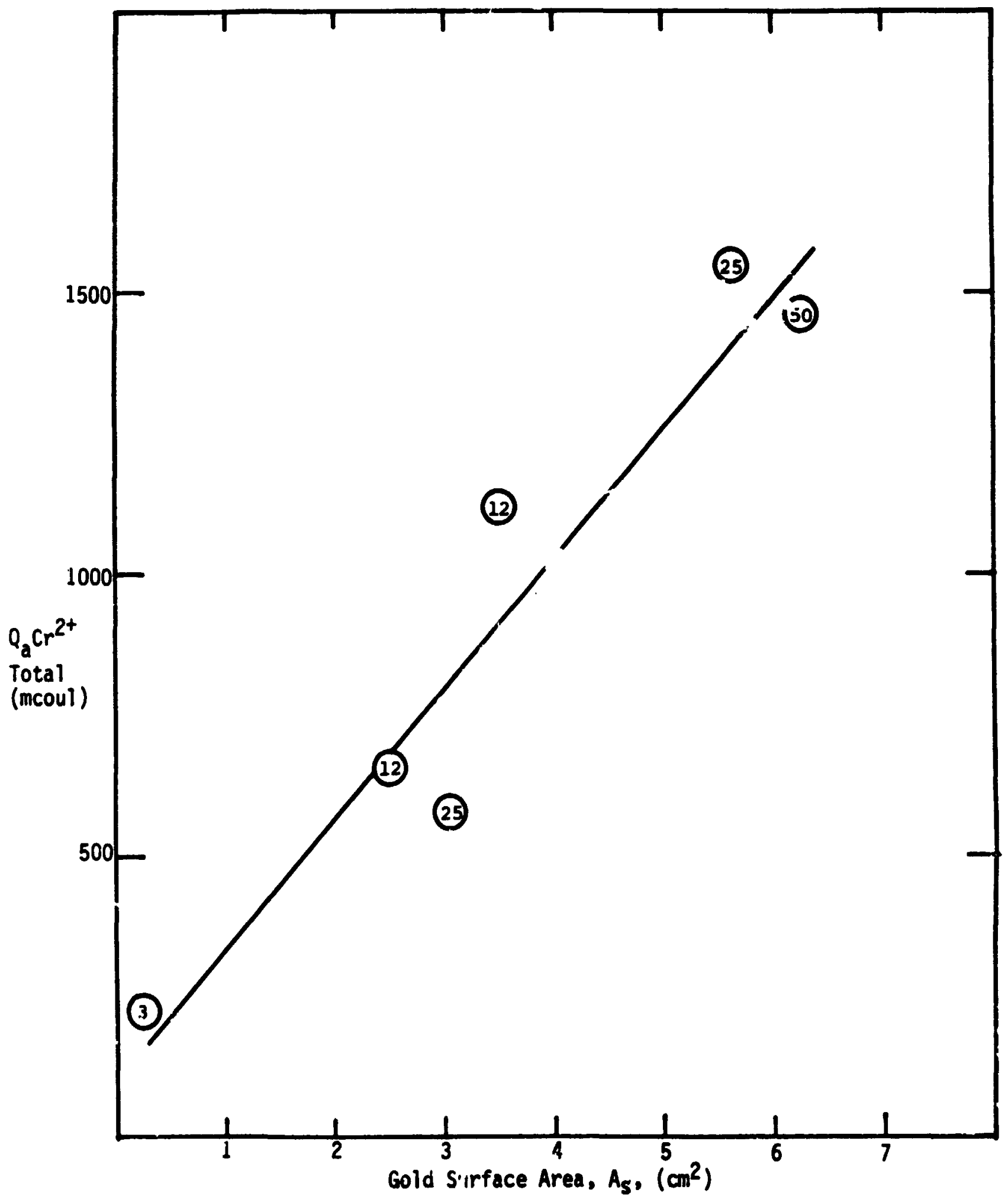

Figure 42. $\mathrm{Cr}^{2+}$ Oxidation charge vs. Gold Surface Area $-94-$ 


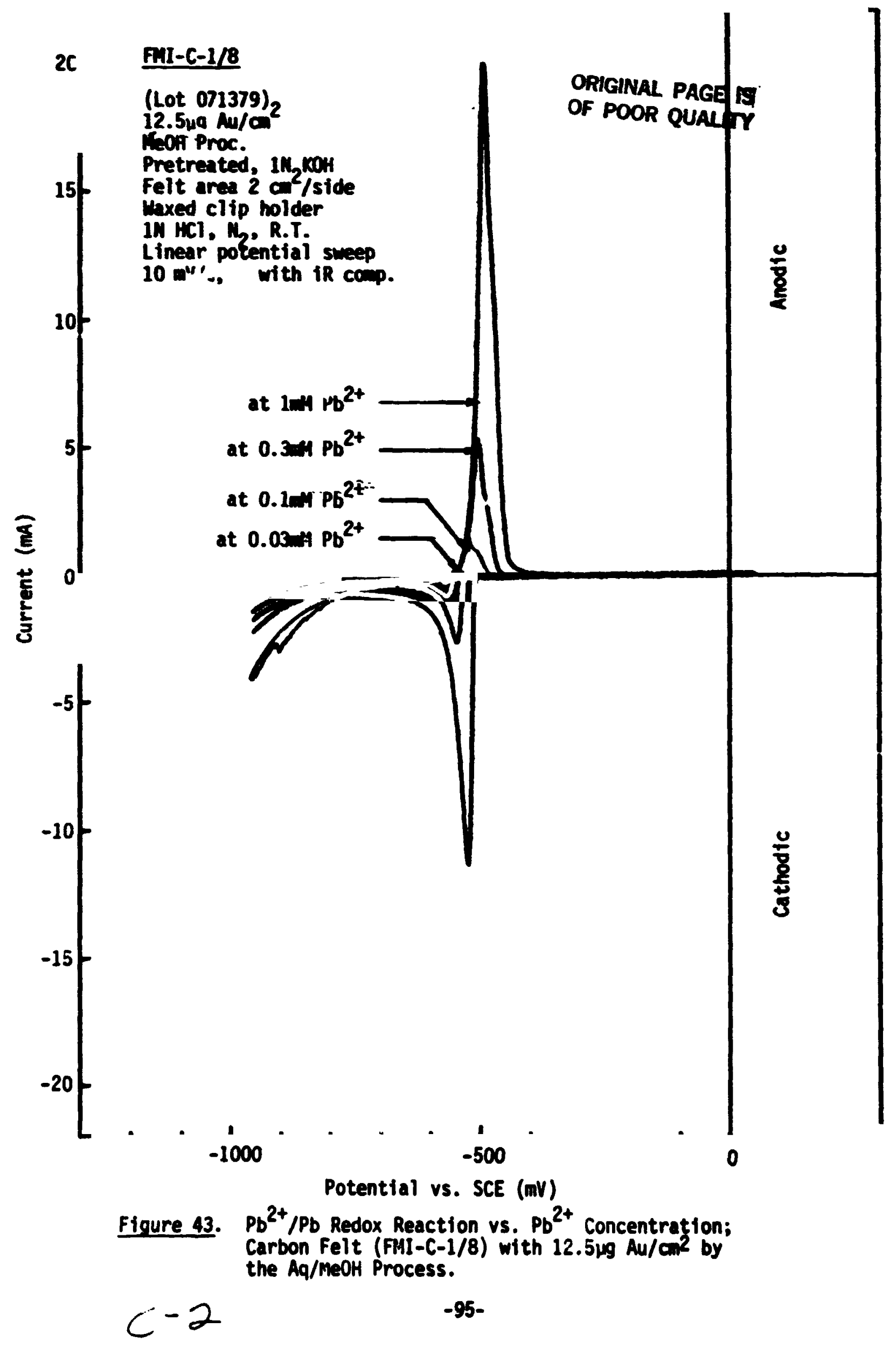




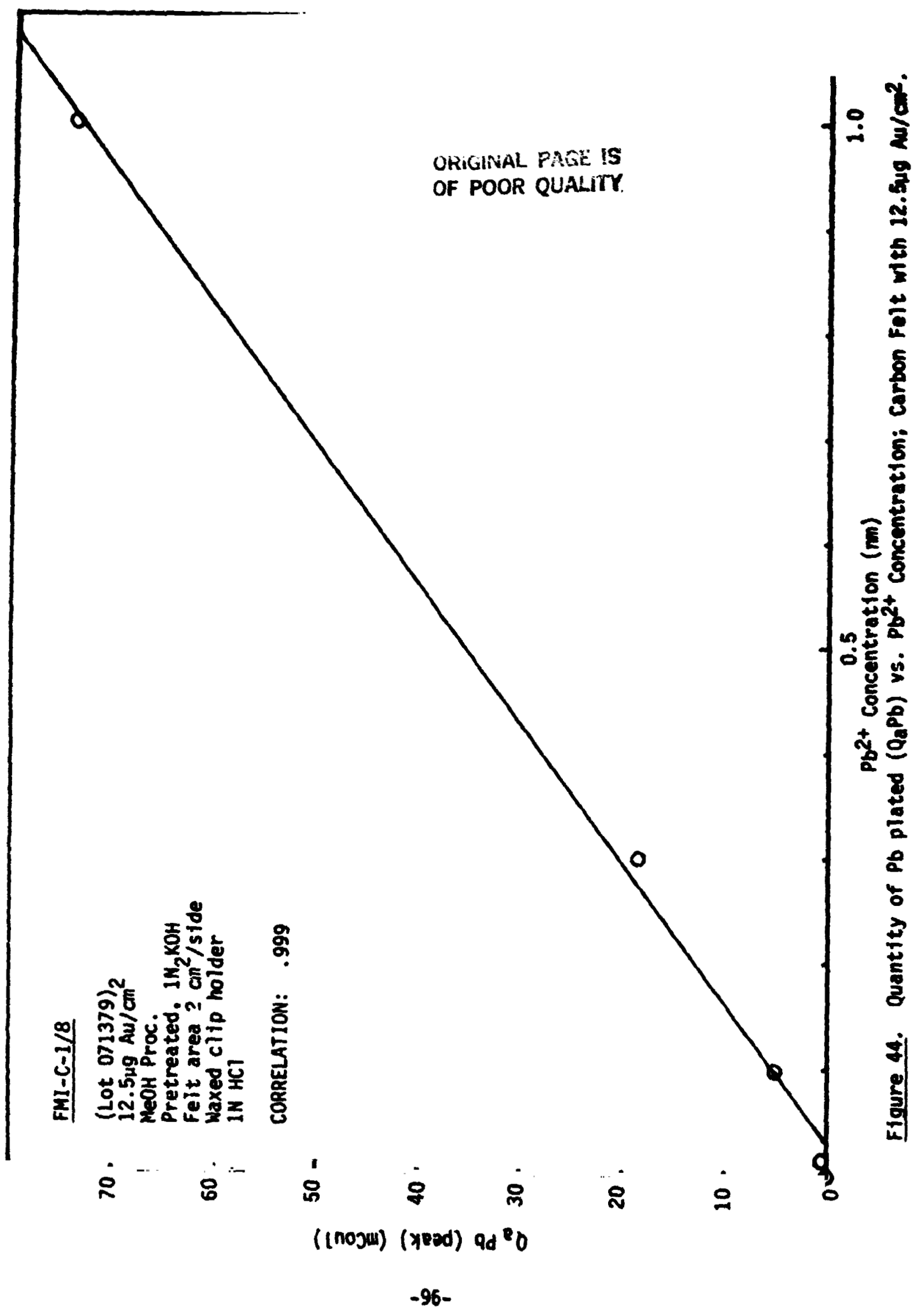


- Limar Ragression Amalysis; Corr. Coeff. 0.996

(n) $n$ - cold Lading (ugiar)

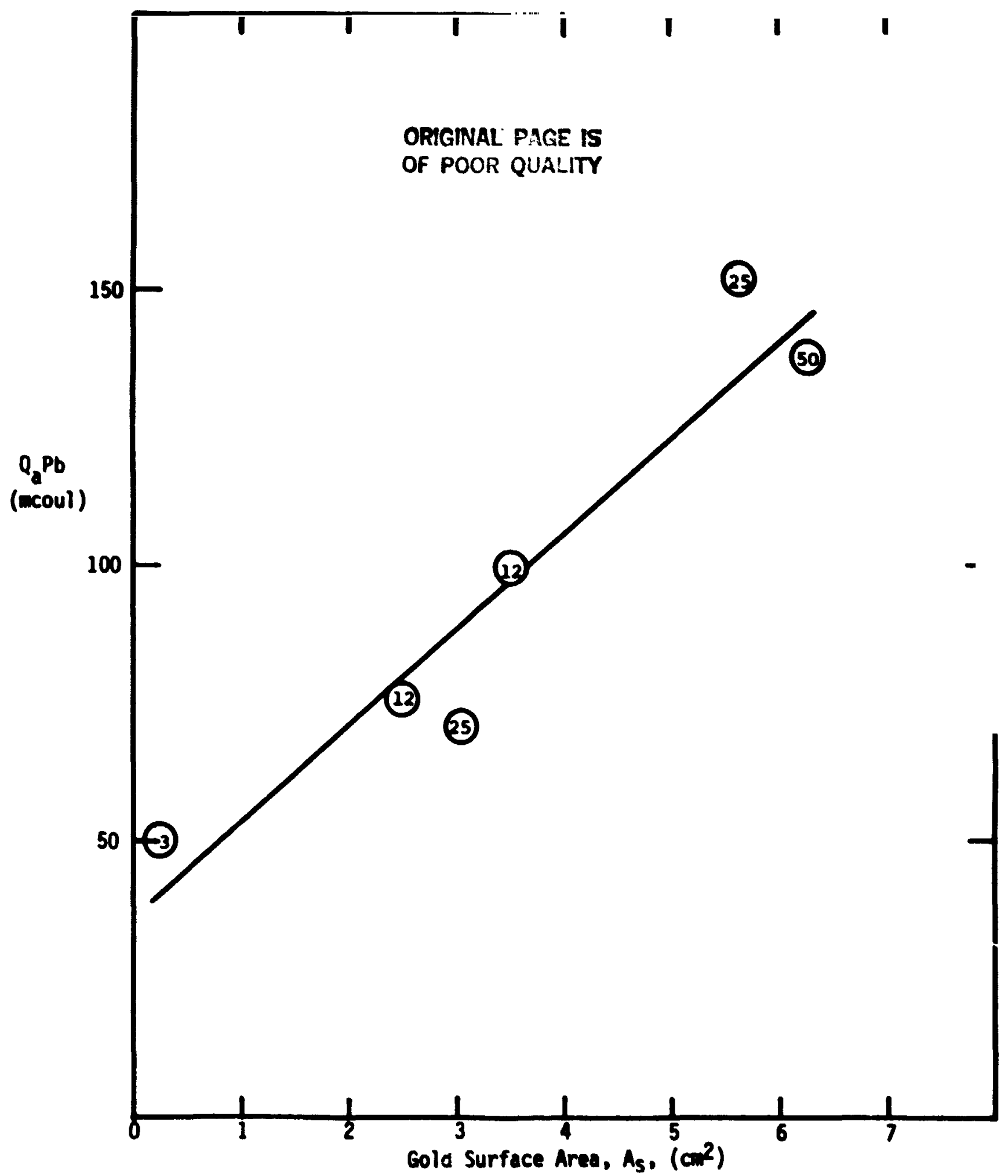

Ffoure 45. Lead Loading $\left(\mathrm{Q}_{\mathrm{a}} \mathrm{Pb}\right)$ versus Gold Surface Area.

$-97$. 


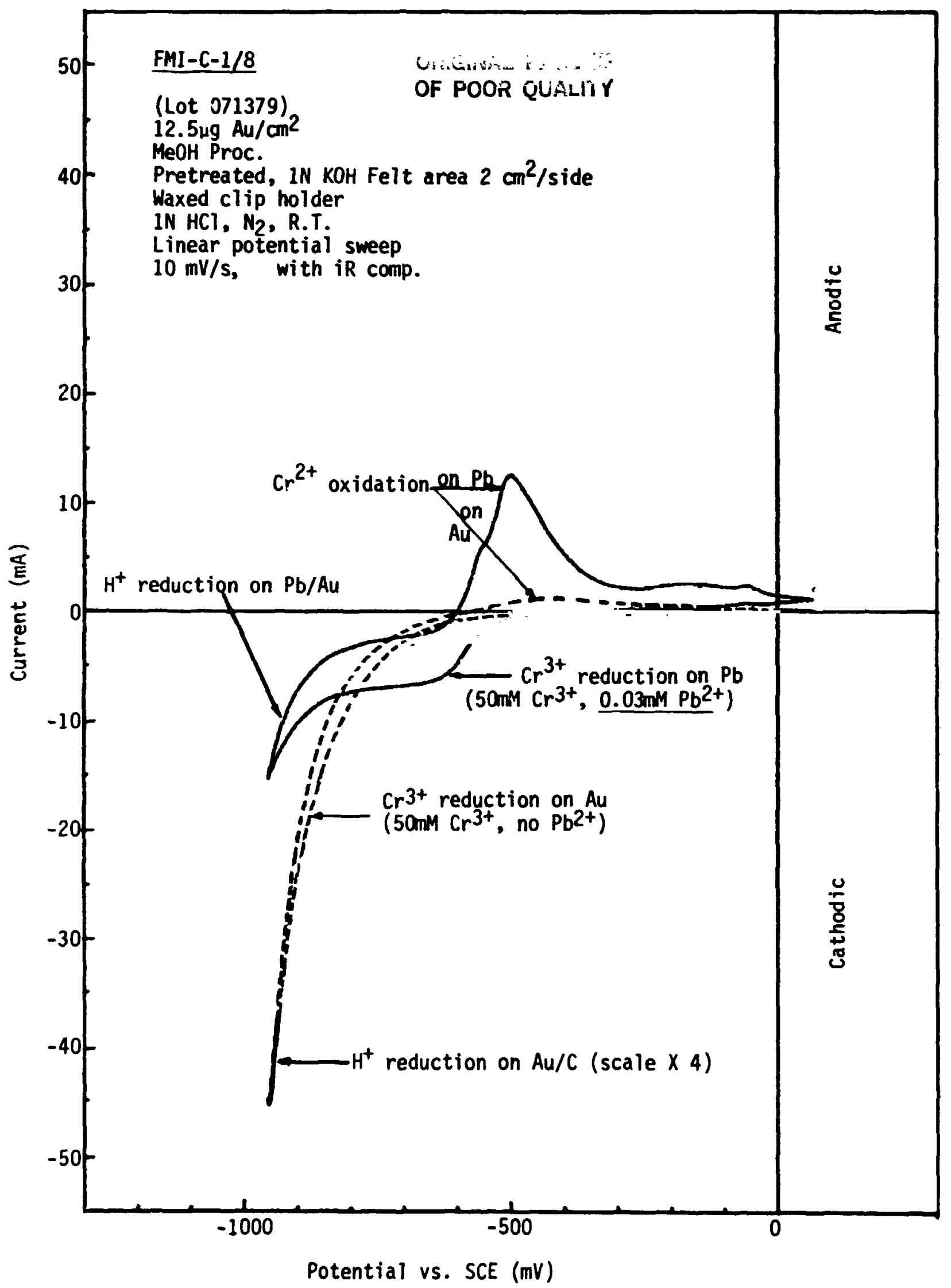

Figure 46. Electrochemical Performance at $0.03 \mathrm{mM} \mathrm{Pb}^{2+}$ Concentration; Carbon Felt (FMI-C-1/8) with $12.5 \mathrm{\mu g} \mathrm{Au} / \mathrm{cm}^{2}$ by the $\mathrm{Aq} / \mathrm{MeOH}$ Process (50mM $\mathrm{Cr}^{3+}$ ). 


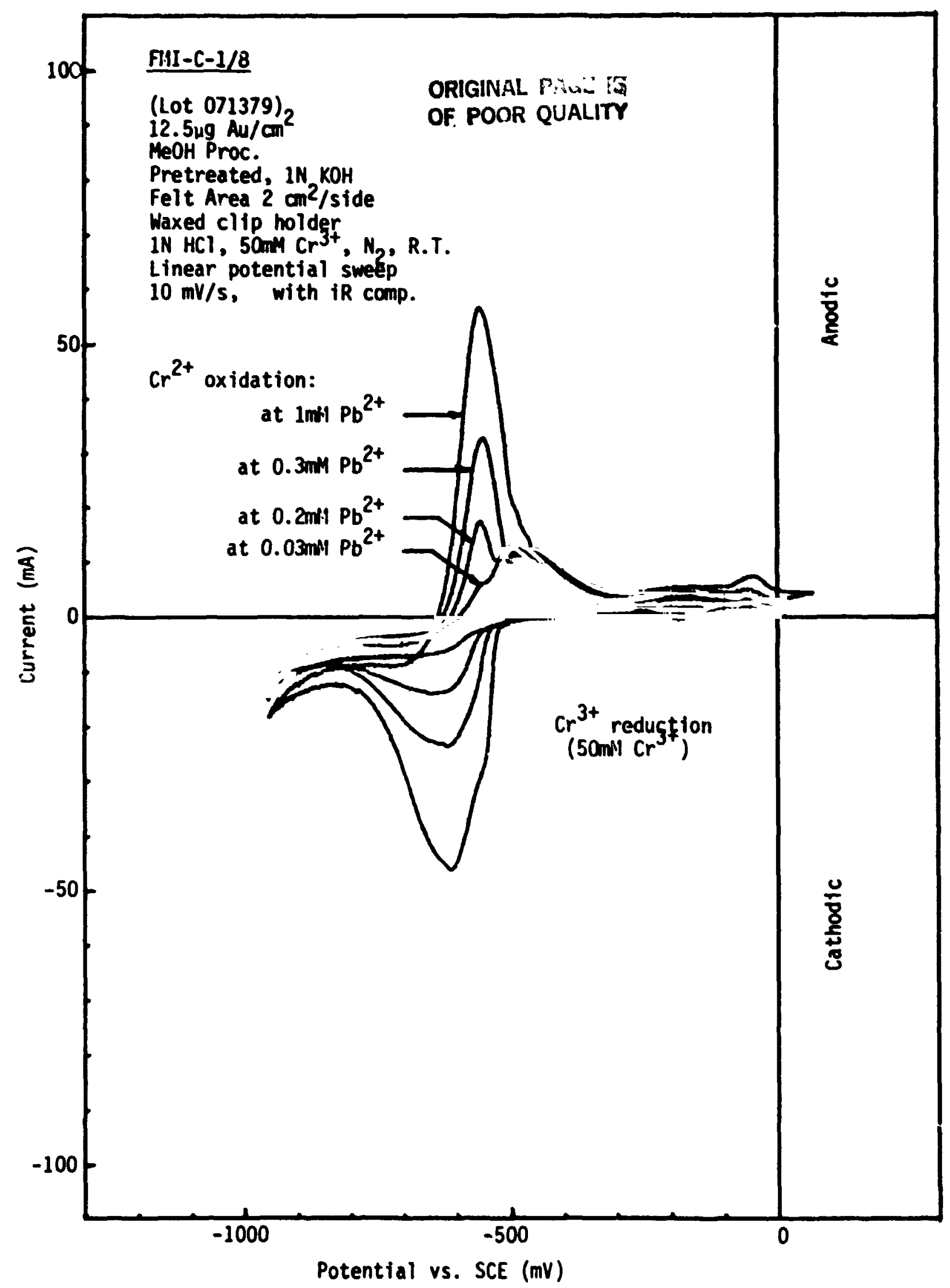

Figure 47. $\mathrm{Cr}^{3+} / \mathrm{Cr}^{2+}$ Redox Reaction vs. $\mathrm{Pb}^{2+}$ Concentration; Carbon Felt (FMI-C-1/3) with 12. bug Au/ $\mathrm{cm}^{2}$ by the $\mathrm{Aq} / \mathrm{MeOH}$ Process $\left(50 \mathrm{mM} \mathrm{Cr}^{3+}\right.$ ). 
Cati.

OF PC::

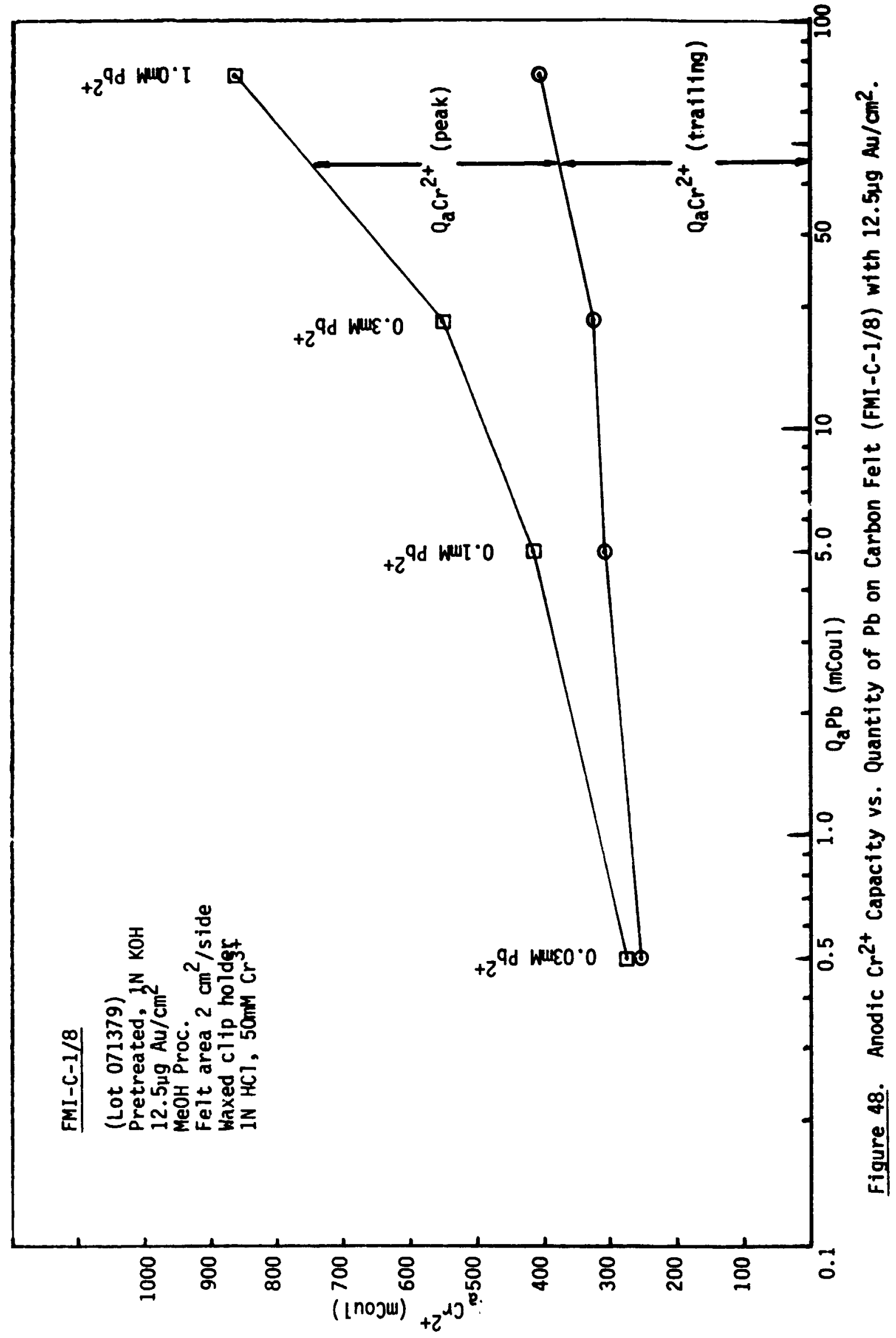


OF Puin $5 \ldots . . .18$

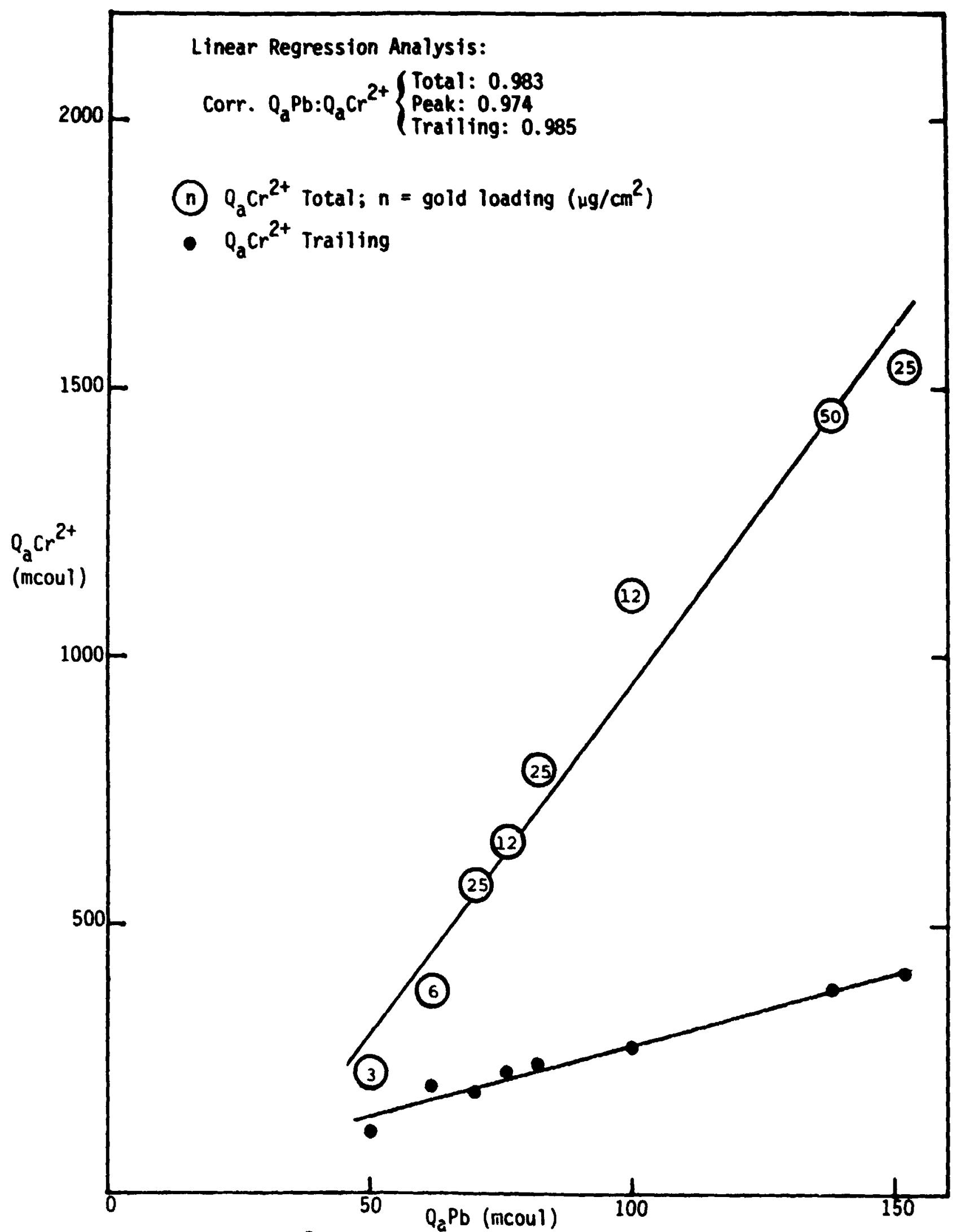

Figure 49. $\mathrm{Cr}^{2+}$ Oxidation Charge vs. Lead Loading for $1 / 8$ in Thick Carbon Felt (FIII-C-1/8). 
Linear Regression Analysis:

Corr. $\mathrm{Q}_{\mathrm{a}} \mathrm{Pb}: \mathrm{Q}_{\mathrm{a}} \mathrm{Cr}^{2+}\left\{\begin{array}{l}\text { Total: } 0.992 \\ \text { Peak: 0.988 } \\ \text { Trailing: } 0.957\end{array}\right.$
ORIGINAi : : :

OF POOR QUALIT'

(n) $Q_{a} C r^{2+}$ Total; $n=$ Gold Loading ( $\left.\mu \mathrm{g} / \mathrm{cm}^{2}\right)$

- $Q_{a} C r^{2+}$ Trailing

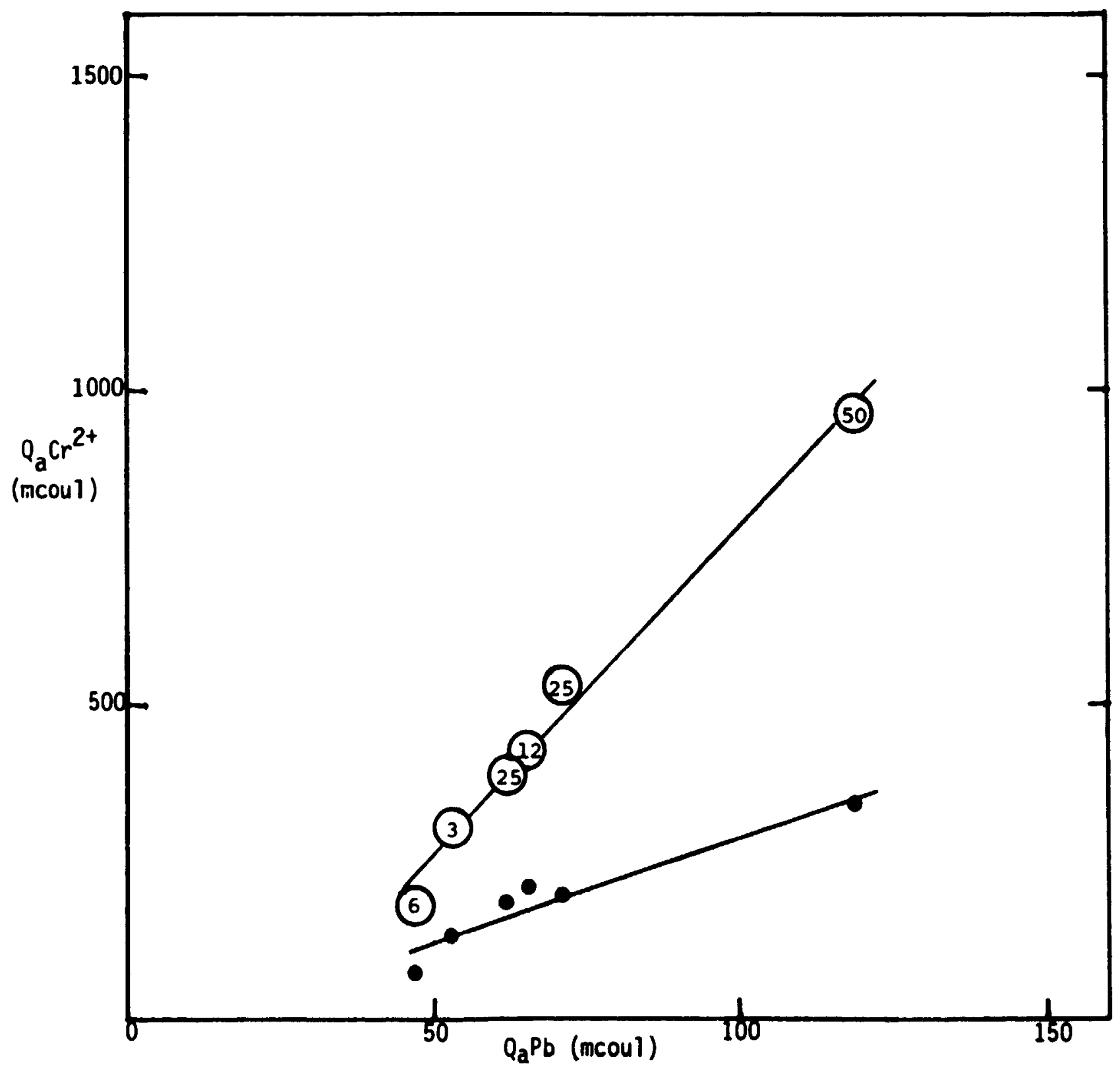

Figure 50. $\mathrm{Cr}^{2+}$ Oxidation Charge vs. Lead Loading for $1 / 8$ in. Thick Graphite Felt (FMII-G-1/8). 


\section{Linear Regression Analysis:}

Corr. $Q_{a} P b: Q_{a} C r^{2+}\left\{\begin{array}{l}\text { Total: } 0.881 \\ \text { Peak: 0.887 } \\ \text { Trailing: } 0.869\end{array}\right.$
ORIGINAL $P: 3$

OF POOR QUALITY

(n) $Q_{a} C r^{2+}$ Total; $n=$ Gold Loading $\left(\mu \mathrm{g} / \mathrm{cm}^{2}\right)$

- $Q_{a} C r^{2+}$ Trailing

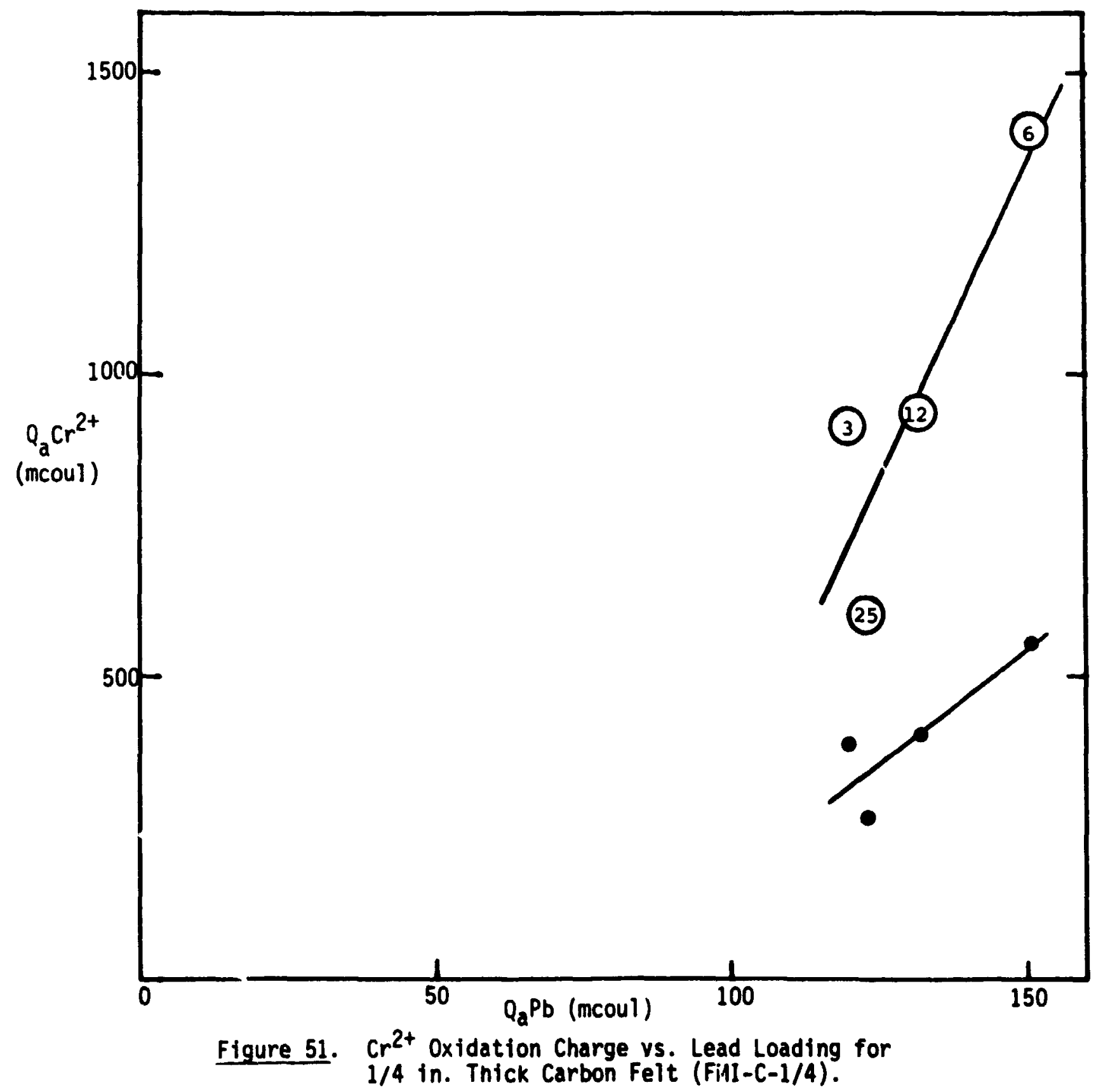




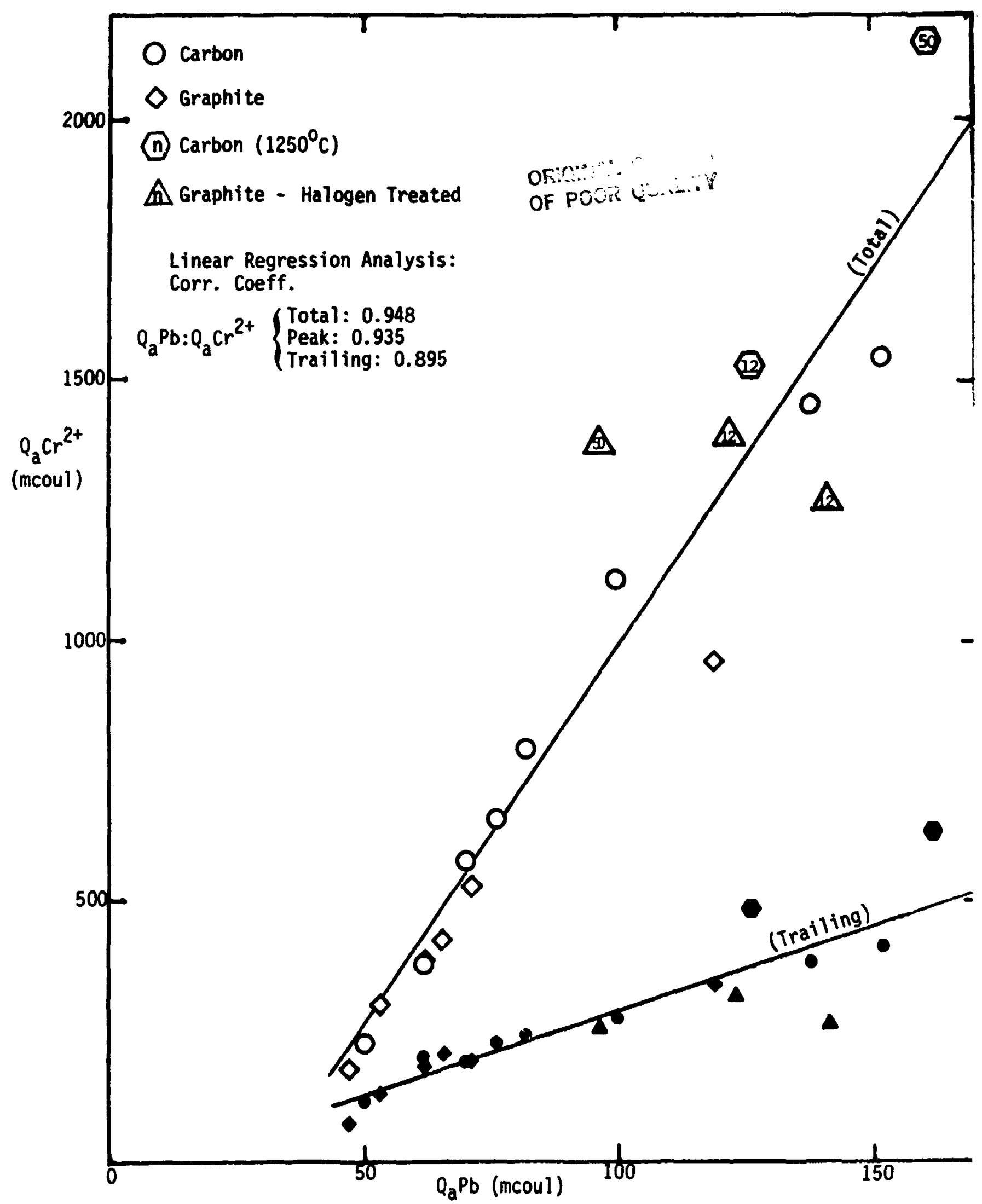

Figure 52. $\mathrm{Cr}^{2+}$ Oxidation Charge vs. Lead Loading for All $1 / 8$ in Thick Felts. 


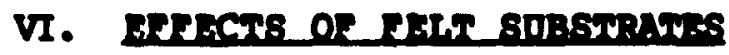

ORIG!Y?: , ';

OF PCON QuititY

By the end of the program, a suffictent range of electrode typas had been teated so that results were avallable for $1 / 8$ inch thick folto processed at four different temperatures, all of which were catalyzed ing the same procedure at a comion gold loading of $12.5 \mathrm{ig} / \mathrm{cm}^{2}$. There was, In addition, the special graphite felt designated "halogen-treated". The samples and lot numbers are listed below (see section II for Section II for additional information): TABLE XIV. Belt Processing Temperature Yardation Tnited.

\begin{tabular}{llcccc}
\multicolumn{1}{c}{ I.D. Code } & Lot No. & & Proc. Temp. & No. of Tests & Data Tables \\
FMI-C-1/8 & N-091880 & & $1250^{\circ} \mathrm{C}$ & 1 & A-V/VI \\
FMI-C-1/8 & $G-071379$ & $21500^{\circ} \mathrm{C}$ & 2 & A-I/IV \\
FMI-C-1/8 & N-122380 & $1630^{\circ} \mathrm{C}$ & 2 & A-VIII/VI \\
FMI-G-1/8 & $G-122779$ & $2300^{\circ} \mathrm{C}$ & 1 & A-II/IV \\
ULC/FMI-G-1/8 & N-0280 & $2300^{\circ} \mathrm{C}$ (H.T.) & 2 & A-V/VI
\end{tabular}

The series of samples is obviously not systematic or completes data from only one test is avallable for two of the samples, and the processing temperatuxe for Lot G-071379 could not be accurate 1 y estab! Ished $\left(1500^{\circ} \mathrm{C}\right)$. Nonetheless the data w11l serve the purpose for a preliminary analysis. A more systematic and comprehensive Investigation is planned for the follow-on program.

The relevant charge data from curve segment integrations have been collected in Table $A-V I$ in the Appendix for all the test samples at the $12.5 \mathrm{~g} / \mathrm{cm}^{2}$ gold loading. In addition to the usual points $\mathrm{l}_{\mathrm{a}} \mathrm{Pb}$ representing lead loading and $\mathrm{O}_{2} \mathrm{Cr}^{2+}$ representing $\mathrm{Cr}^{3+} / \mathrm{Cr}^{2+}$ 
redox activity), an additional charge segment was derived, $\mathrm{Q}_{\mathrm{c}} \mathrm{B}^{+}$, the charge corresponding to $\mathrm{B}^{+}$reduction (hydrogen evolution). This was calculated by integrating the entire cathodic segment of the $\mathrm{PbCl}_{2} / \mathrm{HCl}$ voltammogram (e.g. Figure 20) and deducting the ancdic charge for lead oxidation $\left(\mathrm{Q}_{\mathrm{a}} \mathrm{Pb}\right)$ on the assumption that:

$$
\mathrm{O}_{\mathrm{a}} \mathrm{Pb}^{2+} \text { (deposition) }=\mathrm{Q}_{\mathrm{a}} \mathrm{Pb} \text { (dissolution) }
$$

The charge equivalent to hydrogen evolution then is:

$$
\mathrm{C}_{\mathrm{c}}\left(\mathrm{Pb}^{2+}, \mathrm{H}^{+}\right)-\mathrm{Q}_{\mathrm{a}} \mathrm{Pb}=\mathrm{O}_{\mathrm{C}^{+}} \text {. }
$$

This is illustrated in the representative voltammogram shown earlier in Figure 22. It should be noted that $Q_{c} \mathrm{H}^{+}$, unlike the other charge segments is a relative value that seems to be characteristic of an electrode but is dependent on sweep rate as mentioned in Section IV-D (i.e. current is independent of sweep rate.)

The charge data for hydrogen evolution in $1 \mathrm{mM} \mathrm{PbCl} / 1 \mathrm{~N} \mathrm{HCl}$ is shown versus felt processing temperature in Figure 53. It can be seen that there is a rapid decline in the rate of hydrogen evolution with increasing processing temperature; this is particularly noticeable for the $1250^{\circ} \mathrm{C}$ felt. This phenomenon appears to be an indirect effect of the felt, i.e., the effect is expressed after gold activation; the bare felts do not give a clear indication of a trend, as shown in the values for $\mathrm{H}^{+}$reduction in $1 \mathrm{mM} \mathrm{PbCl}_{2} / 1 \mathrm{~N} \mathrm{HCl}$ at $-950 \mathrm{mV}$ vs SCE, below:

$$
\begin{array}{lcccc}
\text { Felt Proc. Temp }\left({ }^{\circ} \mathrm{C}\right) & 1250 & 1500 & 1630 & 2300 \\
\mathrm{I}_{\mathrm{c}} \mathrm{H}^{+} \text {(mA) } & 1.3 & 0.6-0.8 & 1.0-1.5 & 1.0
\end{array}
$$

This may suggest an influence of the felt on gold particle size, fo: example. 
The $\mathrm{Cr}^{3+} / \mathrm{Cr}^{2+}$ redox activity is displayed in Figure 54 as $\mathrm{Q}_{\mathrm{a}} \mathrm{Cr}^{2+}$ versus felt processing temperature. It can be seen that the $\mathrm{Cr}^{3+} / \mathrm{Cr}^{2+}$ recox activity also declines with increasing felt processing temperature. If these values were analyzed alone, the $1250^{\circ} \mathrm{C}$ felt would seem to be the most favolable. However, if the corresponding hydrogen evolution rates re considered, as the ratio $\mathrm{Q}_{\mathrm{a}} \mathrm{Cr}^{2+}$ Tot. $/ \mathrm{Q}_{\mathrm{a}} \mathrm{B}^{+}$versus felt processing temperature (Figure 55), it can be seen that the $1250^{\circ} \mathrm{C}$ felt electrode was the least efficient and $1630^{\circ} \mathrm{C}$ felt electrode was the most efficient, in terms of the negative electrode charging reaction.

ine charge data points collected for the two "halogen-treated" graphite felts are listed in the last column of Table A-VI in the Appendix. Both of the electrodes tested exhibited very high $\mathrm{Cr}^{3+} / \mathrm{Cr}^{2+}$ redox activity $\left(\mathrm{O}_{\mathrm{a}} \mathrm{Cr}^{2+}\right.$ Total $=1263$ and $\left.1394 \mathrm{mcoul}\right)$ but gave mixed results on hydrogen evolution rate $1 \mathrm{Q}_{\mathrm{a}} \mathrm{H}^{+}=516$ and $119 \mathrm{mcoul})$. The material was closer in performance to the $1250^{\circ} \mathrm{C}$ carbon felt than the untreated graphite felt. Charging "efficiency" values $r=2.45$ and 11.7 were calculated. An electrode with a gold loading of $50 \mathrm{~kg} / \mathrm{cm}^{2}$ also showed a high rate of hydrogen evolution, particularly in the presence of $\mathrm{Cr}^{3+}$. Based on these results, the "halogen treated" felt does not appear promising.

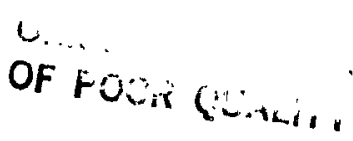




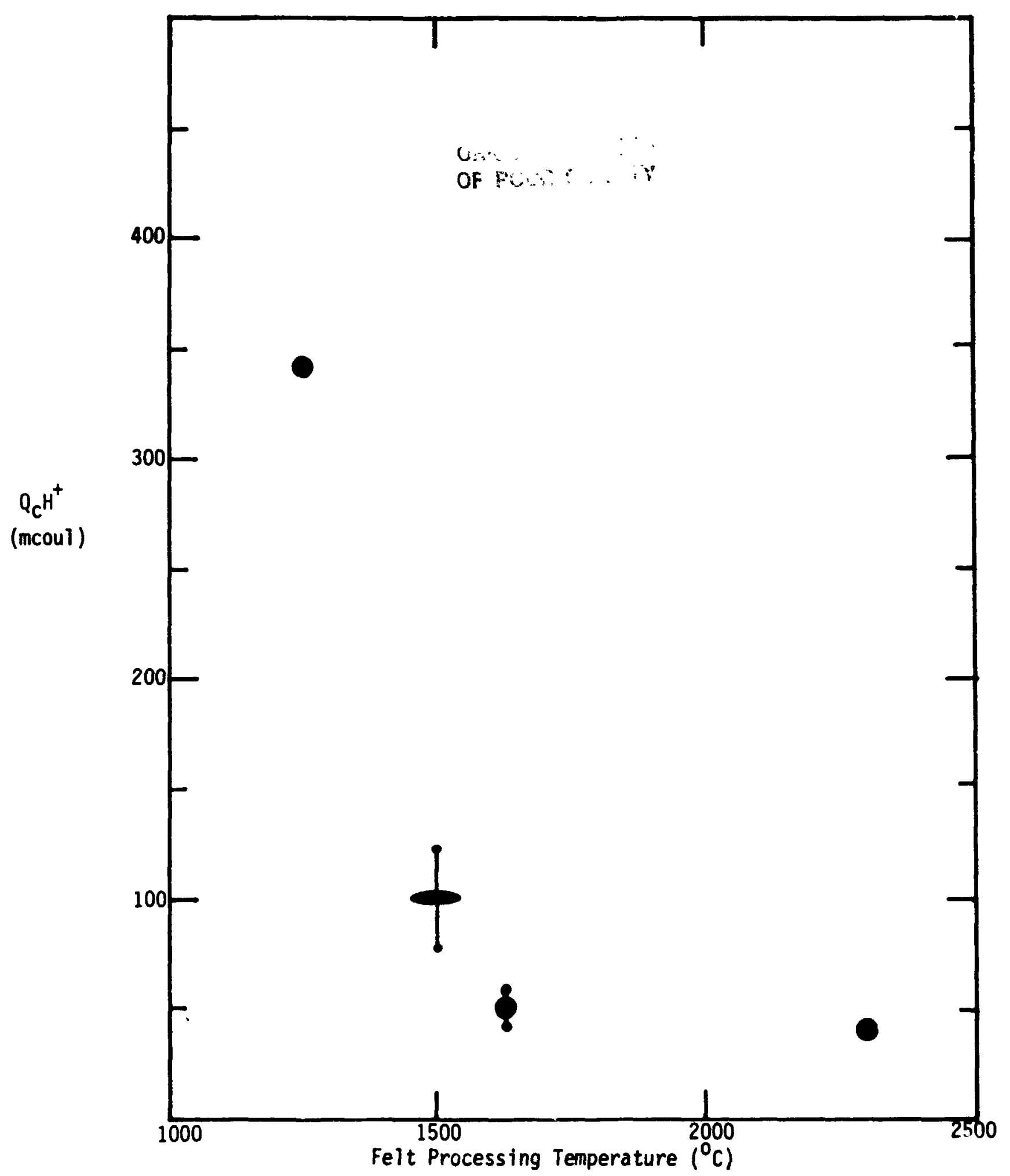

Figure 53. Hydrogen Evolution "Charge" $\left(\mathrm{Q}_{\mathrm{C}} \mathrm{H}^{+}\right)$vs.

Felt Processing Temperature (12.5ug Au/ $\mathrm{cm}^{2}$ ). 
ORI: - :

OF POUit Q a.....is

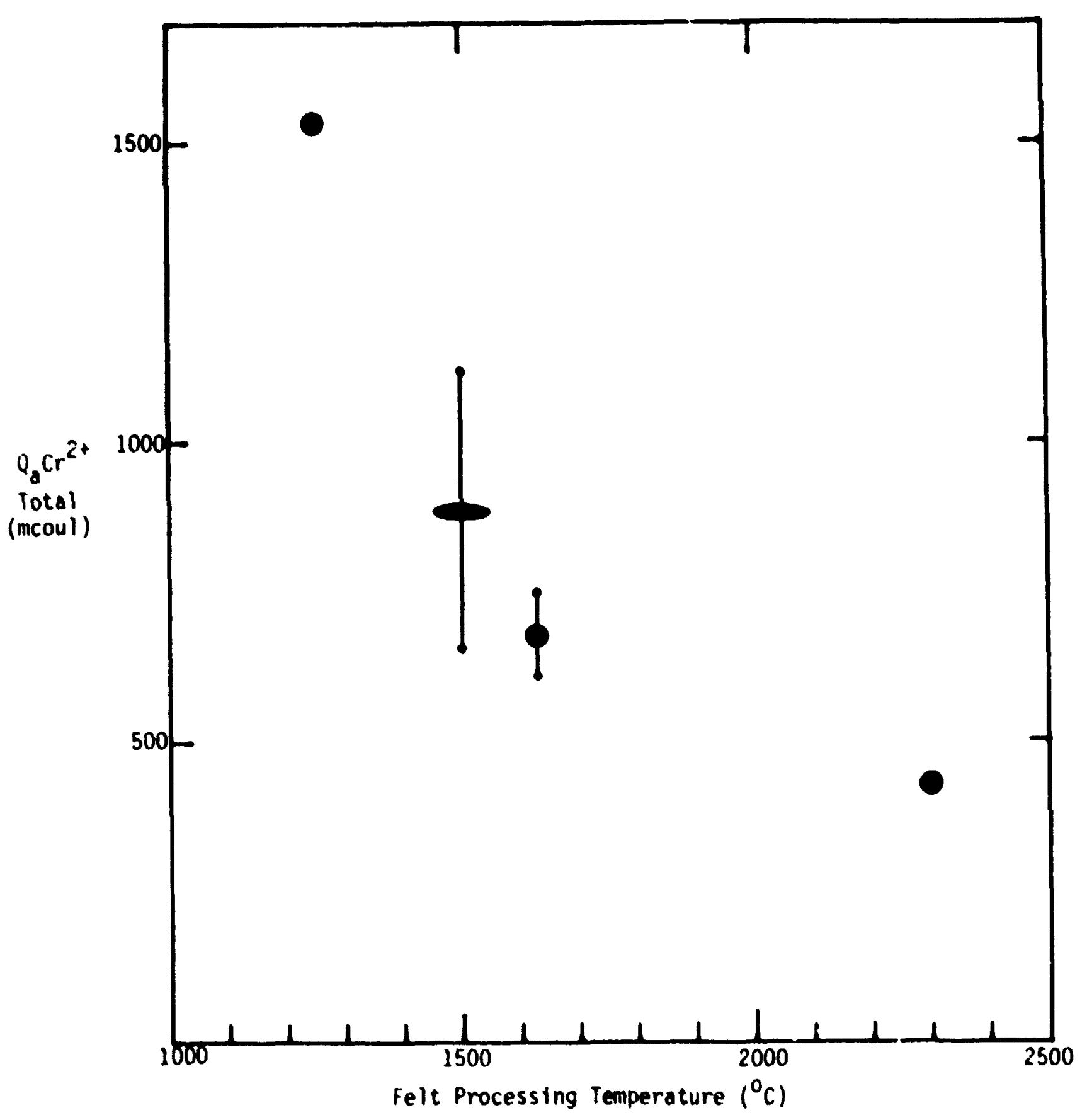

Figure 54. $\mathrm{Cr}^{3+} / \mathrm{Cr}^{2+}$ Redox Activity (as $\mathrm{Q}_{\mathrm{C}} \mathrm{Cr}^{2+}$ ) versys

felt Processing Temperature (12.5ug Au/cm²).

$-109-$ 
Uhin... - .....:S S

OF FOOR QUAL!TY

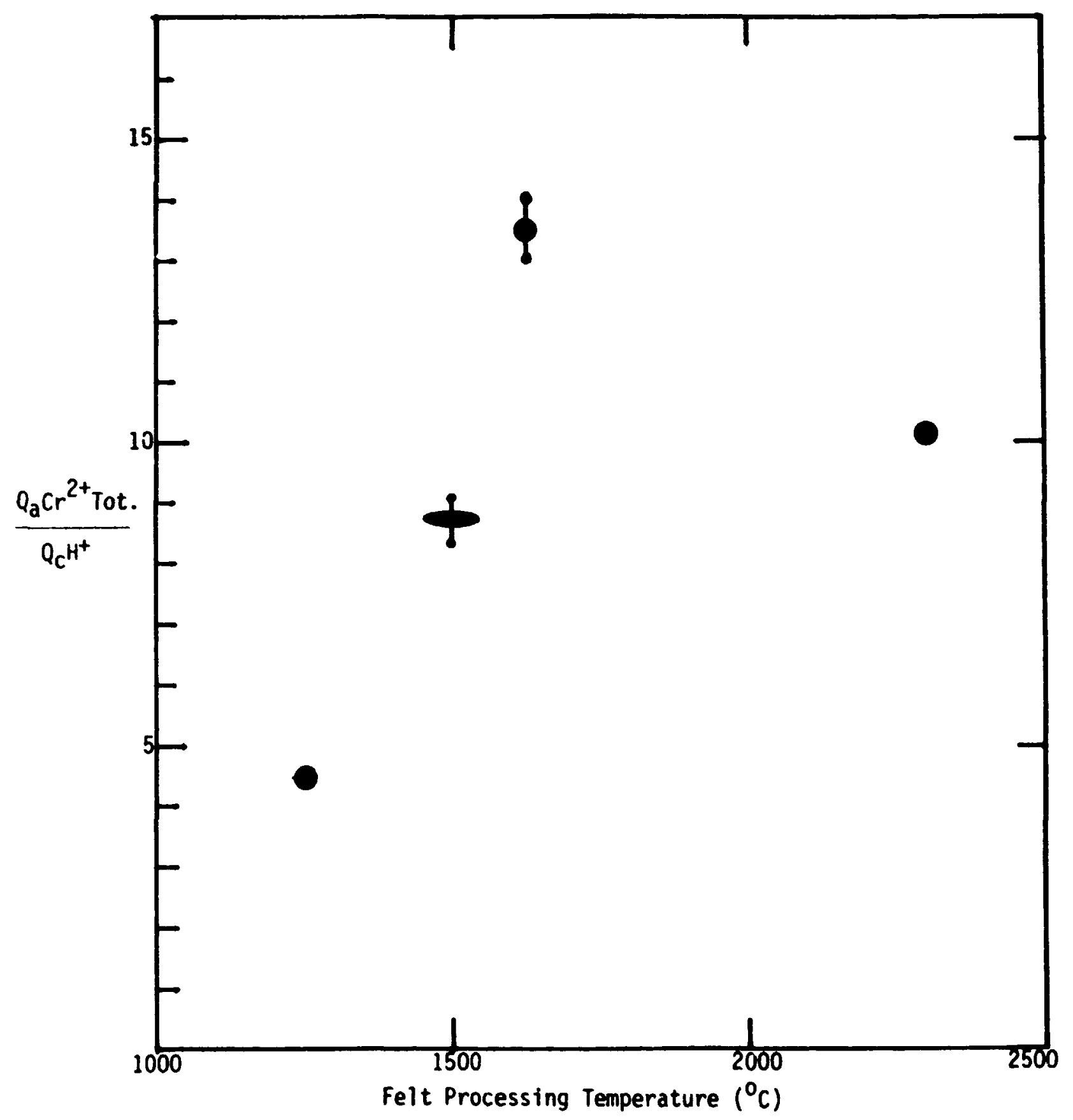

Figure 55. Negative Electrode Charging Efficiency

$\left(Q_{a} C r^{2+}\right.$ Total $\left./ Q_{c} H^{+}\right)$vs. Felt Processing Temperature. 


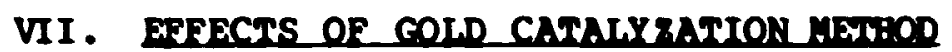

Most of the testing done on this program was performed on electrodes activated by the aqueous/methanol gold process in which the solution was applied to the surface in a dropwise manner. As discussed in Section III, several variations were also examined. These were an aqueous/vacuum fill method, wo alcohol solution inmersion processes, and substitution of acetone for alcohol as the co-solvent/wetting agent. This was intended to be an exploratory investigation rather than a comprehensive study; the primary objective was to coupare the dropwise-alcohol method to catalyration methods deened mechanically more appropriate for preparation of large electrodes specifically as deliverable items on this program. The physica. itructures obtained were discussed in Section III, the electrochemical performance measured is discussed below.

\section{A. Aqueous/Vacuum Process.}

Two sets of electrodes were prepared at four gold liddings (approximately $3,6,12.5$ and $25 \mu \mathrm{g} / \mathrm{cm}^{2}$ ), one set by the aqueous/vacuum process described in Sectic'l III, and one set by the dropwise aqueous/methanol process. These tests were done prior to the introduction of the waxed-clip electrode holder; consequently the tantalum wire holder was used and the electrode dimension was $0.8 \mathrm{~cm}$ diameter $\left(0.5 \mathrm{~cm}^{2}\right)$ rather than $1.3 \times 1.5 \mathrm{~cm}\left(2 \mathrm{~cm}^{2}\right)$ for the waxed-clip holder. The usual current data points were selected from the voltammograms for both sets of electrodes. These are presented in Table A-VII in the Appendix. 
The results appear to be quite similar for both electrode sets with ane exception; the hydrogen evolution rate on gold-on-carbon in BCl be . ore the addition of lead chloride as measured by the current at -950 $a^{\prime \prime}$ versus SCE $\left(I_{c} B^{+}\right)$. The $I_{c} B^{+}$values for the aqueous/vacuum type electrodes were fairly invariant compared to a steady increase with increasing gold loading for the aqueous/methanol type electrodes. The same relative pattern appeared to hold after the addition of lead c lorice (i.e. $\mathrm{I}_{\mathrm{c}} \mathrm{B}^{\top}$ on $\mathrm{Pb} / \mathrm{Au}$ ). This is not an undesirable feature b'it it was thought to suggest a low gold surface area in the case of the aqueous/vacuum type electrodes. As discussed in Section III, this was ficund to be the case when one of the electrodes was examined by transmission electron microscopy. Very large gold particles were found near the surface on one side of the electrode with little evidence of gold on the other side. For these reasons, the aqueous/vacuum process for gold deposition was rejected.

\section{B. Met2anol-Based Processes}

For comparison of the methanol-based processes, Dropwise and Inmersion I and II (see Section III), several electrodes were prepared from one it of $1 / 8$ inch thick carbon felt designated by NASA-LeRC as the substrate of choice for deliverable electrodes ( Lot $\mathrm{N}-122380$; $\left.1630^{\circ} \mathrm{C}\right)$. A control electrode was also prepared by processing a sample of felt in a blank (no gold chloride) methanol solution. The current cia:. points are summarized in Table A-VIII and the charge data points are summarized in Table A-IX in the Appendix.

The level of $\mathrm{Cr}^{3+} / \mathrm{Cr}^{2+}$ redox activity, as $\mathrm{Q}_{\mathrm{a}} \mathrm{Cr}^{2+}$, is plot.ted versus the lead loading, as $Q_{a} \mathrm{~Pb}$, in Figure 56. The data pints for three electrodes tested previously, having the same 12.5 


\section{ORIGINIA PREE IS \\ OF POOR QUALITY}

$\mathrm{ug} / \mathrm{cm}^{2}$ gold loading but fry a different lot of felt, are shown in the same figure. In addition, the line of beat fit for all previous teat data from igure 52 is also shown. It can be seen that the $\mathrm{Cr}^{3+} / \mathrm{Cr}^{2+}$ redox activity is an approxinate function of lead loading, with $Q_{a}$ Pb probably reflecting gold surface area (as discussed in section $v$, and there is reasonably good agreewent with previous data. An exception is one of the electrodes catalyzed by the Double Immersion-I process, which deviates on the high side. The control felt, processed in blank solution, does not show any unusual activity, but may fit the curve better than previous data for bare felt.

values for the cathodic curve segment associated with $\mathrm{B}^{+}$ reduction, $\mathrm{O}_{\mathrm{c}} \mathrm{B}^{+}$(see Figure 22), were also derived for these electrodes. These values and the negative electrode charging efficiencies, $O_{a} \mathrm{Cr}^{2+} \mathrm{Tot}_{\mathrm{C}} / \mathrm{Q}_{\mathrm{c}} \mathrm{H}^{+}$, are presented in Table XV below ("efficiencies" are relative values, as noted earlier):

Table XV. Charaing sfficiencies ys. Catalyzation vethod.

$\begin{array}{lcr}\text { Catalyzation Method } & \begin{array}{c}\mathrm{Q}_{\mathrm{C}} \mathrm{H}^{+} \\ \text {(mCoul) }\end{array} & \begin{array}{r}\mathrm{Q}_{\mathrm{a}} \mathrm{Cr}^{2+} / \mathrm{m}^{2+} \\ \text { (mC } \mathrm{Cr}^{2+} / \mathrm{mC}\end{array} \\ \text { Dropwise } & 56 & \begin{array}{r}13.3 \\ 13.5\end{array} \\ \text { Double Imm. - I } & 45 & 7.2 \\ & 45 & 21.7 \\ \text { Double Imm. - II } & 39 & 10.5 \\ & 52 & 16.5\end{array}$

These results did not show a clear blas for or against the use of either of the immersion methods compared to the dropwise method. The second method was selected for preparation of the deliverable 
electrodes. Subsequently, when the electron microscopy results were received, it was observed that the first process (Double Immersion-I, sample 2) appeared to give smaller more uniform gold particles (see Section III-B) and thus might have been a better choice.

Two electrodes were made by substituting acetone for alcohol in the aqueous/methanol dropwise process, one at $12.5 \mathrm{Hg} g 01 \mathrm{~d} / \mathrm{cm}^{2}$ and one at $50 \mu \mathrm{g} / \mathrm{cm}^{2}$. The gold particle sizes exhibited at the $12.5 \mu \mathrm{g} / \mathrm{cm}^{2}$ loading were uniformly quite large and widely spaced, as discussed in Section III-C (Figures 14 and 15). The electrochemical performance was also somewhat lower than for the methanol processes, in terms of $\mathrm{C}_{\mathrm{a}} \mathrm{Cr}^{2+}$ total versus $\mathrm{Q}_{\mathrm{a}} \mathrm{Pb}$ for example, but not significantly different. The test results are presented in Tables A-VIII and A-IX in the Appendix. The data, from a general perspective, is too limited to draw a conclusion about the use of acetone versus methanol. 
Oropwise Aq. $/ \mathrm{CH}_{3} \mathrm{OH}$, Previous Tests (Lot G071379)

Dropwise Aq. $/ \mathrm{CH}_{3} \mathrm{OH}$, Lot $\mathrm{N}-122380$

Double Immersion-I, Lot $\mathrm{N}-122380$

Double Immersion-1I, Lot N-122380

- - Line of Best Fit for all Previous Tests (Figure 52)

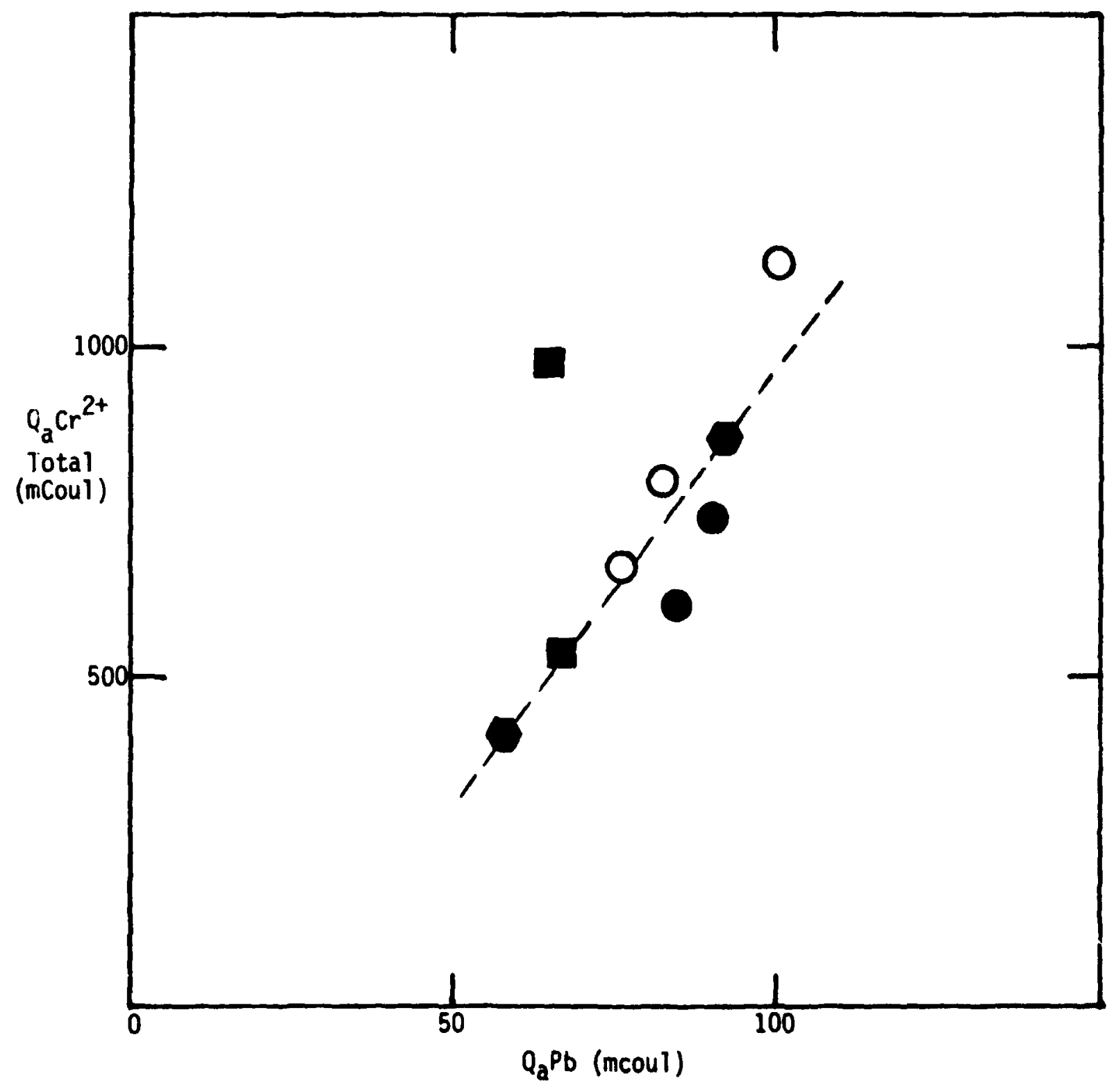

Figure 56. Effects of Catalyzation Method; $\mathrm{Cr}^{2+}$ Oxidation Charge vs. Lead Loading 


\section{EFEFCTS OF VARIATIONS IN TEST PROCEDURES}

Several experiments involving variations in the usual testing procedure were conducted to investigate certain features of the $\mathrm{Cr}^{3+} / \mathrm{Cr}^{2+}$ redox reactions. Two of these were simple alterations carried out during regular testing. The object of the first experiment was to determine the effect of a slower sweep rate on the shape of the anodic portion of the voltammogram. This was accomplished in the $50 \mathrm{~mm}$ $\mathrm{CrCl}_{3}$ after testing one of the felt electrodes by first recording a complete cycle at the usual rate, followed by half of a second cycle. As the current passed into the anodic region, the sweep rate was reduced from the usual $10 \mathrm{mV} / \mathrm{s}$ to $1 \mathrm{mV} / \mathrm{s}$. Attenuation was simultaneously reduced by a factor of ten to compersate for the change. The results were recorded until the completion of the second cycle.

As can be seen in Figure 57, the leading side of the anodic peak at $1 \mathrm{mV} / \mathrm{s}$ duplicates that at $10 \mathrm{mV} / \mathrm{s}$. Thereafter, the traces differ. At $1 \mathrm{mV} / \mathrm{s}$, lead oxidation is apparent as a sharp separate peak in its normal location at $-500 \mathrm{mV}$ vs. SCE but comparatively well separated from the major $\mathrm{Cr}^{2+}$ oxidation peak. The "trailing" $\mathrm{Cr}^{2+}$ anodic current, on the other hand, is considerably diminished from that exhibited at $10 \mathrm{mV} / \mathrm{s}$. The effect is a shift of $\mathrm{Cr}^{2+}$ oxidation out of the "trailing" and into the "peak" region, suggesting that there may be some diffusion limitations at the $10 \mathrm{mV} / \mathrm{s}$ scan rate.

In the second experiment, the results obtained by testing an electrode in the usual sequence of solutions were compared to the performance of a similar electrode tested directly in the solution of final composition. After normal testing of one of the electrodes was completed, a second electrode, cut from an adjacent area of the same 
finished felt, was mounted, waxed, and substituted for the original electrooe in the test cell. The fresh felt electrode was saturated with the solution of final composition (50 $\mathrm{mM} \mathrm{Cr}{ }^{3+}, 1 \mathrm{~mm} \mathrm{PbCl}_{2}, 1 \mathrm{NCl}$ ) by repeated evacuation of the cell in a vacuum desiccator. After the cell had been stirred and purged with nitrogen for twenty minutes, cyclic voltametry was conducted according to established procedure.

It is apparent from the composite in Figure 58 that there are both qualitative and quantitative differences. The cathodic peak for the second electrode is smaller; the anodic peak is also smaller and occurs at a slightly lower potential. There is a pronounced step in the trailing side of the $\mathrm{Cr}^{2+}$ oxidation peak, and the "trailing" peaks thereafter are shifted and diminished. Even though the two electrodes are from an adjacent area of the same gold-activated felt, they might still show some differences; however, it seems quite likely that there are some differences attributable to the test method also. Further investigation, perhaps with extended cycling, would be necessary to clarify this matter.

The third experiment was designed to determine how testing in a bulk solution of chromous, as opposed to chromic, ions would affect various features of the voltammogram, particularly the "trailing" anodic region. A felt eiectrode was first mounted, waxed, and tested by cyclic voltammetry as usual in the $1 \mathrm{~N} \mathrm{BCl}$ and $1 \mathrm{mM} \mathrm{PbCl} / 2 / \mathrm{N} \mathrm{BCl}$ solutions. A solution of $50 \mathrm{mM} \mathrm{CrCl}$ was then prepared in a second test cell by adding the appropriate quantity of distilled chromium metal granules to $50 \mathrm{ml}$ of $1 \mathrm{~mm} \mathrm{PbCl}_{2}$ in $1.1 \mathrm{~N} \mathrm{HCl}$ (It was not possible to generate chromous chloride in situ because the heat necessary to initiate the reaction would have been sufficient to melt the electrode mounting 
wax.). Air was excluded by vigorous bubbling of nitrogen at all times. The cell was equipped with a magnetic stirring bar and heated in a water bath to $90^{\circ} \mathrm{C}$, at which point the chromium metal began to react. The temperature was maintained until dissolution of the chromium was complete (about 1 hour), whereupon the cell was allowed to cool slowly to room temperature.

The test electrode was transferred to the $\mathrm{Cr}^{2+}$ solution by quickly unscrewing the cell bottoms and exchanging covers, a matter of no more than a few seconds. Unfortunately, the solution was observed to darken noticeably from its original pale azure peculiar to chromous ion to a darker blue/blue-green within minutes suggesting partial oxidation. Cyclic voltammetry in the resulting approximate $50 \mathrm{mM} \mathrm{CrCl}{ }_{2}$ solution was conducted in the usual manner, under nitrogen. The resulting voltammogram, shown as a composite in Figure 59, was approximately as expected except that the $\mathrm{Cr}^{3+}$ reduction current was unexpectedly small. Interpretation is difficult because of the undetermined quantity of chromous ion that was oxidized by air during handling. However, it appears that most of the $\mathrm{Cr}^{2+}$ oxidation occurs after lead dissolution, on the gold surface ("trailing" region). 


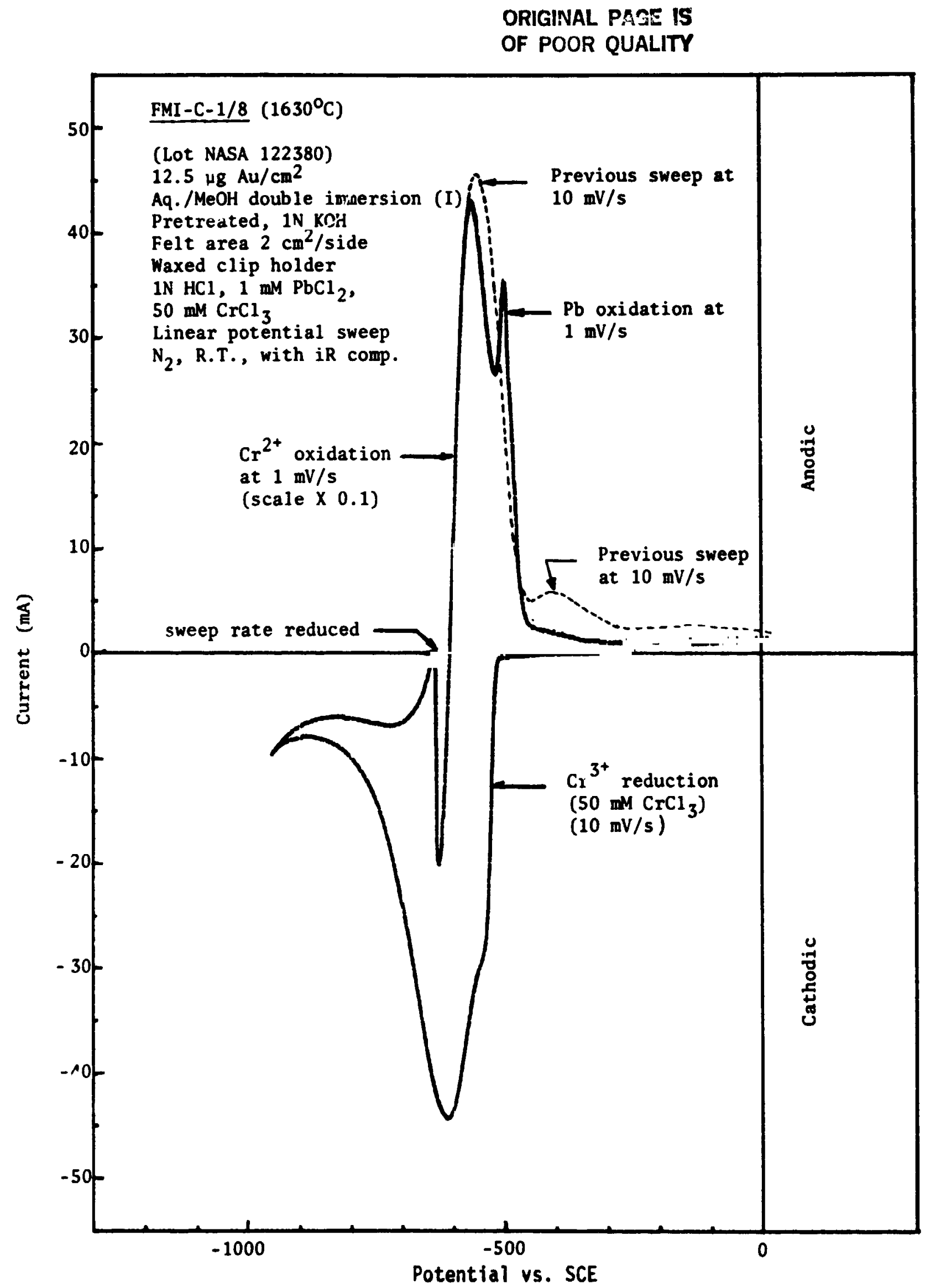

Figure 57. Effect of Change in Sweep Rate on Oxidation of $\mathrm{Cr}^{2+}$. 


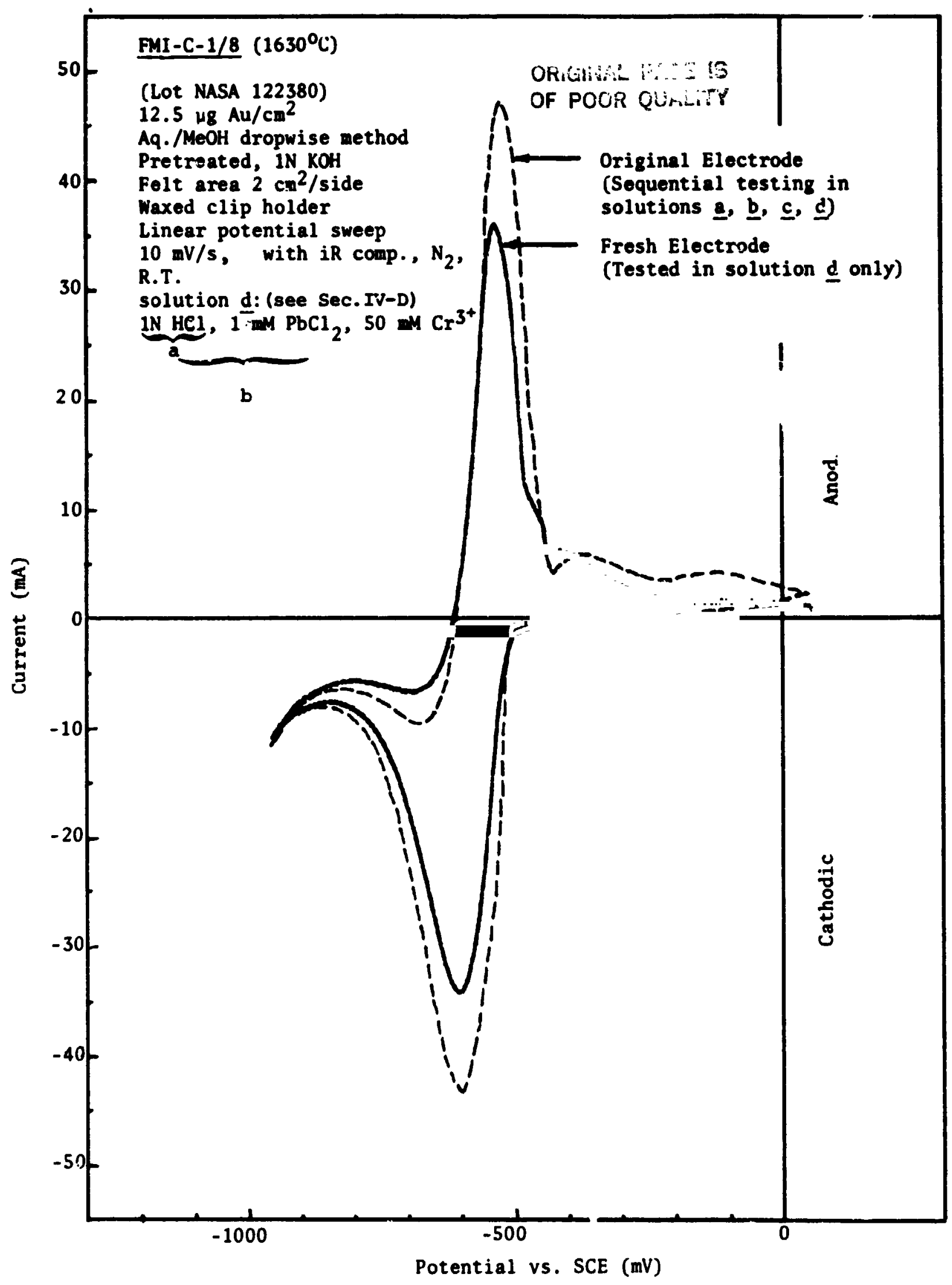

Figure 58. Sequential-Solution Voltarmograms vs. "Complete"-Solution Voltarmograms for Adjacent Electrode Samples. 


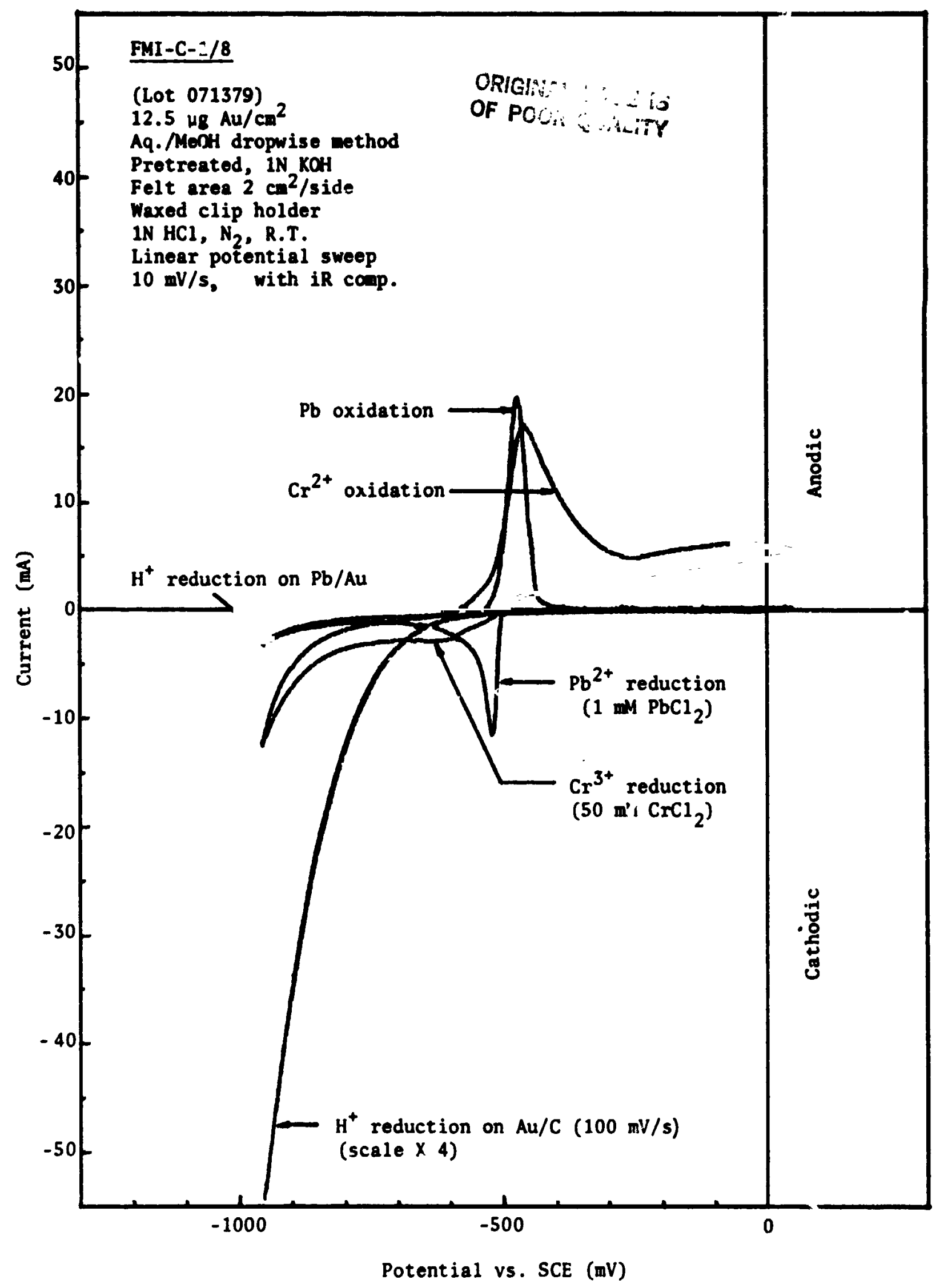

Figure 59. Electrochemical Performance of Carbon Felt Electrode in 250 m/H Chromous Chloride Solution (concentration less than $50 \mathrm{~mm}$ due to air oxidation in handing). 


\section{ALTERNATIVE CATALYST SYSTEYS}

In addition to the gold/lead catalyst system, which was investigated extensively in this program, three other catalyst systems were investigated in an exploratory manner to determine the feasibility of pursuing a more thorough study of any of these candidate systems. These were: gold/bismuth, silver/bismuth and silver/lead. The combinations sesected were based on rotating disk electrode screening studies performed by Giner, Inc. on an earlier program (4).

\section{A. Procedures}

Carbon felt from Lot G-07137؟ (FMI-C-1/8, $1500^{\circ} \mathrm{C}$ ) was used as the substrate for all of these tests, to be consistent with the bulk of the test data collected on the gold/lead system. The substrates were pretreated in $1 \mathrm{~N} \mathrm{KOH}$ in the usual manner prior to catalyzation. For gold sysi:ems. the gold was deposited by the typical method, i.e., dropwise saturation with a gcld chloride aqueous/methanol solution followed by thermal decomposition at $260^{\circ} \mathrm{C}$ (see section III-B). For silver systems, in which silver is the functional analog of gold, the silver was deposited by dropwise saturation with an aqueous/methanol solution substituting silver nitrate for the goid chloride. Thermal decomposition was carried out in a vacuum desiccator at $80^{\circ} \mathrm{C}$ and 150 Torr. Inadings of both 12.5 and $50 \mu \mathrm{g} / \mathrm{cm}^{2}$ were prepared in each case.

The testing was generally performed according to the routine establishei for this program, i.e., ..-1tammograms were recorded sequentially in the following solutions: a! $1 \mathrm{~N} \cdots$, b) $1 \mathrm{~N} \mathrm{HCl}$ with 


\section{ORIGIN.AL PAGE IS \\ OF POOR QUALITY}

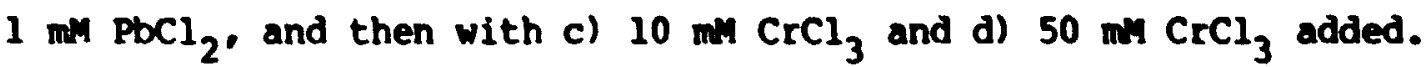
For the bismuth systems, in which bismuth is the analog of lead, $1 \mathrm{mH}$ $\mathrm{BiCl}_{3}$ was substituted for the lead chloride.

\section{B. Besults}

\section{Gold/Bismuth}

The voltannograms for the gold/bismuth system are presented in Figures 60-63. Figure 60 is a composite of the voltanmograms obtained sequentially in solutions $a, b$ and $c$ described immediately above. for the $12.5 \mu \mathrm{g} / \mathrm{cm}^{2}$ gold loading. Figure 61 displays the voltammograms obtained sequentially in $10 \mathrm{~mm}$ and $50 \mathrm{~mm} \mathrm{CrCl}_{3}$ with the same electrode. Figures 62 and 63 follow the sume pattern for the $50_{\mu} \mathrm{g}$ $\mathrm{Au} / \mathrm{cm}^{2}$ loading.

The $\mathrm{Bi}^{3+} / \mathrm{Bi}$ redox reaction occurs at $\sim-150 \mathrm{mV}$ v8. SCE. Since this is about $400 \mathrm{mV}$ less negative than the $\mathrm{Pb}^{2+} / \mathrm{Pb}$ reaction, it is potentially an advantage in that it is less likely that the bismuth will deplate during discharge. Hydrogen evolution is substantially suppressed by the bismuth but less effectively thain by lead. In the presence of $\mathrm{Cr}^{3+}$, the cathodic current minimum usually observed between the trailing side of $\mathrm{Cr}^{3+}$ reduction and the beginning of hydrogen evolution on lead is not observed with bismuth. Finally, the bismuth/gold system appears to be a less effective catalyst for $\mathrm{Cr}^{3+}$ reduction but somewhat better for $\mathrm{Cr}^{2+}$ oxidation. Note that the bismuth reaction is somcwhat suppressed in the presence of $\mathrm{Cr}^{3+}$. It 
would have been useful to examine a shorter oweep range in the presence of $\mathrm{Cr}^{3+}$ below the $\mathrm{Bi}^{3+} / \mathrm{BI}$ reaction also.

\section{Sulyer/Binguth}

The voltannograns for the silver/bismuth syoten are presented in Figures $64-68$ for silver loadings of 12.5 and $50, \mathrm{~g} / \mathrm{cm}^{2}$. The reactions occurring in IN $\mathrm{KCl}$ before the addition of bismuth chloride are shown in Figure 64. It can be seen that the silver catalyst dissolves and replates at about $0.0 \mathrm{~V}$ v8. SCE in hydrochloric acid. This is a considerable disadvantage compared to gold which is stable up to about $+750 \mathrm{mV}$ vs SCF. The overvoltage for hydrogen evolution, on the other hand, is higher on silver than on gold which would be of some advantage. After the addition of biamuth chloride the curves look very sinilar to those obtained for the gold/bismuth system. The silver/bismuth system may be a somewhat better catalyst for $\mathrm{Cr}^{3+}$ reduction than gold/bismuth, but this may be due primarily to the higher hydrogen overvoltage on silver. Again it would have been useful to examine shorter sweeps below the $\mathrm{Bi}^{3+} / \mathrm{Bi}$ riaction, but more particularly to avoid silver oxidation.

\section{Sulverlhead}

For the silver/lead system, a set of voltammograns was recorded using a sweep from $+50 \mathrm{mV}$ to $-950 \mathrm{mV}$ for both 12.5 and 50 $\mu \mathrm{g} / \mathrm{cm}^{2}$ silver loadings. An example of one of the composite voltammograms $\left(50 \mathrm{mM} \mathrm{CrCl}_{3}\right)$ is shown in Figure 69. In order to examine performance without oxidizing and replating the silver on each cycle, the sweep was reduced to $-150 \mathrm{mV}$ to $-950 \mathrm{mV}$. The resulting voltamograms with a second set of electrodes are shown in Figures 70-73. The usual selected 
current data pointe are prosented in Table $A-X$ for both ewec:? rangess

charge data pointe are presented in Table XI in the Appendix. The

allver/lead syotem looks very sinilar to the gold/lead oystem except that

hydrogen evolution rates may be a little lower. 


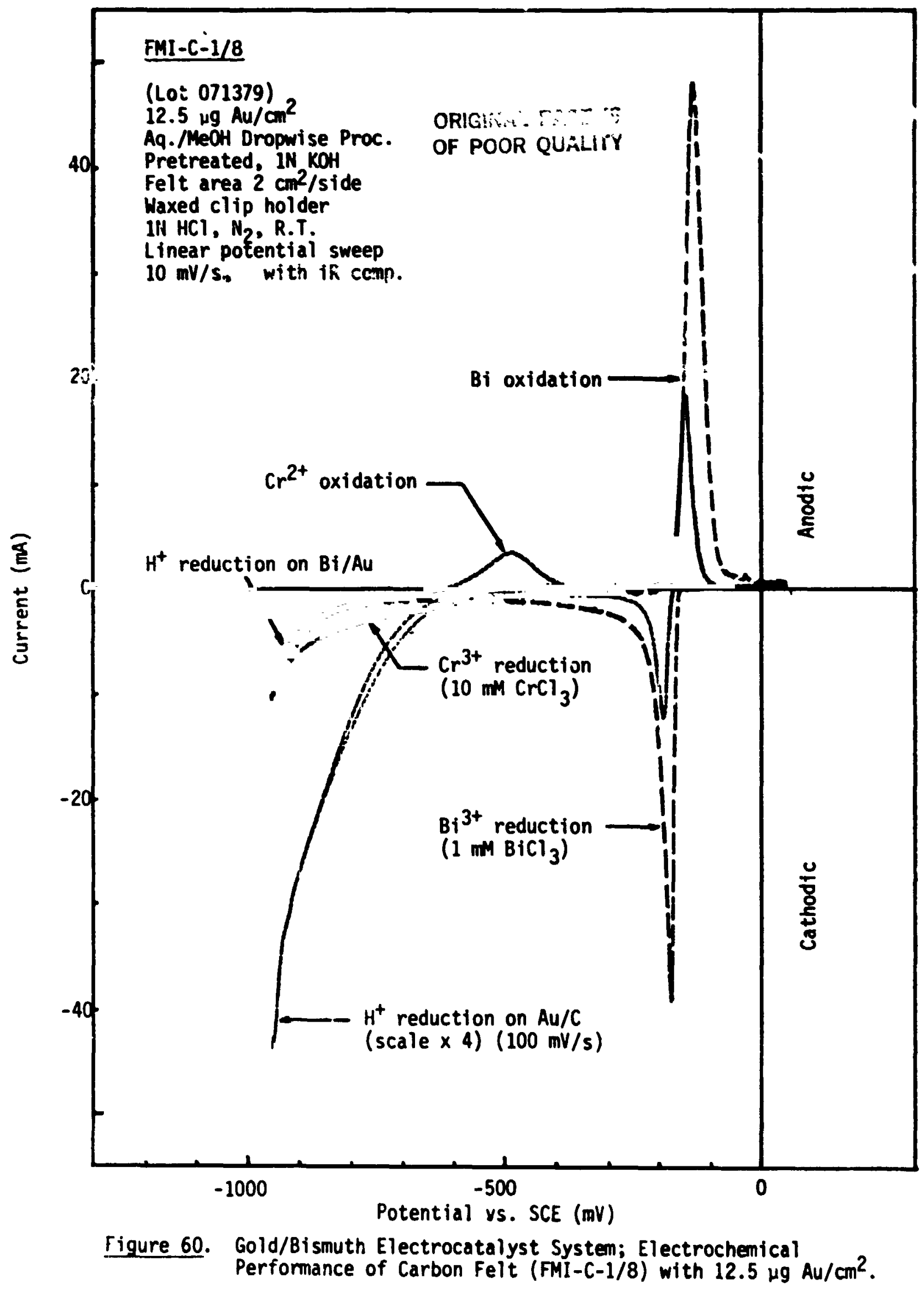




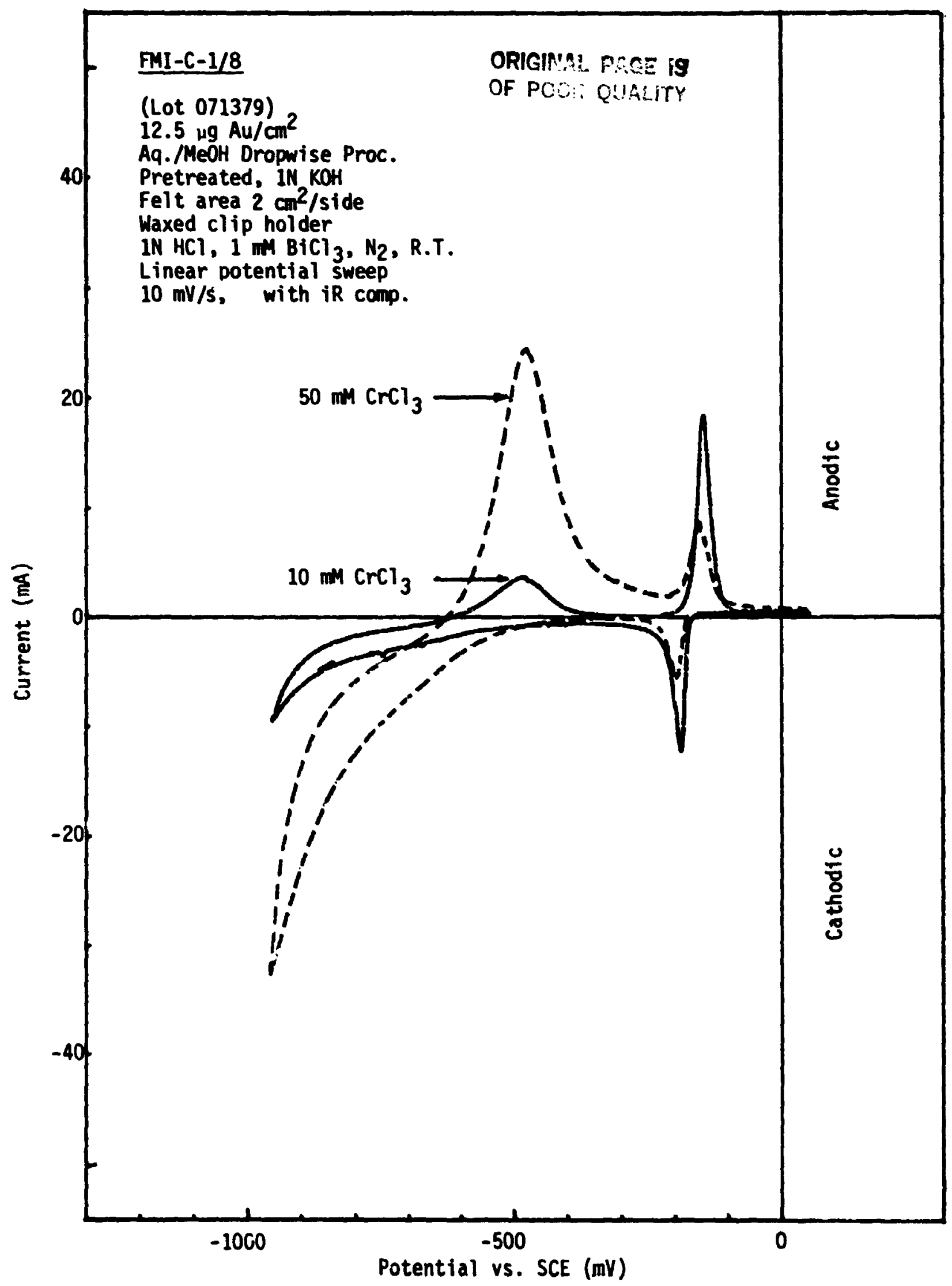

Figure 61. $10 \mathrm{mM}$ vs. $50 \mathrm{~mm} \mathrm{CrCl} 3$ in $1 \mathrm{mM} \mathrm{BtCl} 3$ on Carbon Felt (FMI-C-1/8) with $12.5 \mu \mathrm{gu} / \mathrm{cm}^{2}$. 


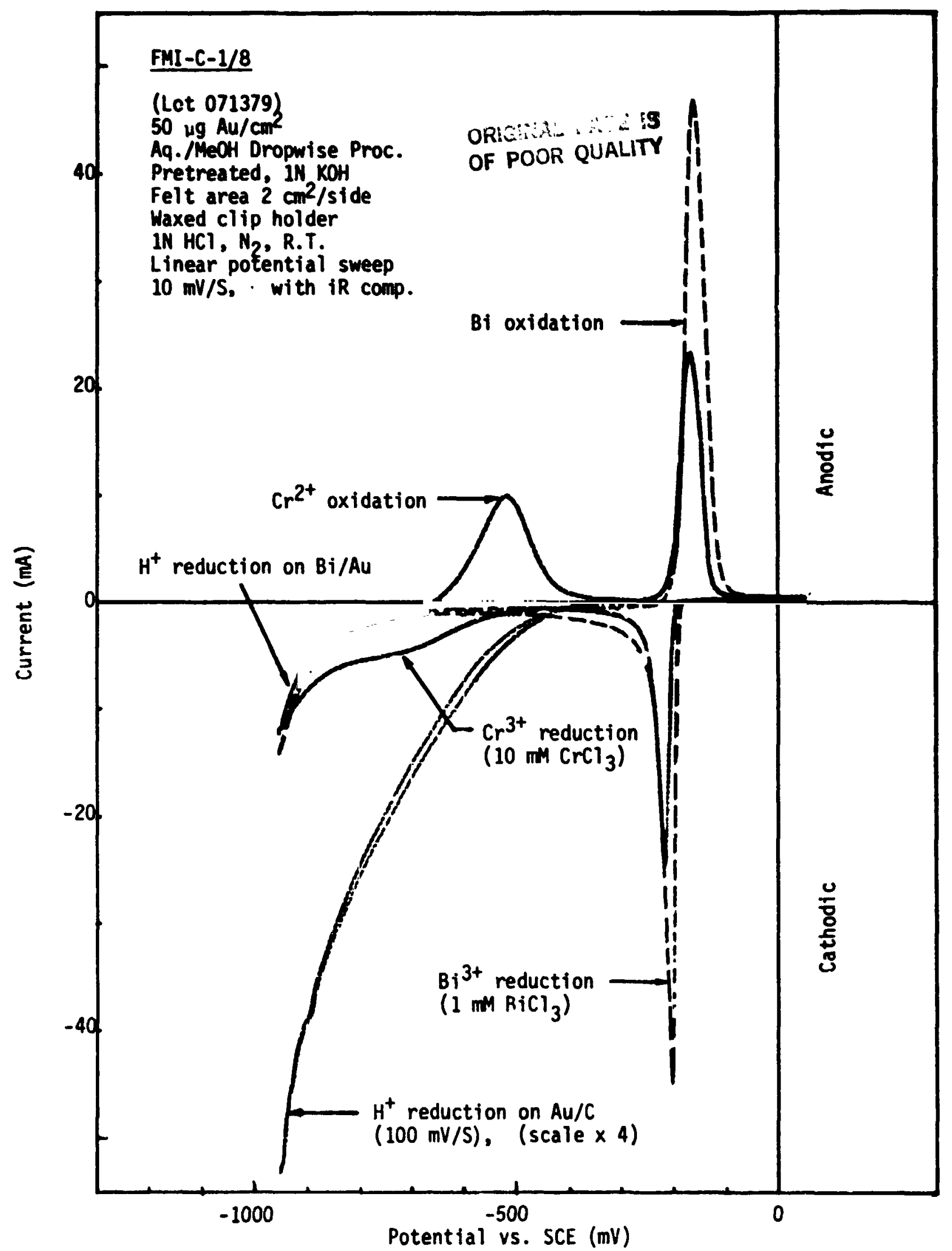

Figure 62. Gold/Bismuth Electrocatalyst System; Electrochemical Performance oi Carbon Felt (FMI-C-1/8) with $50 \mu \mathrm{g} \mathrm{Au} / \mathrm{cm}^{2}$ 


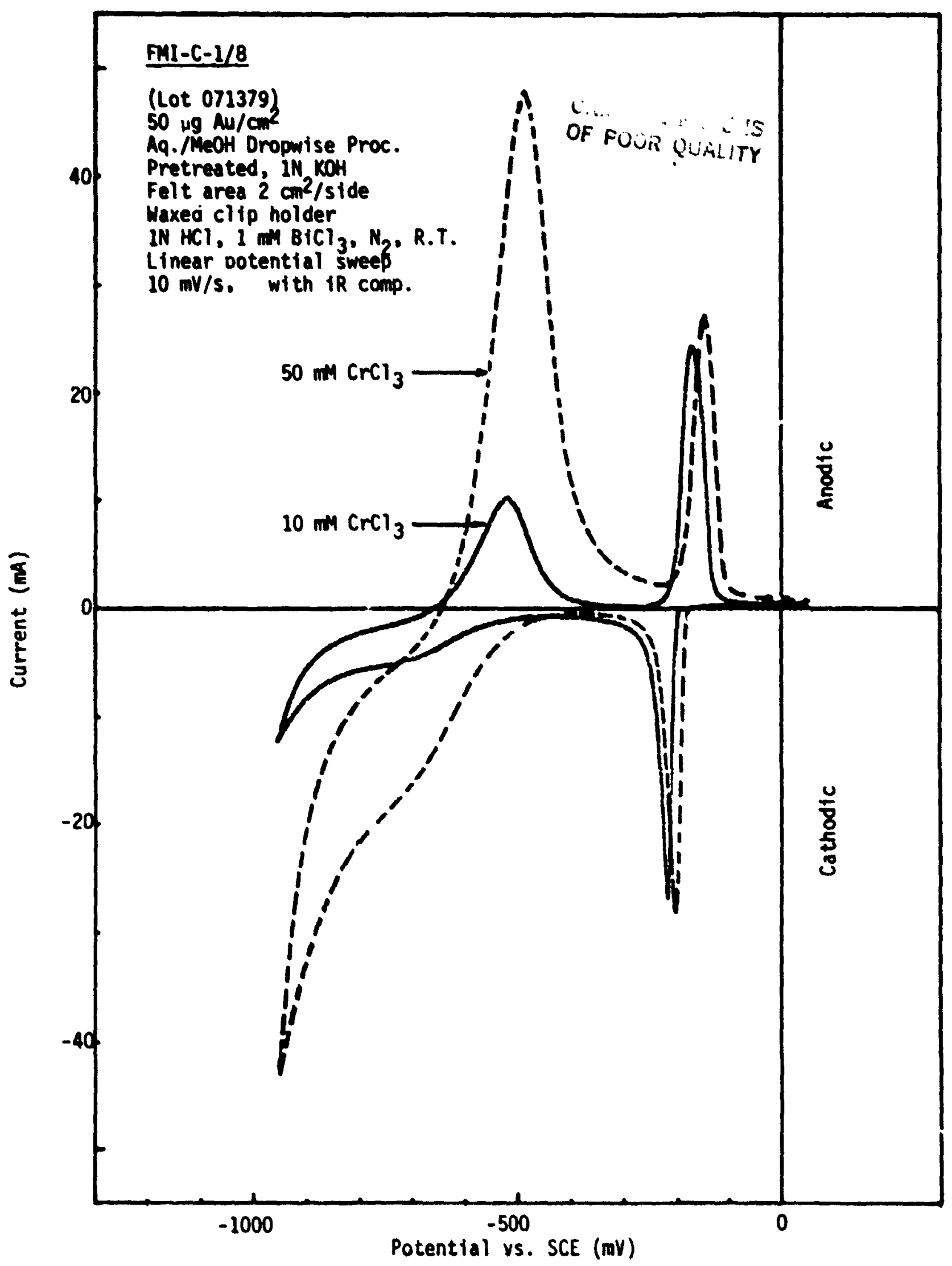

Figure 63. $10 \mathrm{mM} \mathrm{CrCl}_{3}$ vs. $50 \mathrm{mI} \mathrm{CrCl}_{3}$ in $1 \mathrm{aN} \mathrm{BiCl} 3$ on Carbon Falt (FMI-C-1/8) with $50 \mu g \mathrm{Au} / \mathrm{cm}^{2}$ 
Figure 64. Silver Catalyst Dissolution/Deposition on Carbon Felt in 1N HC1

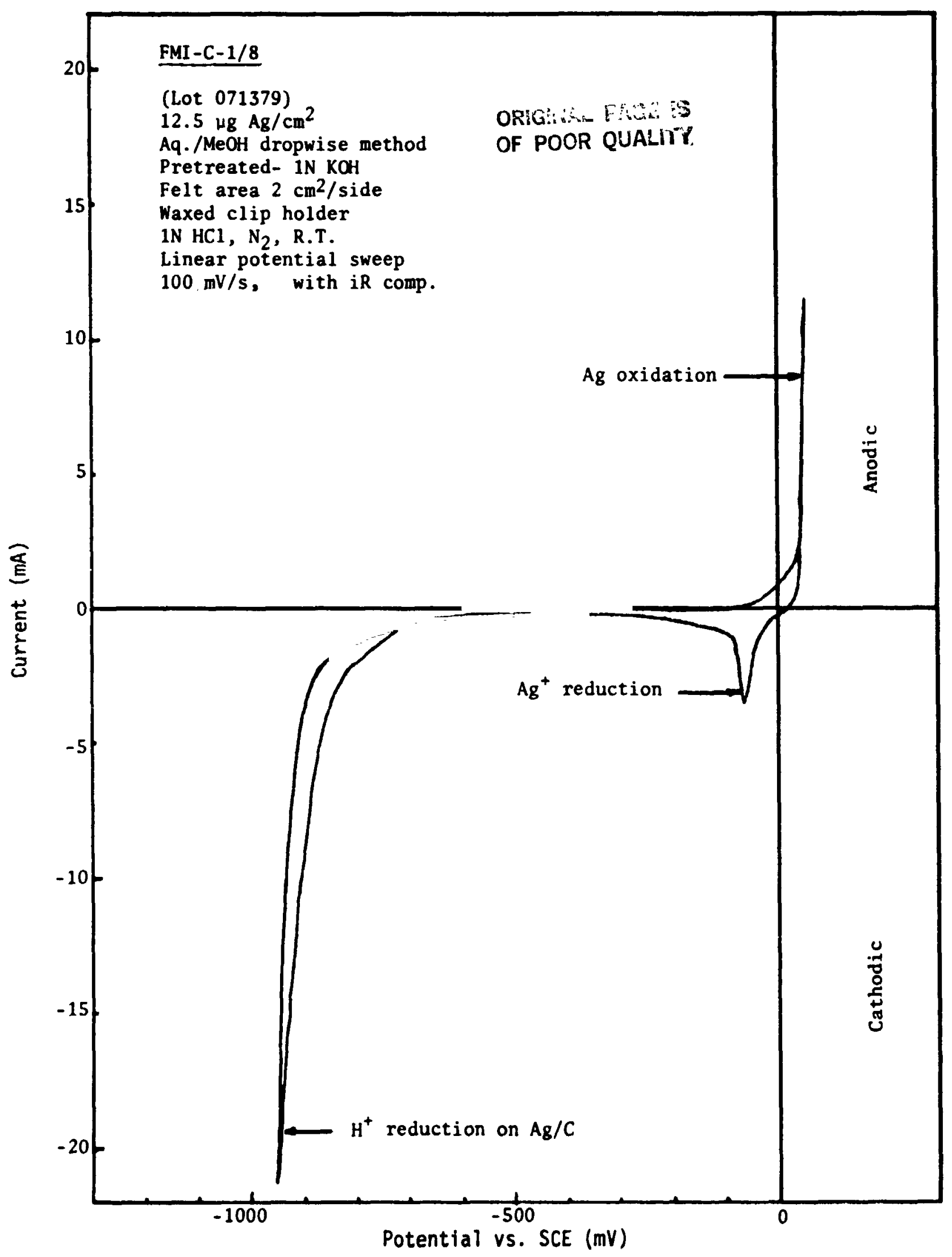

Figure 64. Silver Catalyst Dissolution/Deposition on Carbon Felt in $1 \mathrm{~N} \mathrm{HCl}$. 


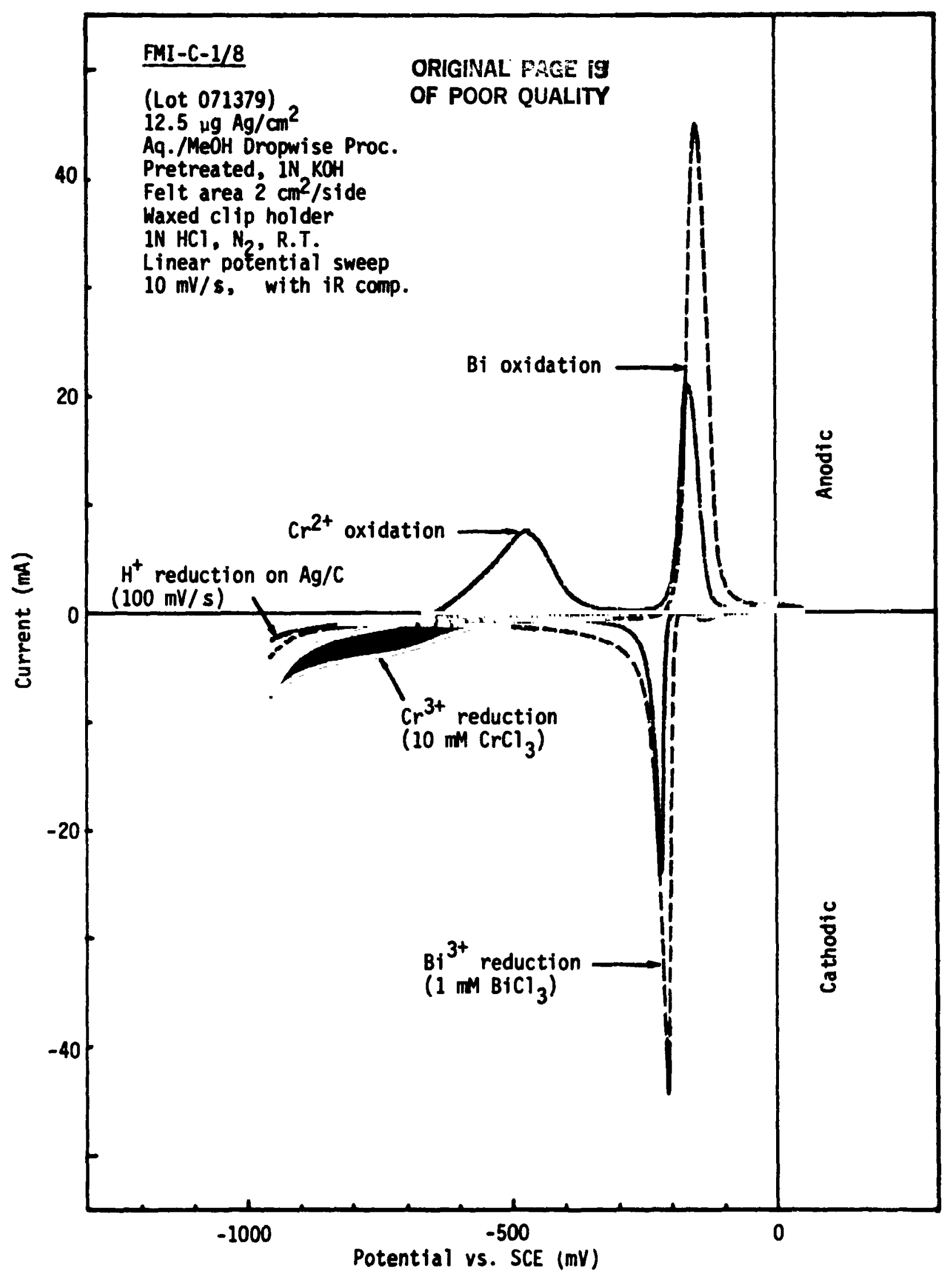

Figure 65. Silver/Bismuth Electrocatalyst System; Electrochemical Performance of Carbon Felt (FMI-C-1/8) Loaded with Silver at $12.5 \mu \mathrm{g} / \mathrm{cm}^{2}$. 


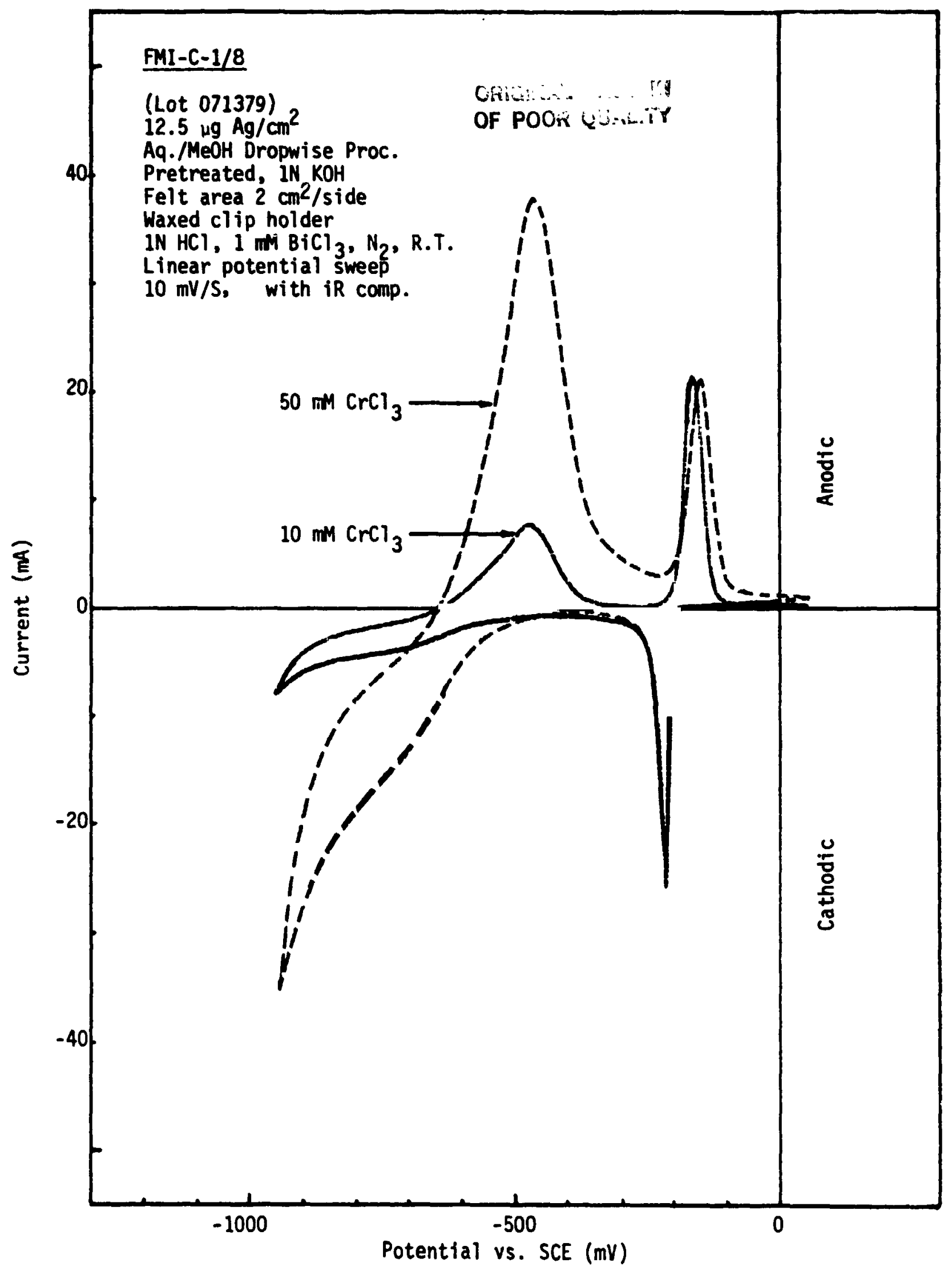

Figure 66. $10 \mathrm{mM} \mathrm{CrCl} 3$ vs. $50 \mathrm{mM} \mathrm{CrCl} 3$ in $1 \mathrm{mM} \mathrm{BiCl} 3$ on Carbon Felt

(FMI-C-1/8) Loaded with Silver at $12.5 \mu \mathrm{g} / \mathrm{cm}^{2}$. 


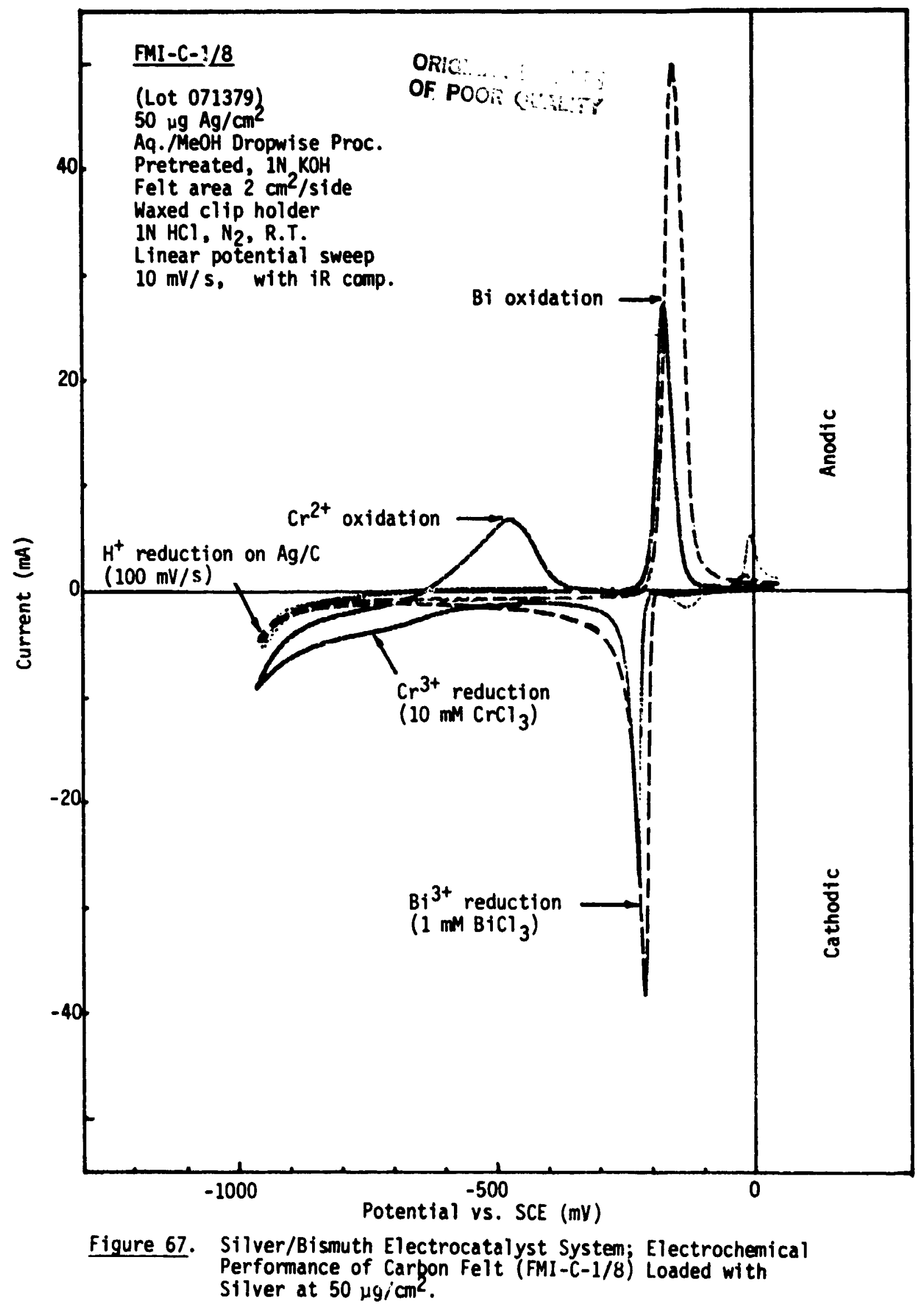




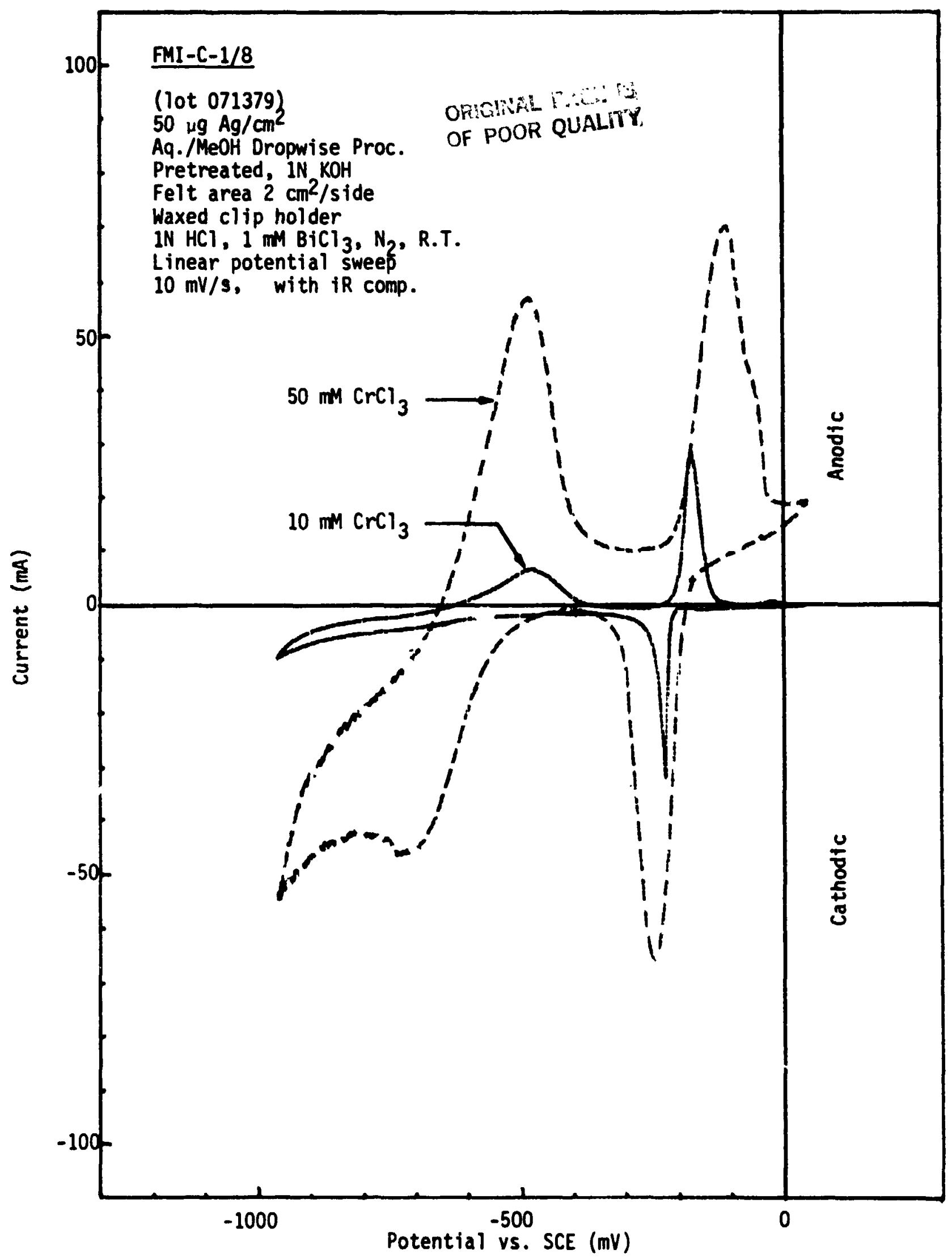

Figure 68. $10 \mathrm{mM} \mathrm{CrCl} 3$ vs. $50 \mathrm{mM} \mathrm{CrCl} 3$ in $1 \mathrm{mM} \mathrm{BiCl} 3$ on Carbon Felt (FMI-C-1/8) Loaded with Silvar at $50 \mu \mathrm{g} / \mathrm{cm}^{2}$. 


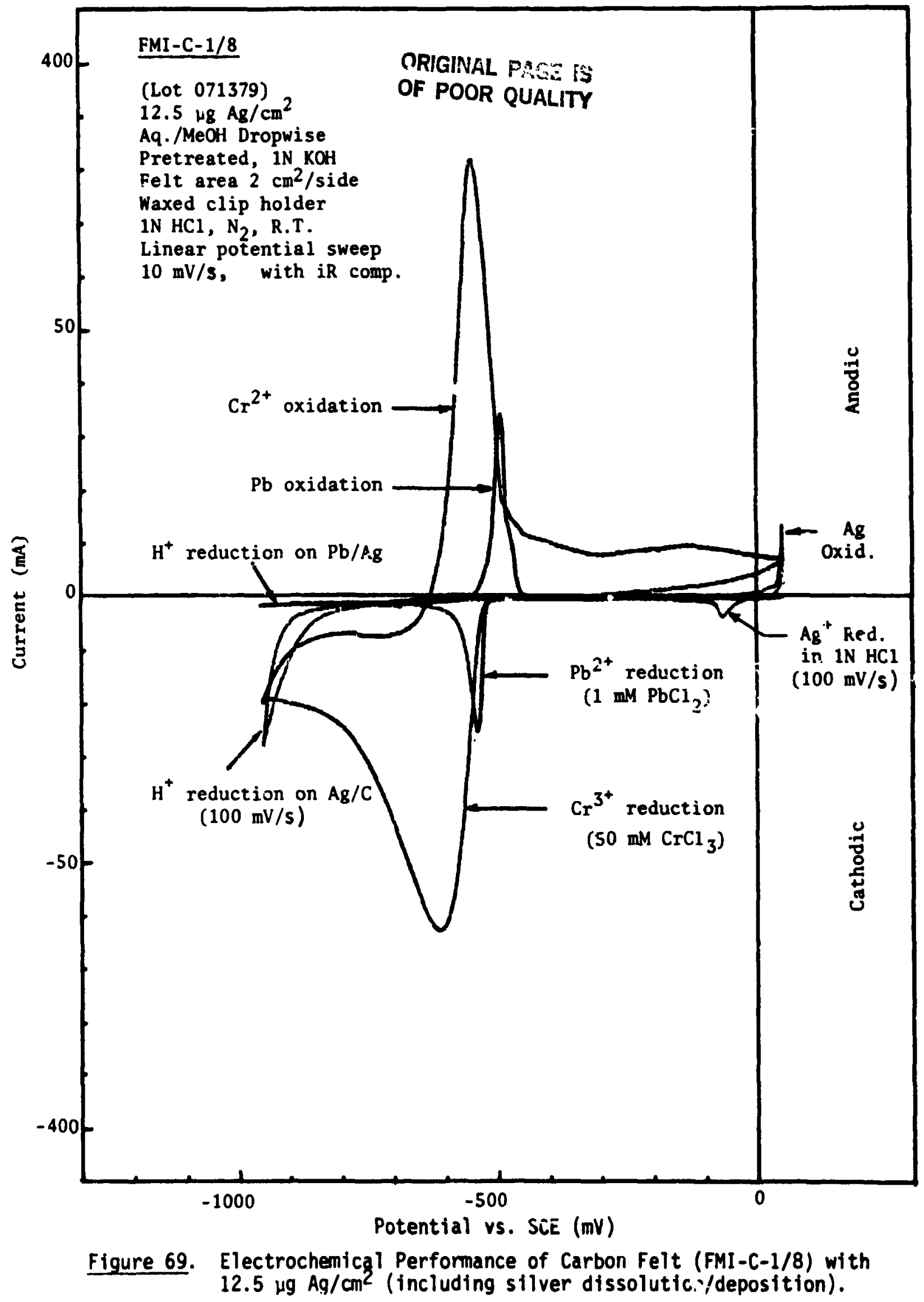




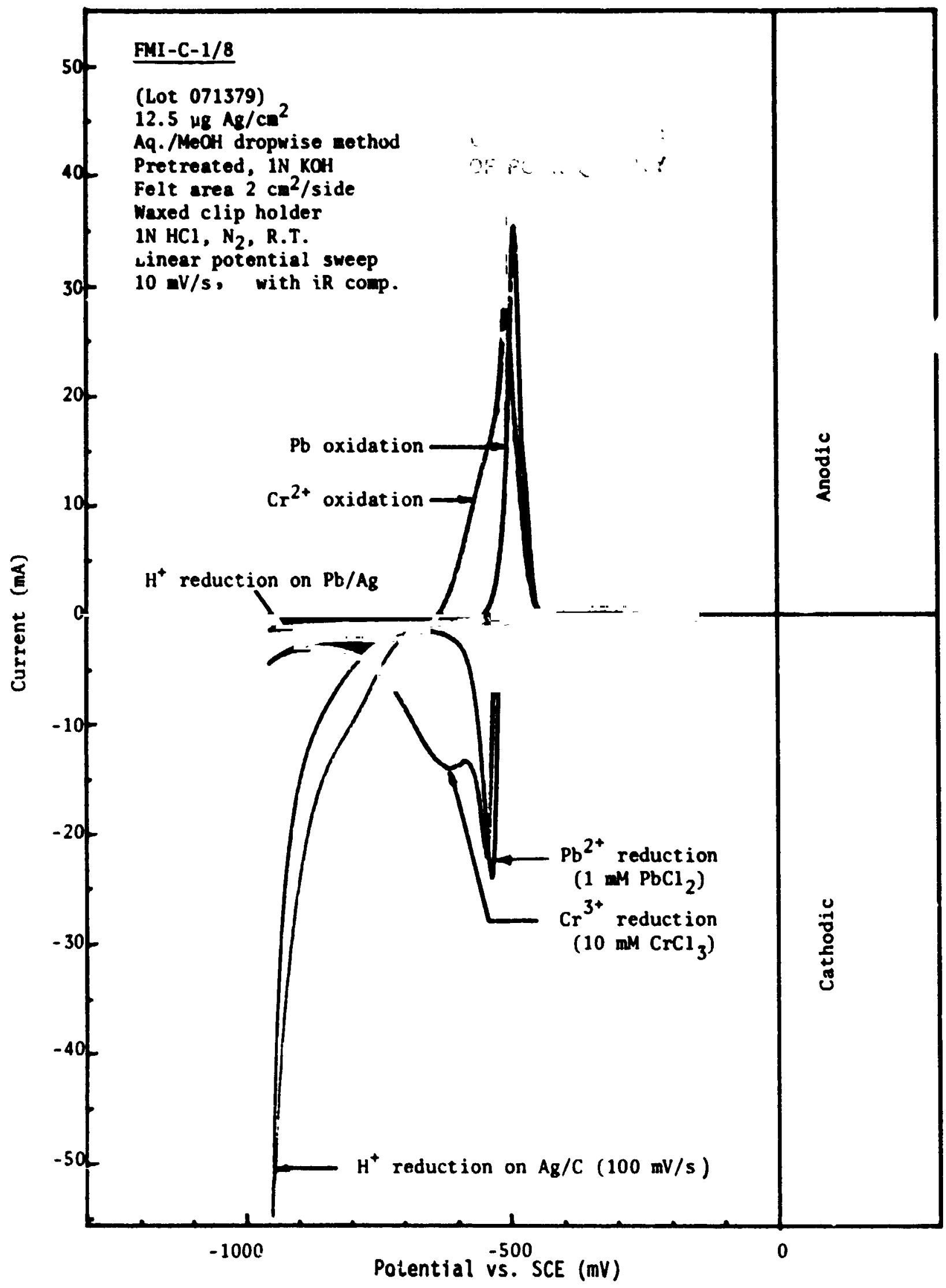

Figure 70. Electrochemical Performance of Carbon Felt with Silver at. $12.5 \mu \mathrm{g} / \mathrm{cm}^{2}$ (short sweep). 


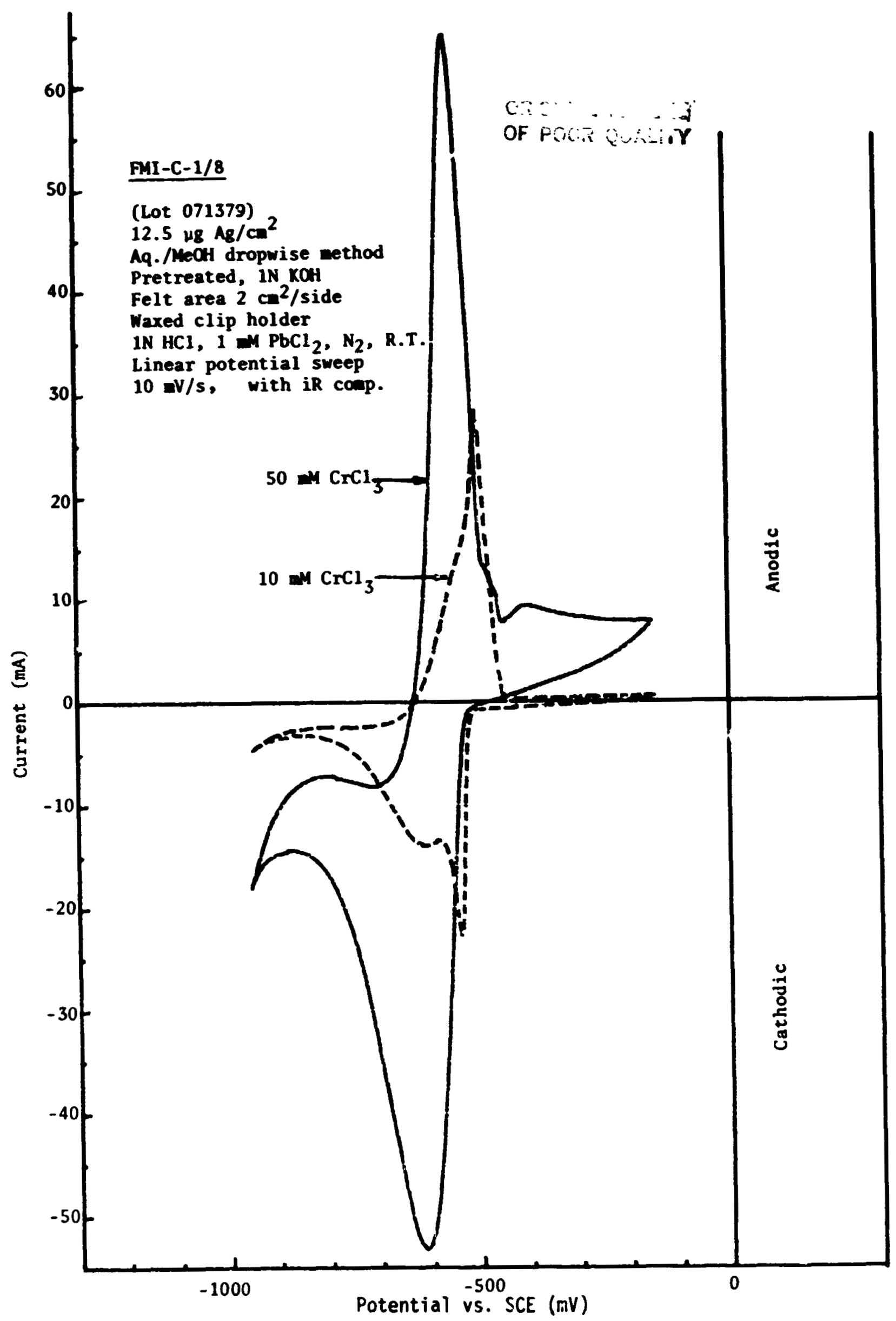

Figure 71. $10 \mathrm{mM} \mathrm{Cr}^{3+}$ vs. $50 \mathrm{mM} \mathrm{Cr}^{3+}$ on Carbon Felt with Silver at $12.5 \mu \mathrm{g} / \mathrm{cm}^{2}$ (short sweep). 


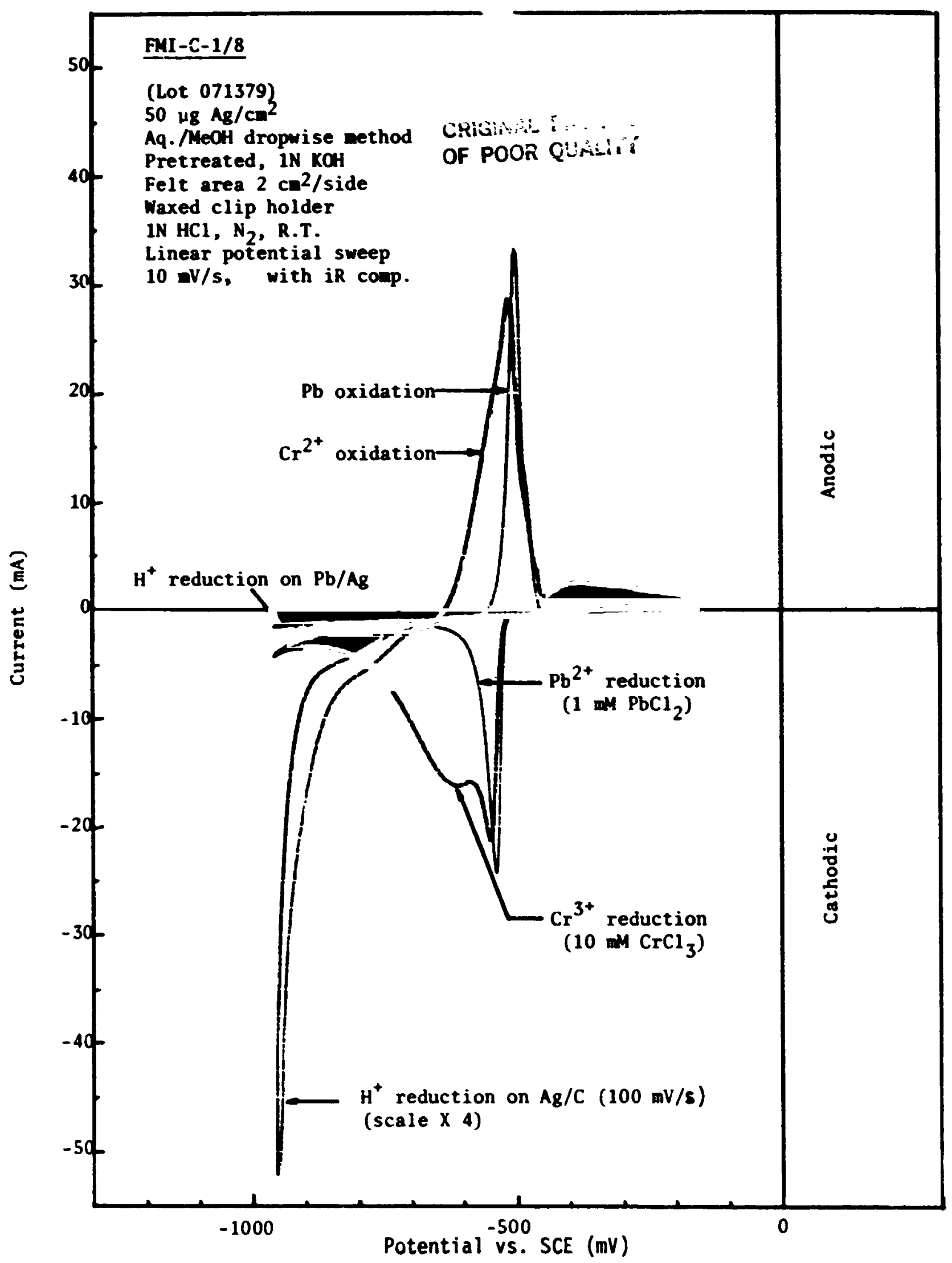

Figure 72. Electrochenical Performance of Carbon Felt with Silver at $50 \mu \mathrm{g} / \mathrm{cm}^{2}$ (short sweep). 


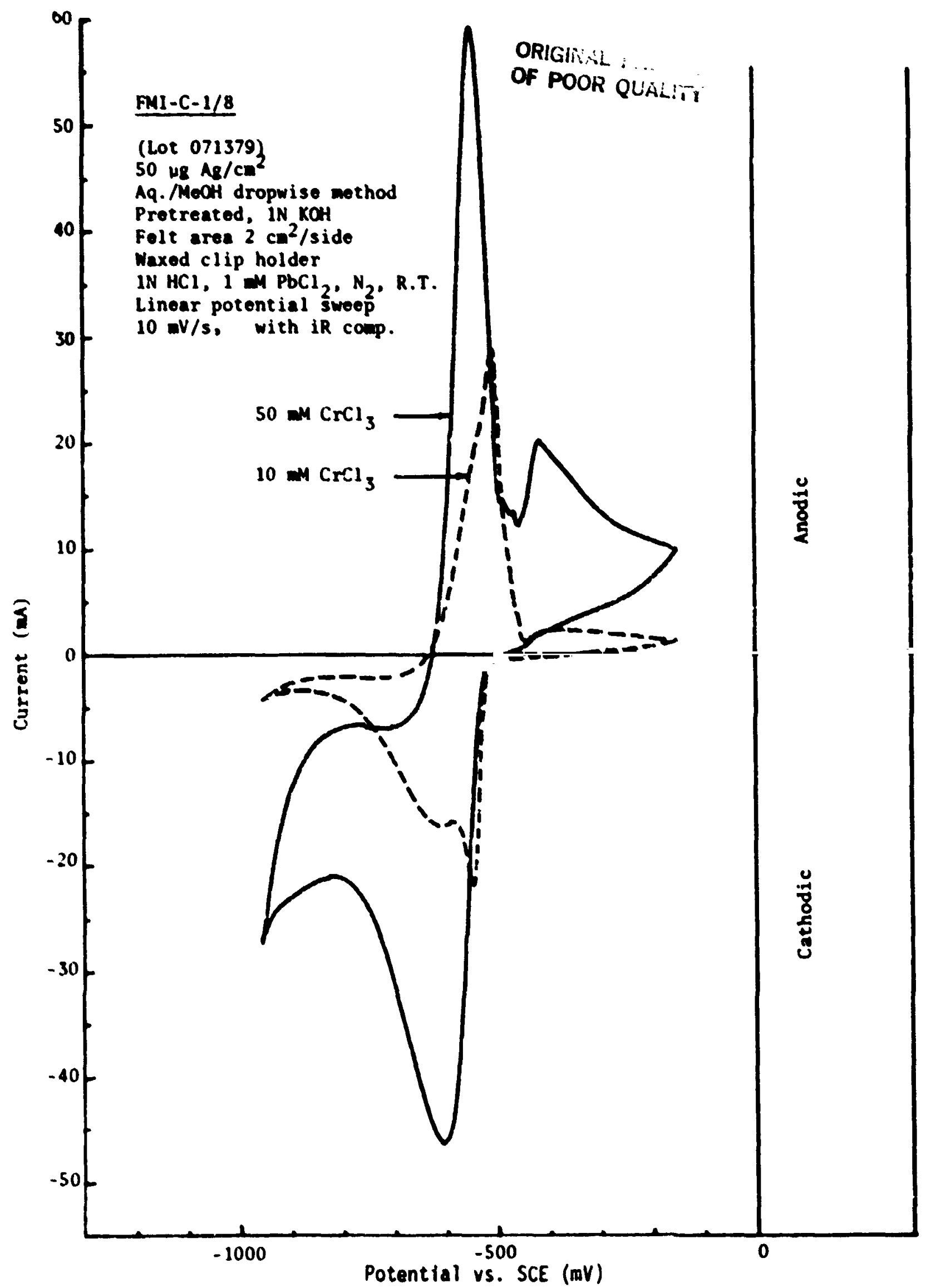

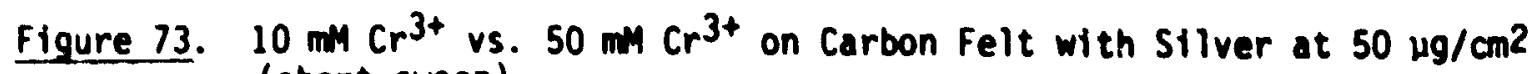
(short sweep). 
ORic....... :

REFERENCES

OF POUi Si......

1. L.H. Thaller, "Redox Flow Cell Energy Storage Systens," Dept. of Energy, Washington, D.C., DOE/NASN1002-79/3, Mational Aernnautics and Space Adnin., Washington, D.C., MSA M-79143 (1979) .

2. L.H. Thaller, "Recent Advances in Redox Flow Cell storage Systems," Dept. of Energy, Washington, D.C., DOE/MSN1002-79-4, National Aeronautics and Space Admin., Mashington, D.C., MSA TM-79186 (1979).

3. J. Giner, L. Swette and $\mathrm{K}$. Cahill, -screening of Redox Couples and Electrode Materials," Final Report, Giner, Inc., Waltham, MA; U.S. Energy Research and Development Admin. and NASA-Lewis Research Center Contract No. NAS3-19760, NASA CR-134705 (1976).

4. J. Giner and K. Cahill, "Advanced Screening of Electrode Couples," Final Report, Giner, Inc., Waltham, MA; U.S. Dept. of Energy, DOE/NASA 0794-80/1; NASA-Lewis Research Center, NASA CR-159738 (1980).

5. V. Jalan, H. Stark and J. Giner, "Requirements for Optimization of Electrodes and Electrolyte for the Iron/Chromium Redox Flow Cell," Final Report, Giner, Inc., Waltham, MA; U.S. Dept. of Energy: DOE/NASA 0097 80/1, NASA-Lewis Research Center NASA CR-165218 (1981). 
CRI:-:

OF FS $\therefore$ :

6. V. Jalan, K. Cahill, D. Deluth and J. Giner, -Electrocatalysts for the $\mathrm{Cr}^{3+} / \mathrm{Cr}^{2+}$ Redox Couple," Extended Abstract5, 157th Spring Meeting of Electrochenical Society. St. Louis, M1ssouri, Vol, 80-1, Paper No. 351, Pp. 874-6, (May $11-16,1980)$.

7. V. Jalan and H. Stark, "Gold-Lead Catalysts for $\mathrm{Cr}^{3+} / \mathrm{Cr}^{2+}$ Redox Reactions," Extended Abstracts, Electrochemical Society Meeting, Hollywood, Florida, Jo1. 80-2, Paper No 150, pp. 410-2, (October, 1980).

8. J. Giner and R. Cahill, "Catalyst Surfaces for the Chromous/Chromic Redox Couple," U.S. Patent No. 4,192,910 (March 11, 1980) and No. 4,270,984, (June 2, 1981).

9. V. Jalan, M. Reid and J. Charleston, U.S. Patent filed, NASA Patent Application, Case No. 13653-1.

10. M.A. Reid and L.H. Thaller, "Improvement and Scale-up of the NASA Redox Storage System," NASA Lewis Research Center; U.S. Dept. of Energy, DOE/NASA/12726-6, National Aeronautics and Space Admin., NASA TM-81632, (paper prepared for the 15th IECEC, Seattle, WA, August, 1980).

11. M.A. Reid, R.F. Gahn, J.S. Ling and J. Charleston, "Preparation and Characterization of Electrodes for the NASA Redox Storage System," NASA-Lewis Research Center; U.S, Dept. of Energy, DOE/NASA 12726-13; NASA TM-82702, (September, 1980) .

12. R.F. Gahn, J. Charleston, J.S. Ling and M.A. Reid, "Performance of Advanced Chromium Electrodes for the NASA Redox Energy Storage System," NASA-Lewis Research Center; U.S. Dept. of Energy, DOE/NASA 12726-15; NASA TM-82724 (November, 1981). 



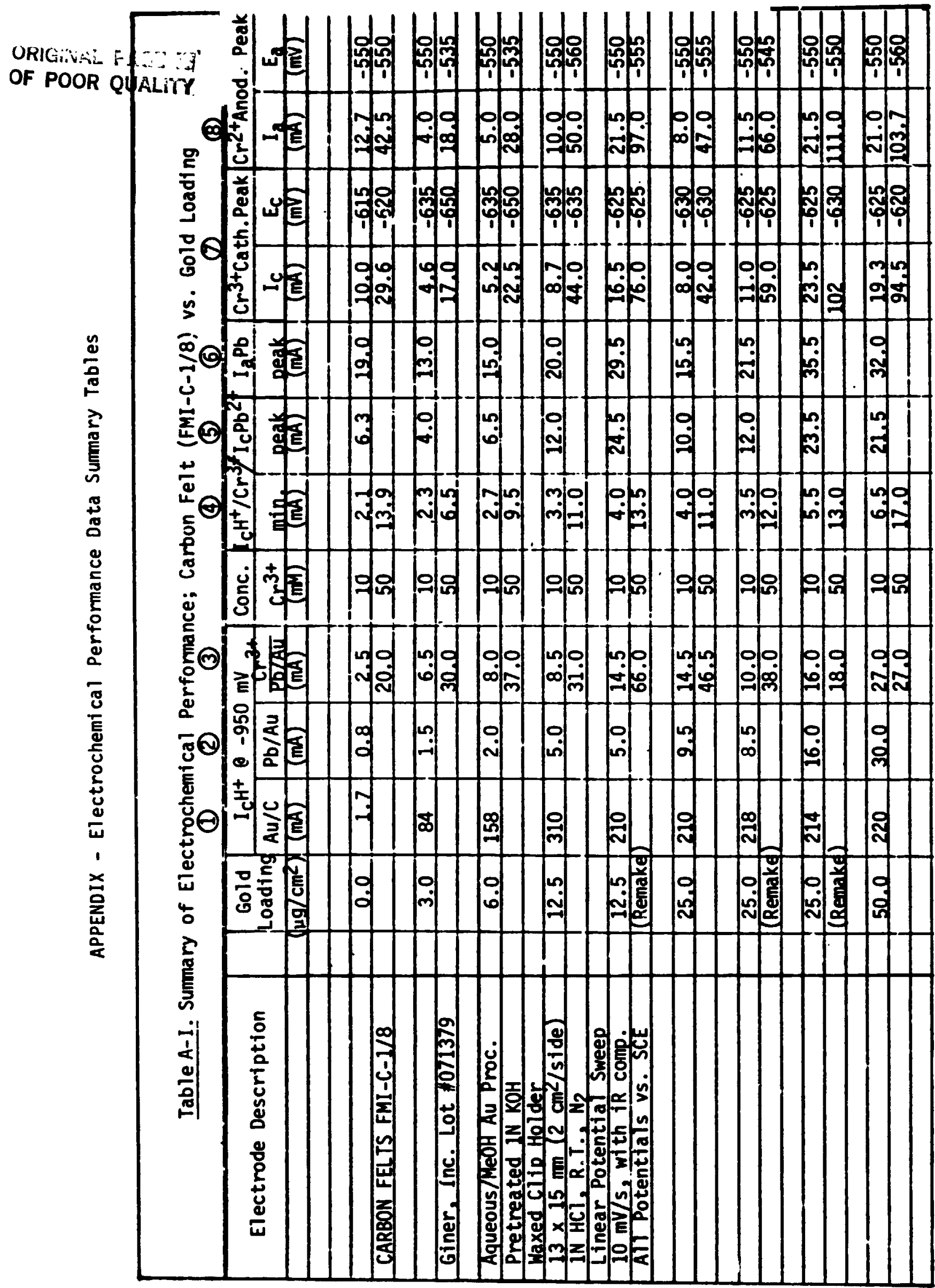




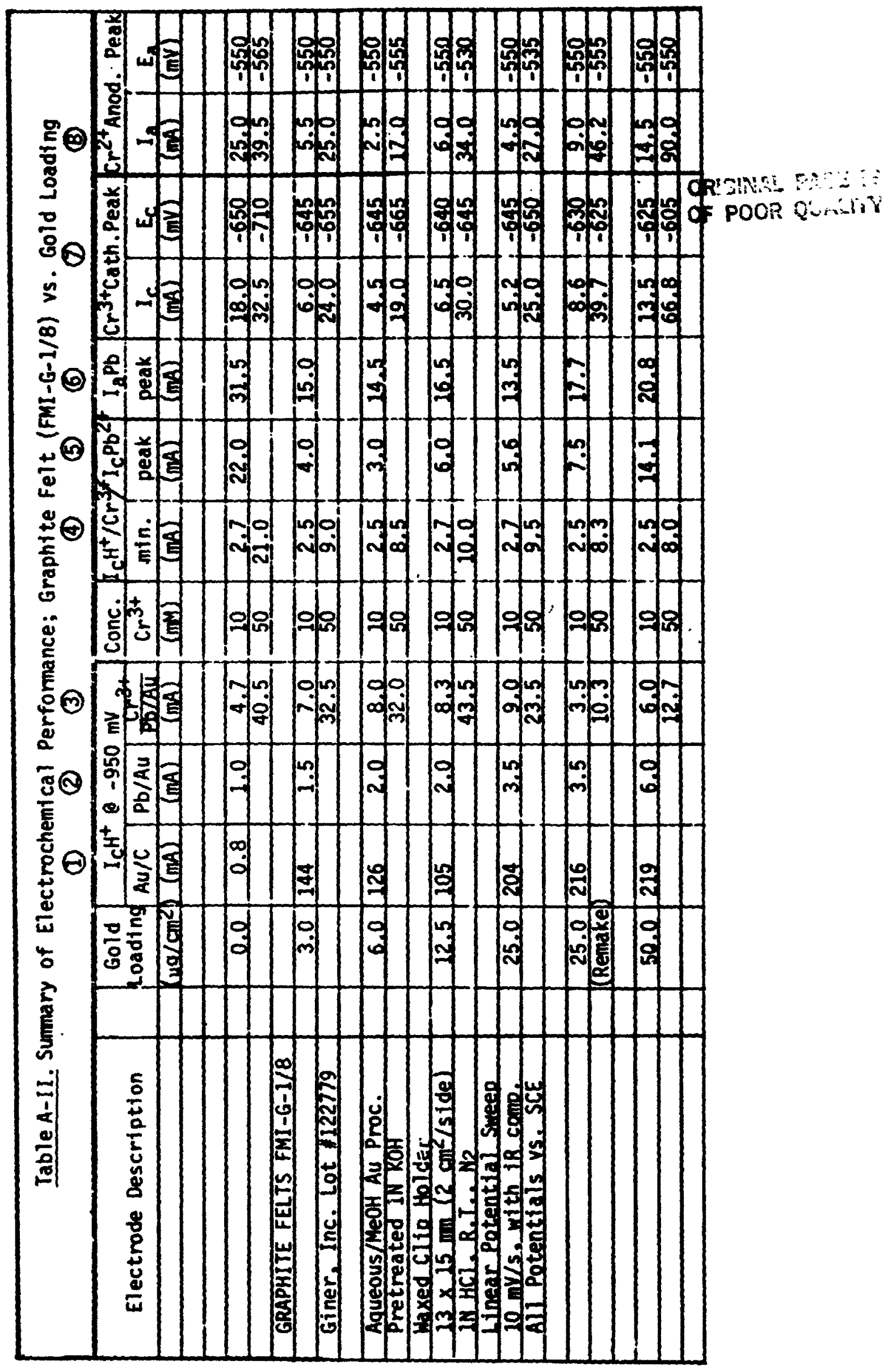




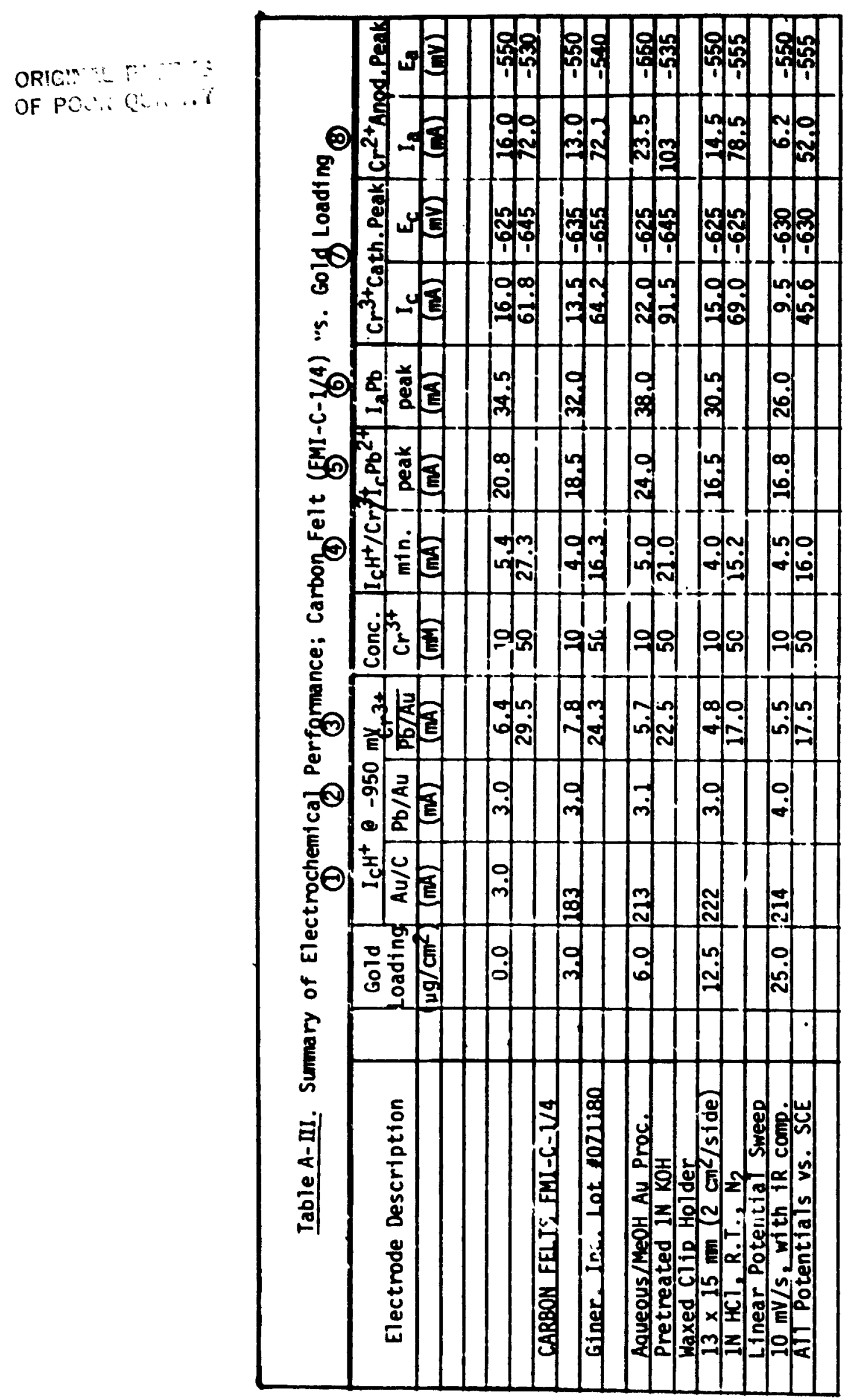


ORIGINAL PEDE IS

OF POOR QUALITY

Table A-IV. Surmary of Anodic Charge Segments vs. Gold Loading

All electrodes prepared by Aqueous/Methanol Gold Process.

Test Solution: $1 \mathrm{~N} \mathrm{HCl}, 1 \mathrm{mM} \mathrm{PbCl} 2,50 \mathrm{mM} \mathrm{Cr}{ }^{3+}$. See Also Figure 22.

Felt Type

Gold

1.D. Code

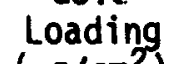

$\left(\mathrm{gg} / \mathrm{cm}^{2}\right) \quad(\mathrm{mCOuI})$

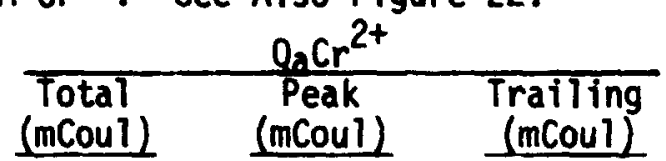

$$
\begin{aligned}
& \text { Carbon } \\
& \text { FMI-C- } 1 / 8 \\
& \text { Lot No. } \\
& \text { G-071379 }
\end{aligned}
$$

$$
0
$$

59.5

545

230

315

3

50.3

223

107

116

6

61.8

369

168

201

12.5

75.7

655

428

227

(Table A-I)

12.5

99.7

1117

844

273

25

70.2

576

387

189

25

81.7

788

542

246

25

152

1547

1134

413

50

138

1453

1058

385

\section{Graphite}

FMI-G-1/8

Lot No.

G-122779

(Table A-II)

0
3
6
12.5
25
25
50

129

526

229

297

53.3

305

174

131

47.0

181

109

72

65.0

428

219

209

61.7

392

207

185

71.0

531

339

192

961

618

343

Carbon
FMI-C-1/4
Lot No.

0

148

974

483

491

3120

916

526

390

$6 \quad 151$

1404

842

562

G-071180

12.5

132

939

537

402

(Table A-III)

25

123

603

336

267

$$
{ }^{*} 100 \mathrm{mCoul}=54 \mu \mathrm{gb} / \mathrm{cm}^{2}
$$


ORIGINAL PAGE ?

OF POOR QUALITY

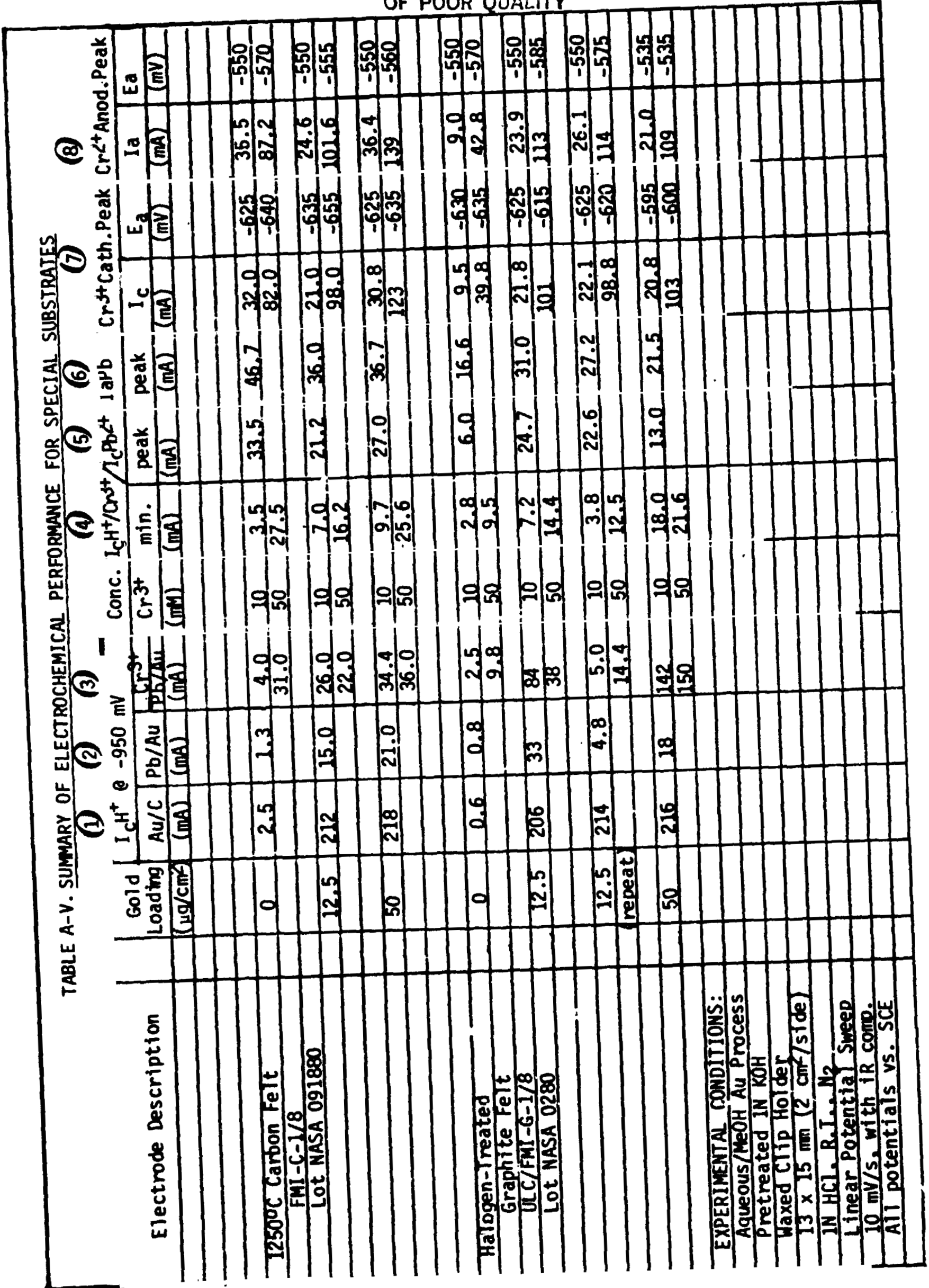


ORAWH Har IS

OF PCOL CURATY

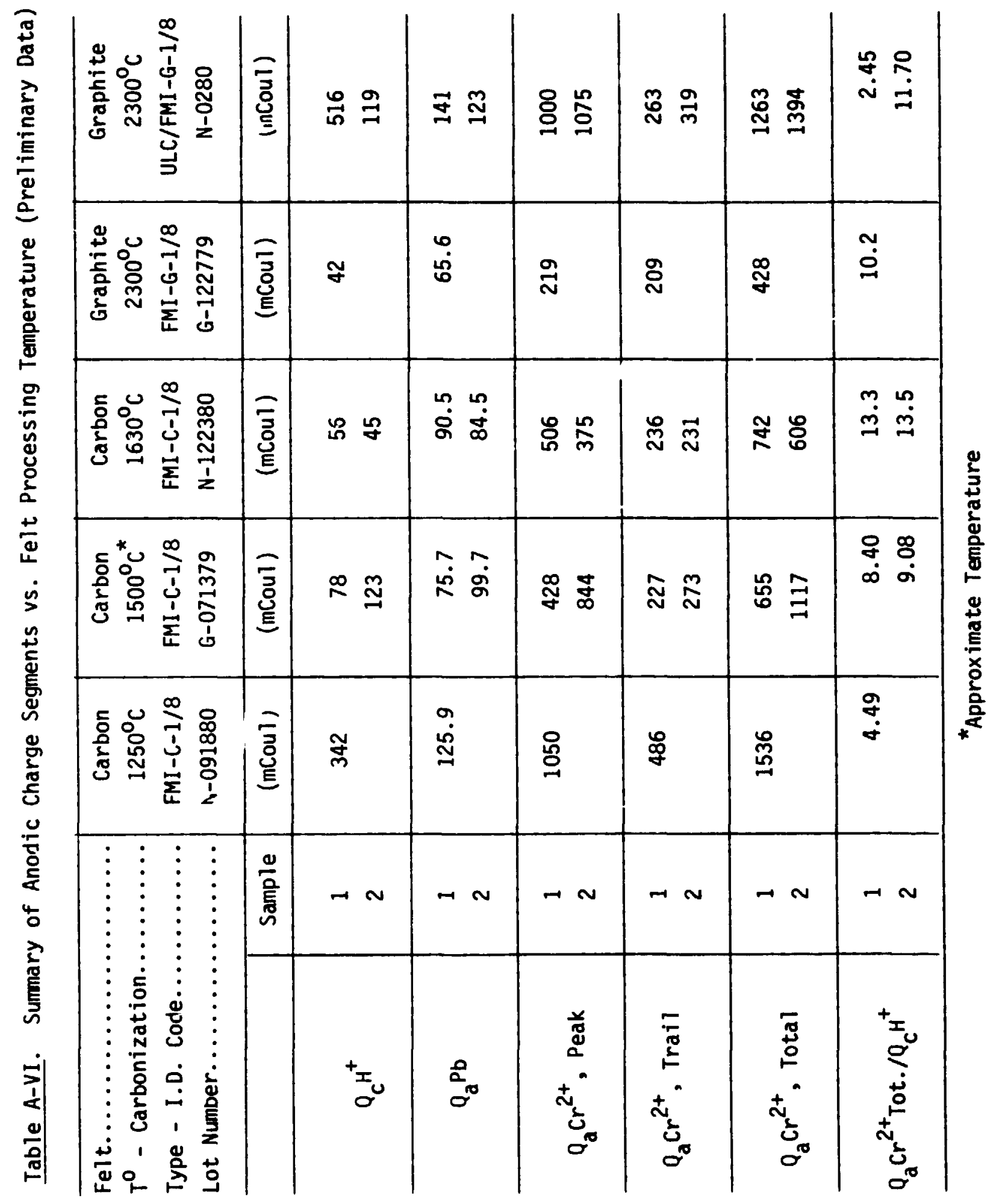




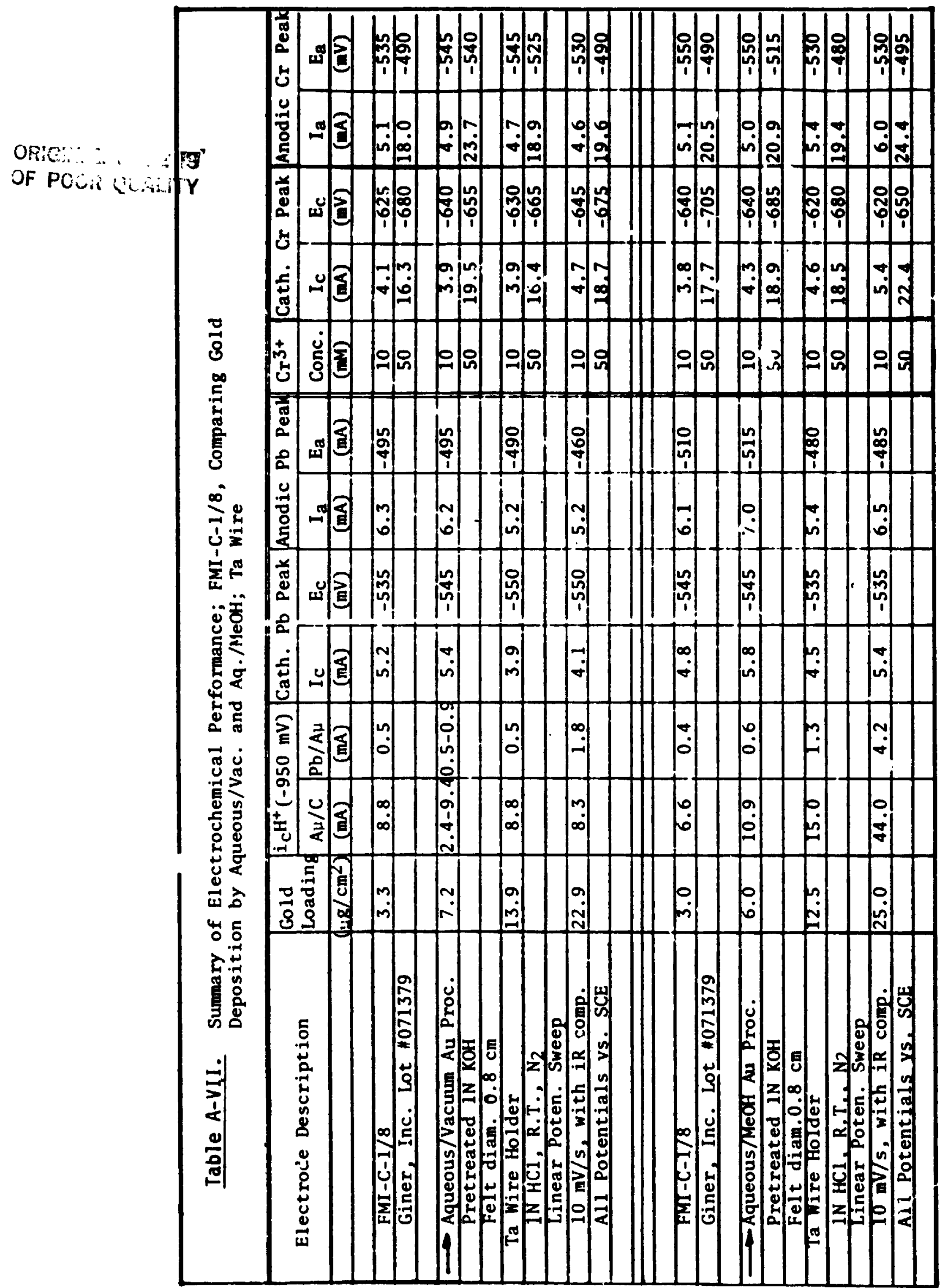




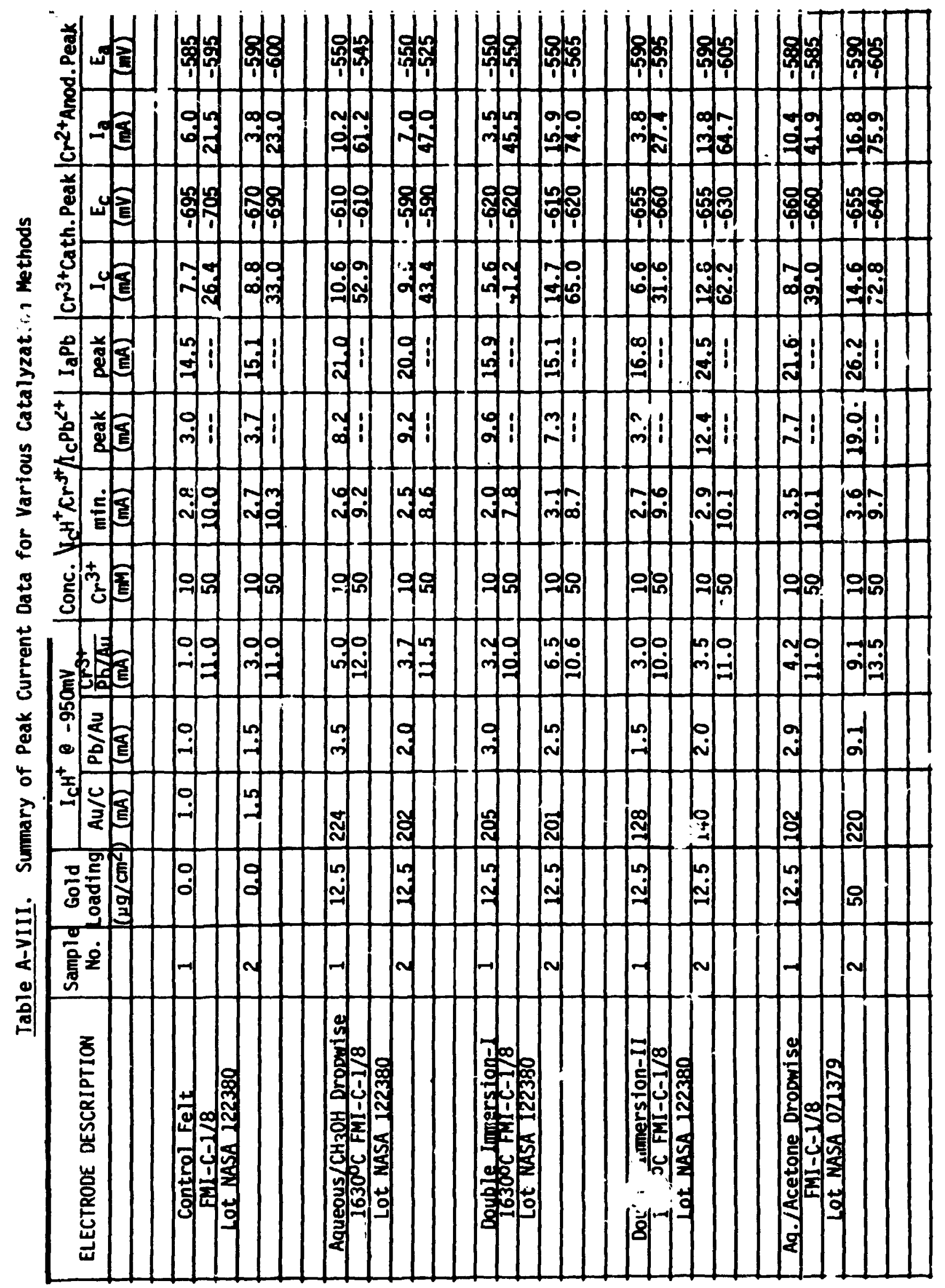




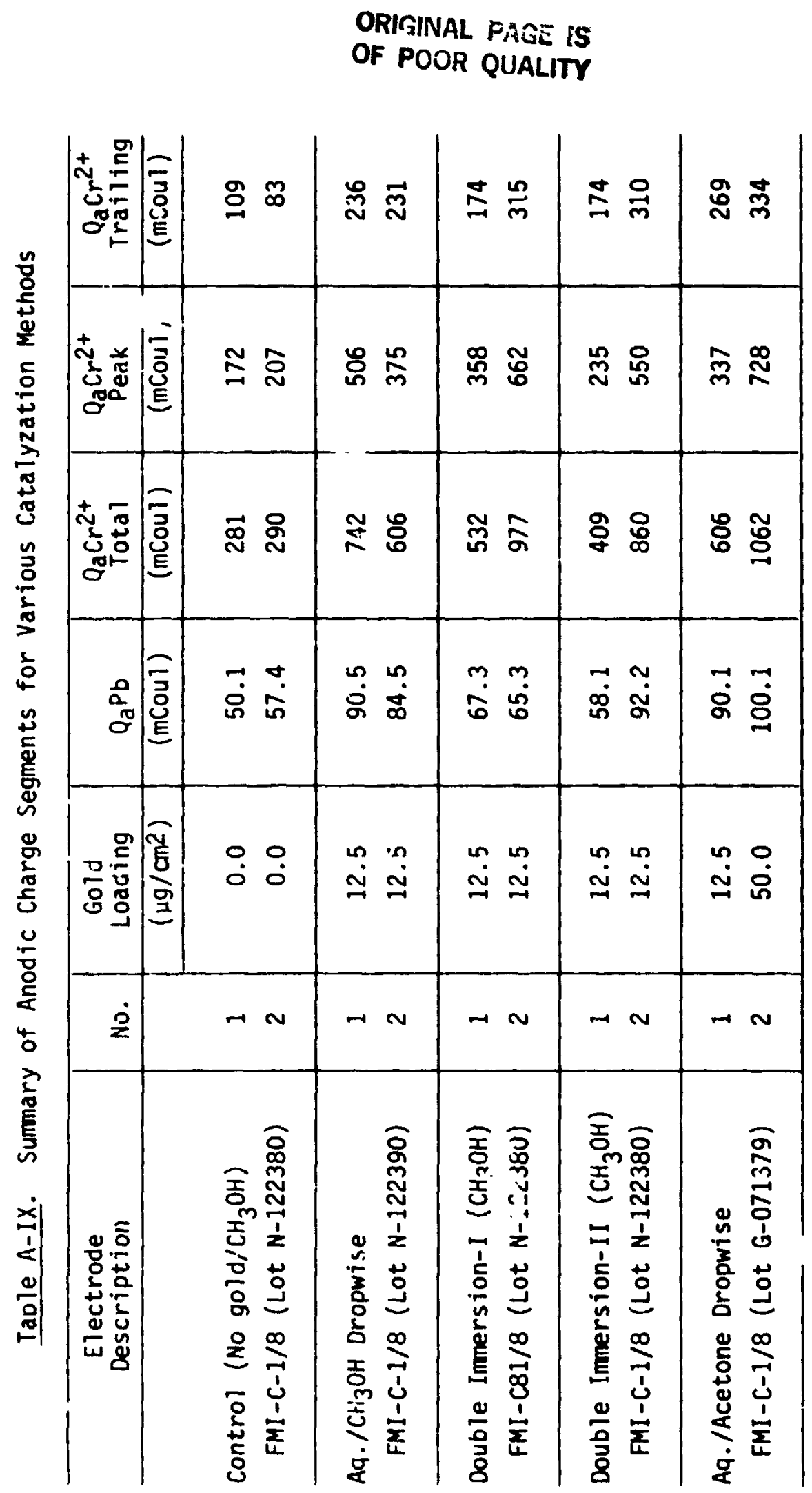




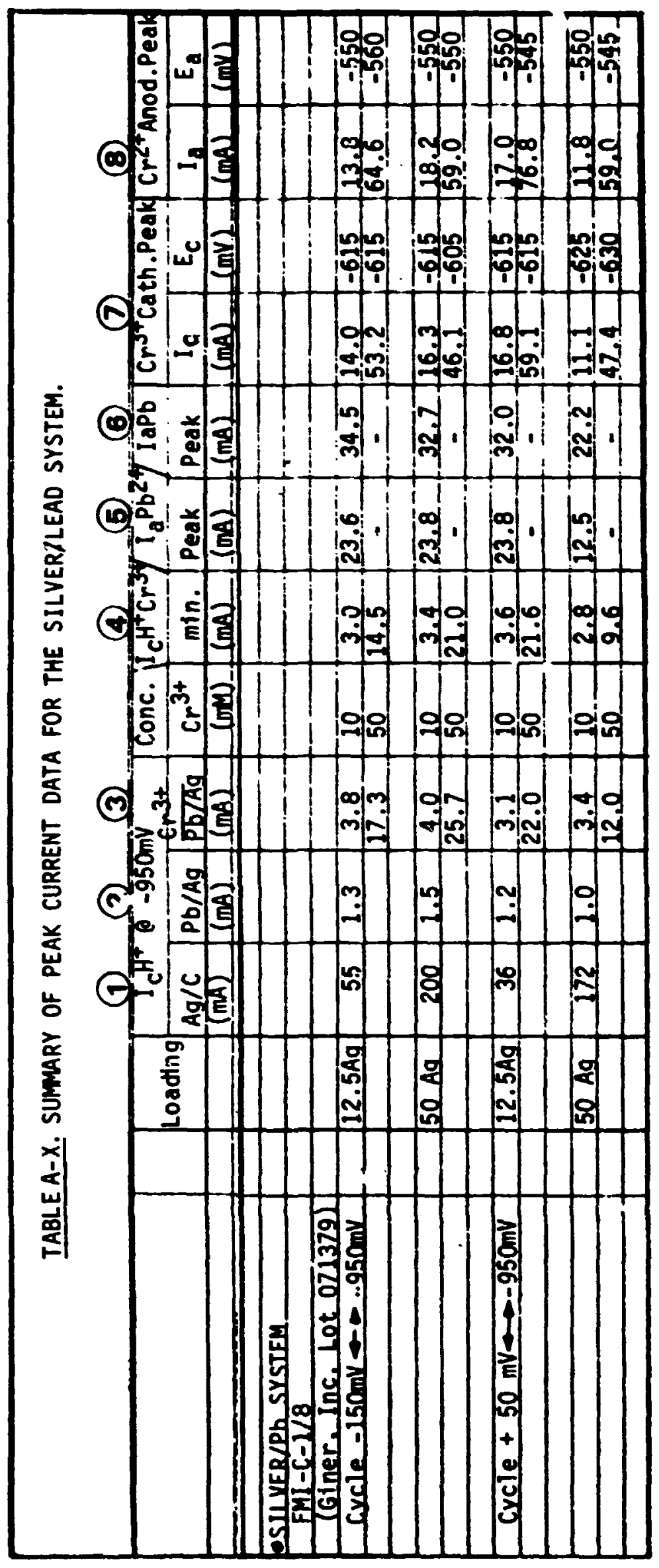

ORIERA: : $\because \cdots$

OF PCOA $\because \cdots \ldots$ 

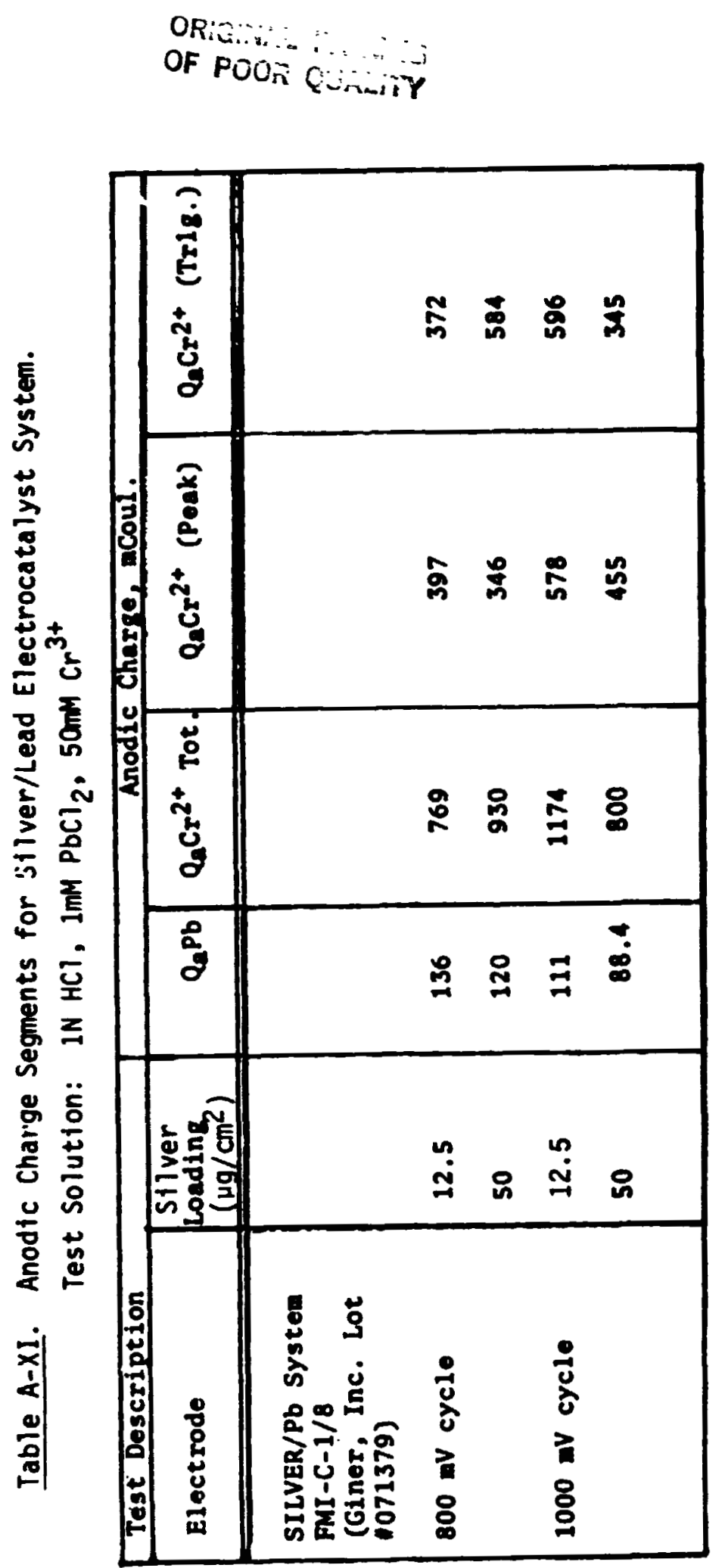

OUS GOVERMMENT PAINTING OFFICE 1983/659-094/319 